UNIVERSIDADE DE SÃO PAULO

FACULDADE DE ECONOMIA, ADMINISTRAÇÃO E CONTABILIDADE DEPARTAMENTO DE ADMINISTRAÇÃO PROGRAMA DE PÓS-GRADUAÇÃO EM ADMINISTRAÇÃO

UMA ANÁLISE DOS PRINCIPAIS RISCOS QUE CONTRIBUEM PARA O AGRAVAMENTO (ESCALATION) DE PROJETOS DE TI DA ADMINISTRAÇÃO PÚBLICA

Enock Godoy de Souza

Orientador: Prof. Dr. Nicolau Reinhard

SÃO PAULO 
João Grandino Rodas

Reitor da Universidade de São Paulo

Prof. Dr. Reinaldo Guerreiro

Diretor da Faculdade de Economia, Administração e Contabilidade

Prof. Dr. Adalberto Américo Fischmann

Chefe do Departamento de Administração

Prof. Dr. Lindolfo Galvão de Albuquerque Coordenador do Programa de Pós-Graduação em Administração 
ENOCK GODOY DE SOUZA

\title{
UMA ANÁLISE DOS PRINCIPAIS RISCOS QUE CONTRIBUEM PARA O AGRAVAMENTO (ESCALATION) DE PROJETOS DE TI DA ADMINISTRAÇÃO PÚBLICA
}

\author{
Tese apresentada ao Departamento de \\ Administração da Faculdade de Economia, \\ Administração e Contabilidade da \\ Universidade de São Paulo como requisito \\ para obtenção do título de Doutor em \\ Administração.
}

Orientador: Prof. Dr. Nicolau Reinhard

Versão corrigida

(versão original disponível na Faculdade de Economia, Administração e Contabilidade)

\section{SÃO PAULO}




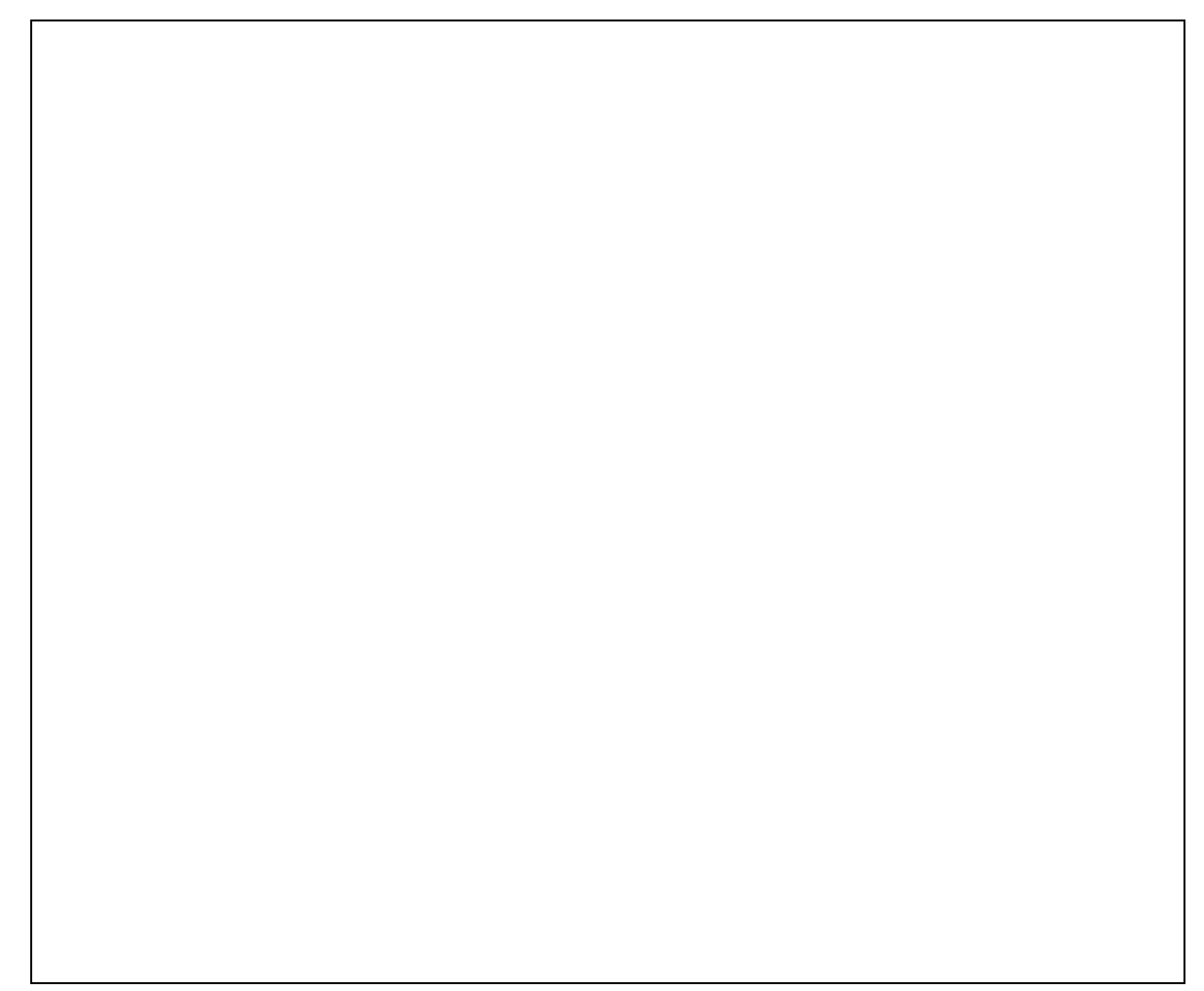

FICHA CATALOGRÁFICA

Elaborada pela Seção de Processamento Técnico do SBD/FEA/USP

Souza, Enock Godoy de

Uma análise dos principais riscos que contribuem para o agravamento (escalation) de projetos de TI da administração pública / Enock Godoy de Souza. -- São Paulo, 2012.

269 p.

Tese (Doutorado) - Universidade de São Paulo, 2012.

Orientador: Nicolau Reinhard.

1. Administração de projetos 2. Agravamento de projetos 3. Sistemas de informação 4. Tecnologia da informação 5 . Administração pública

6. Administração de risco I. Universidade de São Paulo. Faculdade de Economia, Administração e Contabilidade II. Título.

CDD -658.404 
À Nossa Senhora, Santa Maria, mãe de Jesus, que inspirou minha devoção e apaziguou o meu espírito. 


\section{AGRADECIMENTOS}

Agradeço à minha esposa e às minhas filhas pelos sacrifícios que fizeram para que eu pudesse me dedicar aos estudos, e em especial à minha esposa pelo apoio e companheirismo.

Agradeço aos meus pais pelo exemplo, pelo carinho e pelo apoio incondicional.

Agradeço aos amigos Antonio Augusto Barbosa Camargos e Maurício Arantes Andrade pelo incentivo e por não me deixarem desistir.

Agradeço ao amigo Benedito João Gai Neto pela ajuda nos momentos finais da tese. Agradeço aos professores que participaram da banca de qualificação, Prof. Dr. Cesar Alexandre de Souza e Prof. Dr. Edmir Parada Vasques Prado, por suas relevantes recomendações para o desenvolvimento desta pesquisa.

Agradeço a todos os colegas da Secretaria da Fazenda, e da instituição anônima pesquisada, que ajudaram no desenvolvimento deste trabalho.

Agradeço a todos os colegas da Prodesp e dos outros fornecedores da Secretaria da Fazenda e da instituição anônima pesquisada, que ajudaram no desenvolvimento deste trabalho.

Agradeço a todos os entrevistados por disporem de seu tempo e atenção.

Um agradecimento especial a Rodrigo Vasconcellos Franco, Milton Vassari Nunes, Wanderley Moutinho de Jesus e Edson Takeshi Sunami.

Agradeço à Lícia Mutsuko Abe, pelo apoio, pelas dicas e pelos conselhos. Sua ajuda foi fundamental.

Finalmente, agradeço ao Prof. Dr. Nicolau Reinhard pela oportunidade de aprendizado, pelas sábias sugestões e pela visão crítica, que possibilitaram o sucesso desta pesquisa. 
"Os problemas significativos que enfrentamos não podem ser resolvidos no mesmo nível de pensamento em que estávamos quando os criamos". Albert Einstein 


\section{RESUMO}

Sistemas de informação do setor público tem apresentado historicamente uma baixa taxa de conclusão com sucesso. O tamanho e a complexidade dos projetos de sistemas de informação de porte grande em organizações de governo estão aumentando ainda mais. Entretanto, muitas organizações governamentais não possuem a habilidade para gerenciar esse tipo de projeto. Um caso extremo de projeto problemático é o que ocorre na situação de agravamento, na qual recursos continuam sendo comprometidos em um curso de ação destinado ao fracasso.

$\mathrm{O}$ agravamento do projeto aparenta ser consequência de uma combinação de fatores. As principais teorias que explicam o agravamento de projetos focam principalmente nos fatores psicológicos, sociais e organizacionais, os quais são aplicáveis tanto a projetos de sistemas de informação quanto a projetos de outras áreas de aplicação.

Esta pesquisa preenche uma lacuna na literatura por focar nas características específicas do projeto que levam um projeto de Governo Eletrônico a se tornar problemático e entrar em situação de agravamento. Logo, o propósito desta pesquisa é aprimorar o entendimento dos fatores de projeto (riscos) que levam projetos de Governo Eletrônico à situação de agravamento.

Para investigar o fenômeno do agravamento em projetos reais de Governo Eletrônico, esta tese apresenta um estudo de casos múltiplos com três casos, dois da Secretaria da Fazenda do Estado de São Paulo e um terceiro de uma organização pública brasileira anônima. Os casos deste estudo são analisados sob o ponto de vista de um modelo de referência baseado na teoria de problemas complexos (Wicked Problems Theory).

Esta pesquisa concluiu que os principais riscos que levam um projeto de Governo Eletrônico a situação de agravamento são os riscos de complexidade, e os riscos de escopo e requisitos. Esta pesquisa também apresenta algumas maneiras para tratar esses problemas: buscar a simplificação consciente das regras de negócio (requisitos), para aumentar a viabilidade técnica do projeto; aplicar uma metodologia mais adequada às características do projeto; e proteger o projeto da interferência dos prazos políticos. 


\begin{abstract}
Information systems (IS) projects in the public sector have historically been a problematic area with a very low rate of successful completion. The size and complexity of large-scale information systems projects in government organizations are on the rise, but most government organizations lack the ability of managing such projects.

An extreme case of project problems is the escalation situation, where resources continue to be committed to a failing course of action.

Project escalation seems to be promoted by a combination of factors. The main theories that explain project escalation focus mostly on psychological, social and organizational factors related to escalation, which are common for both information systems and non-information systems projects.

This research fills a gap in the literature by focusing on the project characteristics that lead an e-government project to become problematic and escalate. Thus, the purpose of this research is to improve the understanding of project factors (risks) that lead e-government projects to escalation.

In order to investigate the escalation phenomenon in real world e-government projects, this thesis presents a collective case study with three cases, two from the Treasury Secretary of São Paulo State and a third one from an anonymous Brazilian public organization. The case studies are analyzed through the eyes of a reference model based on the Wicked Problems Theory.

This research shows that the main risks that lead an e-government project towards escalation are complexity risks, and scope and requirements risks. This research also reveals some ways of dealing with these issues: seeking to consciously simplify business rules (i.e., requirements) in order to increase technical feasibility; applying a methodology better suited to the project characteristics; and protecting the project from the interference of political deadlines.
\end{abstract}





\section{SUMÁRIO}

LISTA DE ABREVIATURAS E SIGLAS …............................................................... 3

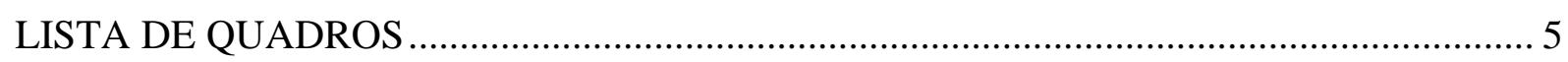

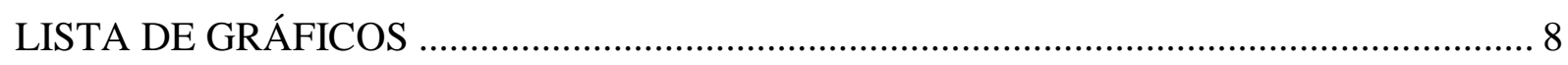

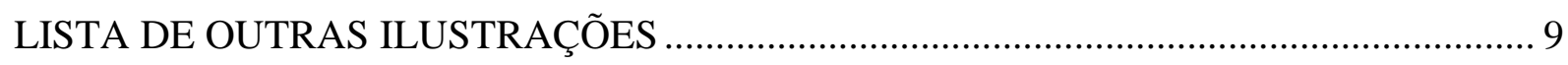

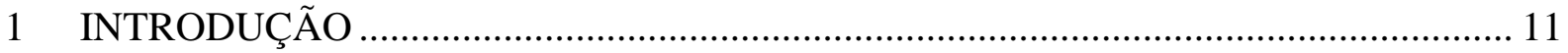

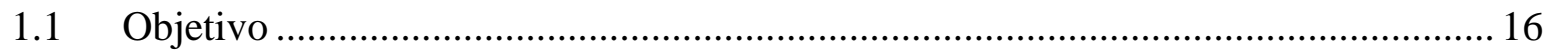

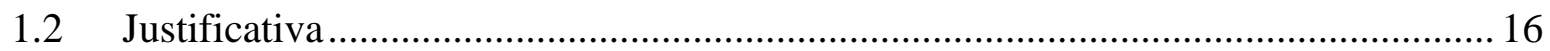

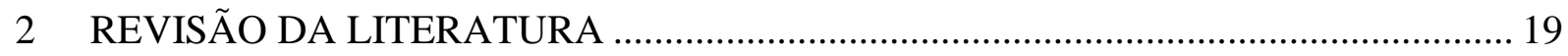

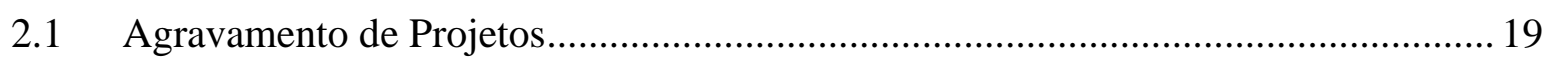

2.1.1 Agravamento de Projetos de Sistemas de Informação .......................................... 28

2.1.2 Aspectos Culturais do Agravamento de Projetos.................................................. 32

2.1.3 Modelos para De-Escalation do Projeto ................................................................... 39

2.1.4 Conclusões sobre a Literatura de Agravamento de Projetos ................................. 46

2.2 Gerenciamento de Riscos em Projetos de SI ............................................................... 48

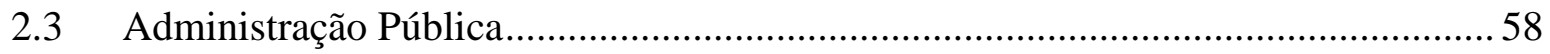

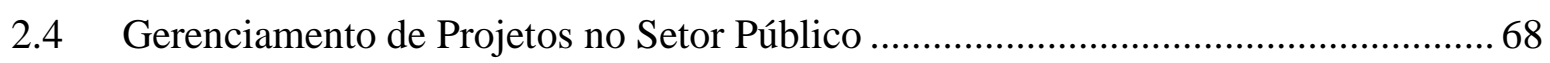

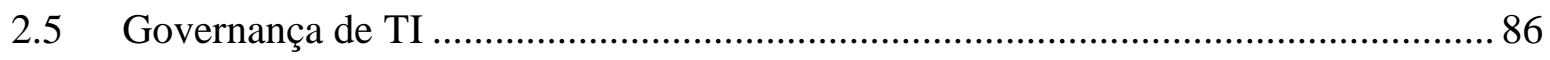

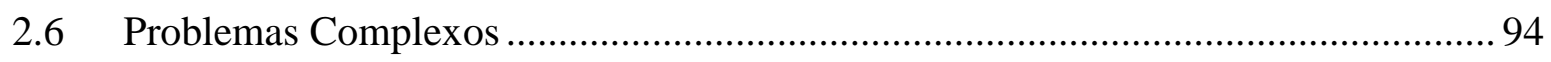

3 MODELO DE REFERÊNCIA E TEORIAS ALTERNATIVAS .................................. 103

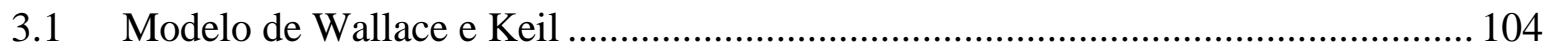

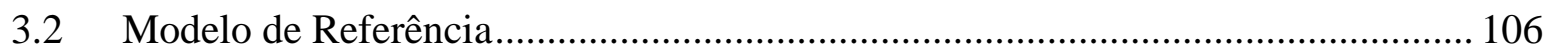

3.3 Modelo baseado nos conceitos de Governança de TI.......................................... 113

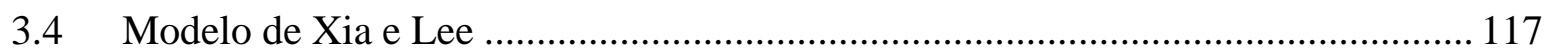

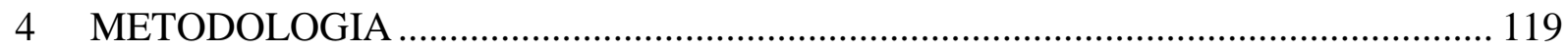

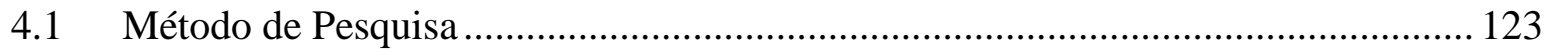

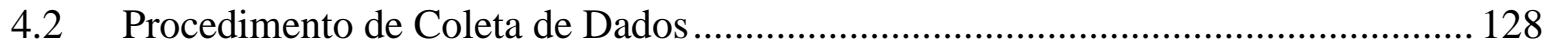

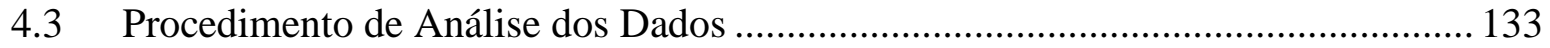

4.4 Resumo da Metodologia Utilizada ....................................................................... 136

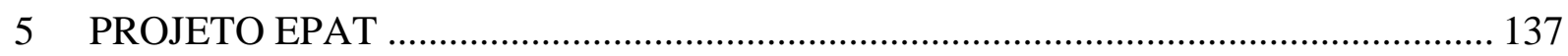

5.1 Primeira Fase do Projeto de BPM: Agravamento ............................................. 143

5.2 Segunda Fase do Projeto de BPM: Reorientação ............................................... 151 
5.3 Análise dos Fatores de Risco do Projeto ePAT …................................................ 152

5.4 Aderência dos Resultados às Teorias ......................................................................... 161

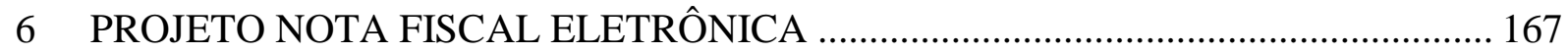

6.1 Primeira Fase do Projeto NF-e: Piloto (Fase Pré-operacional) .............................. 171

6.2 Segunda Fase do Projeto NF-e: Operacional..................................................... 173

6.3 Análise dos Fatores de Risco do Projeto NF-e ................................................. 175

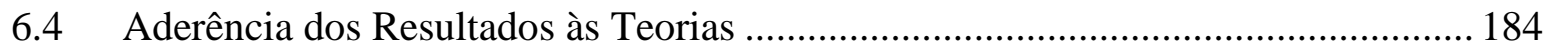

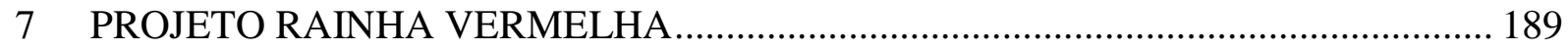

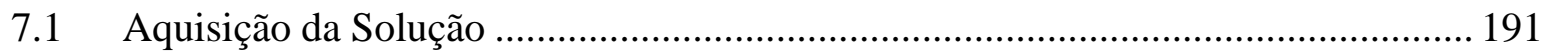

7.2 Primeira Fase do Projeto Rainha Vermelha: Paralelismo ......................................... 194

7.3 Segunda Fase do Projeto Rainha Vermelha: Tentativas de Reorientação ................ 198

7.4 Análise dos Fatores de Risco do Projeto Rainha Vermelha .................................. 207

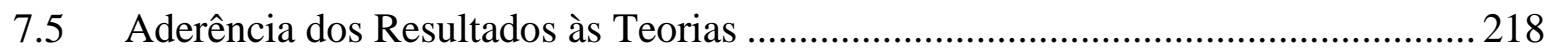

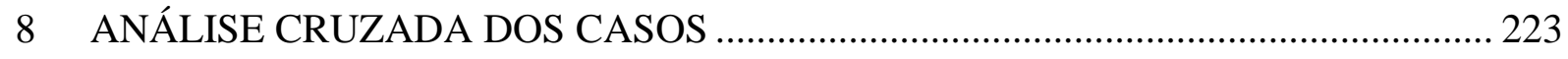

8.1 Aderência dos Casos à Literatura Prévia .............................................................. 228

8.2 Respostas às Questões de Pesquisa ........................................................................... 230

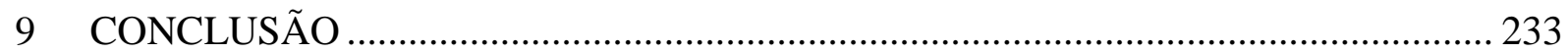

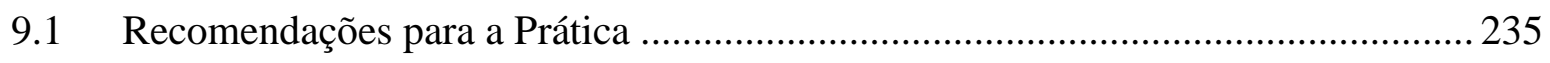

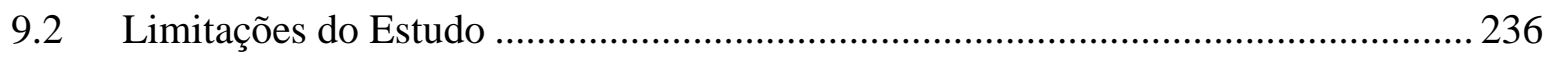

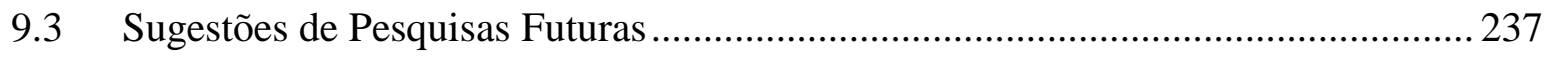

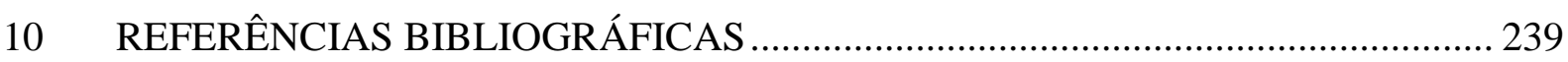

11 ANEXO: LISTA DOS DOCUMENTOS CONSULTADOS ….............................. 259

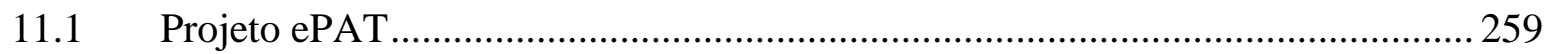

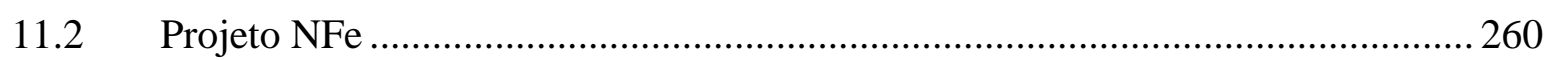

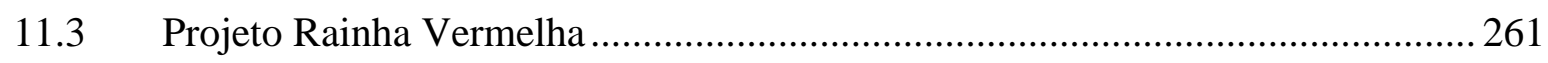




\section{LISTA DE ABREVIATURAS E SIGLAS}

ABRASF: Associação Brasileira dos Secretários de Finanças dos Municípios das Capitais

AFIAC: Assistência Fiscal de Informação, Avaliação e Controle (Secretaria da Fazenda do Estado de São Paulo)

BPM: Business Process Modeling (Modelagem de Processos de Negócio)

CAT: Coordenadoria da Administração Tributária (Secretaria da Fazenda do Estado de São Paulo)

COBIT: Control Objectives for Information and Related Technology

COTEPE: Comissão Técnica Permanente do Imposto sobre Operações Relativas à Circulação de Mercadorias e sobre Prestações de Serviços de Transporte Interestadual e Intermunicipal e de Comunicação

CPM: Coordenadoria de Planejamento Estratégico e Modernização Fazendária (Secretaria da Fazenda do Estado de São Paulo)

DANFE: Documento Auxiliar da Nota Fiscal Eletrônica

DBA: Database Administrator (Administrador de Banco de Dados)

DEG: Digital-Era Governance (Era da Governança Digital)

DA: Diretoria de Arrecadação (Secretaria da Fazenda do Estado de São Paulo)

DEAT: Diretoria Executiva da Administração Tributária (Secretaria da Fazenda do Estado de São Paulo)

DI: Diretoria de Informações (Secretaria da Fazenda do Estado de São Paulo)

DPG: Departamento de Planejamento e Gestão (Secretaria da Fazenda do Estado de São Paulo)

DRF: Diretoria da Representação Fiscal (Secretaria da Fazenda do Estado de São Paulo)

DTI: Diretoria de Tecnologia da Informação (Secretaria da Fazenda do Estado de São Paulo)

EAP: Estrutura Analítica do Projeto

ENAT: Encontro Nacional de Administradores Tributários

ENCAT: Encontro Nacional de Coordenadores e Administradores Tributários Estatuais ePAT: Processo Administrativo Tributário Eletrônico

ERP: Enterprise Resource Planning

eSCM: Electronic Sourcing Capability Model

eSCM-CL: Electronic Sourcing Capability Model - Client

eSCM-SP: Electronic Sourcing Capability Model - Service Provider 
IEC: International Electrotechnical Commission

IPMA: International Project Management Association

ISO: International Organization for Standardization

ITGI: Information Technology Governance Institute

ITSqc: Information Technology Services Qualification Center

MBA: Master in Business Administration

NF-e: Nota Fiscal Eletrônica

NPM: New Public Management (Nova Gestão Pública)

OECD: Organisation for Economic Co-Operation and Development (Organização para Cooperação e Desenvolvimento Econômico)

OGC: Office of Government Commerce

PERT: Program Evaluation and Review Technique

PMI: Project Management Institute

PMBOK: Project Management Body of Knowledge (Guia do Conhecimento em Gerenciamento de Projetos)

PRINCE2: Projects in Controlled Environments

PRODESP: Companhia de Processamento de Dados do Estado de São Paulo

PROFFIS: Programa de Fortalecimento da Gestão Fiscal do Estado de São Paulo

RAC: Real Application Clusters

SEFAZ: Secretaria da Fazenda do Estado de São Paulo

SI: Sistema de Informação

SINIEF: Sistema Nacional de Informações Econômicas e Fiscais

SPED: Sistema Público de Escrituração Digital

SUFRAMA: Superintendência da Zona Franca de Manaus

TI: Tecnologia da Informação

TIC: Tecnologia da Informação e Comunicação

TIT: Tribunal de Impostos e Taxas (Secretaria da Fazenda do Estado de São Paulo)

TIT2000: Antigo sistema de workflow do Tribunal de Impostos e Taxas (Secretaria da Fazenda do Estado de São Paulo)

WBS: Work Breakdown Structure (ver EAP)

XML: Extensible Markup Language

UEP: Unidade de Execução de Programa (Secretaria da Fazenda do Estado de São Paulo)

UCP: Unidade de Controle de Programa (Secretaria da Fazenda do Estado de São Paulo)

UML: Unified Modeling Language 


\section{LISTA DE QUADROS}

Quadro 1: Quatro teorias de agravamento e seus principais constructos 19

Quadro 2: Resultados da pesquisa de Garland e Conlon (1998). 25

Quadro 3: Táticas para manter o comprometimento e táticas para evitar o agravamento do comprometimento... 29

Quadro 4: Propensão a continuar o projeto 31

Quadro 5: Valores do Dinamismo Confuciano 34

Quadro 6: Comparação dos valores culturais de Estados Unidos, Canadá, Hong Kong, Cingapura e Brasil. 36

Quadro 7: Comparação dos valores culturais de Holanda, Finlândia, Cingapura e Brasil ...... 38

Quadro 8: Fatores que contribuem para a transição de agravamento para de-escalation ........ 40

Quadro 9: Fases e atividades que disparam o processo de de-escalation ................................. 42

Quadro 10: Causas-raiz que tornam um projeto problemático .............................................. 51

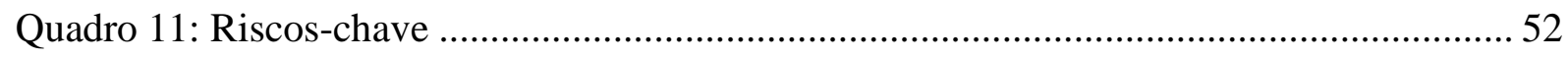

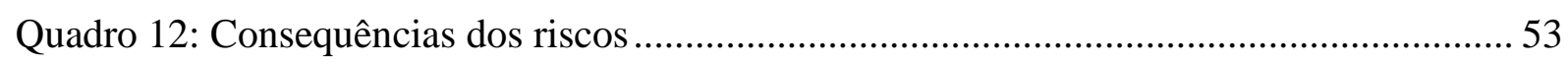

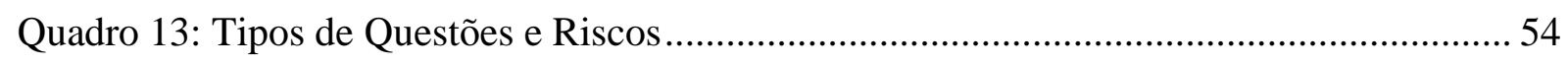

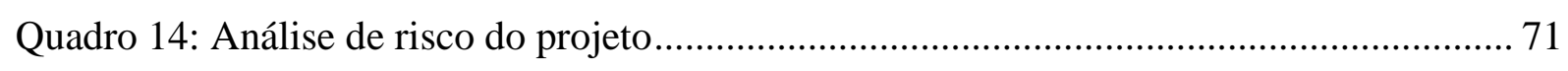

Quadro 15: Métodos de gerenciamento de projetos aplicados às categorias de risco.............. 72

Quadro 16: Agrupamento dos riscos iniciais do mandato do cliente .................................... 107

Quadro 17: Agrupamento dos riscos iniciais de escopo e requisitos .................................... 107

Quadro 18: Agrupamento dos riscos iniciais de execução.................................................. 108

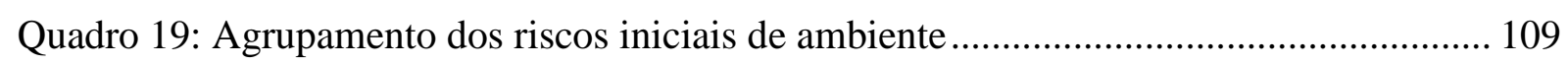

Quadro 20: Riscos relacionados à Governança de TI ......................................................... 115

Quadro 21: Comparação do elemento de complexidade estrutural organizacional do modelo

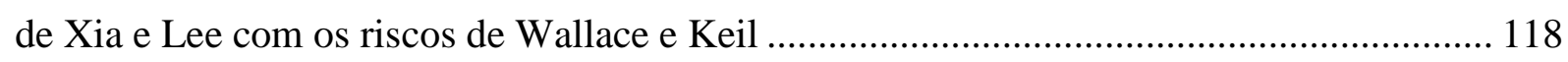

Quadro 22: Fontes de evidência na coleta de dados............................................................ 129

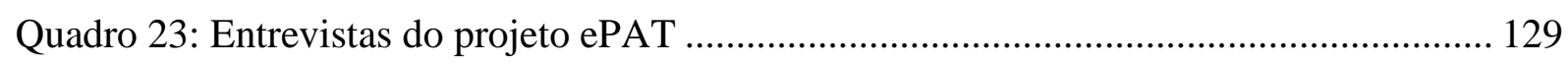

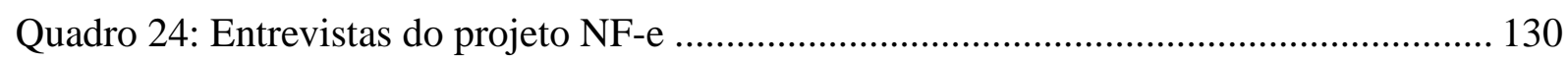

Quadro 25: Entrevistas do projeto Rainha Vermelha.......................................................... 131

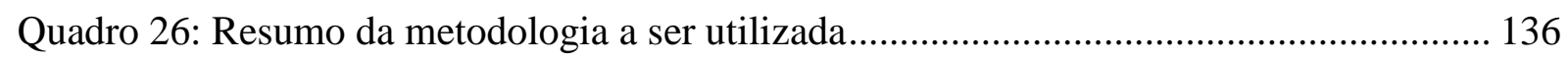

Quadro 27: Alterações de cronograma ocorridas no projeto ePAT, no período de abril a julho de 2010 . 
Quadro 28: Riscos consolidados do mandato do cliente no projeto ePAT ............................ 153

Quadro 29: Médias dos riscos consolidados do mandato do cliente no projeto ePAT ........... 154

Quadro 30: Riscos consolidados de escopo e requisitos no projeto ePAT ............................. 154

Quadro 31: Médias dos riscos consolidados de escopo e requisitos no projeto ePAT ........... 155

Quadro 32: Riscos consolidados de execução no projeto ePAT ............................................ 156

Quadro 33: Médias dos riscos consolidados do mandato do cliente no projeto ePAT .......... 157

Quadro 34: Riscos consolidados de ambiente no projeto ePAT.......................................... 158

Quadro 35: Médias dos riscos consolidados de ambiente no projeto ePAT .......................... 158

Quadro 36: Riscos de Governança de TI no projeto ePAT................................................ 159

Quadro 37: Médias dos riscos de Governança de TI no projeto ePAT................................. 159

Quadro 38: Riscos de complexidade estrutural do modelo de Xia e Lee no projeto ePAT... 160

Quadro 39: Médias dos riscos de complexidade estrutural do modelo de Xia e Lee no projeto

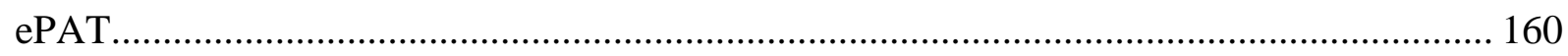

Quadro 40: Avaliação do caso do projeto ePAT em relação às proposições e teorias ........... 165

Quadro 41: Atividades preparatórias do projeto NF-e ........................................................ 170

Quadro 42: Riscos consolidados do mandato do cliente no projeto NF-e ............................. 176

Quadro 43: Médias dos riscos consolidados do mandato do cliente no projeto NF-e ............ 177

Quadro 44: Riscos consolidados de escopo e requisitos no projeto NF-e .............................. 178

Quadro 45: Médias dos riscos consolidados de escopo e requisitos no projeto NF-e ............ 178

Quadro 46: Riscos consolidados de execução no projeto NF-e ........................................... 179

Quadro 47: Médias dos riscos consolidados do mandato do cliente no projeto NF-e ............ 180

Quadro 48: Riscos consolidados de ambiente no projeto NF-e........................................... 181

Quadro 49: Médias dos riscos consolidados de ambiente no projeto NF-e ............................ 182

Quadro 50: Riscos de Governança de TI no projeto NF-e.................................................. 182

Quadro 51: Médias dos riscos de Governança de TI no projeto NF-e.................................. 183

Quadro 52: Riscos de complexidade estrutural do modelo de Xia e Lee no projeto NF-e.... 183

Quadro 53: Médias dos riscos de complexidade estrutural do modelo de Xia e Lee no projeto

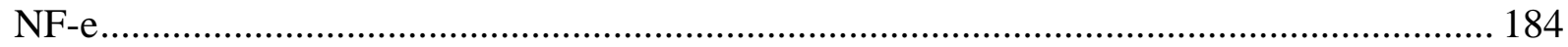

Quadro 54: Avaliação do caso do projeto NF-e em relação às proposições e teorias............. 188

Quadro 55: Riscos consolidados do mandato do cliente no projeto Rainha Vermelha ......... 209

Quadro 56: Médias dos riscos consolidados do mandato do cliente no projeto Rainha

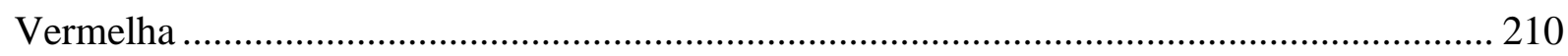

Quadro 57: Riscos consolidados de escopo e requisitos no projeto Rainha Vermelha.......... 211 
Quadro 58: Médias dos riscos consolidados de escopo e requisitos no projeto Rainha Vermelha

Quadro 59: Riscos consolidados de execução no projeto Rainha Vermelha 213

Quadro 60: Médias dos riscos consolidados do mandato do cliente no projeto Rainha Vermelha 214

Quadro 61: Riscos consolidados de ambiente no projeto Rainha Vermelha. 215

Quadro 62: Médias dos riscos consolidados de ambiente no projeto Rainha Vermelha 216

Quadro 63: Riscos de Governança de TI no projeto Rainha Vermelha. 217

Quadro 64: Médias dos riscos de Governança de TI no projeto Rainha Vermelha. 217

Quadro 65: Riscos de complexidade estrutural do modelo de Xia e Lee no projeto Rainha Vermelha.

Quadro 66: Médias dos riscos de complexidade estrutural do modelo de Xia e Lee no projeto Rainha Vermelha 218

Quadro 67: Avaliação do caso do projeto Rainha Vermelha em relação às proposições e teorias.... 222

Quadro 68: Avaliação das proposições e teorias em relação aos casos estudados 225 


\section{LISTA DE GRÁFICOS}

Gráfico 1: Arcabouço de classificação de risco 55

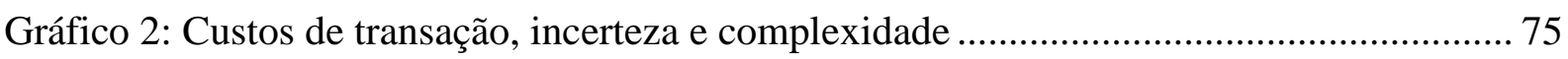

Gráfico 3: Dimensões e estágios do desenvolvimento de governo eletrônico........................... 82

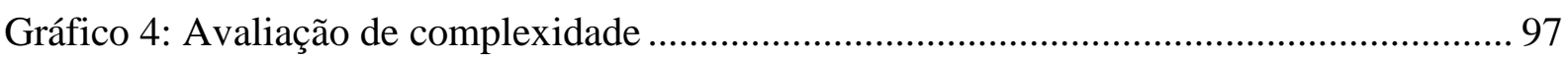

Gráfico 5: Tamanho versus complexidade e os ambientes de desenvolvimento de sistemas de

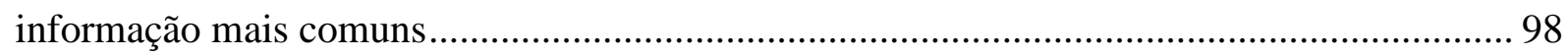

Gráfico 6: Taxonomia da complexidade do desenvolvimento de sistemas de informação ... 101

Gráfico 7: Evolução da data de término prevista para o projeto ePAT.................................. 149

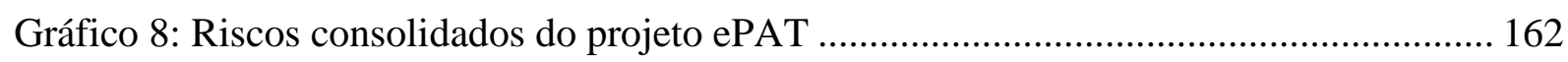

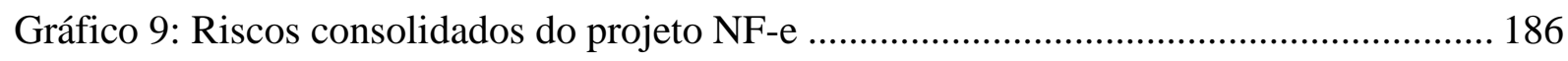

Gráfico 10: Evolução da data de término prevista para o projeto Rainha Vermelha............. 205

Gráfico 11: Riscos consolidados do projeto Rainha Vermelha.............................................. 220 


\section{LISTA DE OUTRAS ILUSTRAÇÕES}

Ilustração 1: Um modelo de processos para o de-escalation do projeto ................................... 41

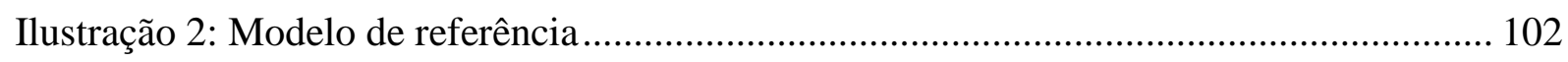

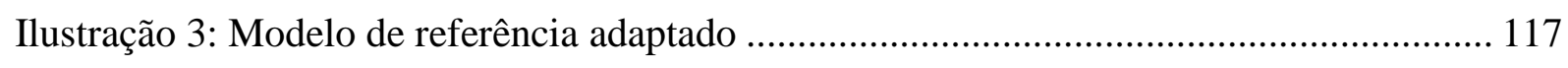

Ilustração 4: Quatro elementos do processo de pesquisa ...................................................... 120

Ilustração 5: Organograma das áreas da Secretaria da Fazenda envolvidas no projeto

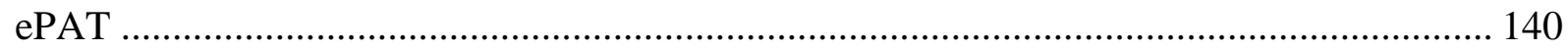

Ilustração 6: Linha do tempo do projeto ePAT - versão de 28/04/2010 ................................ 147

Ilustração 7: Organograma das áreas da Secretaria da Fazenda envolvidas no projeto

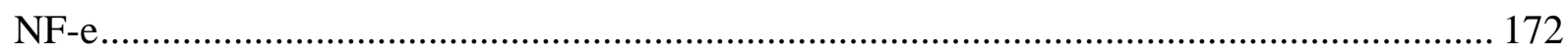

Ilustração 8: Cronograma tabular construído a partir do edital............................................. 193

Ilustração 9: Cronograma construído a partir do edital ......................................................... 194

Ilustração 10: Primeiro cronograma elaborado pelo consórcio Janus, referente à primeira etapa

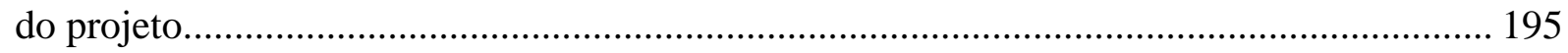

Ilustração 11: Comparação entre o primeiro e o segundo cronogramas .................................. 199

Ilustração 12: Terceiro cronograma oficial do projeto Rainha Vermelha.............................. 201

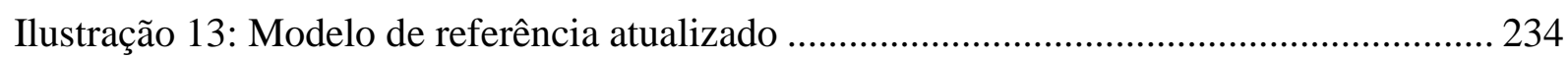




\section{INTRODUÇÃO}

Os projetos de desenvolvimento de sistemas tradicionalmente apresentam taxa muito baixa de conclusão bem-sucedida. Considerando os números do relatório Chaos referentes a 2008, somente $32 \%$ dos projetos de Tecnologia da Informação (TI) da amostra pesquisada foram considerados bem-sucedidos, enquanto $44 \%$ foram entregues com limitações de escopo, de orçamento ou de prazo e 24\% foram considerados fracassados (STANDISH GROUP, 2009).

Na administração pública, a taxa de sucesso é ainda menor. Segundo Heeks (2003, 2004), $15 \%$ dos projetos de TI do setor público de países em desenvolvimento foram considerados bem-sucedidos, enquanto $50 \%$ foram entregues com limitações de escopo, de orçamento ou de prazo e $35 \%$ foram classificados como fracassados.

Os riscos de um projeto de TI se tornar problemático são muitos e variados, incluindo riscos relacionados a aspectos técnicos, gerenciais e mesmo à Governança. Um caso extremo de problemas em projetos ocorre quando o projeto entra em situação de agravamento. Keil (1995) explica que, em alguns casos, o projeto de software pode adquirir uma vida própria, consumindo recursos valiosos sem nunca atingir seu objetivo. $\mathrm{O}$ agravamento é descrito como o contínuo comprometimento de recursos, apesar da existência de feedback negativo a respeito da possibilidade de o projeto atingir seus objetivos (KEIL, 1995).

A literatura sugere que projetos de TI podem ser particularmente suscetíveis a problemas de agravamento em razão da natureza intangível dos softwares, que torna difícil a obtenção de estimativas precisas de grande parte do trabalho a ser completado, o que pode levar a um agravamento do comprometimento por passar a falsa impressão de que o término bemsucedido do projeto está próximo (MONTEALEGRE; KEIL, 2000; PAN et al., 2006).

Além disso, projetos de TI são dinâmicos e geralmente possuem requisitos voláteis (ZMUD, 1980; MONTEALEGRE; KEIL, 2000), o que acarreta mudanças frequentes no escopo (MONTEALEGRE; KEIL, 2000). De acordo com Montealegre e Keil (2000), projetos com essa volatilidade são especialmente difíceis de medir e controlar, e, por isso, são candidatos ao agravamento. 
Smith $(2001$, p. 18,19$)$ sugere uma série de causas raiz que podem tornar um projeto problemático. Dentre elas, podemos destacar a falha do comprador em definir e documentar requisitos (funcionais e não funcionais), a falha do comprador em conseguir o envolvimento dos usuários finais e a falha em congelar uma linha de base dos requisitos e aplicar controle de mudanças.

As falhas listadas por Smith $(2001$, p. 18,19$)$ podem tornar um projeto problemático e, segundo Keil, Mann e Rai (2000), caso projetos problemáticos sejam continuados, quando a alternativa mais racional seria abandoná-los ou redirecioná-los, há o problema do agravamento do projeto. Além disso, os dados da pesquisa de Keil, Mann e Rai (2000) sugerem que de $30 \%$ a $40 \%$ de todos os projetos de TI sofrem algum grau de agravamento.

Projetos problemáticos são muito comuns na administração pública, especialmente em países em desenvolvimento. De acordo com De'(2005), em novembro de 2004, o especialista chefe do Banco Mundial, Robert Schware, disse que por volta de $85 \%$ dos sistemas de Governo Eletrônico implantados em países em desenvolvimento foram considerados falhas totais (35\%) ou parciais (50\%). Esses números são os mesmo apresentados por Heeks (2003, 2004).

Goodyear e Nelson (2007, p. 308) argumentam que o tamanho, a complexidade e a importância dos projetos de TI de grande porte no setor público estão aumentando e que esse tipo de projeto apresenta grande probabilidade de falhar.

Governo Eletrônico é entendido como a transformação dos relacionamentos interno e externo do setor público pelo uso da Tecnologia da Informação e Comunicação (TIC) para promover grande responsabilidade (accountability) do governo, aumentar a eficiência e a efetividade de custos, com maior participação dos eleitores (NAÇÕES UNIDAS, 2004).

Segundo a OECD (2001), a falta de habilidade dos governos para gerenciar grandes projetos de TI ameaça minar os esforços para implantar o Governo Eletrônico. O Relatório prossegue, afirmando que "a não ser que os governos aprendam a gerenciar os riscos associados a grandes projetos de TI, esses sonhos eletrônicos se transformarão em pesadelos" (OECD, 2001, tradução livre). 
Sarantis, Charalabidis e Askounis (2011) também citam a falta de habilidade das organizações governamentais para gerenciar grandes projetos de Governo Eletrônico, e complementam argumentando que um grande número de países formulou planos de ação ambiciosos para o desenvolvimento de projetos de Governo Eletrônico.

A partir de uma pesquisa na literatura, Furlong e Al-Karaghouli (2010) apontam vários desafios que devem ser enfrentados por projetos de Governo Eletrônico: gerenciar partes interessadas com interesses e culturas divergentes, o impacto das realidades políticas nos modelos de desenvolvimento e a necessidade de integração do resultado do projeto no ambiente macro da transformação do negócio, que inclui prazos políticos e o próprio prazo do projeto.

Complementarmente, muitos dos desafios descritos acima estão relacionados a questões de Governança. Weill e Ross (2006, p. 8) definem a Governança de TI como: “A especificação dos direitos decisórios e do framework de responsabilidades para estimular comportamentos desejáveis na utilização de TI".

Para estimular comportamentos desejáveis, é importante ter mecanismos bem estabelecidos para a tomada de decisão. Ao falarem de Governança de TI de uma maneira mais geral, Weill e Ross (2006, p. 159) explicam que mecanismos bem concebidos convertem comportamentos desejáveis de TI em resultados.

Uma das maneiras de estabelecer a Governança dos Projetos é pela aplicação de alguma metodologia que preveja em sua organização uma estrutura de papéis e responsabilidades, além de mecanismos de tomada de decisão. Entretanto, segundo Laia et al. (2011), as organizações da administração pública no Brasil, em grande medida, não possuem ou aplicam metodologias no gerenciamento de projetos, levantamento de requisitos, mapeamento ou gerenciamento de portfólio.

De acordo com o presidente do Standish Group, Jim Johnson (2006, p. 22), usuários e grupos de usuários precisam entender seus papéis e responsabilidades como parte da equipe. Além disso, Johnson (2006, p. 3) descreveu dez fatores críticos de sucesso para um projeto ser bemsucedido: envolvimento do usuário, suporte executivo, objetivos claros de negócio, escopo 
otimizado, processos ágeis, especialização (expertise) em gerenciamento de projetos, gestão financeira, recursos hábeis, metodologia formal e ferramentas.

De' e Sarkar (2010) apresentaram um estudo sobre o fracasso de um projeto de implementação de Governo Eletrônico, descrevendo o não envolvimento dos executivos de negócio, que acarretou na sensação de que o projeto era "esotérico, não trabalhável e descolado da realidade" (DE'; SARKAR, 2010, tradução livre).

Mumford (1985) explica que uma definição de requisitos pobre ocorre quando usuários não são adequadamente consultados sobre suas necessidades ou não são motivados a pensar seriamente sobre elas.

De' (2005) comenta que, normalmente, os aspectos relacionados a conflitos e resistência dos grupos relacionados com a entrega ou consumo dos serviços de Governo Eletrônico são negligenciados na literatura. Particularmente, no caso de países em desenvolvimento, a resistência das partes interessadas desempenha um papel crucial, pois os mecanismos institucionais existentes não tratam adequadamente os aspectos relacionados à interrupção, à interferência e à desintermediação dos serviços prestados por meio de Governo Eletrônico (DE', 2005).

Um dos aspectos dessa resistência é o fato de que novos sistemas na Administração Pública geralmente acarretam uma redistribuição do poder entre os atores-chave. Isso explica a variação na reação de grupos ou pessoas aos novos sistemas, pois os grupos beneficiados tendem a apoiar o sistema, enquanto os grupos ou pessoas que terão seu poder diminuído tendem a ser resistentes (DE', 2005).

Além das dificuldades mencionadas acima, é importante considerar a necessidade de incentivar cada tomador de decisão a escolher a rota mais adequada à organização e ao projeto. Segundo Staw e Ross (1987), o projeto "Deep Tunnel” em Chicago foi estruturado de forma a garantir o comprometimento. Vários autores citam o excesso de comprometimento como um fator que pode favorecer o agravamento (STAW; ROSS, 1987; KEIL, 1995; NEWMAN; SABHERWAL, 1996). 
Staw e Ross (1987) explicam que, em algumas situações, a decisão de perseverar somente agrava o risco, e a boa gestão consistiria na interrupção do projeto, ou seja, em "tirá-lo da tomada". Entretanto, a persistência é um valor cultural associado à percepção de uma liderança forte e a persistência que se transforma em sucesso é largamente recompensada (STAW; ROSS, 1987). Dessa forma, as organizações recompensam e incentivam um comportamento que, apesar de seus pontos positivos, pode levar ao agravamento do projeto.

Staw e Ross (1987) também argumentam que o sistema de recompensas deve ser estruturado de forma a encorajar o sucesso e reduzir as muitas forças que facilitam o agravamento do projeto. As empresas deveriam, por exemplo, recompensar a honestidade em reconhecer a existência de problemas e uma clara avaliação das alternativas, incluindo a de cancelamento do projeto.

O propósito desta pesquisa é aprimorar o entendimento dos riscos de um projeto de TI da Administração Pública se tornar problemático e entrar em situação de agravamento. Consequentemente, esse melhor entendimento propiciará o desenvolvimento de um modelo com mecanismos de detecção precoce, prevenção e contorno.

O texto desta tese foi organizado da seguinte forma:

- O capítulo 2 apresenta uma revisão bibliográfica que contempla os temas pertinentes à esta pesquisa, que incluem:

- Agravamento de Projetos:

- Agravamento de Projetos de Sistemas de Informação;

- Aspectos Culturais do Agravamento de Projetos;

- Modelos para De-Escalation do Projeto;

- Conclusões sobre a Literatura de Agravamento de Projetos;

○ Gerenciamento de Riscos em Projetos de SI;

○ Administração Pública;

- Gerenciamento de Projetos no Setor Público;

- Governança de TI;

○ Problemas Complexos (Wicked Problems);

- O capítulo 3 apresenta o modelo de referência e as teorias alternativas;

- O capítulo 4 explica a metodologia de pesquisa usada neste estudo; 
- Os capítulos 5, 6 e 7 apresentam os casos estudados;

- O capítulo 8 apresenta a análise cruzada dos casos;

- O capítulo 9 apresenta as conclusões do estudo e o modelo de referência atualizado.

\section{$1.1 \quad$ Objetivo}

O objetivo geral deste estudo é desenvolver um modelo para análise do agravamento de projetos de TI na administração pública.

Para atingir esses objetivos, os seguintes passos foram planejados e executados:

- Identificar os principais riscos que podem contribuir para que um projeto de TI na administração pública chegue à situação de agravamento;

- Identificar como os gestores de diferentes projetos de TI do setor público enfrentaram os riscos que influenciaram o agravamento;

- Identificar os principais fatores que dificultam a resolução do problema do agravamento em projetos de TI do setor público.

Dessa forma, as questões de pesquisa propostas são:

- Quais são os principais riscos que podem contribuir para que um projeto de TI do setor público chegue à situação de agravamento?

- Quais estratégias poderiam ser usadas para superar os problemas que promovem o agravamento de projetos de TI do setor público?

\section{$1.2 \quad$ Justificativa}

De forma resumida, as razões que justificam esta pesquisa sobre os riscos que tornam os projetos do setor público problemáticos e candidatos ao agravamento são as seguintes:

- A taxa de sucesso em projetos de TI é muito baixa (STANDISH GROUP, 2009), sendo ainda menor nos projetos de governo eletrônico de países em desenvolvimento (HEEKS, 2003; DE', 2005).

- A quantidade, o tamanho, a complexidade e a importância dos projetos de TI de grande porte no setor público estão aumentando (GOODYEAR; NELSON, 2007). 
- Projetos de TI de grande porte no setor público possuem grande probabilidade de falhar (GOODYEAR; NELSON, 2007).

- Existem indícios de que os gerentes de Sistemas de Informação estão fazendo um trabalho deficiente de identificação ou finalização de projetos que têm grande probabilidade de falhar (PAN et al., 2006).

- Projetos problemáticos deveriam ser detectados o mais cedo possível, para que seja possível aplicar alguma correção de rota em sua execução (PAN et al., 2006).

- Projetos de TI podem ser particularmente suscetíveis a problemas de agravamento (MONTEALEGRE; KEIL, 2000; PAN et al.; 2006).

- A falta de habilidade dos governos para gerenciar grandes projetos de TI ameaça minar os esforços de aplicação de Governo Eletrônico (OECD, 2001).

- A literatura sobre Agravamento de Projetos é principalmente baseada em teorias desenvolvidas nos Estados Unidos e Europa (SHARP; SALTER, 1997; CHOW et al., 1997; KEIL et al.; 2000).

- Apesar de ser largamente reconhecido na literatura e entre os praticantes que a complexidade causa baixo desempenho nos projetos, existe pouca evidência empírica a esse respeito (XIA; LEE, 2004).

- De forma geral, as organizações da administração pública no Brasil não costumam aplicar metodologias no gerenciamento de projetos, no levantamento de requisitos, no mapeamento ou no gerenciamento de portfólio (LAIA et al., 2011). 


\section{REVISÃO DA LITERATURA}

Primeiramente, a revisão bibliográfica abordará o problema do agravamento do projeto (Project Escalation), com foco no agravamento de projetos de desenvolvimento de SI. Além disso, serão abordados também conceitos relacionados à diferença entre o setor público e o privado e os fatores de sucesso e fracasso em projetos de desenvolvimento de SI na Administração Pública.

\subsection{Agravamento de Projetos}

As pesquisas sobre agravamento de projetos em geral, ainda sem ênfase nos projetos de SI, são relativamente antigas nos estudos de Administração, apesar de focadas principalmente em experimentos com estudantes universitários e de Master in Business Administration (MBA) nos Estados Unidos.

As principais teorias que explicam o agravamento de projetos começaram a se desenvolver ainda na década de 1970. De acordo com Keil, Mann e Rai (2000), as quatro principais teorias dessa fase inicial são: Teoria da Autojustificação (Self-Justification Theory), Teoria da Perspectiva (Prospect Theory), Teoria da Agência (Agency Theory) e Teoria do Afastamento e Aproximação (Approach Avoidance Theory). O Quadro 1 resume os principais constructos considerados em cada teoria:

Quadro 1: Quatro teorias de agravamento e seus principais constructos

\begin{tabular}{|l|l|}
\hline \multicolumn{1}{|c|}{ Teoria } & \multicolumn{1}{c|}{ Constructo-chave } \\
\hline $\begin{array}{l}\text { Teoria da Autojustificação } \\
\text { (Dissonância Cognitiva) }\end{array}$ & $\begin{array}{l}\text { Autojustificação Psicológica; } \\
\text { Autojustificação Social; }\end{array}$ \\
\hline Teoria da Perspectiva & Efeito do Sunk Cost; \\
\hline Teoria da Agência & $\begin{array}{l}\text { Incongruência (não alinhamento) entre } \\
\text { os objetivos; } \\
\text { Assimetria da informação; }\end{array}$ \\
\hline Teoria do Afastamento e Aproximação & $\begin{array}{l}\text { Percepção de proximidade ao objetivo } \\
\text { (completion effect }) .\end{array}$ \\
\hline
\end{tabular}

Fonte: adaptado de Keil, Mann e Rai (2000)

Segundo a Teoria da Autojustificação, baseada nos estudos de Festinger (1957) sobre dissonância cognitiva, gestores continuam a comprometer recursos para um curso de ação falho com o objetivo de autojustificar suas decisões anteriores. A necessidade de 
Autojustificação é tanto psicológica/interna quanto social/externa (KEIL; MANN; RAI, 2000).

Drummond e Hodgson (2011, p. 17) explicam que, de acordo com a teoria da dissonância cognitiva, as pessoas buscam estabelecer uma consistência entre suas crenças e seu comportamento. Por isso, e a fim de justificar sua decisão anterior de iniciar o projeto, os gestores, ao enfrentarem adversidades, tendem a aumentar o comprometimento investindo ainda mais dinheiro no projeto, na expectativa de corrigir sua rota.

Heng, Tan e Wei (2003) explicam que, em projetos com feedback negativo apresentado de forma pessimista, a probabilidade de sua continuidade é alta em situações nas quais o tomador de decisão tem baixa responsabilidade por sua situação atual. Uma das explicações de Heng, Tan e Wei (2003) é que o tomador de decisão justifica a continuidade do projeto atribuindo o fracasso atual à má gestão anterior. Essa explicação também é consistente com a teoria da dissonância cognitiva.

Staw e Ross (1978) explicam que a persistência individual no caso de falhas pode ser a decisão mais racional em alguns casos, mas que é necessário estudar os fatores psicológicos que podem introduzir vieses na tomada de decisão sobre a alocação de recursos. Os autores complementam esse raciocínio com a explicação de que indivíduos, após uma falha, processam informação de forma diferente do que fariam após um sucesso, e que esse processamento diferente pode explicar as diferenças no comprometimento com decisões referentes a políticas a serem aplicadas.

Northcraft e Wolf (1984) criticam a pesquisa de Staw e Ross (1978), pois as informações sobre os Sunk Costs e o feedback negativo são apresentadas, mas a expectativa de receita não é mencionada. Logo, a opção pela continuidade não poderia ser considerada totalmente irracional, pois as receitas previstas não foram explicadas e a expectativa de um tomador de decisão poderia ser a de uma grande receita futura.

Drummond e Hodgson (2011, p. 43) comentam que, segundo a pesquisa de Staw e Ross (1978), quando os tomadores de decisão enfrentam situações nas quais as dificuldades podem ser atribuídas a fatores externos que estão fora de seu controle, como, por exemplo, condições climáticas ou econômicas adversas, a probabilidade de seguimento do projeto é maior. Por 
outro lado, quando essas dificuldades são atribuídas, sem sombra de dúvidas, aos erros de julgamento de uma determinada pessoa, é maior a probabilidade de cancelamento do projeto, evitando o agravamento.

Brockner, Shaw e Rubin (1979) estudaram o processo de alocação de recursos e o estabelecimento de um limite de investimento de forma antecipada, a partir de uma experiência com alunos de graduação. Os autores concluíram que a condição de autossustentação, na qual o projeto continua, a menos que uma decisão de encerramento seja tomada, favorece o agravamento quando comparada à condição de término automático, na qual o projeto é encerrado, a menos que uma decisão de continuidade seja tomada.

De acordo com Drummond e Hodgson (2011, p. 18), se admitir a falha de forma privada já é uma decisão difícil, admiti-la em público é ainda mais difícil. Dessa maneira, a existência de uma audiência favorece a situação de agravamento. Entretanto, a audiência pode ser benéfica quando existe um limite de investimento de conhecimento público.

Segundo Brockner, Shaw e Rubin (1979) o estabelecimento antecipado de um limite de investimento, favorece a proteção ao agravamento. Quanto esse limite é publicamente divulgado, a proteção contra o agravamento é ainda maior.

Brockner (1992) defende que a Teoria da Autojustificação apresenta uma descrição mais completa do fenômeno do que a Teoria da Perspectiva, ao contrário do que foi proposto por Whyte (1986). Entretanto, Brockner (1992) sugere que explanações suplementares podem ajudar a explicar de forma mais completa o fenômeno do agravamento. O autor propõe mais estudos, baseados em teorias que expliquem o agravamento no âmbito do indivíduo, como a Teoria da Expectativa ou a Teoria da Perspectiva.

Um constructo importante para entender o agravamento segundo as teorias da Perspectiva e da Autojustificação é o conceito de Sunk Cost, que corresponde aos custos já incorridos que não podem ser recuperados. Whyte (1993) explica que, sob um ponto de vista econômico racional, esses custos passados não deveriam ser levados em conta na tomada de decisão. Entretanto, há indícios de que os tomadores de decisão têm sido influenciados por esses custos, ao contrário do que recomenda a teoria econômica. 
Whyte (1986) apresenta uma reinterpretação das explicações anteriores sobre agravamento a partir da Teoria da Perspectiva (KAHNEMAN; TVERSKY, 1979; TVERSKY; KAHNEMAN, 1981), considerada pelo autor mais abrangente do que a explicação pela Teoria da Autojustificação. Segundo Whyte (1986), o agravamento poderia ocorrer em uma variedade maior de situações, além daquela de autojustificar decisões prévias.

A maneira como o problema é formulado e apresentado interfere na tomada de decisão. Caso um problema seja formulado em função dos ganhos, a tomada de decisão tende a ser mais conservadora ou avessa ao risco. Por outro lado, caso o problema seja formulado em função das perdas, a tomada de decisão tende a ser mais propensa ao risco (KAHNEMAN; TVERSKY; 1979, TVERSKY; KAHNEMAN, 1981).

Whyte (1993) conclui que o agravamento ocorre na tomada de decisão tanto em nível individual quanto em grupo. Além disso, a tomada de decisão em grupo amplifica a tendência de agravamento. Os resultados da pesquisa de Whyte (1993), apesar de consistentes com a explicação da Teoria da Perspectiva, também poderiam ser explicados pela Teoria da Autojustificação. Entretanto, os motivos que levam à autojustificação não parecem ser uma condição necessária para a ocorrência do agravamento.

Garland, Sanderfur e Rogers (1990) fizeram um estudo considerando a presença de Sunk Costs e feedback negativo consistente com a Teoria da Perspectiva. A pesquisa envolveu três experimentos e foi estruturada considerando um cenário de agravamento em um projeto de exploração de petróleo. Os primeiros dois experimentos foram conduzidos com geólogos da área de Petróleo, e seus resultados foram contrários às conclusões de pesquisas anteriores sobre o agravamento, pois quanto maiores os Sunk Costs, menor a probabilidade de os geólogos autorizarem fundos adicionais e menor a probabilidade de estimar os resultados da próxima perfuração sob um ponto de vista otimista.

O terceiro experimento de Garland, Sanderfur e Rogers (1990) foi conduzido com estudantes de graduação. Os resultados desse experimento apontaram na mesma direção que os outros dois, mas foram estatisticamente não significativos, sugerindo que a experiência profissional é uma variável importante, mesmo não tendo sido considerada em outras pesquisas sobre agravamento, como, por exemplo, Rubin e Brockner (1975), Staw e Ross (1978), Brockner, Shaw e Rubin (1979) e Garland (1990). 
Drummond e Hodgson (2011, p. 23) explicam que os estudos conduzidos com profissionais de mercado apresentaram uma tendência menor ao agravamento do que os estudos conduzidos com alunos de graduação.

Quanto à Teoria da Agência (JENSEN; MECKLING, 1976), Keil, Mann e Rai (2000) explicam que pode existir uma incongruência entre os objetivos da gerência, preocupada com o impacto que o cancelamento do projeto teria em sua carreira e reputação, por exemplo, e os objetivos de seus superiores. Essa incongruência de objetivos contribuiria para o agravamento em condições de assimetria de informação, nas quais a gerência teria condições de manter certas informações inacessíveis aos seus superiores (KEIL; MANN; RAI, 2000).

Harrison e Harrell (1993) conduziram um experimento com alunos de MBA, estruturando sua pesquisa a partir da Teoria da Agência. Os autores argumentam que em situações nas quais ocorrer desalinhamento entre os interesses do principal (dono da empresa) e os do agente (administrador/gestor do projeto), conjuntamente com a assimetria da informação, a tomada de decisão do agente atenderá a seus próprios interesses, em detrimento dos interesses do principal. Dessa forma, uma decisão de continuidade ou agravamento do projeto que seria considerada irracional sob o ponto de vista do principal, seria considerada economicamente coerente sob o ponto de vista do agente.

Harrell e Harrison (1994), novamente em um experimento com alunos de MBA, concluíram que, na existência de seleção adversa (desalinhamento entre os interesses do principal e os do agente, conjuntamente com a assimetria da informação), gerentes que iniciaram o projeto e sejam considerados responsáveis por seu fracasso ou sucesso apresentam uma tendência maior de continuar o projeto. Além disso, os autores chegaram às seguintes conclusões:

- As condições associadas com a seleção adversa têm mais influência nas decisões de continuidade quando as projeções não são fortemente negativas;

- Quando as condições para seleção adversa não estão presentes, as pessoas tendem a tomar decisões no melhor interesse do principal;

- A análise conduzida pelos autores concluiu que experiência em supervisão e anos de experiência no negócio não tiveram um efeito significativo nos respondentes desse estudo, em relação aos problemas de agência. 
A Teoria do Afastamento e Aproximação (LEWIN, 1951) explica o agravamento pela disputa entre as forças que encorajam o agravamento e as que encorajam o cancelamento do projeto. Uma das forças que exercem um papel chave é a percepção de proximidade ao objetivo (RUBIN; BROCKNER, 1975; KEIL; MANN; RAI, 2000).

Rubin e Brockner (1975) usam o exemplo de cair em uma armadilha relacionada ao tempo de espera, como a decisão de esperar um ônibus ou fazer o trajeto a pé, supondo-se que a opção de percorrer o trajeto a pé seja razoável e aceitável. Rubin e Brockner (1975) explicam que, no início, é mais provável que seja tomada a decisão de retirada. Entretanto, uma vez que a decisão de esperar seja tomada, conforme o tempo passa, a percepção de que falta menos tempo para o objetivo, chamada tendência de aproximação, cresce mais rapidamente do que a tendência de afastamento. Dessa forma, o agravamento do comprometimento se torna mais provável.

Além disso, quanto maior a ambiguidade entre os custos e recompensas associados com a espera, menos a estrutura cognitiva está preparada para reagir e, consequentemente, essa falta de preparo contribui para as forças que direcionam para a continuidade da espera (RUBIN; BROCKNER, 1975).

Conlon e Garland (1993), apesar de reconhecerem a existência de uma correlação entre o nível de Sunk Costs e a proximidade do término do projeto, argumentam que a propensão dos tomadores de decisão em prosseguir com o projeto está muito mais relacionada à proximidade do término do projeto do que com o nível de Sunk Costs.

Garland e Conlon (1998) replicaram a pesquisa de Conlon e Garland (1993), com algumas adaptações. A primeira diferença está relacionada aos sujeitos da pesquisa. $\mathrm{Na}$ pesquisa anterior, Conlon e Garland (1993) haviam usado estudantes de graduação, enquanto na pesquisa mais recente foram usados, no primeiro experimento, gerentes experientes da área bancária que atuam em um cenário de empréstimos bancários; no segundo experimento foram usados estudantes chineses de pós-graduação nas áreas de Ciências e Engenharia; e no terceiro estudo foram usados estudantes de MBA do segundo ano e com considerável experiência de trabalho. 
Garland e Conlon (1998) apresentam a explicação referente à substituição do objetivo como uma alternativa à hipótese dos Sunk Costs, de forma que os objetivos que motivaram e justificaram o projeto são substituídos por um novo objetivo: terminar o projeto. Em contraste com a teoria dos Sunk Costs, a Teoria da Substituição do Objetivo não é baseada em investimentos passados, na pela percepção (ou crença) de que a conclusão do projeto está próxima (GARLAND; CONLON, 1998). O Quadro 2 apresenta um resumo das conclusões do artigo.

Quadro 2: Resultados da pesquisa de Garland e Conlon (1998)

\begin{tabular}{|c|c|c|}
\hline Estudo & Sujeitos & Conclusões \\
\hline Experimento I & $\begin{array}{l}\text { Gerentes }- \text { setor } \\
\text { financeiro/bancário }\end{array}$ & $\begin{array}{l}\text { - Confirmação da hipótese de que a proximidade de } \\
\text { completar o projeto contribui para a decisão de } \\
\text { continuar; } \\
\text { - O alto nível de Sunk Costs não contribuiu para a } \\
\text { decisão de continuar. }\end{array}$ \\
\hline Experimento II & $\begin{array}{lr}\text { Alunos chineses } & \text { de } \\
\text { pós-graduação } & \text { em } \\
\text { Ciências ou Engenharia }\end{array}$ & $\begin{array}{l}\text { - Confirmação da hipótese de que a proximidade de } \\
\text { completar o projeto contribui para a decisão de } \\
\text { continuar; } \\
\text { - Ao contrário da literatura anterior a respeito de Sunk } \\
\text { Costs, o alto nível de Sunk Costs contribuiu para a } \\
\text { decisão de cancelamento. }\end{array}$ \\
\hline Experimento III & $\begin{array}{l}\text { Estudantes de MBA do } \\
\text { segundo ano e } \\
\text { considerável } \\
\text { experiência }\end{array}$ & $\begin{array}{l}\text { - Confirmação da hipótese de que a proximidade de } \\
\text { completar o projeto contribui para a decisão de } \\
\text { continuar; } \\
\text { - O alto nível de Sunk Costs não contribuiu para a } \\
\text { decisão de continuar. }\end{array}$ \\
\hline
\end{tabular}

Fonte: adaptado de Garland e Conlon (1998).

Keil, Mann e Rai (2000) concluíram que o modelo baseado na Teoria do Afastamento e Aproximação classificou com sucesso $70 \%$ dos projetos (tanto os que sofreram como os que não sofreram agravamento). $\mathrm{O}$ modelo baseado na Teoria da Agência também teve um bom desempenho nos casos de projetos que sofreram e que não sofreram agravamento, com um menor poder de previsão do que a Teoria do Afastamento e Aproximação (KEIL; MANN; RAI, 2000).

Os modelos baseados na Teoria da Autojustificação e na Teoria da Perspectiva foram eficientes na classificação de projetos que sofreram agravamento, mas não tiveram um bom desempenho em projetos que não sofreram agravamento (KEIL; MANN; RAI, 2000).

Em uma crítica às pesquisas anteriores sobre o agravamento, Bowen (1987) propõe que, ao invés de considerarmos o agravamento a partir de um conjunto de erros na tomada de decisão, 
devemos considerá-lo a partir da existência de uma série de dilemas na tomada de decisão. Bowen (1987) argumenta que a conclusão de que o investimento foi um erro só pode ser feita a posteriori; por isso, o fenômeno do agravamento representa meramente uma reconstrução posterior do fato por observadores.

Staw e Ross (1987) explicam que diversos fatores favorecem o aprisionamento em um determinado curso de ação. Segundo esses autores, um projeto pode sair do controle a partir de fatores relacionados ao próprio projeto, além de fatores psicológicos, sociais e organizacionais.

Staw e Ross (1987) sugerem uma série de mudanças na organização para lidar com o problema do agravamento:

- Substituição dos tomadores de decisão que optaram por um determinado curso de ação, para minimizar o comprometimento e, consequentemente, tomar a decisão de forma mais objetiva no caso de reavaliação desse curso de ação;

- Substituir os tomadores de decisão para as decisões subsequentes no mesmo curso de ação, como acontece em certos bancos, que possuem uma equipe que trata de empréstimos problemáticos diferente da equipe que originalmente negociou o empréstimo;

- Reduzir o risco de falha, diminuindo seu impacto na carreira individual do tomador de decisão;

- Melhorar os sistemas de informação para evitar que a informação seja filtrada nos níveis hierárquicos inferiores antes de chegar aos tomadores de decisão;

- Melhorar o sistema de recompensas, incentivando a decomposição do projeto em partes menores e mais facilmente alcançáveis, oferecendo opções de saída ao tomador de decisão e incentivando o reconhecimento honesto dos problemas e um exame claro de suas alternativas, incluindo a opção de desistência.

Meredith (1988) propõe um modelo para facilitar o término antecipado de projetos problemáticos, a fim de que o agravamento seja tratado preventivamente. Esse modelo prevê a participação de auditores externos ao projeto, que, por não estarem ligados emocionalmente a ele, poderiam avaliar sua viabilidade de forma mais isenta. $\mathrm{O}$ autor propõe uma série de 
pontos de auditoria: uma antes do início do projeto, uma após seu início, seguidas por auditorias periódicas.

Drummond e Hodgson (2011) apresentam fatores adicionais que interferem na situação de agravamento:

- Feedback com sinais intermitentes: ambiguidade no feedback, feedback parte positivo e parte negativo, ou hora positivo e hora negativo, dificultam a tomada de decisão e favorecem o fenômeno de framing (DRUMMOND; HODGSON, 2011, p. 62);

- Diminuição das expectativas: passar a aceitar como natural um desempenho menor favorece o agravamento (DRUMMOND; HODGSON, 2011, p. 63);

- Ligação emocional (e irracional) com o objeto do projeto favorece o agravamento (DRUMMOND; HODGSON, 2011, p. 63);

- Incidentes críticos costumam interromper o ciclo do agravamento ao eliminarem as últimas dúvidas quanto à impossibilidade de alcançar o sucesso (DRUMMOND; HODGSON, 2011, p. 71);

- Em grandes organizações, apostas laterais adicionam pressão pela continuidade do projeto (DRUMMOND; HODGSON, 2011, p. 80). As autoras citam o caso das Olimpíadas de Londres, nas quais uma série de partes interessadas, tais como hotéis e restaurantes, investiu nos Jogos Olímpicos e faria pressão pela continuidade no caso de um cancelamento ser considerado.

De maneira geral, a maior parte dos artigos relacionados ao agravamento foi baseada em pesquisas com estudantes de graduação em Administração ou Engenharia e estudantes de MBA com experiência profissional. Consequentemente, apesar da contribuição que experimentos em laboratório, com suas variáveis bem controladas, trazem à teoria, essa contribuição é limitada, pois está afastada do contexto e da complexidade do mundo real.

Esse afastamento do contexto do mundo real pode ser percebido até mesmo nas próprias críticas a respeito de pesquisas de outros autores. Northcraft e Wolf (1984), por exemplo, explicam que, de forma geral, as pesquisas sobre Sunk Costs na área de psicologia têm explicado de forma limitada o feedback negativo, e a informação fornecida raramente é suficiente para se efetuarem os cálculos de custos e receitas futuras. 
Drummond e Hogdson (2011, p. 6) defendem o uso de estudos de caso em pesquisas sobre agravamento, pois eles permitem que o pesquisador investigue as percepções do tomador de decisão, suas emoções e as influências do contexto, além de serem baseados em problemas reais.

\subsubsection{Agravamento de Projetos de Sistemas de Informação}

Em uma pesquisa relacionada a projetos de SI, Keil (1995) considera fatores de projeto, psicológicos, sociais e organizacionais, baseado no modelo proposto por Staw e Ross (1987) para projetos em geral.

Dentre os fatores de projeto que poderiam favorecer o agravamento, Keil (1995) adota: (1) a existência de evidências de que um contínuo investimento poderia produzir um grande retorno; (2) considerar o projeto como um investimento em pesquisa e desenvolvimento e (3) classificar as dificuldades encontradas como problemas temporários.

Em relação aos fatores psicológicos, Keil (1995) inclui um histórico de sucessos em projetos anteriores, alto nível de comprometimento (responsabilidade) pessoal com os resultados do projeto, os erros na avaliação/processamento das informações e a ligação emocional com o projeto.

Newman e Sabherwal (1996) explicam que, de forma geral, o comprometimento é positivo para o sucesso do projeto, mas em determinados casos, caso esse comprometimento se torne excessivo, ele pode contribuir para o agravamento do projeto. Além disso, inviabilidade de alternativas, baixo valor residual (salvage value), alto custo adicional para interromper ou cancelar o projeto, o valor atribuído à superação de obstáculos (turnarounds), o apoio explícito e público de executivos influentes ao projeto contribuem para seu agravamento. $\mathrm{O}$ Quadro 3 apresenta um resumo das táticas para manter o comprometimento e para evitar o agravamento do comprometimento. 


\section{Quadro 3: Táticas para manter o comprometimento e táticas para evitar} o agravamento do comprometimento

\begin{tabular}{|l|l|}
\hline \multicolumn{1}{|c|}{ Táticas para manter o comprometimento } & \multicolumn{1}{|c|}{$\begin{array}{c}\text { Táticas para evitar o agravamento do } \\
\text { comprometimento }\end{array}$} \\
\hline Enfatizar a grande rentabilidade do projeto. & $\begin{array}{l}\text { Promover reavaliações periódicas da viabilidade do } \\
\text { projeto. }\end{array}$ \\
\hline $\begin{array}{l}\text { Atribuir os problemas encontrados no projeto a } \\
\text { causas temporárias. }\end{array}$ & Quebrar o sistema em entregas modulares. \\
\hline $\begin{array}{l}\text { Preferir projetos de sistemas de informação apoiados } \\
\text { por um grande grupo de partes interessadas do que } \\
\text { projetos apoiados por um ou dois indivíduos. }\end{array}$ & $\begin{array}{l}\text { Separar a responsabilidade dos indivíduos, isto é, } \\
\text { excluir os indivíduos que inicialmente aprovaram o } \\
\text { projeto do grupo que vai reavaliá-lo posteriormente. }\end{array}$ \\
\hline $\begin{array}{l}\text { Buscar suporte de outras partes interessadas para } \\
\text { apoiar o projeto explicita e publicamente. }\end{array}$ & $\begin{array}{l}\text { Reduzir a severidade das punições decorrentes de } \\
\text { falhas. }\end{array}$ \\
\hline Enfatizar os valores de persistência e superação. & \\
\hline
\end{tabular}

Fonte: adaptado de Newman e Sabherwal (1996)

Keil (1995) aponta também como fatores sociais a competitividade existente entre as áreas envolvidas no projeto, a necessidade de se justificar perante o público externo (clientes e o mercado em geral) e as normas/valores da empresa, como, por exemplo, a valorização da persistência e da atitude heroica de salvar um projeto problemático.

Finalmente, Keil (1995) descreve os fatores organizacionais, dentre os quais a existência de defensores do projeto com grande influência na organização e que continuem a financiar e proteger o projeto, a construção de um feudo, recursos negligentes e controles de gestão pouco rigorosos.

Heng, Tan e Wei (2003) analisam o efeito da direção do feedback (positivo ou negativo), a maneira como o feedback é apresentado (otimista ou pessimista) aos tomadores de decisão e seu efeito no agravamento do projeto em condições de alta e baixa sensação de responsabilidade (accountability) pelo projeto.

Heng, Tan e Wei (2003) usam como ponto de partida a hipótese de que gerentes de projetos que tenham participado desde o início de seus projetos de sistemas provavelmente se sentirão mais responsáveis do que gerentes de projetos que tenham assumido o comando de um projeto posteriormente. Esta hipótese está alinhada com a Teoria da Autojustificação de Festinger (1957).

Em condições de alta sensação de responsabilidade, as pessoas ficam mais propensas a continuar seus projetos de sistemas ao receberem feedback positivo e/ou feedback de qualquer 
tipo apresentado de forma otimista/positiva. Logo, os efeitos da direção do feedback (positivo ou negativo) e o otimismo em relação à continuidade do projeto são aditivos em condições de alta percepção de responsabilidade (HENG; TAN; WEI, 2003).

Drummond e Hodgson (2011, p. 15) explicam que os riscos de agravamento aumentam quando os tomadores de decisão podem ser pessoalmente responsabilizados pelo fracasso do projeto.

Em condições de baixa sensação de responsabilidade, as pessoas ficam mais propensas a continuar seus projetos de sistemas ao receberem feedback positivo apresentado de forma otimista ou feedback negativo apresentado de forma pessimista. Logo, os efeitos da direção do feedback (positivo ou negativo) e o otimismo em relação à continuidade do projeto são interativos em condições de baixa percepção de responsabilidade (HENG; TAN; WEI, 2003).

Drummond e Hodgson (2011, p. 21) usam o termo framing para observar que a maneira como o problema é apresentado interfere na tomada de decisão. Conforme mencionado anteriormente, de acordo com a Teoria da Perspectiva, os tomadores de decisão tendem a ser mais avessos ao risco quando o problema é formulado em função dos ganhos e mais propensos ao risco quando o problema é formulado em função das perdas (KAHNEMAN; TVERSKY, 1979; TVERSKY; KAHNEMAN, 1981).

Aprofundando o estudo do conceito de framing, Dunegan (1993) explica que a maneira pela qual o problema é apresentado interfere também no modelo cognitivo usado para processar a informação. Considerando-se, por exemplo, uma equipe de projetos com $40 \%$ de projetos bem-sucedidos e $60 \%$ de projetos malsucedidos, a informação de que "a equipe tem uma taxa de sucesso de 40\%" apresenta o fato de forma positiva, ao passo que a informação de que "a equipe tem uma taxa de fracasso de 60\%" apresenta o mesmo fato, mas de forma negativa. De acordo com as pesquisas de Dunegan (1993), ao expressarmos a informação de forma positiva disparamos um modelo cognitivo mais automático e superficial, e ao expressarmos a mesma informação de forma negativa, disparamos um modelo cognitivo mais cauteloso e sistemático. Consequentemente, a apresentação da informação de forma negativa tende a disparar uma análise mais aprofundada e rigorosa do problema. 
Segundo Heng, Tan e Wei (2003), nos casos de alta responsabilidade, as pessoas tendem a resolver as contradições entre a direção do feedback e a forma pela qual ele é apresentado, aumentando sua percepção subjetiva de que o projeto dará certo e, consequentemente, a tendência a continuar o projeto. O Quadro 4 resume as conclusões de Heng, Tan e Wei (2003).

Quadro 4: Propensão a continuar o projeto

\begin{tabular}{|l|l|l|l|}
\hline $\begin{array}{c}\text { Responsabilidade } \\
\text { (accountability) }\end{array}$ & Feedback & Apresentação & $\begin{array}{c}\text { Propensão a } \\
\text { continuar o projeto }\end{array}$ \\
\hline Alta & Positivo & Otimista & Alta \\
\hline Alta & Negativo & Otimista & Alta \\
\hline Alta & Positivo & Pessimista & Alta \\
\hline Alta & Negativo & Pessimista & Baixa \\
\hline Baixa & Positivo & Otimista & Alta \\
\hline Baixa & Negativo & Otimista & Baixa \\
\hline Baixa & Positivo & Pessimista & Baixa \\
\hline Baixa & Negativo & Pessimista & Alta \\
\hline
\end{tabular}

Fonte: baseado em Heng, Tan e Wei (2003)

Drummond e Hogson (2011, p. 20) explicam esse comportamento otimista a partir da teoria da Dissonância Cognitiva. Os autores argumentam que a relutância em descartar os Sunk Costs direciona o reinvestimento e o subsequente otimismo exagerado.

Nos casos de baixa responsabilidade, as pessoas tendem a resolver as contradições entre a direção do feedback e a forma com que ele é apresentado, diminuindo sua percepção subjetiva de que o projeto dará certo e, consequentemente, a tendência a continuar o projeto (HENG; TAN; WEI, 2003).

Contrariamente ao senso comum, em condições de baixa responsabilidade, quando um feedback negativo é apresentado de forma pessimista, as pessoas apresentam grande motivação para continuar o projeto (HENG; TAN; WEI, 2003). Os autores apresentam três possíveis explicações a esse comportamento:

- Atribuir os problemas do projeto à má gestão anterior;

- Oportunidade de superar as adversidades; 
- Competição, quando as pessoas percebem a consequência da falha como pouco severa (não ser responsabilizado pelo insucesso do projeto).

\subsection{2}

\section{Aspectos Culturais do Agravamento de Projetos}

A literatura sobre Agravamento de Projetos é principalmente baseada em teorias desenvolvidas nos Estados Unidos e Europa (CHOW et al., 1997; SHARP; SALTER, 1997; KEIL et al., 2000). Existem pesquisas que criticam a aplicabilidade das teorias desenvolvidas nesses países a outros contextos culturais (TSE et al., 1988; BOYACIGILLER; ADLER, 1991; CHOW et al., 1997; SHARP; SALTER, 1997; KEIL et al., 2000; HOFSTEDE; HOFSTEDE; MINKOV, 2010).

Chow et al. (1997) desenvolveram uma pesquisa na qual foram analisados três aspectos: responsabilidade inicial, a forma pela qual as informações econômicas são apresentadas e o contexto cultural do país. Essa pesquisa foi conduzida com participantes dos Estados Unidos e de Taiwan, e um aspecto importante mencionado no texto é a característica cultural chinesa de preocupação maior com a preservação da credibilidade entre as pessoas (HO, 1976).

Ho (1976) explica que o conceito denominado face em inglês está relacionado tanto ao prestígio e reputação perante as outras pessoas, quanto à confiança que as outras pessoas depositam em seu caráter moral. Essa perda da face implicaria sanções sociais e internas (psicológicas).

No dicionário Houaiss (2007, p. 1004), algumas das explicações sobre a palavra “desmoralizar" (especialmente 2 e 3 ) apresentam características semelhantes à descrição que Ho (1976) faz do conceito de loosing face:

1. "fazer perder ou perder o senso moral, tornar(-se) imoral; corromper(-se)";

2. "fazer perder ou perder o ânimo, a força moral, a confiança em si próprio; desencorajar(-se), desanimar(-se)";

3. "fazer perder ou perder o bom nome, a boa reputação; desacreditar(-se), depreciar(se), desonrar(-se)". 
Tse et al. (1988), em uma pesquisa conduzida na China, Hong Kong e Canadá, sugere que a preocupação dos chineses em não serem desmoralizados os tornaria mais propensos a continuar em um determinado curso de ação, mesmo que os sinais de fracasso fossem aparentes, pois o reconhecimento do fracasso desmoralizaria sua reputação como tomadores de decisão.

Em geral, a pesquisa de Chow et al. (1997) encontrou apenas indícios fracos de que indivíduos responsáveis por decisões anteriores de continuidade do projeto teriam maior propensão a investir recursos adicionais no projeto quando comparados com indivíduos que não tivessem essa responsabilidade. Chow et al. (1997) argumentam que sua pesquisa foi construída a partir do conceito de informações orientadas ao futuro, que, de acordo com a pesquisa de Harrison e Harrell (1993), diminui o efeito da responsabilidade inicial.

Além disso, também foram encontrados apenas indícios fracos de que indivíduos que recebem informação apresentada de maneira negativa têm mais propensão a investir recursos adicionais no projeto do que indivíduos que recebem informação apresentada de maneira positiva (CHOW et al., 1997).

Em relação à maior propensão dos chineses de Taiwan em continuar o projeto, essa hipótese foi fortemente suportada pelos dados, o que é consistente com a teoria de que os chineses teriam maior preocupação em manter sua reputação e credibilidade (CHOW et al., 1997). Alternativamente, Chow et al. (1997) explicam que os chineses poderiam ser simplesmente mais propensos a risco do que os estadunidenses. Entretanto, essa alternativa não é corroborada por pesquisas relacionadas às diferenças culturais entre países. As pesquisas realizadas por Hofstede, Hofstede e Minkov (2010, p. 193) atribuem índice de 69 à variável de fuga à incerteza de Taiwan, enquanto dos Estados Unidos foi atribuído o índice de 46 (HOFSTEDE; HOFSTEDE; MINKOV, 2010, p. 194), o que significa que a cultura dos Estados Unidos é classificada como mais propensa ao risco do que a de Taiwan.

Segundo Hofstede, Hofstede e Minkov (2010, p. 191), o índice de fuga à incerteza está relacionado a quanto os membros de uma determinada cultura se sentem ameaçados por situações ambíguas ou incertas. Ele indica em que medida a cultura direciona seus membros a se sentirem confortáveis ou desconfortáveis em situações não estruturadas. 
Em outra pesquisa sobre Agravamento do Projeto baseada em aspectos culturais, Sharp e Salter (1997) defendem a hipótese de que gerentes asiáticos (representados por Hong Kong e Cingapura) teriam menor propensão de agir em interesse próprio (menor efeito da Teoria da Agência) e seriam mais propensos ao agravamento se recebessem informação apresentada de forma negativa (maior impacto da Teoria da Perspectiva), em comparação com os norteamericanos (estadunidenses e canadenses).

Ao formularem suas hipóteses, Sharp e Salter (1997) consideraram dois fatores culturais citados por Hofstede, Hofstede e Minkov (2010, p. 30): o individualismo/coletivismo e o dinamismo confuciano. Segundo Hofstede, Hofstede e Minkov (2010, p. 92), em culturas individualistas as pessoas se preocupam consigo próprias e com seus parentes mais próximos. Em culturas mais coletivistas, desde o nascimento as pessoas são integradas em grupos mais coesos, em alguns casos em um grupo familiar expandido (avós, tios). Além disso, as pessoas são protegidas pelo grupo em troca de uma forte lealdade (HOFSTEDE; HOFSTEDE; MINKOV, 2010, p. 92).

Segundo Sharp e Salter (1997), em culturas com maior coletivismo, como, por exemplo, nos países asiáticos, os efeitos da Teoria da Agência seriam menores.

No caso do dinamismo confuciano ou da orientação a longo ou a curto prazo, valores associados à orientação a longo prazo são a poupança e a perseverança; valores associados à orientação a curto prazo são o respeito pela tradição, o cumprimento das obrigações sociais, e a proteção da própria credibilidade (HOFSTEDE; HOFSTEDE; MINKOV, 2010).

Os valores associados ao dinamismo confuciano são apresentados no Quadro 5 (CHINESE CULTURE CONNECTION, 1987).

Quadro 5: Valores do Dinamismo Confuciano

\begin{tabular}{|ll|ll|}
\hline \multicolumn{2}{|c|}{ Longo Prazo } & & \multicolumn{1}{c|}{ Curto Prazo } \\
\hline$\bullet$ & $\begin{array}{l}\text { Relações ordenadas, com respeito à } \\
\text { hierarquia; }\end{array}$ & $\bullet$ & $\begin{array}{l}\text { Retribuir na mesma moeda (o bem e o } \\
\text { mal); }\end{array}$ \\
\hline$\bullet$ & Frugalidade (parcimônia); & $\bullet$ & Inflexibilidade pessoal; \\
\hline$\bullet$ & Perseverança (persistência); & $\bullet$ & Proteger sua credibilidade (face); \\
\hline & Ter um sentimento/sentido de vergonha. & $\bullet$ & Respeito pelas tradições. \\
\hline
\end{tabular}

Fonte: baseado em Chinese Culture Connection (1987) 
Segundo Sharp e Salter (1997), em culturas com valores confucianos mais difundidos (maior orientação de longo prazo), como no caso dos países asiáticos, os efeitos da Teoria da Perspectiva seriam maiores, pois o sentimento de vergonha é mais intenso e o efeito de uma apresentação negativa das informações seria maior; além disso, os gerentes asiáticos seriam mais propensos ao agravamento do projeto do que os gerentes norte-americanos.

De forma resumida, Sharp e Salter (1997) apresentaram as seguintes conclusões:

- Os resultados suportam a utilização da Teoria da Agência para explicar o Agravamento de Projetos em culturas mais individualistas e utilitaristas (ex: Estados Unidos e Canadá), mas oferecem indícios muito fracos de que essa teoria explica o Agravamento de Projetos em países mais coletivistas e com maior senso de lealdade (ex.: Hong Kong e Cingapura);

- O efeito de uma apresentação negativa das informações é forte tanto na Ásia quanto na América do Norte. Apesar de o efeito parecer universal, sua intensidade não é a mesma e seria um engano assumir que os efeitos são idênticos nos vários países;

- Os gerentes asiáticos são mais propensos a assumir riscos em operações e menos propensos a assumir riscos financeiros do que os gerentes norte-americanos. Logo, os gerentes asiáticos são mais propensos a assumir riscos em projetos. Os autores sugerem mais pesquisas para avaliar a importância da orientação a longo prazo e da preocupação com a desmoralização (lose face) e identificar outros motivos para o agravamento.

- Muitas das pesquisas anteriores, principalmente no campo da Psicologia, usaram alunos de graduação para avaliar o agravamento. Existem indícios de que os resultados com alunos de graduação não são generalizáveis para populações mais velhas.

No caso de pesquisas conduzidas no Brasil a respeito do Agravamento de Projetos, seria interessante considerar os índices culturais brasileiros, comparando-os com os índices de outros países pesquisados, conforme o Quadro 6 (os valores em negrito correspondem às variáveis usadas na pesquisa): 
Quadro 6: Comparação dos valores culturais de Estados Unidos, Canadá, Hong Kong, Cingapura e Brasil

\begin{tabular}{|l|r|r|r|r|r|}
\hline \multicolumn{1}{|c|}{ País } & \multicolumn{1}{c|}{$\begin{array}{c}\text { Distância } \\
\text { do Poder }\end{array}$} & \multicolumn{1}{c|}{$\begin{array}{c}\text { Individualismo/ } \\
\text { Coletivismo }\end{array}$} & $\begin{array}{l}\text { Masculinidade/ } \\
\text { Feminilidade }\end{array}$ & $\begin{array}{c}\text { Fuga à } \\
\text { Incerteza }\end{array}$ & $\begin{array}{c}\text { Dinamismo } \\
\text { Confuciano }\end{array}$ \\
\hline Estados Unidos & 40 & $\mathbf{9 1}$ & 62 & 46 & $\mathbf{2 9}$ \\
\hline Canadá & 39 & $\mathbf{8 0}$ & 52 & 48 & $\mathbf{2 3}$ \\
\hline Hong Kong & 68 & $\mathbf{2 5}$ & 47 & 29 & $\mathbf{9 6}$ \\
\hline Cingapura & 74 & $\mathbf{2 0}$ & 49 & 76 & $\mathbf{4 8}$ \\
\hline Brasil & 69 & $\mathbf{3 8}$ & & $\mathbf{6 5}$ \\
\hline
\end{tabular}

Fonte: baseado em Hofstede, Hofstede e Minkov (2010)

Para interpretar melhor o Quadro 6, é importante enfatizar as características das pesquisas realizadas por Hofstede, Hofstede e Minkov (2010), como a variação da escala entre 0 e 100 e o fato de que as pesquisas originais foram conduzidas nas diversas unidades da IBM, o que contribuiu para validar as diferenças entre países, pois a cultura organizacional da própria IBM influenciou todos os países. Entretanto, ao pesquisar o setor público de um país específico, podemos questionar se as conclusões de Hofstede, Hofstede e Minkov (2010) continuam aplicáveis.

Segundo Hofstede, Hofstede e Minkov (2010, p. 61), o índice de distância do poder mede o quanto os membros menos poderosos das instituições (família, escola, comunidade) e organizações em um país esperam e aceitam que o poder seja distribuído de maneira não igualitária. Quanto maior o índice de distância do poder, menos igualitária é a expectativa de distribuição de poder.

Em relação ao índice de individualismo/coletivismo, explicado anteriormente, convém explicitar que quanto maior o índice, mais individualista é a cultura do país. Consequentemente, quanto menor o índice, mais coletivista é a cultura (HOFSTEDE; HOFSTEDE; MINKOV, 2010, p. 94).

Quanto ao índice de masculinidade/feminilidade, Hofstede, Hofstede e Minkov (2010, p. 140) explicam que, em culturas mais masculinas, as diferenças de gênero são claramente distintas, e é esperado que os homens sejam assertivos, fortes e focados no sucesso material, enquanto as mulheres devem ser mais modestas, afetuosas e preocupadas com a qualidade de vida. Em uma sociedade mais feminina, é esperado que tanto homens quanto mulheres sejam modestos, afetuosos e preocupados com a qualidade de vida. Quanto maior o índice de masculinidade/feminilidade, mais masculina é a cultura do país. 
$\mathrm{O}$ índice de fuga à incerteza, explicado anteriormente, deve ser interpretado da seguinte forma: quanto mais alto o índice, maior a aversão à incerteza e, consequentemente, ao risco (HOFSTEDE; HOFSTEDE; MINKOV, 2010, p. 191).

Em relação ao índice de dinamismo confuciano, que também já foi explicado anteriormente, vale a pena ressaltar que quanto maior o índice, mais a orientada ao longo prazo é a cultura do país. Consequentemente, quanto menor o índice, mais orientada ao curto prazo é a cultura (HOFSTEDE; HOFSTEDE; MINKOV, 2010, p. 239).

Considerando-se os valores apresentados no Quadro 6, pelas características culturais enfatizadas no estudo de Sharp e Salter (1997), o Brasil apresenta um índice de individualismo/coletivismo mais baixo, o que significa que é um país com uma cultura mais coletivista e um índice de dinamismo confuciano mais alto, tendo, portanto, uma maior orientação ao longo prazo. Essas características colocam o Brasil mais próximo das culturas asiáticas do que das culturas norte-americanas. Consequentemente, com base nos argumentos de Sharp e Salter (1997), a explicação do Agravamento de Projetos pela Teoria da Agência seria menos efetiva no Brasil. Por outro lado, os efeitos, de acordo com a Teoria da Perspectiva, seriam maiores e teríamos uma propensão ao agravamento maior que a dos norteamericanos, de forma análoga ao que acontece nos países asiáticos pesquisados.

Por outro lado, os funcionários públicos consideram riscos e recompensas de maneira diferente da dos funcionários de uma empresa privada (OSBORNE; GAEBLER, 1997, p. 22), e privilegiam a conformidade ao desempenho (WIRICK, 2009, p. 19). Consequentemente, privilegiar a conformidade, protegendo interesses próprios em detrimento do desempenho pode ser considerado um problema de agência. Logo, de acordo com a mesma lógica de Sharp e Salter (1997), a explicação do Agravamento de Projetos pela Teoria da Agência seria mais efetiva no setor público do que no setor privado.

Keil et al. (2000), em uma pesquisa focada na área de Sistemas de Informação, avaliam o impacto de aspectos culturais de propensão ao risco e percepção sobre o risco, para explicar como o nível de Sunk Cost influencia o comportamento de Agravamento do Projeto. A pesquisa foi realizada com estudantes de graduação e mestrado, e foram contemplados três países diferentes: Finlândia, Holanda e Cingapura. Os autores consideraram que a propensão ao risco e a percepção do risco são fatores individuais, mas influenciados por fatores culturais, 
como, por exemplo, o índice de Fuga à Incerteza de Hofstede, Hofstede e Minkov (2010, p. 187).

De forma resumida, Keil et al. (2000) chegaram às seguintes conclusões:

- Considerando-se as três culturas pesquisadas, a propensão ao risco apresenta um efeito inverso em relação à percepção do risco (quanto maior a propensão ao risco, menor a percepção do risco), mas nenhum efeito direto na intenção de continuar o projeto;

- O relacionamento entre a propensão ao risco e a percepção do risco é mais forte em culturas com menor aversão à incerteza (ou seja, em culturas com maior propensão ao risco);

- Em todas as culturas, a percepção do risco tem um impacto inverso significativo na intenção de continuar o projeto (quanto maior a percepção do risco, menor a intenção de continuar o projeto);

- Em todas as culturas, o nível de Sunk Costs apresenta um efeito direto na intenção de continuar o projeto (quanto maior o nível de Sunk Costs, maior a intenção de continuar o projeto) e independe da percepção do risco.

Considerando as três culturas pesquisadas, Keil et al. (2000) não conseguiram comprovar o impacto do nível de Sunk Costs na percepção do risco e nem um efeito direto da propensão ao risco na intenção em continuar o projeto (o impacto é somente indireto, por meio do efeito inverso na percepção do risco). O Quadro 7 apresenta os valores culturais dos países pesquisados por Keil et al. (2000), juntamente com os valores relacionados ao Brasil.

\section{Quadro 7: Comparação dos valores culturais de Holanda, Finlândia, Cingapura e Brasil}

\begin{tabular}{|l|r|r|r|r|r|}
\hline \multicolumn{1}{|c|}{ País } & $\begin{array}{c}\text { Distância } \\
\text { do Poder }\end{array}$ & $\begin{array}{c}\text { Individualismo/ } \\
\text { Coletivismo }\end{array}$ & $\begin{array}{c}\text { Masculinidade/ } \\
\text { Feminilidade }\end{array}$ & $\begin{array}{c}\text { Fuga à } \\
\text { Incerteza }\end{array}$ & $\begin{array}{c}\text { Dinamismo } \\
\text { Confuciano }\end{array}$ \\
\hline Holanda & 38 & 80 & 14 & $\mathbf{5 3}$ & 44 \\
\hline Finlândia & 33 & 63 & 26 & $\mathbf{5 9}$ & -- \\
\hline Cingapura & 74 & 20 & 48 & $\mathbf{8}$ & 48 \\
\hline Brasil & 69 & 38 & 49 & $\mathbf{7 6}$ & 65 \\
\hline
\end{tabular}

Fonte: baseado em Hofstede, Hofstede e Minkov (2010)

No caso do Brasil, o índice de fuga à incerteza é maior do que nos três países pesquisados. Isso significa que existe uma menor tolerância no Brasil à ambiguidade e incerteza. Dessa forma, como o relacionamento entre a propensão ao risco e a percepção do risco é mais forte em culturas com menor índice de fuga à incerteza (maior propensão ao risco), podemos 
concluir que o impacto da propensão individual ao risco na percepção do risco será menor no caso do Brasil. Em outras palavras, as características individuais de propensão ao risco terão impacto menor na percepção do risco.

\subsubsection{Modelos para De-Escalation do Projeto}

Segundo Montealegre e Keil, o processo de de-escalation contempla o redirecionamento ou cancelamento do projeto quando a decisão de prosseguir não é o melhor curso de ação. $O$ redirecionamento pode incluir uma mudança radical ou redefinição do escopo do projeto (MONTEALEGRE; KEIL, 2000).

Iacovou e Dexter $(1998,2004)$ propõem que o tratamento do processo de agravamento seja visto como o gerenciamento de uma crise, e listam uma série de ações para promover o processo de de-escalation:

- Desenvolvimento de um plano de recuperação;

- Delineamento de forma estrita do escopo do projeto;

- Avaliação rigorosa da liderança do projeto;

- Revisão do caso de negócio (Business Case) do projeto;

- Reestimativa do plano do projeto;

- Gerenciamento cuidadoso das expectativas do usuário;

- Desenvolvimento de canais abertos de comunicação;

- Introdução de marcos e entregas frequentes;

- Gerenciamento cuidadoso dos problemas pessoais da equipe do projeto;

- Adaptação adequada das práticas de desenvolvimento de TI.

Keil e Robey (1999), a partir de uma revisão da literatura, apresentam uma lista de fatores que podem prevenir ou favorecer o agravamento de um projeto. A partir de entrevistas com auditores de sistemas, os autores elaboraram uma série de fatores que contribuem para a transição de agravamento para de-escalation, conforme o Quadro 8. 
Quadro 8: Fatores que contribuem para a transição de agravamento para de-escalation

\begin{tabular}{|c|c|}
\hline $\begin{array}{l}\text { Mudança no suporte da } \\
\text { alta administração }\end{array}$ & $\begin{array}{l}\text { Os executivos que aprovaram o projeto tendem a manter seu comprometimento, } \\
\text { favorecendo o processo de agravamento. Dessa forma, sua substituição por novos } \\
\text { executivos facilita o processo de de-escalation, pois estes deverão reavaliar a } \\
\text { viabilidade do projeto e não estarão comprometidos com decisões tomadas } \\
\text { anteriormente. }\end{array}$ \\
\hline $\begin{array}{l}\text { Choques externos na } \\
\text { organização }\end{array}$ & $\begin{array}{l}\text { Eventos externos, geralmente não relacionados com o projeto em particular, podem } \\
\text { disparar sua reavaliação. Isso inclui mudanças na propriedade, desastres naturais, } \\
\text { escândalos públicos e outros eventos fora do controle da organização. }\end{array}$ \\
\hline $\begin{array}{l}\text { Mudança do campeão do } \\
\text { projeto (executivo que é } \\
\text { o principal defensor do } \\
\text { projeto) }\end{array}$ & $\begin{array}{l}\text { Assim como as mudanças na alta administração, a mudança do campeão do projeto } \\
\text { pode disparar uma reorganização do projeto. Esse executivo está propenso a um } \\
\text { comprometimento exagerado com o projeto. }\end{array}$ \\
\hline $\begin{array}{l}\text { Tolerância da } \\
\text { organização às falhas }\end{array}$ & $\begin{array}{l}\text { Ao reduzir o impacto negativo que um redirecionamento ou cancelamento do } \\
\text { projeto teria na carreira do tomador de decisão, a organização encoraja o processo } \\
\text { de de-escalation. }\end{array}$ \\
\hline $\begin{array}{l}\text { A presença de limites } \\
\text { explícitos e divulgados }\end{array}$ & $\begin{array}{l}\text { Ao estabelecer limites públicos que não possam ser ultrapassados pelo projeto, os } \\
\text { tomadores de decisão apresentam uma tendência maior de cumpri-los, do que no } \\
\text { caso de limites não divulgados. }\end{array}$ \\
\hline $\begin{array}{l}\text { Consideração de usos } \\
\text { alternativos para os } \\
\text { recursos financeiros que } \\
\text { suportam o projeto }\end{array}$ & $\begin{array}{l}\text { O agravamento do projeto está relacionado a um alto custo de oportunidade. Com a } \\
\text { tomada de consciência de outras possíveis aplicações dos recursos financeiros do } \\
\text { projeto, aumenta a chance de os tomadores de decisão partirem para um processo } \\
\text { de de-escalation. }\end{array}$ \\
\hline $\begin{array}{l}\text { Consciência } \\
\text { (conhecimento) dos } \\
\text { problemas do projeto }\end{array}$ & $\begin{array}{l}\text { Projetos de SI são frequentemente caracterizados como problemas muito } \\
\text { complexos. Quando se conduz uma avaliação mais realista das complexidades } \\
\text { técnicas e sociais de um projeto, essa avaliação pode favorecer o processo de de- } \\
\text { escalation. }\end{array}$ \\
\hline $\begin{array}{l}\text { Visibilidade dos custos } \\
\text { do projeto }\end{array}$ & $\begin{array}{l}\text { Quando os custos são mais visíveis ou salientes, essa característica ajuda a } \\
\text { promover o processo de de-escalation. }\end{array}$ \\
\hline $\begin{array}{l}\text { Clareza do critério para } \\
\text { sucesso ou falha }\end{array}$ & $\begin{array}{l}\text { Se os participantes do projeto não sabem que estão falhando, eles são mais } \\
\text { propensos a continuar gastando recursos. Explicações claras sobre os limites do } \\
\text { critério de sucesso podem levar ao processo de de-escalation. }\end{array}$ \\
\hline $\begin{array}{l}\text { Práticas organizacionais } \\
\text { para avaliação dos } \\
\text { tomadores de decisão: } \\
\text { processos } x \text { resultados }\end{array}$ & $\begin{array}{l}\text { Algumas empresas focam o resultado ao invés de enfatizar os meios para atingir os } \\
\text { resultados. Ao premiar somente o resultado, a organização pode intimidar o } \\
\text { tomador de decisão, que aumentaria seu comprometimento com uma decisão } \\
\text { anterior para comprovar que esta foi correta. Ao invés disso, premiando o processo } \\
\text { ao invés de seus resultados, a organização diminui a pressão psicológica sobre o } \\
\text { tomador de decisão, e o comprometimento sustentado, que poderia levar ao } \\
\text { agravamento, também é reduzido. }\end{array}$ \\
\hline $\begin{array}{l}\text { Avaliação } \\
\text { regular/periódica } \\
\text { projetos }\end{array}$ & $\begin{array}{l}\text { Muitos projetos em situação de agravamento continuam e continuaram com pouca } \\
\text { monitoração ou revisão. Revisões devem ser não periódicas e suas consequências } \\
\text { não devem ser severas; certa liberdade para os gerentes de ser mantida. }\end{array}$ \\
\hline $\begin{array}{l}\text { Separação } \text { de } \\
\text { responsabilidades para } \\
\text { aprovação e avaliação } \\
\text { dos projetos }\end{array}$ & $\begin{array}{l}\text { Um princípio consagrado em auditoria é a separação da decisão de alocar recursos } \\
\text { da responsabilidade de avaliar projetos. Os tomadores de decisão serão } \\
\text { provavelmente menos objetivos ao avaliar projetos nos quais tiveram grande } \\
\text { envolvimento. }\end{array}$ \\
\hline
\end{tabular}

Fonte: baseado em Keil e Robey (1999)

A partir dos doze fatores que contribuem para a transição de agravamento para de-escalation, Keil e Robey (1999) propõe um modelo para promover o de-escalation, apresentado na Ilustração 1 . 


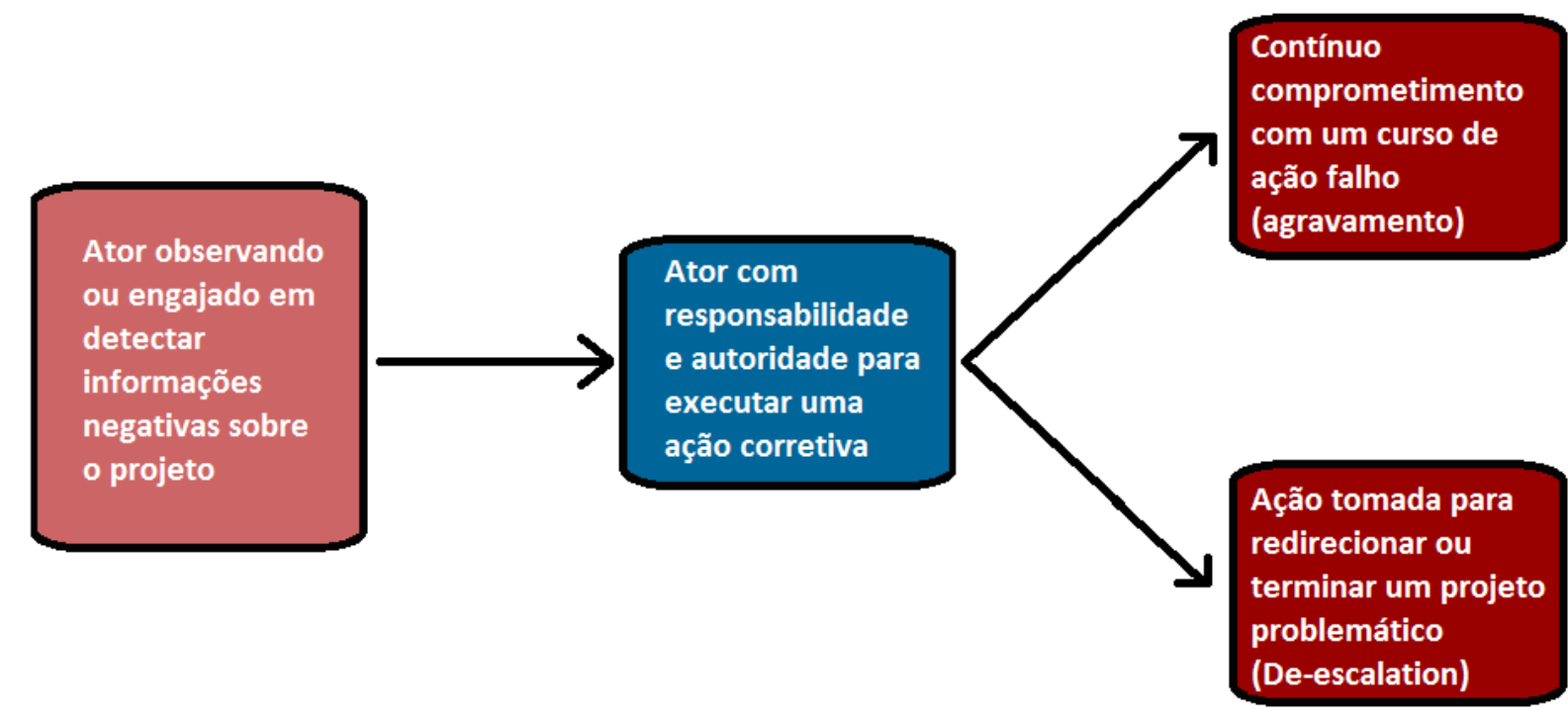

Ilustração 1: Um modelo de processos para o de-escalation do projeto Fonte: adaptada de Keil e Robey (1999).

Esse modelo começa com a detecção de informações negativas. Após a superação do "efeito mãe" (a relutância em transmitir más notícias) e do "efeito surdez" (filtrar as notícias recebidas, ignorando as más notícias), um ator com autoridade suficiente para essa decisão deve disparar o processo de de-escalation (KEIL; ROBEY, 1999).

Dessa forma, uma vez que as más notícias tenham sido comunicadas e recebidas, há uma série de ações que podem ser tomadas para trazer o projeto para o controle. As ações mais comuns para redirecionar projetos são: (1) redefinir o projeto, (2) aprimorar a gestão do projeto, e (3) mudar a liderança do projeto (KEIL; ROBEY, 1999).

Montealegre e Keil (2000) propõem um modelo de processos para de-escalation composto de quatro fases: (1) reconhecimento do problema, (2) reavaliação do curso de ação anterior, (3) busca de cursos de ação alternativos e (4) implementação da estratégia de saída. A pesquisa de Montealegre e Keil (2000) é baseada no largamente noticiado caso do Aeroporto Internacional de Denver.

A partir de uma revisão na literatura, Montealegre e Keil (2000) listam uma série de condições ou atividades que podem contribuir para o processo de de-escalation:

- Mudanças na alta direção ou no papel de campeão do projeto (Project Champion);

- Limites para a continuidade do projeto publicamente definidos;

- Disponibilidade de investimentos alternativos (custo de oportunidade); 
- Determinar quais são os critérios mínimos que devem ser atingidos para que o projeto possa ser considerado bem-sucedido;

- Tornar a ocorrência de resultados negativos menos ameaçadora aos membros do projeto;

- Avaliação regular dos projetos;

- Separação entre responsabilidade pela iniciação e avaliação/acompanhamento dos projetos;

- Atratividade às partes interessadas;

- Pressão externa na organização;

- Feedback negativo sem ambiguidade;

- Visibilidade dos custos do projeto;

- Esforços para desinstitucionalizar o projeto.

Montealegre e Keil (2000) argumentam que no caso do sistema de controle de bagagens do Aeroporto Internacional de Denver, a solicitação de proposta correspondia a um sistema muito maior e mais complexo do que qualquer um que a empresa vencedora da licitação (BAE Systems) já havia construído antes. Além disso, a sensação de que o projeto não estava progredindo provocou uma frustração crescente nos habitantes de Denver.

O caso do Aeroporto Internacional de Denver sugere que o fenômeno de-escalation não ocorre de forma súbita, mas sim num processo gradual. Além disso, os autores observam que este caso é caracterizado como um processo emergente, cujo resultado é imprevisível (MONTEALEGRE; KEIL, 2000). O Quadro 9 apresenta as fases e atividades que disparam o processo de de-escalation.

Quadro 9: Fases e atividades que disparam o processo de de-escalation

\begin{tabular}{|c|c|}
\hline Fases & $\begin{array}{l}\text { Atividades que dispararam a fase do } \\
\text { processo de de-escalation }\end{array}$ \\
\hline $\begin{array}{l}\text { (1) Reconhecimento do } \\
\text { problema; }\end{array}$ & $\begin{array}{ll}\text { - } & \text { Reconhecer o feedback negativo; } \\
\text { - } \quad \text { Responder às pressões externas; }\end{array}$ \\
\hline $\begin{array}{l}\text { (2) Reavaliação do curso } \\
\text { de ação anterior; }\end{array}$ & $\begin{array}{l}\text { - Esclarecer a magnitude do problema; } \\
\text { - } \quad \text { Redefinir o problema; }\end{array}$ \\
\hline $\begin{array}{l}\text { (3) Busca de cursos de } \\
\text { ação alternativos; }\end{array}$ & $\begin{array}{l}\text { - } \quad \text { Identificar e legitimar o novo curso de ação; } \\
\text { - } \quad \text { Gerenciar as impressões/interpretações; }\end{array}$ \\
\hline $\begin{array}{l}\text { (4) Implementação da } \\
\text { estratégia de saída. }\end{array}$ & $\begin{array}{l}\text { - } \quad \text { Atratividade às partes interessadas; } \\
\text { - } \quad \text { Desinstitucionalizar o projeto. }\end{array}$ \\
\hline
\end{tabular}


Ao explicar o processo de esclarecimento da magnitude do problema, Montealegre e Keil (2000) citam a pesquisa de Brockner, Shaw e Rubin (1979), para separar duas condições conflitantes:

- Condição de autossustentação: o projeto continua, a não ser que uma decisão de encerramento seja tomada;

- Condição de término automático: o projeto será encerrado, a não ser que uma decisão de continuidade seja tomada.

Brockner, Shaw e Rubin (1979) explicam que, no caso da condição de término automático, os custos se tornam mais salientes. Em uma pesquisa anterior, Rubin e Brockner (1975) concluíram que, quando os custos se tornam mais salientes, há uma tendência menor ao agravamento.

Ao forçar os tomadores de decisão a agir de forma ativa para que o projeto continue, como no caso da condição de término automático, os custos da continuidade se tornam mais aparentes, reduzindo o comportamento de agravamento (BROCKNER et al., 1979; MONTEALEGRE; KEIL, 2000).

A possibilidade de a culpa poder ser distribuída de forma difusa e, consequentemente, não afetar a credibilidade das partes envolvidas, é um fator que facilita o processo de deescalation (MONTEALEGRE; KEIL, 2000).

Montealegre e Keil (2000) classificam o processo de de-escalation de projetos de TI como um fenômeno complexo. Além disso, cada tomada de decisão nas fases do processo de deescalation também pode ser entendida como uma tomada de decisão complexa, pois, além de depender de diversos fatores, seu resultado é imprevisível. Os autores sugerem que mais pesquisas são necessárias, para se entender de forma mais completa a dinâmica de deescalation e em que medida as conclusões do caso do Aeroporto Internacional de Denver podem ser generalizadas.

Pan et al. (2006) propõem um arcabouço (framework) diferente do apresentado por Montealegre e Keil (2000), composto de três estágios: descongelamento, mudança e recongelamento. Esse arcabouço é baseado na Teoria da Mudança de Lewin (1951). 
De acordo com Ewusi-Mensah e Przasnyski (1991), em um estudo sobre o abandono de projetos de sistemas de informação, oito dos vinte e um projetos abandonados estavam no estágio de implementação, e quatro deles já haviam gasto muito mais do que o previsto em seu orçamento. Segundo Pan et al. (2006), isso sugere que os gerentes de SI estão fazendo um trabalho pobre na identificação ou finalização de projetos que têm grande probabilidade de falhar.

O caso descrito por Pan et al. (2006) apresenta indícios de problemas já nos estágios iniciais, incluindo conflitos entre o gerente do projeto representante da área de SI, os usuários e o fornecedor, a respeito do design. Além disso, usuários internos reclamaram da baixa qualidade do protótipo e da dificuldade do fornecedor em compreender seus requisitos. Por outro lado, o gerente do projeto e o fornecedor reclamaram da indecisão dos usuários e apontaram as constantes solicitações de mudança como a principal causa dos atrasos.

O caso de Governo Eletrônico descrito por Pan et al. (2006) apresenta indícios consistentes com a Teoria da Agência (JENSEN; MECKLING, 1976), como a explicação do executivo principal (E-envoy) de que havia delegado a liderança do projeto ao gerente do projeto e ao comitê diretivo de aquisições eletrônicas (e-procurement), e que eles haviam falhado em alertá-lo sobre os problemas.

Foram identificados vários problemas já nos estágios iniciais do processo de desenvolvimento (PAN et al., 2006):

- Escopo do projeto ambicioso - a implementação cruzava oito departamentos de usuários;

- Estratégia de projeto ineficaz - abordagem "big bang";

- Envolvimento de diversos representantes de partes interessadas (partes interessadas demais);

- Baixa qualidade do produto e serviço pobre executado pelo fornecedor;

- Composição irracional dos representantes dos usuários no grupo do projeto;

- Falta de comunicação direta entre os usuários e o fornecedor;

- Níveis variáveis de comprometimento das partes interessadas;

- Pouco envolvimento do executivo principal (E-envoy) e do comitê executivo de aquisições eletrônicas ( $e$-procurement) no processo de desenvolvimento; 
- Inflexibilidade do contrato de preço fixo firme;

- Nenhuma mudança seria permitida após o aceite do protótipo.

Flynn et al. (2009), após uma revisão da literatura, classificam os tratamentos a serem usados para de-escalation em três abordagens: (1) Gerenciamento de Crises, a partir da pesquisa de Iacovou e Dexter (1998, 2004); (2) Gerenciamento da Mudança, baseada na pesquisa de Pan et al. (2006); (3) Resolução de Problemas, a partir da pesquisa de Montealegre e Keil (2000).

Flynn et al. (2009) propõem a utilização de um modelo integrado de gestão de de-escalation, composto de seis fases para lidar com projetos em situação de agravamento:

A) Prevenir: elaboração de um Termo de Abertura do Projeto e respostas proativas aos desvios do planejamento ajudam a prevenir o agravamento;

B) Detectar: identificar o agravamento empregando boas práticas de monitoramento e encorajando a transparência e veracidade na apresentação de más notícias;

Gerenciamento de mudanças: criar um ambiente de segurança social e psicológica que possibilite a mudança. O gerenciamento de mudanças contempla as seguintes fases:

C) Interromper: quebrar o pensamento em grupo e interromper o comprometimento com o curso de ação falho;

D) Reavaliar e replanejar: reavaliar a viabilidade do projeto e replanejar para tornar visível a nova direção;

E) Implementar o novo curso de ação: executar o novo plano de projeto ou desmantelar o projeto;

F) Aprender: refletir sobre as lições aprendidas por meio de uma avaliação postmortem (após essa fase, devemos implementar as lições aprendidas, retornando à fase inicial).

Para a avaliação da maturidade é proposto o modelo De-escalation Maturity Model - DMM, composto de cinco níveis (FLYNN et al., 2009):

Nível 1: Disciplina para alterar o Plano do Projeto, referente à fase D - reavaliar e replanejar;

Nível 2: Disciplina para detectar desvios do Plano do Projeto e prevenir o agravamento, referente às fases $\mathrm{A}$ - prevenir - e B - detectar; 
Nível 3: Disciplina para executar o Plano do Projeto, conforme a fase E implementar;

Nível 4: Disciplina para encorajar o relato de más notícias e mudar atitudes e comportamentos, de acordo com as fases B - detectar - e C - interromper;

Nível 5: Disciplina para investir em aprendizagem organizacional, conforme à fase $\mathrm{F}$ aprender - e levando em conta a realimentação do processo.

\subsubsection{Conclusões sobre a Literatura de Agravamento de Projetos}

A variedade dos textos pesquisados permite uma análise rica sobre como prevenir problemas de agravamento nos projetos de SI. Brockner (1992) e Keil, Mann e Rai (2000) reconhecem a necessidade de avaliar o problema sob enfoques diferentes, para explicar o fenômeno do agravamento de forma mais completa.

O primeiro aspecto de prevenção está relacionado a como lidar com as causas do agravamento, segundo as principais teorias. No caso da Teoria da Autojustificação, as recomendações são as seguintes:

- Estabelecer de forma antecipada um limite de investimento e divulgar publicamente esse limite (BROCKNER et al.,1979);

- Estruturar a continuidade do projeto a partir da condição de término automático: o projeto será encerrado, a não ser que uma decisão de continuidade seja tomada (BROCKNER et al.,1979; MONTEALEGRE; KEIL, 2000);

- Substituição dos tomadores de decisão que optaram por um determinado curso de ação (STAW; ROSS, 1987; NEWMAN; SABHERWAL,1996), mediante, por exemplo, o uso de auditores externos em auditorias periódicas (MEREDITH, 1988).

Em relação à Teoria da Perspectiva, existem diretrizes complementares:

- Incentivar um modelo de tomada de decisão mais alinhado com a Teoria Econômica, de forma que os Sunk Costs não interfiram na tomada de decisão;

- Evitar que a informação seja filtrada nos níveis hierárquicos inferiores antes de chegar aos tomadores de decisão (STAW; ROSS, 1987);

- Evitar contradições entre a direção do feedback e a forma como ele é apresentado, diminuindo a ambiguidade (HENG; TAN; WEI, 2003). 
No caso da Teoria da Agência, além da substituição dos tomadores de decisão, que também é sugerida pela Teoria da Autojustificação, seria interessante desenvolver mecanismos para alinhar o interesse do agente com o do principal, dentre os quais, por exemplo, tornar a ocorrência de resultados negativos menos ameaçadora aos membros do projeto, conforme sugerido por Newman e Sabherwal (1996) e Montealegre e Keil (2000).

Dentre as sugestões da Teoria do Afastamento e Aproximação, destacam-se:

- Estruturar a governança do projeto, buscando reduzir a ambiguidade entre os custos e recompensas associados à decisão de continuar ou cancelar o projeto (RUBIN; BROCKNER, 1975);

- Estruturar o sistema de recompensas para reduzir as forças que encorajam o agravamento, recompensando a honestidade no reconhecimento da existência de problemas e uma clara avaliação das alternativas, por exemplo (STAW; ROSS, 1987).

Os fatores relacionados à Teoria do Afastamento e Aproximação são particularmente importantes se considerarmos as conclusões de Keil, Mann e Rai (2000), referentes a quais das quatro principais teorias são mais efetivas.

Os fatores relacionados à Teoria da Perspectiva também apresentam maior relevância para a prática no Brasil, se considerarmos a análise de Sharp e Salter (1997) a respeito dos países asiáticos e as semelhanças desses países com o Brasil em relação aos índices de coletivismo e dinamismo confuciano.

De forma resumida, Drummond e Hodgson (2011, p. 121) argumentam que os seis principais direcionadores para o agravamento são:

- Tendência ao otimismo;

- Ligação emocional com o investimento (sunk costs) que já foi realizado e perdido;

- Custos de encerramento proibitivos;

- Valor residual (salvage value) percebido;

- Diminuir as expectativas e passar a se contentar com um desempenho inferior;

- Evitar a tomada de decisão.

Complementarmente, as autoras explicam que existem cinco razões principais que induzem à resolução de problemas de agravamento (DRUMMOND; HODGSON, 2011, p. 123): 
- Pressão econômica devastadora;

- Pressão psicológica devastadora;

- Ocorrência de um incidente crítico;

- Estabelecimento de um limite;

- Atingir um limiar crítico.

Alguns autores sugerem outras medidas para tratar fatores relacionados à complexidade do próprio projeto, como, por exemplo, incentivar a decomposição do projeto em partes menores e mais facilmente alcançáveis (STAW; ROSS, 1987; NEWMAN; SABHERWAL,1996) e desenvolver soluções alternativas (STAW; ROSS, 1987; NEWMAN; SABHERWAL,1996; MONTEALEGRE; KEIL, 2000). A recomendação de decompor o projeto em partes menores é reforçada por extensa literatura da área de gestão de projetos, como os defensores de metodologias ágeis (SCHWABER, 2004; SUTHERLAND; SCHWABER, 2011).

Apesar de o tema Governança não ser citado explicitamente como um fator importante na prevenção do agravamento, várias das sugestões listadas neste item estão relacionadas à estrutura de responsabilidades e ao sistema de recompensas. Consequentemente, é relevante avaliar como a governança pode colaborar na prevenção do fenômeno de agravamento.

Finalmente, parte das recomendações, apesar não envolver a estrutura de governança, trata de aspectos culturais que as organizações deveriam enfatizar para lidar melhor com o agravamento, como incentivar o reconhecimento do problema e diminuir as contradições e ambiguidades na passagem do feedback aos tomadores de decisão (STAW; ROSS, 1987; HENG; TAN; WEI, 2003).

\subsection{Gerenciamento de Riscos em Projetos de SI}

As pesquisas em Gerenciamento de Riscos em Projetos de SI também oferecem contribuições para o entendimento dos problemas relacionados ao Agravamento de Projetos. O propósito desta revisão não é discutir métodos para o gerenciamento de riscos, mas sim apresentar os principais riscos identificados na literatura que possam afetar os projetos de desenvolvimento de SI. 
O PMI (2008, p. 275) define risco como "um evento ou condição incerta que, se ocorrer, tem um efeito em pelo menos um objetivo do projeto". Além disso, o PMI (2008, p. 275) explica que o risco do projeto é um evento que está sempre no futuro, e que os objetivos do projeto contemplam seu escopo, cronograma, custo e qualidade.

Chapman e Ward (1997, p. 7) definem o risco de um projeto como as implicações da existência de incerteza significativa sobre o nível de desempenho que um projeto pode atingir. Além disso, uma fonte de risco é qualquer fator que possa afetar o desempenho do projeto, e o risco ocorre quando o efeito é simultaneamente incerto e significativo em relação ao desempenho do projeto.

Wallace e Keil (2004) definem o risco como fatores que, quando presentes, afetam um projeto de SI de forma adversa, a não ser que o gerente do projeto tome as contramedidas apropriadas.

É interessante notar que as definições do termo "Risco" na área de SI são mais focadas em ameaças, enquanto o PMI (2008) adota a postura de considerar tanto os riscos negativos, classificados como ameaças, quanto os riscos positivos, chamados de oportunidades.

No âmbito deste trabalho, usaremos a definição mais simplificada do PMI (2008, p. 275), com foco somente nas ameaças do projeto, pois a preocupação deste estudo está relacionada aos riscos negativos que possam levar o projeto à situação de agravamento.

Keil, Mann e Rai (2000) explicam que o agravamento ocorre quando projetos problemáticos são continuados ao invés de serem abandonados ou redirecionados. Pan et al. (2006) argumentam que projetos problemáticos devem ser detectados o mais cedo possível, para que seu redirecionamento ocorra antes que suas condições piorem. Consequentemente, o estudo do agravamento do comprometimento deve contemplar também o entendimento das características dos projetos problemáticos, pois essa situação precede o agravamento.

A literatura sobre gerenciamento de riscos é ampla, apresentando trabalhos que abordam o problema sob pontos de vista muito diferentes. O PMI (2008) e Chapman e Ward (1997), por exemplo, apresentam métodos para gerenciamento de riscos, enquanto Remenyi (1999), Smith (2001) e Wallace e Keil (2004) propõem listas de riscos mais comuns em projetos de 
desenvolvimento e implementação de SI. Lientz e Larssen (2006) indicam um método para gerenciamento de riscos, juntamente com os riscos mais comuns.

Outro tipo de abordagem para o estudo do risco é sua consideração como um processo socialmente construído, no qual os riscos são negociados e contestados pelos atores e grupos sociais (LIM; SIA; YEOW, 2011).

Considerando-se a natureza positivista deste estudo, juntamente com seu foco nos riscos relevantes ao invés de nos processos relevantes, a revisão bibliográfica focará trabalhos que apresentem listas de riscos mais comuns em projetos de desenvolvimento e implementação de SI. Vale ressaltar que esta escolha não implica considerar que trabalhos com outros focos não sejam relevantes, mas apenas que eles não são os mais aplicáveis a esta pesquisa.

Smith $(2001$, p. 18,19) propõe uma série de causas-raiz responsáveis por tornar um projeto problemático, conforme a classificação acima. Essas causas são separadas pelo autor de acordo com as fases genéricas de um projeto: concepção do projeto, iniciação/mobilização do projeto, design do sistema, desenvolvimento do sistema, implementação do sistema e operação do sistema, conforme apresentado no Quadro 10. 
Quadro 10: Causas-Raiz que tornam um Projeto Problemático

\begin{tabular}{|c|c|}
\hline Fase & Causa-Raiz \\
\hline \multirow{6}{*}{$\begin{array}{l}\text { Concepção do } \\
\text { Projeto }\end{array}$} & Projeto baseado em premissas frágeis ou business case irrealista; \\
\hline & $\begin{array}{l}\text { Falha do comprador na definição clara dos objetivos do projeto, dos benefícios } \\
\text { esperados e do critério de sucesso; }\end{array}$ \\
\hline & Projeto baseado em uma tecnologia em estado-da-arte ou imatura; \\
\hline & $\begin{array}{l}\text { Falta de comprometimento (ownership/commitment) ou competência do comprador no } \\
\text { nível executivo; }\end{array}$ \\
\hline & Expectativas irrealistas do comprador em relação a prazo ou financiamento; \\
\hline & Falha do comprador em quebrar um projeto complexo em fases ou projetos menores; \\
\hline \multirow{11}{*}{$\begin{array}{ll}\text { Iniciação } & \text { ou } \\
\text { Mobilização } & \text { do } \\
\text { Projeto } & \end{array}$} & Fornecedor estabelecer expectativas irrealistas sobre custos, prazos e capacidade; \\
\hline & Falha do comprador em definir e documentar requisitos (funcionais e não-funcionais); \\
\hline & $\begin{array}{l}\text { Falha no estabelecimento de uma relação aberta, robusta e justa entre comprador e } \\
\text { fornecedor; }\end{array}$ \\
\hline & $\begin{array}{l}\text { Falha do fornecedor por não investir recursos suficientes para o entendimento do } \\
\text { escopo antes da assinatura do contrato; }\end{array}$ \\
\hline & Falha do comprador em conseguir o envolvimento dos usuários finais; \\
\hline & $\begin{array}{l}\text { Fornecedor subestimar os recursos (esforço - homem/hora) necessários para completar } \\
\text { o projeto; }\end{array}$ \\
\hline & Falha do fornecedor em definir as tarefas do projeto, entregas e processo de aceitação; \\
\hline & Falha em gerenciar ativamente os riscos e manter planos robustos de contingência; \\
\hline & Planejamento, gestão e execução do projeto deficientes (pobres); \\
\hline & Falha em definir claramente os papéis e responsabilidades no contrato e subcontratos; \\
\hline & Escopo completo e contrato de preço fixo (requisitos, design e desenvolvimento); \\
\hline \multirow[t]{9}{*}{ Design do Sistema } & Falha em congelar uma linha de base dos requisitos e aplicar controle de mudanças; \\
\hline & Escolha pobre da plataforma técnica e/ou da arquitetura. \\
\hline & Escolha pobre do método de design/desenvolvimento; \\
\hline & Fornecedor iniciar uma fase antes do término da fase anterior; \\
\hline & Falha em executar revisões de projeto efetivas e tomar ações decisivas; \\
\hline & Falta ou perda de recursos habilitados no fornecedor; \\
\hline & $\begin{array}{l}\text { Padrões de entrega do fornecedor deficientes (design, codificação, teste, gestão de } \\
\text { configuração, etc.); }\end{array}$ \\
\hline & $\begin{array}{l}\text { Deficiência do fornecedor no rastreamento de requisitos (requisitos, design, codificação } \\
\text { e teste); }\end{array}$ \\
\hline & $\begin{array}{l}\text { O comprador retém a autoridade do design, incluindo o direito de aprovar/rejeitar } \\
\text { designs de baixo nível; }\end{array}$ \\
\hline \multirow{7}{*}{$\begin{array}{l}\text { Desenvolvimento de } \\
\text { sistemas }\end{array}$} & Atrasos que façam o projeto ficar defasado em relação à tecnologia; \\
\hline & Falha em congelar o design e aplicar controle de mudanças; \\
\hline & $\begin{array}{l}\text { Treinamento inadequado do fornecedor e falha na supervisão dos seus funcionários } \\
\text { mais inexperientes; }\end{array}$ \\
\hline & $\begin{array}{l}\text { Revisão inadequada das especificações, codificação e documentação feitas pelo } \\
\text { fornecedor; }\end{array}$ \\
\hline & Gerenciamento pobre dos subcontratados pelo fornecedor; \\
\hline & Falta de uma abordagem formal do fornecedor na engenharia da integração e nos testes; \\
\hline & Atenção insuficiente do fornecedor aos requisitos não-funcionais; \\
\hline \multirow[t]{4}{*}{$\begin{array}{l}\text { Implementação do } \\
\text { sistema }\end{array}$} & $\begin{array}{l}\text { Falha do comprador em gerenciar as mudanças implícitas no projeto (pessoas, } \\
\text { processos e tecnologia); }\end{array}$ \\
\hline & Treinamento inadequado do usuário; \\
\hline & Falha catastrófica no sistema, sem um arranjo de contingência efetivo; \\
\hline & Perda de uma data crucial para implantação; \\
\hline \multirow[t]{3}{*}{ Operação do sistema } & Falha do comprador em medir o benefício realmente entregue e tomar ação corretiva; \\
\hline & Falha do comprador em manter/aprimorar o sistema após a implantação; \\
\hline & Mudanças no ambiente competitivo ou macroeconômico. \\
\hline
\end{tabular}

Fonte: adaptado de Smith (2001, p. 18,19) 
Smith (2001, p. 8) classifica um projeto como problemático quando ele exibe uma ou mais das seguintes características:

- Excede o prazo em mais de 50\%, excluindo-se o impacto no prazo em razão de mudanças no escopo que tenham sido combinadas entre as partes;

- Excede o orçamento em mais de 35\%, excluindo-se o impacto no orçamento em razão de mudanças no escopo que tenham sido combinadas entre as partes;

- É causa de grande insatisfação do cliente (comprador) a ponto de o futuro do projeto ser questionado;

- Falta de comprometimento do comprador com o sucesso do projeto;

- Falha substancial no suporte ao processo de negócio para o qual foi projetado;

- Falha substancial na entrega dos benefícios planejados;

- O resultado para o comprador e o fornecedor não é do tipo "ganha-ganha".

Segundo Remenyi (1999, p. 4), há um entendimento de que o projeto foi um fracasso quando:

- O projeto foi iniciado, mas abandonado antes de completado;

- O projeto foi totalmente desenvolvido, mas nunca usado;

- O projeto foi totalmente desenvolvido e entrou em operação, mas foi abandonado após um curto período de tempo;

- Não foi totalmente desenvolvido conforme o esperado, mas teve seu escopo substancialmente diminuído e não mais oferece as funcionalidades inicialmente previstas.

Remenyi (1999, p. 50) classifica os riscos de um projeto de desenvolvimento de sistemas em três grandes categorias: negócio, desenvolvimento e arquitetura. O Quadro 11 apresenta as principais categorias de risco propostas:

Quadro 11: Riscos-chave

\begin{tabular}{|l|l|l|l|}
\hline & Conhecimento & \multicolumn{1}{|c|}{ Fundação } & \multicolumn{1}{c|}{ Prazo } \\
\hline Negócio & Entendimento & Comprometimento & $\begin{array}{l}\text { Mudança no } \\
\text { negócio }\end{array}$ \\
\hline Desenvolvimento & $\begin{array}{l}\text { Estimativas e } \\
\text { planejamento }\end{array}$ & $\begin{array}{l}\text { Rotatividade de } \\
\text { pessoal }\end{array}$ & $\begin{array}{l}\text { Ferramentas de } \\
\text { desenvolvimento }\end{array}$ \\
\hline Arquitetura & $\begin{array}{l}\text { Competência } \\
\text { técnica }\end{array}$ & $\begin{array}{l}\text { Plataforma } \\
\text { tecnológica }\end{array}$ & $\begin{array}{l}\text { Ciclo de vida da } \\
\text { tecnologia }\end{array}$ \\
\hline
\end{tabular}

Fonte: adaptado de Remenyi (1999, p. 59) 
Remenyi (1999, p. 51) explica que os riscos relacionados ao negócio são mais básicos e que seu impacto no sucesso do projeto tende a ser mais severo do que o de riscos de desenvolvimento ou arquitetura. Em segundo lugar, de acordo com o critério de quais riscos são mais problemáticos, estão os riscos de desenvolvimento. Remenyi (1999, p. 61-73) apresenta também as consequências dos eventos de risco citados acima, conforme o Quadro 12.

Quadro 12: Consequências dos riscos

\begin{tabular}{|l|l|l|l|}
\hline \multicolumn{1}{|c|}{ Categoria } & \multicolumn{1}{|c|}{ Domínio/Perspectiva } & \multicolumn{1}{c|}{ Risco } & \multicolumn{1}{c|}{ Consequência } \\
\hline Negócio & Conhecimento & Entendimento & Desperdício \\
\hline Negócio & Fundação & Comprometimento & $\begin{array}{l}\text { Ilhas de sistemas de } \\
\text { informação }\end{array}$ \\
\hline Negócio & Prazo & Mudança no negócio & Perda de relevância \\
\hline Desenvolvimento & Conhecimento & Estimativas e planejamento & Irritação e desconfiança \\
\hline Desenvolvimento & Fundação & Rotatividade de pessoal & $\begin{array}{l}\text { Curva de aprendizado e } \\
\text { atrasos }\end{array}$ \\
\hline Desenvolvimento & Prazo & $\begin{array}{l}\text { Ferramentas } \\
\text { desenvolvimento }\end{array}$ & $\begin{array}{l}\text { Retrabalho (redesenho do } \\
\text { sistema) }\end{array}$ \\
\hline Arquitetura & Conhecimento & Competência técnica & Redução da qualidade \\
\hline Arquitetura & Fundação & Plataforma tecnológica & Instabilidade \\
\hline Arquitetura & Prazo & Ciclo de vida da tecnologia & $\begin{array}{l}\text { Diluição da vantagem de } \\
\text { negócio }\end{array}$ \\
\hline
\end{tabular}

Fonte: adaptado de Remenyi (1999, p. 61-73)

Os riscos de negócio envolvem o entendimento do sistema (risco de um entendimento incompleto ou inadequado do projeto pelas partes interessadas), o comprometimento (usuários não comprometidos com o sistema) e as mudanças (REMENYI, 1999, p. 51-54).

Os riscos de desenvolvimento incluem os riscos relacionados a estimativas e planejamento, rotatividade de pessoal e uso de hardware e/ou software inadequados (REMENYI, 1999, p. $54-55)$.

Em relação à arquitetura, esses riscos contemplam a competência técnica da equipe envolvida, a plataforma tecnológica adequada sob o ponto de vista de hardware e software, e os ciclos de vida da própria tecnologia, que pode se tornar redundante ou obsoleta (REMENYI, 1999, p. 55-57). 
Lientz e Larssen (2006) propõem um método de gerenciamento de riscos para identificar e rastrear os riscos mais comuns nos projetos de TI. Os autores, que apresentam mais de 150 riscos em seu livro, classificam os riscos de TI em três grandes grupos (LIENTZ; LARSSEN, 2006, p. 10):

- Questões e riscos internos;

- Questões e riscos externos;

- Questões e riscos específicos das atividades de TI.

O Quadro 13 apresenta as principais categorias de risco propostas por Lientz e Larssen (2006):

Quadro 13: Tipos de Questões e Riscos

\begin{tabular}{|l|l|}
\hline Questões e riscos internos & Equipes; \\
\cline { 2 - 2 } & O trabalho; \\
\cline { 2 - 2 } & Unidades de negócio; \\
\cline { 2 - 2 } & Gerenciamento; \\
\cline { 2 - 2 } & Projetos; \\
\cline { 2 - 2 } & Resistência a mudança. \\
\hline Questões e riscos externos & Fornecedores, consultores e terceirização; \\
\cline { 2 - 2 } & Matriz; \\
\cline { 2 - 2 } Questões e riscos específicos & Internacional e subsidiárias; \\
\cline { 2 - 2 } das atividades de TI & Tecnologia; \\
\cline { 2 - 2 } & Parceiros de negócio. \\
\cline { 2 - 2 } & Paćlise; \\
\cline { 2 - 2 } & Desentes de software; \\
\cline { 2 - 2 } & Implementação; $;$ \\
\cline { 2 - 2 } & Operação e suporte. \\
\hline
\end{tabular}

Fonte: adaptado de Lientz e Larssen (2006, p. 10)

Keil et al. (1998) e Wallace e Keil (2004) propõem um arcabouço de categorização do risco composto de quatro quadrantes, considerando a percepção da importância relativa do risco e o nível percebido de controle, conforme o Gráfico 1. 


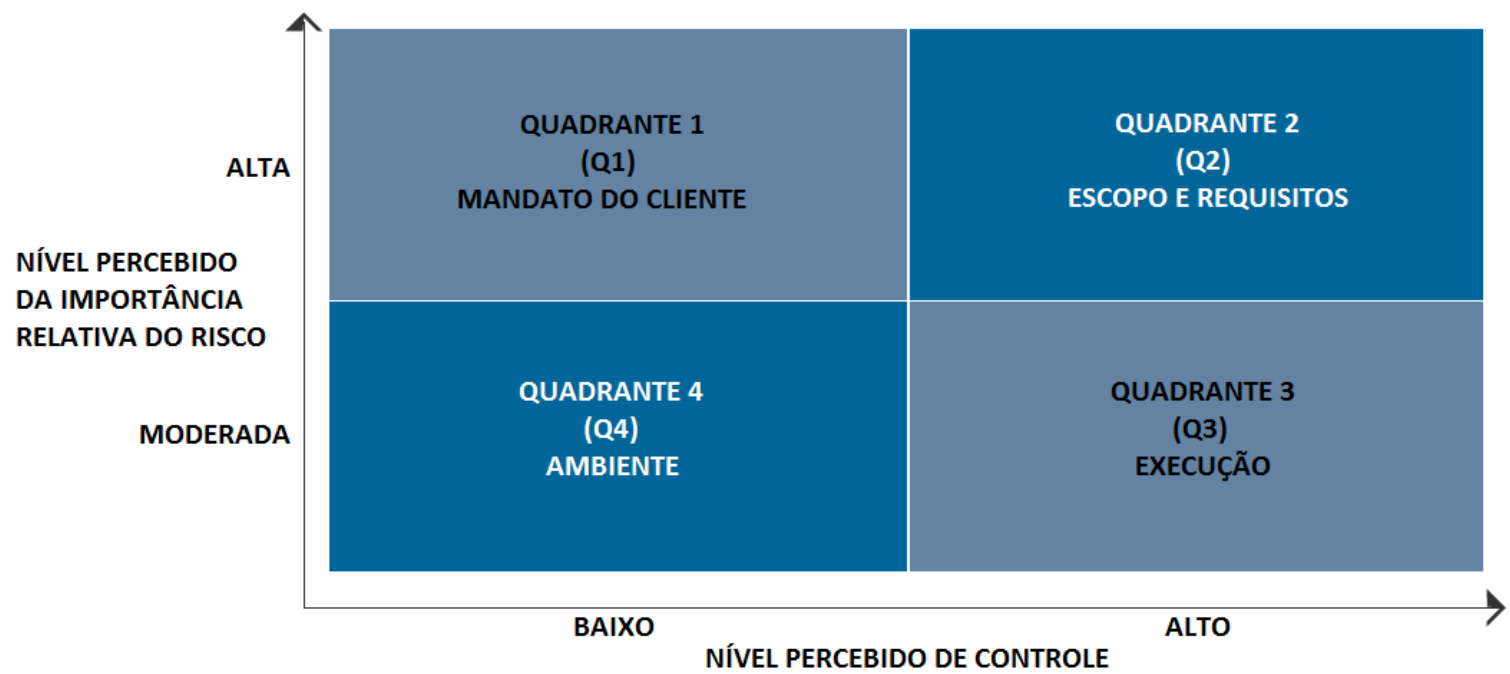

Gráfico 1: Arcabouço de classificação de risco

Fonte: adaptado de Keil et al. (1998) e Wallace e Keil (2004)

O quadrante 1 contempla os riscos relacionados ao usuário e ao cliente, incluindo a falta de envolvimento da alta administração. Apesar de serem importantes para o sucesso, esses fatores estão fora do controle do gerente de projetos (WALLACE; KEIL, 2004). De acordo com Wallace e Keil (2004), os riscos associados ao quadrante 1 são os seguintes:

- Falta de participação do usuário;

- Usuários resistentes a mudanças;

- Conflitos entre os usuários;

- Usuários com atitudes negativas em relação ao projeto;

- Usuários não comprometidos com o projeto;

- Falta de cooperação dos usuários;

- Falta de apoio da alta direção ao projeto;

- Falta de comprometimento ou pouco comprometimento da organização com o projeto.

$\mathrm{O}$ quadrante 2 foca nos riscos associados à inabilidade do gerente de projetos em compreender o escopo do sistema e as funcionalidades requeridas. Os gerentes de projeto deveriam ser capazes de controlar os riscos relacionados com esse quadrante (WALLACE; KEIL, 2004). Conforme Wallace e Keil (2004), os riscos associados ao quadrante 2 são os seguintes:

- Critério de sucesso do projeto indefinido;

- Requisitos de sistema conflitantes;

- Requisitos de sistema que mudam frequentemente; 
- Objetivos e escopo do projeto que mudam frequentemente;

- Requisitos do sistema identificados de forma inadequada;

- Requisitos de sistema obscuros (não claros);

- Requisitos de sistema incorretos;

- Metas do projeto mal definidas;

- Falta de entendimento pelos usuários sobre as capacidades e limitações do sistema;

- Dificuldade em definir entradas e saídas do sistema.

De acordo com Wallace e Keil (2004), o quadrante 3 foca nos riscos relacionados à execução do projeto, tais como uma equipe inadequada, metodologia inadequada, falha na definição de papéis e responsabilidades, planejamento e controle do projeto executados de forma precária. Da mesma forma que no caso do quadrante 2 , os gerentes de projeto deveriam ser capazes de controlar os riscos relacionados com o quadrante 3 . O quadrante 3 apresenta os seguintes riscos (WALLACE; KEIL, 2004):

- Membros da equipe de desenvolvimento treinados de forma inadequada;

- Falta de comprometimento com o projeto por parte dos membros da equipe;

- Membros da equipe inexperientes;

- Conflitos frequentes na equipe de desenvolvimento;

- Rotatividade frequente dos membros da equipe;

- Equipe de desenvolvimento sem familiaridade com as ferramentas de desenvolvimento;

- Equipe de desenvolvimento sem familiaridade com as tarefas a serem automatizadas;

- Atitudes negativas da equipe de desenvolvimento;

- Faltam nos membros da equipe as habilidades especializadas requeridas pelo projeto;

- O projeto envolve o uso de uma tecnologia nova;

- Alto nível de complexidade técnica;

- A tarefa a ser automatizada é altamente complexa;

- O projeto afeta um grande número de unidades e/ou departamentos dos usuários;

- Ser um dos maiores projetos já empreendidos pela organização;

- Necessidade de integração com um grande número de sistemas;

- Tecnologia imatura;

- O projeto envolve o uso de uma tecnologia que não foi usada em projetos anteriores;

- Falta de uma metodologia efetiva de gerenciamento de projetos; 
- Estimativa inadequada do cronograma do projeto;

- Faltam habilidades de liderança do projeto nas pessoas envolvidas;

- Progresso do projeto não monitorado suficientemente de perto;

- Estimativa inadequada dos recursos necessários;

- Planejamento precário do projeto;

- Marcos do projeto não definidos de forma clara;

- Estimativa inadequada do orçamento do projeto;

- Gerente do projeto não efetivo;

- Gerente do projeto inexperiente;

- Comunicação não efetiva.

O quadrante 4 foca nos riscos ambientais, tanto internos quanto externos, incluindo mudanças na organização com potencial para afetar o projeto (WALLACE; KEIL, 2004).

- Recursos deslocados do projeto em razão de mudanças nas prioridades da organização;

- Mudança na gestão organizacional durante o projeto;

- Políticas corporativas com efeitos negativos no projeto;

- Ambiente organizacional instável;

- Organização passando por uma reestruturação durante o projeto;

- Dependência de um fornecedor externo;

- Muitos fornecedores externos envolvidos no desenvolvimento do projeto.

Wallace e Keill (2004) analisaram o impacto das quatro grandes categorias de risco no processo (se o projeto foi completado no prazo e no orçamento) e no produto (se o produto atende às necessidades que motivaram o projeto). As conclusões da análise estatística conduzida por Wallace e Keil (2004) foram as seguintes:

- Os riscos do mandato do usuário $(\mathrm{Q} 1)$, escopo e requisitos $(\mathrm{Q} 2)$ e execução $(\mathrm{Q} 3)$ tem impacto significativo nos resultados do produto;

- Os riscos ambientais (Q4) não afetaram significativamente os resultados do produto ou do processo;

- Quando o risco de execução (Q3) é baixo, altos níveis dos riscos de mandato do usuário $(\mathrm{Q} 1)$ ou escopo e requisitos $(\mathrm{Q} 2)$ têm pouco impacto nos resultados do processo; 
- Quando o risco de execução (Q3) é alto, os efeitos dos riscos de mandato do usuário (Q1) e escopo e requisitos (Q2) são significativamente maiores, duas e nove vezes maiores, respectivamente. Dessa forma, gerentes de projeto que sabem que seu risco de execução (Q3) é alto e que não conseguem diminuí-lo, deveriam desenvolver estratégias para mitigar os riscos de mandato do usuário (Q1) e escopo e requisitos (Q2);

- Se os riscos de escopo e requisitos (Q2) são altos, os riscos de execução (Q3) devem ser gerenciados para prevenir um resultado indesejado no produto. Quando os riscos de escopo e requisitos (Q2) são altos, os efeitos dos riscos de execução (Q3) nos resultados do produto são 3,5 vezes maiores do que quando os riscos de escopo e requisitos $(\mathrm{Q} 2)$ são baixos.

Dessa forma, de acordo com Wallace e Keil (2004), para produzir um produto bem-sucedido, os gerentes de projeto de software deveriam aprender a controlar os riscos de execução, pois seu bom gerenciamento poderia prevenir problemas em outros quadrantes. Além disso, em situações nas quais orçamento e prazo são as principais prioridades, os riscos de escopo e requisitos, bem como os de execução, deveriam ser priorizados.

De acordo com os autores, a conclusão mais importante a ser derivada da pesquisa é que os riscos de execução são mais relevantes do que qualquer outro tipo de risco no que diz respeito aos resultados do processo e do produto (WALLACE; KEIL, 2004).

De forma geral, as principais listas de riscos apresentam uma similaridade muito grande. Em alguns casos, como no dos riscos de execução da classificação de Wallace e Keil (2004), com 28 riscos, o nível de detalhe é maior do que em outras listas, como as propostas por Remenyi (1999) ou Smith (2001). Dessa forma, seria possível agrupar os riscos de execução propostos por Wallace e Keil (2004) na classificação mais genérica proposta por Remenyi (1999) ou Smith (2001).

\subsection{Administração Pública}

Para fundamentar a análise dos problemas relacionados ao Agravamento de Projetos na Administração Pública, é importante avaliar quais são as diferenças entre o setor público e o 
setor privado, apontadas na literatura, com potencial para influenciar e impactar os projetos de desenvolvimento de SI.

Segundo Rainey (1997, p. 3), existe uma tendência mundial antigoverno que levou muitos países a diminuir o tamanho do governo e substituí-lo por empresas privadas. Por outro lado, existem também evidências de que o desempenho das empresas públicas é melhor do que se imagina (RAINEY, 1997, p. 13).

Morse e Buss (2007, p. 8) explicam que a primeira onda global de reforma administrativa é o chamado New Public Management (NPM), baseado na ideia de gerir o governo como se este fosse uma empresa. Os autores explicam que, apesar das várias críticas sofridas pelo NPM, ele influenciou a administração pública de maneiras variadas e, paradoxalmente, favoreceu a colaboração e o engajamento dos cidadãos.

De acordo com Dunleavy et al. (2006), o modelo proposto pelo NPM é baseado em três características integradoras principais:

- Desagregação: dividir as grandes hierarquias do setor público, buscando formatos multifirma similares aos da iniciativa privada;

- Competição: permitir múltiplas formas de fornecimento e criar maior concorrência entre os potenciais fornecedores;

- Incentivos: maior ênfase em incentivos pecuniários baseados em metas específicas ao invés de envolver gestores e equipe, recompensando o desempenho a partir de metas difusas de prestação de serviço.

De acordo com Dunleavy et al. (2006), apesar de alguns pontos positivos do NPM, mesmo seus defensores já reconhecem algumas de suas limitações e consequências negativas para a administração pública. Os autores explicam que estamos em um momento de transição no qual está emergindo um novo modelo denominado Era da Governança Digital (Digital-Era Governance - DEG), com foco na reintermediação, em considerar as necessidades como um todo (redesenhá-las de ponta a ponta) e em concretizar os ganhos de produtividade viabilizados pela TI.

A importância dos projetos de TI é amplificada nesse novo modelo, pois, segundo Dunleavy et al. (2006), as características unificadoras e distintivas que atualmente estão emergindo do 
desenvolvimento do setor público, no que diz respeito à sua gestão e estrutura, estão principalmente relacionadas a mudanças na TI e a alterações nos sistemas de informação.

Wirick (2009, p. 24) propõe uma série de Fatores Críticos para explicar o sucesso em projetos da administração pública:

- Uma metodologia de gerenciamento de projetos voltada especificamente para as necessidades dos projetos da organização e que seja escalável em função do risco do projeto;

- Um diálogo interativo entre as partes interessadas que continue por todo o projeto;

- Um processo detalhado para identificar usuários e requisitos suplementares;

- Suporte da administração para o processo de Gerenciamento de Projetos;

- Gerentes de projetos capazes, com o conhecimento e as habilidades interpessoais necessários, tais como:

- Enxergar o projeto como um empreendimento para um grupo e selecionar uma equipe com habilidades variadas para resolver os problemas;

- Compartilhar o crédito pelo sucesso;

- Gerenciar processos complexos que possam ser demandados pela lei ou por regras administrativas;

- Responder rápida e positivamente às adversidades, as quais são constantes em projetos do setor público;

- Gerenciar conflitos entre as partes interessadas e reconhecer até mesmo os interesses dos opositores ao projeto;

○ Lidar com a imprensa quando necessário.

McGregor Jr. (1993, p. 178) explica que existem muitas teorias tanto sobre o sucesso quanto sobre o fracasso na administração pública. Entretanto, os casos de sucesso ocorrem na presença das seguintes condições:

- A intervenção não pode ser tecnicamente inconsistente;

- Uma coalizão de interesses com autoridade suficiente deve desejar a intervenção, estar preparada para se manter firme e viabilizar sua implementação;

- Devem existir clareza sobre as tarefas críticas a serem executadas e precisão na sua execução. 
Rainey (1997, p. 67-70) explica que existem várias formas de classificação para organizações, as quais incluem propriedade, financiamento, tamanho, tarefa ou função. Entretanto, as organizações públicas não são tão diferentes das organizações privadas; por essa razão, um hospital público se pareceria mais com um hospital privado do que com uma escola pública. Da mesma forma, um hospital privado tem mais semelhanças com um hospital público do que com uma indústria privada.

Osborne e Gaebler (1997, p. 21) explicam que, apesar de muitas pessoas acreditarem que se deve governar da mesma forma com que se administra uma empresa, o governo é uma instituição fundamentalmente diferente. A motivação dos empresários é a busca pelo lucro, enquanto as autoridades governamentais são motivadas pela perspectiva de permanecer no poder, ou seja, de serem reeleitas.

Rainey (1997, p. 73) aponta uma série de características que distinguem a administração pública e as organizações públicas da administração de empresas e das organizações privadas. Essas características são separadas em fatores ambientais, transações entre o ambiente e a organização e papéis, estruturas e processos organizacionais.

Entre os fatores ambientais, Rainey (1997, p. 73) menciona a ausência de mercados econômicos para os resultados e o embasamento nas apropriações governamentais por recursos financeiros. Em razão disso, existe um incentivo menor para cortar custos, menor eficiência operacional e desempenho menos efetivo. Há também uma menor eficiência na alocação de recursos e menor disponibilidade de indicadores e informações claras de mercado (preço, lucro, participação) para uso em decisões gerenciais.

De acordo com Osborne e Gaebler (1997, p. 21), as diferenças entre as fontes de custeio clientes no caso das empresas e contribuintes no caso do governo - juntamente com o fato de o governo operar como um monopólio, em contraste com a situação de competição na qual as empresas normalmente operam, fazem com que os incentivos sejam diferentes no governo em relação às empresas.

Drummond e Hodgson (2011, p. 23) explicam que as decisões no setor público não são sempre determinadas somente pela racionalidade econômica, e que o distanciamento dos 
projetos do setor público em relação aos rigores da força dos mercados pode favorecer o agravamento.

Outro fator ambiental corresponde à presença de limitações legais e monitoramento por órgãos do legislativo, executivo, judiciário e agências regulatórias. Consequentemente, existem mais limitações nas operações e procedimentos e menor autonomia para os gerentes que devem tomar as decisões correspondentes (RAINEY, 1997, p. 73). A presença dessas limitações implica uma quantidade maior de restrições nos projetos do setor público, dificultando seu gerenciamento (WIRICK, 2009, p. 3).

Além disso, há uma tendência de proliferação de controles administrativos formais e um grande número de fontes externas de autoridade formal e influência, com grande fragmentação entre elas (RAINEY, 1997, p. 73).

De acordo com Osborne e Gaebler (1997, p. 22), o fato de o governo ser democrático e aberto faz com que seus movimentos sejam mais lentos comparativamente às empresas privadas, que podem tomar decisões de forma mais rápida e sem tanta exposição ao escrutínio público.

Considerando ainda os fatores ambientais, Rainey (1997, p. 73) também cita a presença de influências políticas externas mais intensas, que acarretam uma grande diversidade e intensidade de influências políticas informais nas decisões (barganha, lobby, opinião pública, etc.), além de maior necessidade de suporte político de clientes, eleitorado e autoridades para obtenção de autorização para a ação.

Em relação às transações entre o ambiente e a organização, Rainey (1997, p. 73) cita uma série de características:

- Organizações públicas e seus gestores estão frequentemente envolvidos na produção de bens públicos ou lidando com externalidades significativas. Logo, os resultados não são facilmente transferíveis para o mercado a um valor de mercado.

- Atividades de governo são comumente coercitivas, monopolistas ou inevitáveis. O governo tem poderes de coerção e sanção únicos e é frequentemente o único fornecedor. Além disso, a participação no consumo e financiamento é, geralmente, obrigatória (ex.: inspeção ambiental dos veículos na cidade de São Paulo). 
- Atividades do governo geralmente têm grande impacto e significado simbólico. Existe um escopo maior de preocupações, que inclui o critério de interesse do público em geral.

- Existe um maior escrutínio público dos administradores públicos.

- Existem expectativas únicas de justiça, prontidão, honestidade, abertura e responsabilidade.

Osborne e Gaebler (1997, p. 22) explicam que os funcionários governamentais consideram riscos e recompensas de maneira diferente dos funcionários de uma empresa privada.

De acordo com Wirick (2009, p. 3), os diversos mecanismos de vigilância, juntamente com as punições previstas, fazem com que os administradores públicos sejam mais avessos ao risco. Consequentemente, a conformidade com os parâmetros pelos quais o setor público é controlado tem precedência em relação aos objetivos do projeto.

Rainey (1997, p. 73-74) também lista as características relacionadas com papéis, estrutura e processos:

- Grande ambiguidade, multiplicidade e conflito relacionados aos objetivos, incluindo objetivos conflitantes.

- Características distintivas de papéis gerenciais gerais, como, por exemplo, um papel mais político e exposto a interferências políticas externas.

- Práticas de liderança e autoridade, como, por exemplo, uma menor autonomia e flexibilidade na tomada de decisão, em razão de restrições organizacionais e pressões políticas externas.

- Estrutura organizacional diferente da estrutura da iniciativa privada, não necessariamente mais burocrática.

- Processos de tomada de decisão estratégica mais influenciados por intervenções, interrupções e maior envolvimento de autoridades externas.

- Estrutura de incentivos e desincentivos: maiores limitações referentes à promoção, recompensa e ação disciplinar. Os trabalhadores percebem um relacionamento menor entre recompensa e desempenho. 
- Características individuais, atitudes e comportamentos relacionados ao trabalho, como por exemplo, menor sensibilidade a incentivos monetários e maior nível de motivação em um trabalho público.

- Desempenho individual e organizacional diferente do desempenho encontrado na iniciativa privada. Vários estudos mostram a gestão pública como menos eficiente, enquanto outros defendem sua eficiência e desempenho geral.

Wirick (2009, p. 1) explica que muitas organizações do setor público fornecem serviços diretamente ao público, apesar de esses serviços estarem sendo cada vez mais terceirizados. $\mathrm{O}$ atendimento às necessidades de um público muito amplo complica o gerenciamento de projetos na área pública, pois torna a identificação de objetivos mais complexa (WIRICK, 2009, p. 3).

Cavalcanti (2005, p. 23) argumenta que embora a administração pública também esteja sujeita à necessidade de eficiência, a interferência de questões relacionadas ao poder, além de sua natureza política, justifica a necessidade de estudos específicos e especializados.

Nos países emergentes, a complexidade da gestão pública é ainda maior, em razão das características de seu ambiente político, influenciado por fatores como o patrimonialismo, o clientelismo, o corporativismo, o nepotismo e o coronelismo (CAVALCANTI, 2005, p. 23).

A partir de suas pesquisas, Cavalcanti (2005, p. 194) sugere a utilização de oito estratégias de ação para gestores públicos, baseadas em uma visão mais orgânica e emergente:

- Compartilhar quadros de referência;

- Explorar os limites da formalidade;

- Fazer o jogo da burocracia;

- Induzir o envolvimento dos outros;

- Promover a coesão interna;

- Criar escudos contra as transgressões;

- Superar restrições internas;

- Permitir o florescimento das estruturas. 
De acordo com Rainey (1997, p. 168), a tomada de decisão estratégica no serviço público ocorre sob as seguintes condições:

- Ambiguidade das políticas (as diretrizes não são tão bem definidas quanto nas empresas privadas);

- Maior abertura, participação e influência da mídia e de outros entes políticos;

- Restrições de prazo mais artificiais em razão da rotatividade dos políticos eleitos e da duração de seus mandatos;

- Instabilidade das coalizões políticas que podem ser forjadas ao redor de uma política ou situação particular.

Nos projetos do setor público, a quantidade de partes interessadas costuma ser maior do que em projetos da iniciativa privada, pois existe a necessidade de coordenar esforços nos diversos níveis da administração (federal, estadual e municipal), além da necessidade de atender ao público e também de se sujeitar a uma série de mecanismos de vigilância, como tribunais de contas e imprensa, entre outros A existência de um número maior de partes interessadas implica objetivos múltiplos nos projetos da administração pública, alguns deles ambíguos e contraditórios (WIRICK, 2009, p. 3).

Projetos que englobam muitas organizações requerem muito mais mudanças organizacionais e são muito mais difíceis de gerenciar em razão do grande número de partes interessadas envolvidas. Adicionalmente, essas partes interessadas possuem geralmente grande poder político (YOUNG, 2007).

Segundo Prasser (2007), especialmente no setor público, existe um problema crônico relacionado à necessidade de estabelecer metas e prioridades. Dessa forma, para satisfazer um grande número de partes interessadas e não desapontar algumas delas, é mais fácil investir uma maior quantidade de recursos.

Rainey (1997, p. 348) explica a necessidade de considerar o prazo adequado para obter o apoio coletivo. O autor recomenda a identificação e aproveitamento da "janela de oportunidade". 
Wirick (2009, p. 6) e o PMI (2006a, p. 15) também citam a diferença do horizonte de planejamento das organizações públicas, que tende a ser menor que o das empresas privadas, por estar alinhado ao ciclo das eleições. Consequentemente, o comprometimento com objetivos estratégicos está limitado ao ciclo eleitoral no qual esses objetivos foram estabelecidos.

No caso de pesquisas no Brasil, Diniz et al. (2009) citam as influências do processo eleitoral na transição do governo de Fernando Henrique Cardoso para o governo Lula, dentre as quais o fato de que, durante o processo eleitoral, a possibilidade de descontinuidade política causou a desmotivação das equipes para projetos de longo prazo. Os autores complementam a informação, explicando que um dos efeitos da transição entre os dois governos foi a grande descontinuidade dos trabalhos relacionados à TIC.

Em um relatório sobre as ameaças relacionadas a grandes projetos de Governo Eletrônico, a OECD (2001) argumenta que as organizações do setor público operam em um ambiente muito diferente do setor privado. Logo, a compreensão dessas diferenças é importante para podermos entender por que projetos de governo falham e quais desafios seus gerentes de projetos enfrentam.

A mudança é inerente às políticas públicas e acarreta alterações nas especificações dos sistemas, que precisam ser ajustados. Isso prejudica o desenvolvimento de sistemas, pois mesmo pequenas mudanças em políticas públicas podem ocasionar grandes mudanças nas estruturas de TI. Além disso, o tempo necessário para que ocorra uma mudança na legislação pode ser muito menor do que o tempo necessário para efetuar o ajuste correspondente no sistema, e, em muitos casos, prazos irrealistas são politicamente determinados pelas autoridades (OECD, 2001).

Wirick (2009, p. 8) apresenta uma lista de razões que explicam por que os projetos do setor público são mais difíceis do que os projetos do setor privado:

- Ambiente com metas e resultados frequentemente conflituosos;

- Envolvem muitas camadas de partes interessadas, com interesses variados;

- Devem atender ao interesse político e operar sob o escrutínio da mídia;

- Possuem menor tolerância à falha; 
- Ocorrem em organizações que têm dificuldade em identificar medidas de resultado e missões;

- São executados sob restrições onerosas impostas pelas regras administrativas;

- Demandam a cooperação e desempenho de organizações externas à equipe do projeto;

- Os recursos humanos são mais difíceis de gerenciar, em razão dos benefícios do emprego no serviço público;

- São executados em organizações que podem não estar confortáveis ou acostumadas com a ação direta e o sucesso do projeto;

- São executados em ambientes que podem incluir adversários políticos.

Segundo Prasser (2007), existem importantes lições aprendidas em grandes projetos na Austrália e em outros países:

- A fase conceitual é essencial para estabelecer um consenso sobre as necessidades de negócio que inclua todas as partes interessadas. A necessidade de negócio deve ser claramente separada da necessidade política;

- Ao se montar a estrutura de gerenciamento do projeto, deve-se estabelecer uma separação clara entre o patrocinador do projeto e o gerente do projeto. O patrocinador deve fornecer apoio político, mas não deve tentar gerenciar o projeto;

- Deve existir uma crescente ênfase na definição e no planejamento, para garantir que uma análise adequada foi feita sobre como os objetivos do projeto podem ser atingidos;

- Deve existir um aprimoramento nos procedimentos, para identificar, avaliar e gerenciar o risco de grandes projetos.

As análises post mortem sobre fracassos costumam apontar alguns problemas em comum (GILLIES, 2007):

- Alinhamento do projeto com as diretrizes estratégicas;

- Requisitos de negócio explicados de forma superficial;

- Esforço da área de negócio e impacto do projeto subestimados;

- Benefícios do caso de negócio não testados;

- Falta de plano ou projeto para concretizar os benefícios. 
Segundo Gillies (2007), a causa-raiz para esses problemas é a má governança e a má organização do lado do negócio. Gillies (2007) explica que a governança das áreas de negócio privilegia o benefício mais imediato, mas sua estrutura de recompensas é falha em relação aos benefícios de longo prazo, mais relacionados aos projetos. Consequentemente, os executivos de negócio relutam em colocar seus melhores profissionais nos projetos, pois estes costumam fazer falta na operação do negócio. Finalmente, Gillies (2007) comenta que as habilidades de transformação organizacional costumam ser mais desenvolvidas nos profissionais de TI, mas faltam nos profissionais de negócio.

\subsection{Gerenciamento de Projetos no Setor Público}

Após apresentar os aspectos apontados na literatura referentes às diferenças entre o setor público e a iniciativa privada que potencialmente influenciam e impactam os projetos de desenvolvimento de SI, o passo seguinte é avaliar a literatura sobre o Gerenciamento de Projetos no setor público.

Esta revisão é composta de duas partes: a primeira apresenta uma introdução ao assunto e uma visão geral das principais metodologias prescritas em livros-texto acerca da gestão de projetos no setor público; a segunda corresponde a uma revisão bibliográfica mais sistemática da gestão de projetos no setor público, na qual enfatiza os fatores considerados importantes para uma implementação bem-sucedida e as principais causas de fracassos.

Carneiro (2010) explica que muito do que conhecemos hoje em Gerenciamento de Projetos se originou no setor público dos Estados Unidos, e cita como exemplos o Gráfico de Gantt, usado primeiramente no Hoover Dam (represa no Estado do Colorado), a ferramenta Program Evaluation and Review Technique (PERT), usada pela marinha na construção do míssil Polaris, no final dos anos 50, além da Estrutura Analítica do Projeto (EAP - Work Breakdown Structure - WBS) e da Técnica do Valor Agregado, desenvolvidos pelo Departamento de Defesa.

Carneiro (2010) faz uma síntese das principais metodologias de gerenciamento de projetos, contemplando as melhores práticas do PMI (2008), o modelo Prince2 (OGC, 2009a, 2009b) e o modelo IPMA (2006, 2011), e apresentando alguns casos reais de sucesso na implantação 
de metodologias de gerenciamento de projetos no setor público. Entretanto, as especificidades do setor público são tratadas apenas superficialmente nesse livro, e seu texto não menciona estratégias para gerenciamento de requisitos ou prevenção do agravamento.

Considerando-se a literatura mais prescritiva sobre Gerenciamento de Projetos no setor público, o Office of Government Commerce (OGC), um órgão do governo britânico ligado ao gabinete do Primeiro Ministro, possui publicações referentes ao Gerenciamento de Projetos e Portfólios (OGC, 2011).

A metodologia Prince2 foi desenvolvida como o padrão oficial para gerenciamento de projetos no setor público no Reino Unido, popularizou-se e passou a ser adotada pelo setor privado (OGC, 2011). Essa metodologia foi concebida inicialmente para tratar de projetos de desenvolvimento de sistemas, mas, em razão de sua aceitação pelo mercado, seu escopo foi expandido para contemplar qualquer tipo de projeto.

A metodologia Prince2 apresenta uma publicação direcionada para Gerentes de Projeto (OGC, 2009a) e outra para a alta administração e membros do comitê diretivo do projeto (OGC, 2009b), estabelecendo seus papéis e responsabilidades.

A metodologia Prince2 prevê quatro níveis hierárquicos envolvidos no projeto (OGC, 2009a, p. 33; OGC, 2009b, p. 12; Turley, 2010, p. 2):

- Nível corporativo ou de gerenciamento de programa;

- Nível diretivo, que contempla o comitê do projeto (Project Board);

- Nível de gerenciamento, em que se posiciona o gerente do projeto;

- Nível de entrega, em que são efetivamente produzidas as entregas de gerenciamento e as entregas técnicas;

Uma das atribuições previstas para o comitê do projeto é a autoridade para encerrar o projeto, tanto no caso de sucesso quanto no caso de um término antecipado em razão de seu cancelamento (TURLEY, 2010, p. 34). A metodologia Prince2 recomenda que se um projeto não é mais útil à organização ele deve ser cancelado. $\mathrm{O}$ manual da metodologia reforça o fato de que cancelar um projeto ruim é um evento positivo para a organização (OGC, 2009a, p. 11). 
Uma diferença importante da metodologia Prince 2 em relação à abordagem do PMI é que, no caso do Prince2, a responsabilidade pelo sucesso do projeto é atribuída ao comitê do projeto (TURLEY, 2010, p. 40), enquanto no PMI essa responsabilidade é concentrada no gerente do projeto (PMI, 2008, p. 41).

A montagem do comitê do projeto é considerada fundamental para que o projeto seja bemsucedido. A metodologia sugere que o comitê seja composto de: um executivo que assumiria o papel de autoridade máxima do projeto e seria responsável por defender o ponto de vista do negócio; e outros dois atores-chave, o usuário sênior, que representa todos os usuários que usarão o produto do projeto, e o fornecedor sênior, que representa todos os responsáveis pela construção do produto (OGC, 2009b, p. 15).

Segundo a metodologia Prince2 (OGC, 2009b, p. 21), é importante que o nível hierárquico do Executivo dentro da organização seja compatível com o nível de autoridade que lhe foi conferido no papel de Executivo no projeto. Caso os outros membros do comitê do projeto tenham níveis de autoridade maiores na hierarquia corporativa, o Executivo pode ter dificuldade na aplicação de sua autoridade, prejudicando a tomada de decisão necessária para o projeto (OGC, 2009b, p. 21).

A metodologia Prince2 (OGC, 2009b, p. 15) também enfatiza que, quando a composição do comitê do projeto for deficiente, o projeto terá dificuldades. Além disso, se o comitê do projeto for afetado por grandes conflitos internos, o projeto estará quase que certamente condenado ao fracasso (OGC, 2009b, p. 15).

O PMI (2006a) apresenta um complemento ao seu livro de melhores práticas, com ênfase nas diferenças dos projetos governamentais, que incluem (1) restrições legais nos projetos de governo, (2) responsabilidade perante o público e (3) utilização de recursos públicos. Complementarmente, o PMI (2006a) enfatiza a existência de várias partes interessadas (agências regulatórias, imprensa, entre outras) que interferem em um projeto do setor público, mas que geralmente não interferem em projetos da iniciativa privada.

O padrão do PMI (2006a) para projetos governamentais não apresenta controles específicos para a prevenção do agravamento. Dessa forma, podemos concluir que o processo explicado no padrão de Gestão de Portfólios (PMI, 2006b) continua válido. 
Wirick (2009), em um livro com a chancela do PMI, apresenta um conjunto de estratégias para atingir o sucesso em projetos do setor público. A proposta é alinhada ao padrão de gerenciamento de projetos do PMI (2008) e ao seu padrão complementar para projetos de governo (PMI, 2006a).

O padrão de Gerenciamento de Portfólios (PMI, 2006b) apresenta recomendações para selecionar e priorizar projetos, além de diretrizes e processos para fazer o monitoramento e controle dos projetos em andamento. Em linhas gerais, os padrões de Gerenciamento de Projetos (PMI, 2008) e Gerenciamento de Portfólios (PMI, 2006b) apresentam uma visão mais mecanicista da organização, abordando apenas de forma superficial os aspectos políticos e conflituosos encontrados nas organizações do setor público.

Wirick (2009, p. 26) propõe que o nível de documentação do projeto seja proporcional ao seu risco, calculado a partir de um modelo, conforme o Quadro 14.

\section{Quadro 14: Análise de risco do projeto}

\begin{tabular}{|c|c|c|}
\hline Categoria de Risco & Descrição & $\begin{array}{l}\text { Classificação do } \\
\text { Projeto (pontos) } \\
\end{array}$ \\
\hline \multirow{3}{*}{$\begin{array}{l}\text { Quantidade de partes } \\
\text { interessadas }\end{array}$} & Poucas partes interessadas, geralmente internas. & 1 a 3 \\
\hline & Algumas partes interessadas externas. & 3 a 5 \\
\hline & Muitas partes interessadas externas. & 5 a 10 \\
\hline \multirow[t]{3}{*}{ Tamanho do Projeto } & $\begin{array}{l}\text { Menos de dois meses de duração e menos de dez trabalhadores } \\
\text { em tempo integral. }\end{array}$ & 1 a 3 \\
\hline & $\begin{array}{l}\text { De dois a seis meses de duração e entre dez e trinta trabalhadores } \\
\text { em tempo integral. }\end{array}$ & 3 a 5 \\
\hline & $\begin{array}{l}\text { Mais de seis meses de duração e mais de trinta trabalhadores em } \\
\text { tempo integral. }\end{array}$ & 5 a 10 \\
\hline \multirow[t]{3}{*}{$\begin{array}{l}\text { Interesse Público e } \\
\text { Impacto }\end{array}$} & $\begin{array}{l}\text { Pouco impacto no público, pouco interesse da imprensa e dos } \\
\text { agentes oficiais. }\end{array}$ & 1 a 3 \\
\hline & $\begin{array}{l}\text { Algum impacto no público, algum interesse da imprensa e dos } \\
\text { agentes oficiais. }\end{array}$ & 3 a 5 \\
\hline & $\begin{array}{l}\text { Muito impacto no público, muito interesse da imprensa e dos } \\
\text { agentes oficiais. }\end{array}$ & 5 a 10 \\
\hline \multirow{3}{*}{$\begin{array}{l}\text { Uso de Tecnologia } \\
\text { ou Métodos }\end{array}$} & Tecnologia bem conhecida e já aplicada no passado. & 1 a 3 \\
\hline & $\begin{array}{l}\text { Alguma nova tecnologia ou métodos. Falta de familiaridade da } \\
\text { organização com a solução. }\end{array}$ & 3 a 5 \\
\hline & $\begin{array}{l}\text { Nova tecnologia. A organização confia em fornecedores para } \\
\text { intermediar ou aplicar a tecnologia. }\end{array}$ & 5 a 10 \\
\hline \multirow[t]{3}{*}{ Impacto Estratégico } & Pouco impacto nas metas e resultados estratégicos. & 1 a 3 \\
\hline & O projeto está integrado às diretrizes e metas estratégicas. & 3 a 5 \\
\hline & $\begin{array}{l}\text { O projeto está diretamente envolvido com as metas estratégicas } \\
\text { da organização. }\end{array}$ & 5 a 10 \\
\hline
\end{tabular}


Segundo Wirick (2009, p. 28), devemos atribuir os pontos segundo o Quadro 14 e, após somar todas as notas, classificar os projetos e aplicar métodos de gerenciamento de projetos conforme a categoria de risco. O Quadro 15 explica a relação entre o número de pontos, a categoria de risco e os métodos de gerenciamento recomendados.

Quadro 15: Métodos de gerenciamento de projetos aplicados às categorias de risco

\begin{tabular}{|l|l|l|}
\hline $\begin{array}{c}\text { Categoria de } \\
\text { Risco do Projeto }\end{array}$ & Pontos & \multicolumn{1}{c|}{ Métodos de Gerenciamento de Projeto } \\
\hline Categoria A & Até 10 & $\begin{array}{l}\text { Versão reduzida de termo de abertura do projeto e relatório sintético de } \text { status } \\
\text { mensal. }\end{array}$ \\
\hline Categoria B & 10 a 30 & $\begin{array}{l}\text { Termo de abertura do projeto, EAP, registro de riscos e relatório sintético de } \\
\text { status mensal. }\end{array}$ \\
\hline Categoria C & 30 a 40 & $\begin{array}{l}\text { Termo de abertura do projeto, processo formal de levantamento de requisitos, } \\
\text { EAP, diagrama de rede, análise e registro dos riscos, relatório de status mensal } \\
\text { e plano de gerenciamento das comunicações. }\end{array}$ \\
\hline Categoria D & 40 a 50 & $\begin{array}{l}\text { Termo de abertura do projeto, processo formal de levantamento de requisitos, } \\
\text { EAP, diagrama de rede, orçamento, análise de valor agregado, análise dos } \\
\text { riscos e registro dos riscos, análise qualitativa e quantitativa de riscos, plano } \\
\text { de gerenciamento das comunicações, plano de gerenciamento das aquisições, } \\
\text { relatório de status mensal e reuniões com as partes interessadas. }\end{array}$ \\
\hline
\end{tabular}

Fonte: adaptado de Wirick (2009, p. 26-28)

Em relação ao gerenciamento do escopo, Wirick (2009, p. 73) reconhece que, em razão da maior quantidade de partes interessadas, a construção de um consenso a respeito do escopo de um projeto no setor público é mais complexa do que na iniciativa privada. Entretanto, o autor resume suas recomendações à visão tradicional e mecanicista da Engenharia, listando elementos previstos pelo PMI (2008), tais como um processo formal de levantamento de requisitos, EAP e processos de controle.

O arcabouço para Gerenciamento de Projetos no Setor Público proposto por Kassel (2010) apresenta sugestões semelhantes às do PMI (2008), sem entrar em detalhes a respeito de como fazer o acompanhamento do projeto com rigor suficiente para prevenir o agravamento. $\mathrm{O}$ autor sugere a utilização de instrumentos comuns para o gerenciamento do escopo, como por exemplo, a EAP, mas não entra em detalhes a respeito da diferença entre gerenciar o escopo do projeto no setor público ou na iniciativa privada.

No caso do Brasil, não existe uma metodologia-padrão disseminada por todas as organizações nos diversos níveis de governo. Entretanto, algumas organizações do setor público desenvolveram metodologias próprias, baseadas nas práticas de mercado difundidas na iniciativa privada. A metodologia de gerenciamento de projetos do Tribunal de Contas da 
União (TCU, 2006), por exemplo, é baseada nas práticas de gerenciamento de projetos da terceira versão do Guia PMBOK (PMI, 2004).

Furlong e Al-Karaghouli (2010) discutem a efetividade da aplicação de metodologias de gerenciamento de projetos baseadas nas chamadas "melhores práticas" de mercado (ex: PMBOK) em grandes projetos de Governo Eletrônico. Os autores concluem que essas metodologias, desenvolvidas com foco na era da manufatura, não atendem de forma adequada todas as necessidades dos projetos atuais, relativas aos seus ambientes culturais e organizacionais.

Opondo-se à aplicação dos métodos tradicionais de gerenciamento de projetos, alguns artigos apresentam casos de projetos do setor público que foram desenvolvidos com o uso de metodologias ágeis, especialmente o arcabouço (framework) Scrum, desenvolvido na década de 1990 por Sutherland e Schwaber (2011).

Melo e Ferreira (2010) apresentam um estudo de caso sobre a adoção do Scrum no Banco Central do Brasil, com resultados considerados satisfatórios e evidências de efeitos positivos dessa adoção no aprendizado dos profissionais envolvidos nos projetos e melhorias na qualidade do código, na produtividade e na satisfação do cliente.

No México, o Scrum foi usado no projeto bem-sucedido do desenvolvimento do portal Internet do Governo do Estado de Puebla (ACEVES; DÍAZ; LUNA-REYES, 2010). Nos Estados Unidos, o Scrum foi usado na agência federal denominada National Institutes of Health (NIH), resultando em melhor comunicação na equipe, produtos com maior usabilidade e maior parceria dos usuários com a equipe de desenvolvimento. Por outro lado, a implantação do Scrum, mesmo tendo sido parcial, foi difícil de obter e de manter (UPENDER, 2005).

Osterby e Hanson (2011, p. 110) argumentam que a maioria das abordagens de governança de projetos funciona bem em projetos pequenos e em equipes pequenas. Acrescentam, entretanto, que ainda não existem evidências de que as metodologias ágeis, incluindo o Scrum, podem ser usadas em projetos governamentais de grande porte. 
Poppendieck (2002), por outro lado, argumenta que metodologias adaptativas, especialmente o Scrum, são as mais preparadas para lidar com projetos de alta complexidade (wicked projects).

O Scrum foi inspirado em um artigo sobre desenvolvimento de produto, escrito por Takeuchi e Nonaka (1986), que propõem uma alternativa mais efetiva ao desenvolvimento linear. Os autores defendem um desenvolvimento concorrente, no qual equipes autogerenciadas trabalhem conjuntamente, de forma semelhante à movimentação da formação scrum do jogo de Rúgbi.

O Scrum se propõe a ser um framework iterativo e incremental, e as equipes no Scrum são autogerenciadas (SUTHERLAND; SCHWABER, 2011). Os trabalhadores coletivamente estão mais preparados para concluir sobre a melhor forma de fazer o trabalho do que estariam seus gerentes (SCHWABER, 2007).

Essa proposta de autogestão está alinhada à visão de Ciborra (1993, p. 75) e Ouchi (1980), baseada na Teoria dos Custos de Transação (COASE, 1937), segundo a qual, quando a complexidade do problema excede a capacidade de coordenação da hierarquia, o clã se torna a forma mais eficiente de organização. Müller (2011, p. 302) complementa explicando que estruturas mais ou menos complexas são necessárias para economizar nos custos de transação, dependendo da complexidade do projeto.

Particularmente, no caso de alta especificidade do ativo, juntamente com alta incerteza, é pouco provável que o mercado consiga atender a necessidade com custos de transação aceitáveis (OUCHI, 1980). Dessa forma, contrário ao recomendado pela literatura prescritiva sobre o gerenciamento de riscos, em projetos mais complexos e com alta especificidade, a hierarquia é mais adequada do que o mercado e o clã é mais adequado do que a hierarquia. $\mathrm{O}$ Gráfico 2 apresenta a visão dos custos de transação a respeito das estruturas de governança e sua relação com a complexidade e a incerteza. 


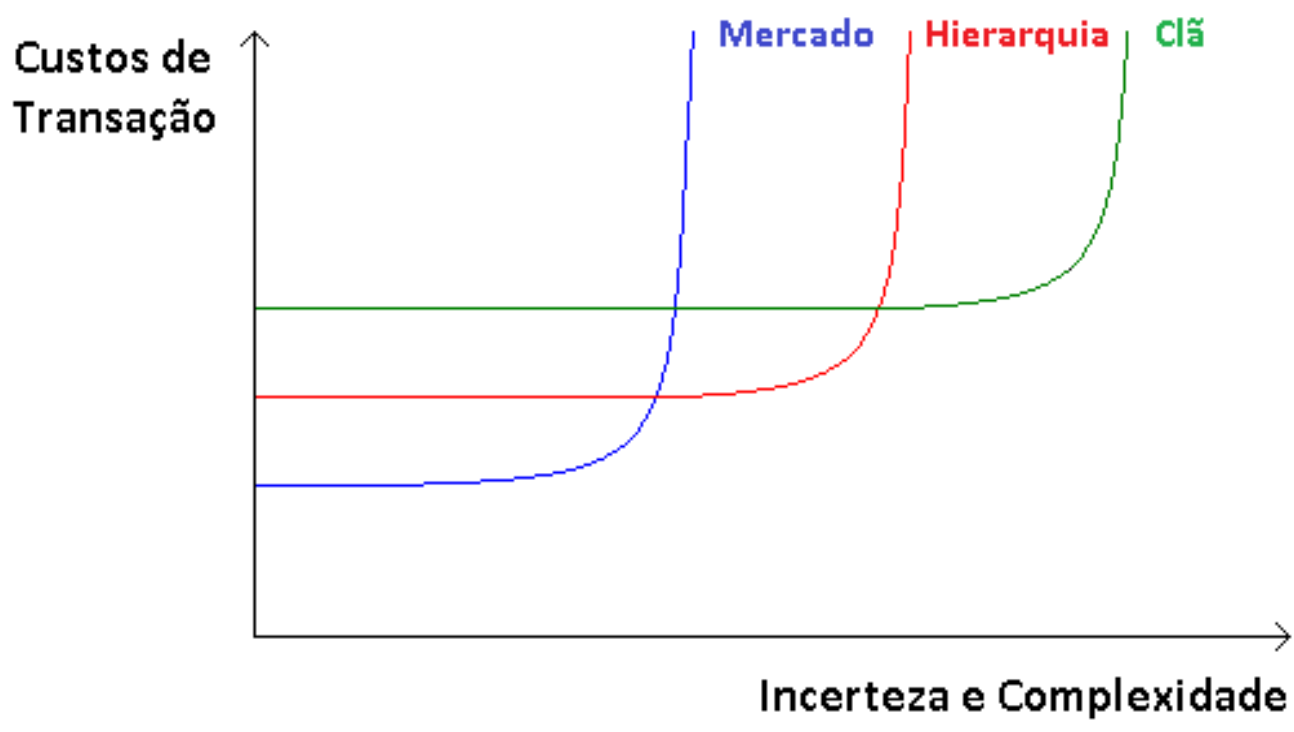

Gráfico 2: Custos de transação, incerteza e complexidade Fonte: baseado em WIILIAMSON (1975, p. 40) e Ouchi (1980)

O Scrum busca reduzir a complexidade tratando o projeto em pedaços de tempo menores (sprints), nos quais o prazo, o escopo e a equipe estão fixos. Um sprint pode durar de uma a quatro semanas e seu prazo é fixado durante o planejamento e, a priori, não pode ser alterado. Caso não seja possível completar todo o escopo previsto, encerramos o sprint no prazo previsto e consideramos que o sprint falhou (SUTHERLAND; SCHWABER, 2011).

No Scrum o projeto começa com uma visão do sistema que deve ser construído. A visão pode ser inicialmente vaga, mas deve se tornar mais clara com o andamento do projeto (SCHWABER, 2004, p. 7). A visão precisa ser compartilhada, deve unificar o entendimento sobre o que vai ser construído e, além disso, ser abrangente, motivadora, clara e simples (PILCHER, 2010, p. 25-27).

O Product Owner é o papel responsável por tomar as decisões de negócio referentes ao produto, até mesmo a definição da visão e do Product Backlog, que é uma lista priorizada dos requisitos funcionais e não funcionais. $\mathrm{O}$ escopo é fixo dentro de um sprint, mas flexível e adaptável às necessidades do projeto a cada sprint, a partir da priorização dada pelo Product Owner, (SCHWABER, 2004, p. 8).

Brown (2001) explica as falhas nos projetos de TI da Administração Pública por meio da Teoria das "Organizações Permanentemente Falhas" de Meyer e Zucker (1989). Segundo Brown (2001), apesar da teoria ter sido originalmente pensada para explicar falhas em 
organizações, é possível generalizá-la para projetos da administração pública que estejam em estado de falha permanente (BROWN, 2001; MCGREGOR JR., 1993, p. 176).

Segundo Goodyear e Nelson (2007, p. 309), quando agências governamentais empreendem projetos, sua falha tem efeitos críticos em um grande número de usuários de seus serviços. $\mathrm{O}$ custo da falha é maior e mais visível em grandes projetos. Além disso, pelo menos no caso do setor público, projetos de TI de grande porte e orientados à integração têm alta probabilidade de falhar.

Segundo a Teoria das Organizações Permanentemente Falhas, quando o desempenho e a persistência estão separados, é possível que exista um grupo de atores dependentes que se beneficiam da continuidade da organização (BROWN, 2001). No caso dos projetos de TI da administração pública, Brown (2001) cita como possíveis atores: os formuladores de políticas públicas, os gestores das organizações nas quais os sistemas de TI serão introduzidos, as equipes que seriam afetadas pelo cancelamento do projeto, os órgãos de auditoria e os consultores e fornecedores da iniciativa privada (BROW, 2001).

Segundo Brown (2001), os fatores que contribuem para a falha em projetos de TI no setor público são:

- Os problemas inerentes ao próprio desenvolvimento de software;

- Os problemas de capacidade insuficiente de gestão;

- Os problemas criados pelos métodos de aquisição utilizados.

Brown (2001) conclui, explicando que os requisitos da Teoria das Organizações Permanentemente Falhas, relativos à persistência e a atores dependentes, são preenchidos no caso dos projetos de TI do setor público. Brown (2001) cita uma série de projetos de TI do setor público do Reino Unido que fracassaram, sem entrar em detalhes sobre qual metodologia foi usada para gerenciá-los.

Wirick (2009, p. 18) explica que os projetos do setor público podem falhar pelos mesmos motivos que levam os projetos do setor privado a falhar, mas que, além disso, existem alguns motivos complementares inerentes aos projetos públicos. 
Projetos falham em qualquer setor da economia em razão dos seguintes fatores (WIRICK, 2009, p. 18):

- Falha em identificar as necessidades dos clientes ou usuários do produto do projeto;

- Criação de um cronograma excessivamente otimista e falha em antecipar o impacto de entregas atrasadas;

- Não conseguir os recursos necessários para completar o projeto;

- Não dedicar tempo suficiente ao planejamento do projeto;

- Mudanças nas prioridades da alta administração;

- Emprego de uma tecnologia que não funcionou conforme o esperado;

- Não conseguir um bom desempenho dos fornecedores;

- Sobrecarga de projetos concorrentes e falta de processos sólidos para a priorização de projetos;

- Não identificar, analisar e tratar os riscos do projeto adequadamente;

- Estabelecer premissas que não são validadas e aceitas;

- Dissolver-se em razão de conflitos entre as partes interessadas;

- Ser impactado por eventos inesperados;

- Não aplicar métodos sólidos e repetíveis de gerenciamento de projetos;

- Não contar com o benefício de um gerente de projetos experiente;

- Falta de engajamento e envolvimento das partes interessadas no decorrer do projeto;

- Não identificar lições aprendidas de projetos anteriores;

- Estabelecer um escopo muito amplo para o projeto, inviabilizando que o escopo seja bem definido.

Especificamente no setor público, projetos podem falhar pelos seguintes fatores adicionais (WIRICK, 2009, p. 19):

- Processo político confuso ou emaranhado;

- Falta dos recursos necessários em razão do requisito de usar a equipe disponível ao invés de contratar especialistas;

- Restritos por causa de regras do serviço civil que limitam a designação de atividades à equipe do projeto;

- Perda da autorização do orçamento;

- Perda de suporte em razão de mudanças na administração causadas por ciclos eleitorais; 
- Sobrecarga de regras administrativas e processos requeridos para comprar e contratar;

- Falha em atender às agências reguladoras;

- Adotar uma abordagem excessivamente conservadora por causa da natureza contenciosa do ambiente do projeto;

- Serem impactados por fornecedores menos capazes, selecionados por um processo de compra focado excessivamente nos custos ou influenciado por fatores não relevantes para o desempenho;

- Serem comprometidos em razão do viés dos gerentes do serviço público, que priorizam a conformidade em detrimento do desempenho;

- Falha em identificar as metas do projeto em razão da existência de muitas partes interessadas e de desafios em identificar as métricas do sucesso.

Aichholzer e Schmutzer (2000) explicam que a aplicação da Tecnologia da Informação e Comunicação (TIC) implica grandes desafios organizacionais para agências do governo, especialmente em dois aspectos cruciais:

1. Reestruturação das funções administrativas e processos;

2. Coordenação e cooperação entre departamentos diferentes e níveis diferentes do governo.

Aichholzer e Schmutzer (2000) reconhecem a existência de uma barreira no nível micropolítico, pois a probabilidade de concretizar-se uma reorganização depende muito da forma pela qual as aplicações de TIC se relacionam com a distribuição de poder existente na organização.

Krishna e Walsham (2005) argumentam que o uso bem-sucedido de TI nos países ricos despertou o interesse e criou expectativas nos países em desenvolvimento acerca do uso da TI para acelerar seu desenvolvimento.

Em um estudo de caso prático no Estado de São Paulo, Humes (2006, p. 180) cita o exemplo da implantação do SIAFEM/SP, que aumentou o poder da Secretaria de Planejamento no âmbito do Estado e de algumas diretorias no âmbito de suas secretarias, como a diretoria financeira da Secretaria de Saúde, que passou a ter maior controle sobre as verbas destinadas aos hospitais. 
Segundo Humes (2006, p. 204), a introdução do SIAFEM/SP causou mudanças no exercício de poder de diversas partes interessadas, denominadas por Humes (2006, p. 204) de atores organizacionais. Além disso, conforme a autora:

"A implantação do sistema foi resultante do exercício de poder pelo Governo e pelas Secretarias da Fazenda e do Planejamento, mas ao mesmo tempo, o sistema se tornou uma fonte de poder, uma vez que foi institucionalizado como sistema contábil e financeiro do Estado de São Paulo."

Krishna e Walsham (2005) apresentam dois casos de sucesso que ocorreram na província indiana de Andhra Pradesh. Os autores consideraram como critério de sucesso a sustentabilidade e as perspectivas de diferentes partes interessadas que participaram do estudo. Como evidência da sustentabilidade, os autores argumentam que os sistemas permaneceram em operação pelo menos durante os quatro anos contemplados pela pesquisa. Quanto ao ponto de vista de diferentes partes interessadas, os autores citaram o consenso existente na província a respeito do sucesso dos projetos, enfatizando que nem mesmo a oposição questionava seu sucesso.

Segundo Krishna e Walsham (2005), existem pelo menos cinco grandes diferenças na condução de projetos entre o setor público de países desenvolvidos ou o de países emergentes. Os autores ressaltam que essas questões foram bem tratadas no caso da província de Andhra Pradesh:

- Divergência entre o sistema planejado e o sistema existente: a necessidade de uma reestruturação nos sistemas organizacionais é muito maior nos países em desenvolvimento;

- Mudança organizacional: há menor flexibilidade para mudanças sistêmicas, e as pessoas não podem ser contratadas ou demitidas facilmente, pois os empregos são escassos e a seguridade social praticamente inexiste. Além disso, o serviço público é considerado mais estável e, consequentemente, um projeto de TI que ameaçasse o emprego dos funcionários sofreria grande resistência e oposição;

- Mudança nos processos: processos não podem ser facilmente alterados, entre outros motivos, pelos interesses legais e pela corrupção que frequentemente está embutida no processo. Só é possível remodelar esses processos com grande envolvimento e comprometimento político; 
- Custos: o hardware e o software são relativamente mais caros em países em desenvolvimento;

- Sistemas excessivamente hierárquicos: como os sistemas são mais hierarquizados e em razão das grandes dificuldades citadas acima, o comprometimento e o envolvimento devem ocorrer em um nível alto da hierarquia.

Os fatores considerados mais importantes pelos autores foi a liderança e envolvimento do governador da província, bem como sua familiaridade com a TI e seu entusiasmo. Além disso, o governador assumiu um compromisso de longo prazo, interessou-se pela implementação e incentivou seus subordinados a fazerem o mesmo, mostrando-se aberto a aprender, até mesmo com seus erros. Finalmente, o governador usou ostensivamente suas habilidades políticas em favor dos projetos (KRISHNA; WALSHAM, 2005).

O apoio da alta administração é citado em vários textos sobre gerenciamento de projetos como um fator fundamental para obter sucesso. Dentre esses textos podemos destacar Albertin (2001), Johnson (2006, p. 22), Wirick (2009, p. 24) e Kerzner (2009, p. 76).

De acordo com Kerzner (2009, p. 76), quem gerencia os projetos são as pessoas e não as metodologias. Dessa forma, a alta administração deveria desenvolver uma cultura corporativa que desse suporte à gestão de projetos e deixasse clara a confiança na metodologia que estivesse em uso.

Além dos aspectos relacionados à atitude e comprometimento do próprio governador, Krishna e Walsham (2005) também destacam:

- O envolvimento e integração bem-sucedida de vários grupos, como, por exemplo, os funcionários do governo, consultorias externas internacionais (Mckinsey e KPMG) e consultorias de TI indianas;

- Estruturas organizacionais inovadoras, que quebraram a resistência dos funcionários do setor público à participação de empresas privadas, por meio de treinamentos e desenvolvimento por estágios;

- Orientação às pessoas na seleção de projetos, priorizando a melhoria nos serviços públicos e atendimento aos cidadãos. Além disso, projetos que poderiam sofrer maior resistência interna foram adiados; 
- Aprender e persistir: aprender a partir de suas próprias experiências é essencial, bem como ser capaz de se adaptar ao contexto e se apropriar de tecnologias e práticas desenvolvidas originalmente em outros locais.

Weerakody, Sarikas e Patel (2005) apresentam uma pesquisa a respeito dos problemas de integração que ocorrem em grandes projetos de Governo Eletrônico, e argumentam que os problemas técnicos são multiplicados no setor público, em razão dos processos burocráticos e ineficientes e dos sistemas legados desconectados que precisam ser integrados.

Weerakody, Sarikas e Patel (2005) argumentam que, apesar da viabilidade técnica e da disponibilidade de tecnologia, as agências do governo encontram muitos obstáculos ao tentar desenvolver de forma bem-sucedida suas implantações de sistemas de informação e comunicação. Os autores atribuem essa dificuldade à necessidade de considerar aspectos técnicos, políticos e organizacionais ao promover a integração entre os sistemas.

Layne e Lee (2001) propõem um modelo de quatro estágios pelos quais o Governo Eletrônico deve passar. A descrição dos quatro estágios de Layne e Lee (2001), apresentados no Gráfico 3, é a seguinte:

- Catálogo: presença on-line, apresentação de catálogo e formulários para download;

- Transação: serviços e formulários on-line, base de dados de trabalho com suporte a transações on-line;

- Integração vertical: sistemas locais integrados com sistemas de maior nível, dentro de funcionalidades similares;

- Integração horizontal: sistemas integrados por meio de diferentes funções e ponto único de contato para o cidadão. 


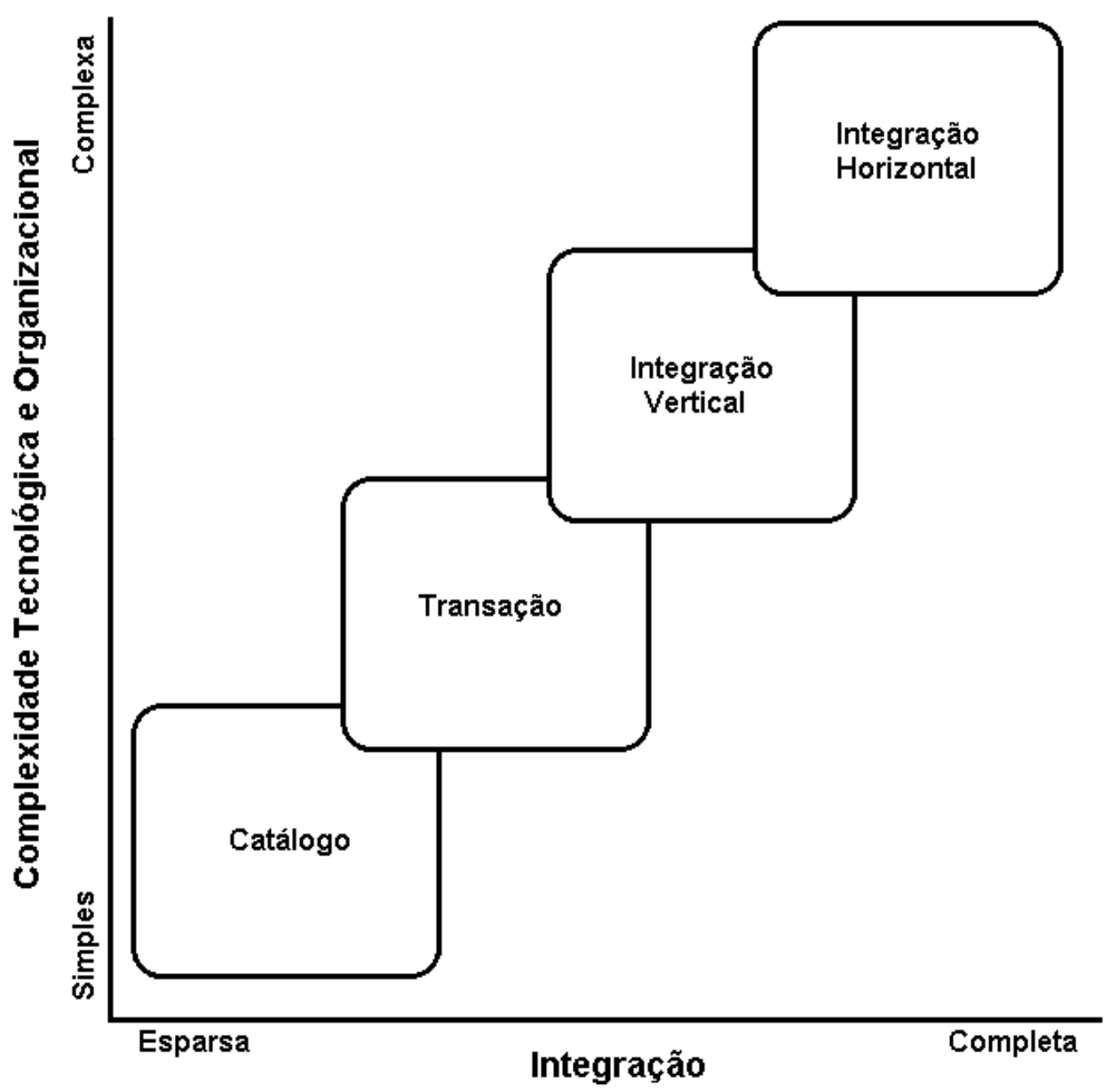

Gráfico 3: Dimensões e estágios do desenvolvimento de governo eletrônico Fonte: adaptado de Layne e Lee (2001)

De acordo com Weerakody, Sarikas e Patel (2005), a transição do estágio de catálogo para as integrações (vertical e horizontal) requer o redesenho dos processos no âmbito funcional e organizacional, tanto interna quanto externamente às organizações que participam da integração.

Furlong e Al-Karaghouli (2010) realizaram uma pesquisa bibliográfica, agrupando os vários desafios que devem ser enfrentados por projetos de Governo Eletrônico:

- Gerenciar partes interessadas com interesses e culturas divergentes;

- O impacto das realidades políticas nos modelos de desenvolvimento;

- A necessidade de integração do resultado do projeto no ambiente macro da transformação do negócio, que inclui prazos políticos e o próprio prazo do projeto. 
Angelopoulos et al. (2010) explicam que o tamanho da área administrativa e seu nível de profissionalismo são determinantes primários da adoção de TI na administração pública. Os autores apontam diversas barreiras para a implementação de projetos de Governo Eletrônico:

- A integração de várias aplicações e componentes de TI dentro e fora da organização é custosa e demorada em razão da heterogeneidade dos ambientes computacionais envolvidos;

- Necessidade de segurança e privacidade na estratégia de Governo Eletrônico;

- Carência de profissionais de TI capacitados;

- Problemas de financiamento (quando o governo e as prioridades mudam, o projeto pode perder suporte e financiamento);

- Barreiras organizacionais, tais como a fragmentação, problemas de relacionamento e comunicação entre departamentos funcionais e aceitação dos benefícios estratégicos das novas iniciativas pela gerência sênior;

- Problemas relacionados à qualidade.

Em relação às pesquisas sobre Governo Eletrônico conduzidas no Brasil, Diniz et al. (2009) apresentam um modelo para analisar o Governo Eletrônico, contemplando inclusive sua etapa de projeto. Diniz et al. (2009) propõem também as seguintes etapas:

- Elaboração de políticas de Governo Eletrônico;

- Concepção de Projetos de Governo Eletrônico;

- Implantação de Projetos de Governo Eletrônico;

- Operação e manutenção de Projetos de Governo Eletrônico;

- Avaliação e Controle (em paralelo às quatro etapas listadas acima).

Em relação aos atores relevantes, o modelo proposto por Diniz et al. (2009) é composto da alta cúpula do governo, responsável pela formulação de políticas públicas; da alta cúpula local, composta por dirigentes de instituições ou do nível executivo da administração pública; e a equipe técnica, que detém o conhecimento de TIC e/ou o conhecimento de negócio.

O modelo de Diniz et al. (2009) considera três aspectos principais que influenciam os projetos de TICs:

- Aspectos políticos: partes interessadas, envolvidas de forma direta ou indireta no projeto, podem possuir demandas implícitas ou explícitas; 
- Aspectos institucionais: a estrutura hierárquica funcional, o poder e a responsabilidade dos atores envolvidos, o processo de aquisições, os modelos de terceirização adotados para as TICs, o grau de burocratização, dentre outros aspectos institucionais, influenciam os projetos de Governo Eletrônico;

- Aspectos técnicos: padrões tecnológicos, complexidade técnica do projeto, a metodologia de desenvolvimento e outras influências técnicas relacionadas às TICs ou ao negócio estão fortemente relacionados com a etapa de implantação do projeto.

Santos e Araújo (2009), em uma pesquisa sobre a aplicação de técnicas de levantamento de requisitos em projetos de sistemas corporativos (que envolvam vários órgãos) na administração pública, apontam alguns problemas encontrados:

- Dificuldade de localizar usuários qualificados para definir os requisitos do sistema (o solicitante é diferente do usuário);

- A prioridade de determinado requisito varia, dependendo do ponto de vista do órgão (cada órgão prioriza suas próprias necessidades);

- Reclamações sobre requisitos não contemplados, como consequência da informalidade na gestão de requisitos;

- Novas funcionalidades às vezes desagradam alguns clientes e somente são percebidas quando o produto já está em operação;

- Falta de comunicação formal e proativa com os clientes, que precisam investir seu tempo para descobrir se seus requisitos serão ou não atendidos;

- Pressões políticas que impactam o escopo já definido.

Moreno, Gobbo Jr. e Cavenaghi (2007) descrevem os principais problemas encontrados em um estudo de caso de um projeto de implantação de um sistema integrado (Enterprise Resource Planning - ERP) em um município paulista:

- Baixa motivação do quadro de servidores para aceitar a nova postura da administração;

- Resistência das pessoas em abandonar os sistemas antigos e utilizar o sistema integrado;

- Necessidade de uma utilização integrada, pois as diversas unidades precisam funcionar corretamente para não se prejudicarem mutuamente;

- Necessidade de adaptação das pessoas às novas tecnologias e sistemas de trabalho; 
- Migração das informações dos sistemas antigos, com formato e estrutura de dados diferentes;

- Utilização de softwares livres (incluindo softwares de automação de escritório), pois as versões livres são diferentes e geralmente mais limitadas que as versões comerciais;

- A customização dos novos sistemas a determinadas características específicas da Prefeitura Municipal;

- Necessidade de readaptação das estruturas físicas da rede.

Zwicker e Souza (2003, p. 65) explicam que os ERPs possuem características que os distinguem dos sistemas convencionais (internos ou pacotes):

- São softwares desenvolvidos no formato de pacotes comerciais;

- Contêm embutidos no seu software os modelos de processos de negócio que ajudaram a formar sua base conceitual e que são tratados pelo fabricante como "melhores práticas";

- Apresentam a característica de alta integração dos sistemas e de suas bases de dados, usando uma base de dados corporativa ao invés de bases de dados locais;

- Abrangem grande parte das funcionalidades das empresas (grande abrangência funcional);

- Demandam certos ajustes ou customizações para que possam ser usados em uma empresa específica.

Zwicker e Souza (2003, p. 69) explicam que, por usar modelos de processos, um ERP demanda customizações, ou seja, ajustes no pacote para que ele se adeque à empresa. Além disso, alguns processos da empresa devem ser alterados para se adequarem ao modelo do ERP.

Prasser (2007) explica que grandes projetos, em razão do seu status, tamanho e complexidade, muitas vezes têm liberdade para optar pela não utilização de práticas apropriadas de gerenciamento de projetos no estabelecimento de seu escopo, na avaliação e na implementação e, consequentemente, falham em conseguir uma função ou propósito claros.

Segundo Laia et al. (2011), de forma geral, as organizações do setor público no Brasil não possuem ou aplicam metodologias para o gerenciamento de projetos, o levantamento de 
requisitos ou o gerenciamento de portfólio. Além disso, suas iniciativas não costumam sofrer qualquer tipo de escrutínio ou seleção dos projetos para liberação de recursos.

Prasser (2007) argumenta que existe um paradoxo, o de que, apesar da grande experiência com projetos públicos, os governos cometem repetidamente os mesmos erros. $\mathrm{O}$ autor atribui esse paradoxo às constantes reestruturações em departamentos e instituições, às mudanças na forma de arquivamento e ao declínio do conceito de serviço público como uma carreira permanente. Esses fatores facilitariam a perda do conhecimento organizacional.

\subsection{Governança de TI}

O relatório da OECD (2001) argumenta que os riscos relacionados à governança dos projetos deveriam ser identificados e mais bem gerenciados. Uma recomendação importante do relatório é de que os projetos de Governo Eletrônico deveriam ser golfinhos e não baleias. A OECD (2001) apresenta uma série de diretrizes relacionadas a projetos de TI no setor público:

- Estabelecer estruturas de governança apropriadas;

- Pensar pequeno;

- Usar tecnologias conhecidas;

- Identificar e gerenciar o risco;

- Garantir a conformidade com as melhores práticas de gerenciamento de projetos;

- Tornar os gerentes de negócio responsáveis (accountable);

- Recrutar e reter talentos;

- Gerenciar o conhecimento de forma prudente;

- Estabelecer ambientes de confiança com fornecedores privados;

- Envolver os usuários finais.

Prasser (2007) define os projetos denominados de "elefantes brancos" como grandes, caros e dependentes de prazos maiores do que o originalmente estimado, mas que, por outro lado, trazem prestígio para a administração. Dessa forma, o prestígio se torna mais relevante do que a função e, consequentemente, o resultado do projeto apresenta um desempenho ruim quando avaliamos sua função ou seu resultado financeiro. 
Os problemas apontados por Prasser (2007) no caso dos projetos "elefantes brancos" incluem:

- As metas são pouco claras do início ao término do projeto;

- Metas políticas (claras ou obscuras) interferem com a determinação das metas do projeto;

- A avaliação de viabilidade inicial é limitada e não é feita de forma independente, ocasionando expectativas exageradas, otimistas ou que não são especificadas;

- A seleção dos serviços a serem oferecidos é geralmente direcionada pela oferta ao invés de pela demanda;

- Análise de riscos pobre;

- Muitos custos incorridos (Sunk Costs), favorecendo o agravamento do projeto;

- Especificações que são alteradas durante a fase de implementação do projeto;

- Orçamentos mal desenvolvidos e crescentes;

- Prazos comprimidos incertos ou estabelecidos para atender ao ciclo eleitoral, com pouco acompanhamento das partes interessadas relevantes;

- Fraca governança do projeto, com pouca separação entre a gestão do projeto e o cliente do projeto, o que resulta em interferência excessiva no design, no orçamento e na gestão;

- Longo tempo de execução, de forma que o impacto total, incluindo os custos, não é considerado até que o projeto esteja próximo do término;

- Metas que mudam com frequência.

Um modelo de governança muito usado no mercado e no serviço público é o COBIT. O termo COBIT, do inglês Control Objectives of Information and Related Technology, é um arcabouço de governança de TI que aborda várias necessidades das organizações para obter uma boa governança (ITGI, 2007, p. 5).

O COBIT define a governança de TI como uma responsabilidade dos executivos e do conselho de diretores, que consiste de liderança, estruturas organizacionais e processos, para garantir que a área de TI da empresa dê sustentação e viabilidade aos objetivos e estratégias da organização (ITGI, 2007, p. 5).

Essa definição contrasta com outras, como, por exemplo, a da ISO/IEC 38500, que define a Governança de TI como o sistema pelo qual o uso atual e futuro da TI é dirigido e controlado. 
Governança Corporativa de TI envolve a avaliação e orientação da utilização da TI para apoiar a organização e o acompanhamento de seu uso para alcançar planos, incluindo a estratégia e as políticas para o uso de TI na organização (ISO; IEC, 2008).

Weill e Ross (2006, p. 8) definem a Governança de TI como: “A especificação dos direitos decisórios e do framework de responsabilidades para estimular comportamentos desejáveis na utilização de TI".

O modelo COBIT é baseado em um Balanced Score Card (KAPLAN; NORTON, 1992) genérico, com diversas metas de negócio, que implicam metas de TI. Para atender a cada meta de TI, alguns processos devem ser implementados. O modelo possui 34 processos agrupados em 4 domínios (ITGI, 2007, p. 12):

- Planejamento e Organização (PO - Plan and Organise);

- Aquisição e Implementação (AI - Acquire and Implement);

- Entrega e Suporte (DS - Deliver and Support);

- Monitoração e Avaliação (ME - Monitor and Evaluate).

Entre os processos de Planejamento e Organização propostos pelo COBIT, existem alguns que possuem impacto direto na gestão e governança dos projetos. O processo "PO1 - Definir um plano estratégico de TI", por exemplo, possui um objetivo de controle relacionado à gestão do portfólio de projetos de TI. O modelo não explica como a gestão de portfólios deve ser operacionalizada, mas oferece diretrizes de operação, como, dentre outras, a necessidade de justificar cada projeto, a atribuição clara de responsabilidades (accountability) $e$ a necessidade de alinhamento estratégico do portfólio de projetos com a estratégia da empresa (ITGI, 2007, p. 30).

No COBIT, a gestão do portfólio de projetos é uma responsabilidade que deve ser executada pelo chefe do desenvolvimento (head development), pelo chefe das operações (head operations) e pelo dono do processo de negócio (business process owner), sob a supervisão do Diretor da área de Informática (CIO). Responsáveis por várias áreas devem ser consultados, como o executivo chefe da empresa, o chefe da área de arquitetura de TI, o chefe da parte administrativa de TI e o escritório de projetos. Além disso, o executivo de negócios, 
o diretor financeiro e a área de auditoria devem ser informados sobre o processo (ITGI, 2007, p. 31).

Apesar de apontar a necessidade de gestão do portfólio, o COBIT não apresenta recomendações específicas relacionadas a como evitar ou contornar problemas que promovem o agravamento de projetos.

O processo denominado "PO4 - Definir os processos, organização e relacionamentos de TI" possui vários objetivos de controle com impacto na gestão de projetos. O modelo recomenda que a organização tenha (ITGI, 2007, p. 42-43):

- Um arcabouço de processos de TI;

- Comitê de estratégia de TI;

- Comitê diretor de TI (steering committee);

- Função de TI encaixada na estrutura organizacional de acordo com sua importância para a empresa;

- Estrutura organizacional da área de TI;

- Estabelecimento de papéis e responsabilidades;

- Responsabilidade pela garantia da qualidade;

- Responsabilidade pelos riscos, segurança e conformidade;

- Propriedade dos dados e sistemas;

- Segregação de responsabilidades;

- Requisitos de pessoal;

- Identificar os profissionais-chave (para minimizar a possibilidade de que uma função crítica dependa de um único indivíduo);

- Políticas e procedimentos de contratação de pessoal;

- Relacionamentos com outras áreas da empresa.

Outros processos, tais como o "PO5 - Gerenciar o investimento em TI", que estabelece as diretrizes para a gestão financeira do portfólio de projetos, o "PO7 - Gerenciar recursos humanos", o "PO8 - Gerenciar a qualidade" e o "PO9 - Gerenciar os riscos", também produzem impactos na gestão de projetos (ITGI, 2007). 
O processo específico que estabelece diretrizes para a gestão de projetos no modelo proposto pelo COBIT é o "PO10 - Gerenciar projetos". Dentre os objetivos de controle desse processo, podemos destacar alguns que os departamentos de TI deveriam ter (ITGI, 2007, p. 68-69):

- Arcabouço de gerenciamento de programas;

- Arcabouço de gerenciamento de projetos;

- Abordagem de gerenciamento de projetos adequada ao tamanho e complexidade dos projetos;

- Comprometimento das partes interessadas;

- Declaração do escopo do projeto;

- Fase de iniciação do projeto;

- Plano de projeto integrado;

- Recursos do projeto;

- Gerenciamento de riscos do projeto;

- Plano de qualidade do projeto;

- Controle de mudanças no projeto;

- Planejamento dos métodos de garantia do projeto (assurance);

- Medição de desempenho, relatórios e monitoração do projeto;

- Encerramento formal do projeto.

A ISO possui um padrão de Governança de TI denominado ISO/IEC 38500 - Corporate Governance of Information Technology (ISO; IEC, 2008). O padrão ISO/IEC 38500 apresenta uma visão de alto nível, baseada em princípios. Além de fornecer orientações gerais sobre o papel do corpo diretivo, o padrão recomenda que as organizações utilizem normas apropriadas para consolidar sua Governança de TI (ISO; IEC, 2008).

Os princípios adotados pelo padrão ISO/IEC 38550 (ISO; IEC, 2008) são os seguintes:

- Responsabilidade: indivíduos e grupos dentro da organização devem compreender e aceitar suas responsabilidades em relação à oferta e demanda de TI. Aqueles com responsabilidade pelas ações devem possuir a responsabilidade correspondente;

- Estratégia: a estratégia de negócios da organização leva em conta as atuais e futuras capacidades de TI, e os planos estratégicos de TI satisfazem as necessidades atuais e contínuas da estratégia de negócios da organização; 
- Aquisição: as aquisições relativas à TI são feitas por motivos válidos, com base adequada, análise contínua e tomada de decisão clara e transparente. Deve existir um equilíbrio adequado entre benefícios, oportunidades, custos e riscos, considerando curto e longo prazo.

- Desempenho: TI é adequada ao seu propósito de atender à organização, fornecendo serviços, níveis e qualidade de serviço para atender aos requisitos de negócio atuais e futuros;

- Conformidade: TI está em conformidade com toda a legislação e regulamentos obrigatórios. Políticas e práticas estão claramente definidas, implementadas e executadas.

- Comportamento Humano: políticas de TI, práticas e decisões demonstram respeito pelo Comportamento Humano, incluindo as necessidades atuais e contínuas de todas as pessoas envolvidas no processo.

O corpo diretivo deve governar a TI por meio de três atividades principais (ISO; IEC, 2008):

- Avaliação do uso atual e futuro da TI;

- Preparação direta e execução de planos e políticas para assegurar que o uso de TI atenda aos objetivos de negócios;

- Monitoração da conformidade e desempenho das políticas com os planos.

O Consórcio ITSqc (Information Technology Services Qualification Center), liderado pela Universidade Carnegie Mellon, publicou um modelo de capacidade para aquisição na área de TI denominado eSourcing Capability Model - eSCM. O eSCM é um modelo de "melhores práticas" que permite às organizações clientes avaliarem e melhorarem sua capacidade de desenvolver relações mais eficazes com seus fornecedores, contribuindo para a melhor gestão dessas relações. Existe uma versão do modelo para organizações que fornecem serviços, denominado eSCM-SP - service providers - e uma versão para clientes, o eSCM-CL (ITSqc, 2011).

O eSCM é um modelo de "melhores práticas" para medir a capacidade de clientes e fornecedores, com três propósitos (HEFLEY; LOESCHE, 2006):

(1) orientar os prestadores de serviços a melhorar sua capacidade de fornecimento em todo o ciclo de vida; 
(2) fornecer aos clientes uma forma objetiva de avaliar a capacidade dos prestadores de serviços;

(3) Oferecer aos prestadores de serviços um padrão, para ajudá-los a se diferenciar de seus competidores.

A versão do eSCM para as organizações clientes, o eSCM-CL, é composto de 95 práticas que tratam das capacidades críticas necessárias à organização cliente envolvida na contratação de serviços de TI (HEFLEY; LOESCHE, 2006). De acordo com Fernandes e Abreu (2008), os principais objetivos do eSCM-CL são:

- Fornecer aos clientes um conjunto de melhores práticas para ajudá-los a melhorar suas capacidades nas atividades de aquisição;

- Ajudar organizações clientes a estabelecer, gerenciar e sustentar melhoria contínua em suas relações de aquisição;

- Ajudar as organizações clientes a mitigar os riscos em suas relações de aquisição;

- Ajudar as organizações clientes a criar competência na gestão de suas atividades de aquisição;

- Assegurar a satisfação das partes interessadas relevantes ao longo do ciclo de vida do processo de aquisição;

- Fornecer meios para as organizações clientes avaliarem de maneira objetiva suas próprias capacidades em serviços de aquisição de TI.

Gillies (2007) apresenta a visão do conselho de administração de uma organização, considerando tanto empresas privadas quanto órgãos da administração pública. A autora apresenta o ponto de vista de que a razão dos problemas enfrentados pelos projetos de TI reside na sua má governança, e ressalta que o conselho de administração deveria se preocupar com a tomada de decisão, a responsabilização (accountability) e os processos, deixando os gráficos de Gantt para o gerente do projeto.

Gillies (2007) enfatiza que, em muitos dos projetos fracassados, a área de negócio não entendeu ou não aceitou seu papel no projeto e os gestores de TI preencheram esse vazio tomando decisões que deveriam ser do negócio. Na maioria dos projetos, mais de $60 \%$ do trabalho envolve habilidades que não são de TI, como, por exemplo, desenho de processos, mudança organizacional, identificação dos benefícios, desenvolvimento do produto, 
gerenciamento da mudança e treinamento. Consequentemente, Gillies (2007) conclui que existe uma decisão de negócio que precede cada decisão de TI e que a área de negócio deve ser responsabilizada (tornar-se "accountable") por essa decisão.

Young (2007) argumenta que entregar o escopo combinado dentro do prazo e do orçamento é insuficiente para considerar um projeto bem-sucedido. $\mathrm{O}$ autor argumenta que o sucesso do produto resultante é um fator primordial para considerar o projeto "um sucesso", pois, afinal, as organizações não investem seus recursos em um projeto apenas para que ele seja entregue dentro do prazo e do orçamento.

Dessa forma, como o sucesso do produto não depende da capacidade do gerente de projetos de TI, o autor sugere que a Governança de um Projeto de TI deveria incorporar o executivo de negócio, que deveria ser responsabilizado e premiado de acordo com seu desempenho. Dessa forma, as diretrizes de Governança de TI deveriam ser focadas, primeiramente, nas responsabilidades dos altos executivos de negócios. Consequentemente, um aspecto-chave da Governança dos Projetos de TI é como motivar as partes interessadas e, especialmente, o patrocinador, a entregar os resultados prometidos (YOUNG, 2007).

Gillies (2007) explica que o conselho de administração deveria:

- Garantir que a Governança de TI seja entendida e implementada por toda a organização;

- Diferenciar a Governança de TI e da Gestão de TI;

- Os gerentes e executivos de negócio devem ser proprietários da gestão e dos resultados dos projetos de TI;

- Insistir na existência de pontos claros de responsabilização das áreas de negócio em projetos estratégicos;

- Monitorar os riscos dos projetos, entregas e resultados, ao invés de acompanhar relatórios de status baseados em gráficos de Gantt;

- Garantir uma estrutura de recompensas que reconheça a responsabilidade das áreas de negócio pela entrega do projeto e de seus benefícios.

Young (2007) recomenda algumas questões de governança que deveriam ser tratadas e respondidas em diferentes momentos do ciclo de vida: 
- Quais são os benefícios esperados?

- Quanta mudança organizacional é necessária para concretizar os benefícios?

- Como os benefícios serão medidos e como o patrocinador será recompensado?

- Quem deveria ser o patrocinador?

- Os benefícios estão se concretizando?

- A cultura organizacional é adequada para que eventos inesperados (riscos) possam ser antecipados?

\subsection{Problemas Complexos}

Keil e Robey (1999) argumentam que projetos de SI são frequentemente caracterizados como problemas muito complexos. Deephouse et al. (1996) também defendem o ponto de vista de que gerenciar projetos de software, da determinação dos requisitos até a implementação, é uma tarefa complexa.

Schwaber (2004, p. 5) afirma que, atualmente, quase todos os projetos de software podem ser classificados como complexos e que alguns deles são impossíveis de implantar, a menos que parte de sua complexidade seja tratada ou resolvida.

De acordo com Xia e Lee (2004), projetos de desenvolvimento de sistemas de informação são inerentemente complexos porque precisam lidar não somente com aspectos tecnológicos, mas também com fatores organizacionais que estão muito distantes do controle da equipe do projeto.

Goodyear e Nelson (2007, p.311) explicam que projetos de TI de grande porte e alta complexidade estão se tornando cada vez mais frequentes em organizações do setor público. Alguns exemplos citados são o sistema de gestão de bagagens do Aeroporto de Denver (MONTEALEGRE; KEIL, 2000) e o sistema Taurus da Bolsa de Valores de Londres (DRUMMOND, 1996), entre outros. 
Flyvbjerg (2011, p. 322) explica que os grandes projetos costumam apresentar as seguintes características:

- São inerentemente arriscados, em razão do longo horizonte de planejamento e da complexidade das interfaces;

- Os processos de tomada de decisão, planejamento e gestão comumente envolvem múltiplos atores com interesses conflitantes;

- A tecnologia e o design são geralmente não padronizados (fora do padrão);

- Frequentemente, ocorre um comprometimento exagerado com algum conceito do projeto em seus estágios iniciais, resultando em aprisionamento (lock-in), tornando a análise de alternativas fraca ou ausente e levando ao agravamento do comprometimento nos estágios finais;

- Em razão das grandes somas de dinheiro envolvidas, problemas de agência são comuns;

- O escopo e o nível de ambição do projeto mudam comumente de forma significativa, conforme o tempo passa;

- Evidências estatísticas mostram que a complexidade e os eventos não planejados são frequentemente ignorados (não são levados em conta), tornando inadequadas as reservas de contingência de custo e prazo;

- Consequentemente, desinformação sobre custos, cronogramas, benefícios e riscos é a norma durante o desenvolvimento do projeto e a tomada de decisão;

- O resultado é um estouro no orçamento e redução nos benefícios do projeto, que prejudicam sua viabilidade durante a fase de implementação do projeto.

O conceito de Wicked Problems, referente a problemas complexos, foi formulado inicialmente por Rittel e Webber (1973). Pries-Heje e Baskerville (2008) explicam que esses problemas são formulados de maneira pobre e confusa, e são permeados de valores conflitantes de muitos tomadores de decisão e outras partes interessadas.

Problemas complexos compartilham algumas características (RITTEL; WEBBER, 1973; PRIES-HEJE; BASKERVILLE, 2008):

- Podem ser formulados somente a partir de uma solução;

- Como cada resultado da decisão é obscuro, o problema não pode ser subdividido ou resolvido aos poucos; 
- Suas soluções são baseadas em valores (pessoais e culturais), e não podem ser consideradas verdadeiras ou falsas, mas somente boas ou más;

- O espaço de soluções é ilimitado e as soluções são irreversíveis;

- Problemas complexos não podem ser abordados, criados ou ter suas alternativas avaliadas sem envolver um considerável grau de incerteza.

Problemas complexos são completamente diferentes dos problemas tradicionais, pois são mal definidos, ambíguos e associados a fortes questões morais, políticas e profissionais (RICHTEY, 2011).

Rittel e Webber (1973) explicam que o oposto dos problemas complexos são os problemas domesticados (tame) ou benignos. No caso de um problema domesticado, a definição do problema é clara (existe consenso), bem como seu propósito.

Poppendieck (2002) escreve que os projetos complexos (Wicked Projects) são resultado do uso de técnicas tradicionais para tratar um problema complexo como se fosse um problema domesticado. A autora argumenta que essa receita levará ao desastre.

Deephouse et al. (1996) explicam que um bom processo de desenvolvimento de software certamente não é o único fator que influencia o resultado do projeto - outros fatores incluem a complexidade da aplicação, a estabilidade dos requisitos, a capacidades dos membros da equipe e a qualidade das ferramentas de software.

Schwaber (2004, p. 5) classifica os projetos de desenvolvimento de sistemas em quatro níveis de dificuldade, usando como referência a complexidade de se obter consenso a respeito do problema (complexidade dos requisitos) e a complexidade relacionada à existência ou não de certeza (complexidade da tecnologia):

- Simples;

- Complicado;

- Complexo;

- Em situação de anarquia.

O Gráfico 4 apresenta a avaliação da complexidade proposta por Schwaber (2004, p. 5). 


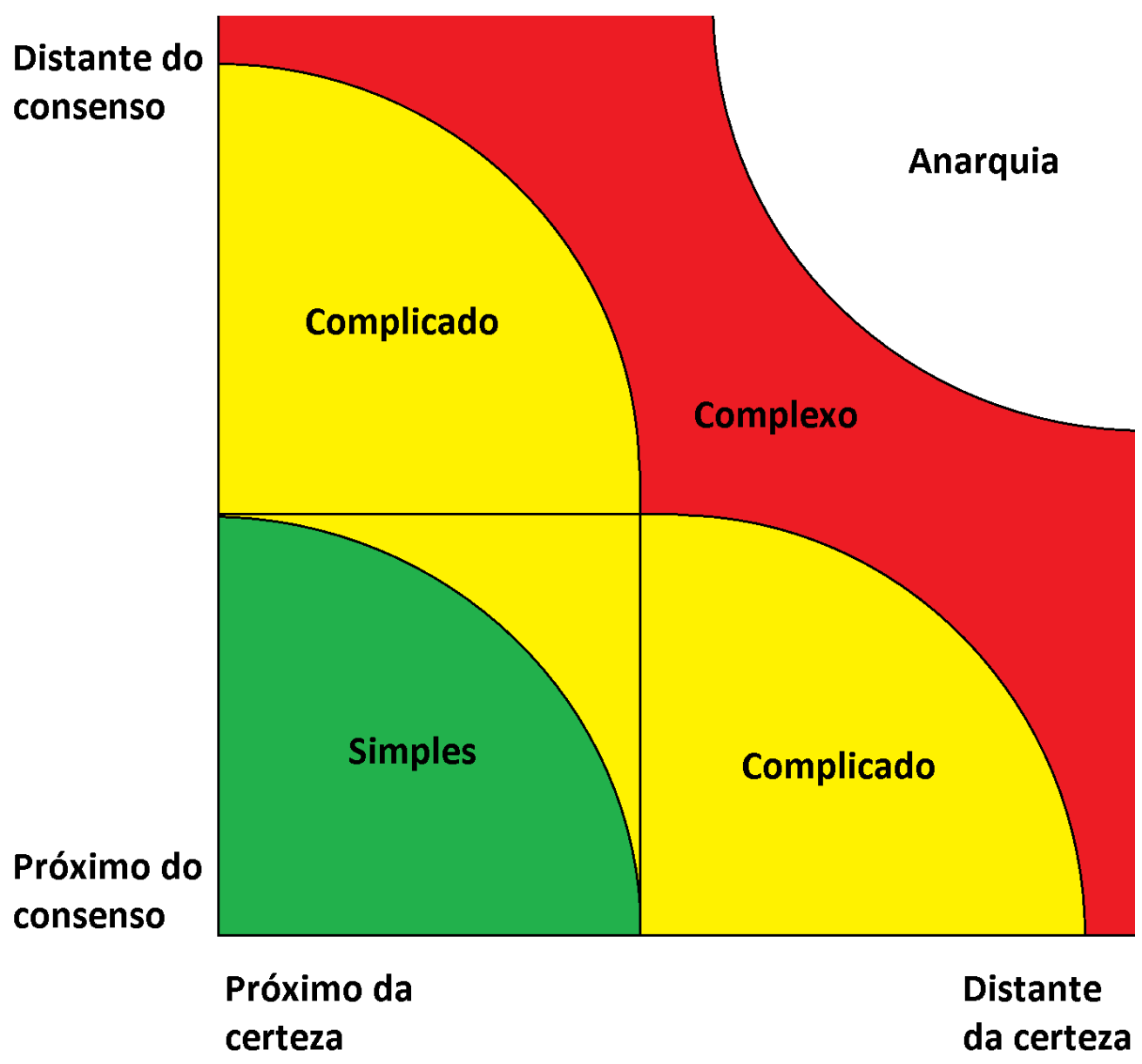

Gráfico 4: Avaliação da complexidade Fonte: adaptado de SCHWABER (2004, p. 5)

Rittel e Webber (1973) informam que era mais fácil chegar a um consenso sobre a natureza de um problema no início do período industrial e, então, atribuir a tarefa a alguém habilitado. Entretanto, mais recentemente tem se tornado menos aparente em que reside o problema e, ao intervir nele, pode haver consequências de grande severidade em outros pontos.

Goodyear e Nelson (2007, p. 310) apresentam uma classificação dos ambientes de desenvolvimento existentes a partir de duas variáveis: tamanho e complexidade. O Gráfico 5 apresenta essa classificação. 


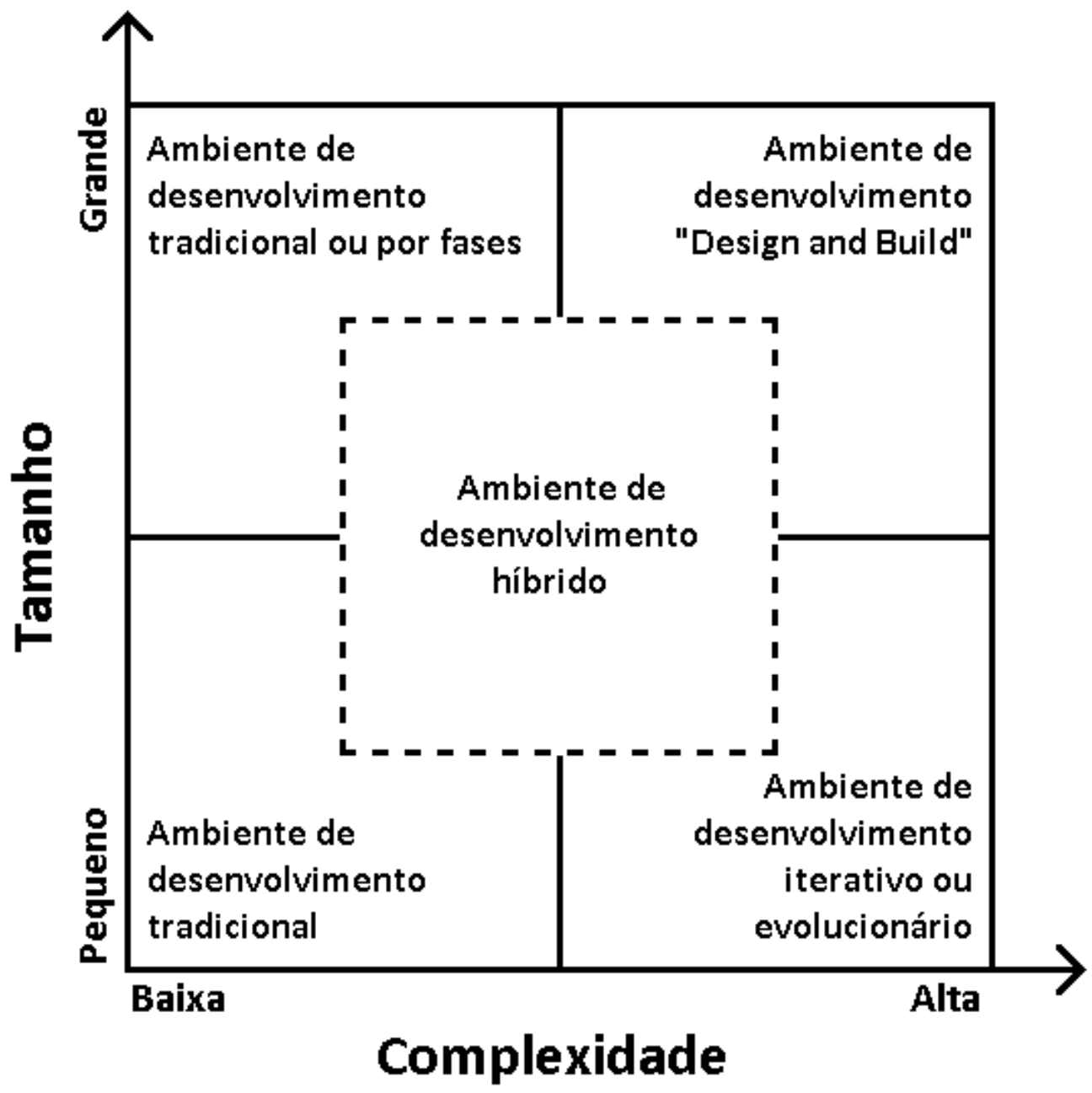

Gráfico 5: Tamanho versus complexidade e os ambientes de desenvolvimento de sistemas de informação mais comuns

Fonte: adaptado de Goodyear; Nelson (2007, p. 310)

Goodyear e Nelson (2007, p. 310) explicam que, quando a complexidade é baixa e o projeto tem pequeno porte, a escolha da estratégia de desenvolvimento de sistemas é flexível, pois praticamente qualquer técnica de desenvolvimento de sistemas é efetiva. Em projetos pequenos com complexidade maior, abordagens mais iterativas e evolucionárias são mais adequadas.

A redução da complexidade por meio da decomposição do projeto em partes menores e mais facilmente alcançáveis não é exclusiva da área de SI. Staw e Ross (1987) já propõem essa estratégia, que favorece o desenvolvimento de saídas alternativas pelo tomador de decisão. Os autores também recomendam que o reconhecimento honesto dos problemas deve ser incentivado, juntamente com um exame claro de suas alternativas, incluindo a opção de desistência. 
Em sistemas de grande porte e baixa complexidade, o modelo tradicional em cascata ou um desenvolvimento mais gradual, separado em fases, é desejável. Nos sistemas de porte e complexidade moderados, algumas abordagens híbridas, como o desenvolvimento baseado em componentes ou algumas metodologias ágeis, são mais adequadas (GOODYEAR; NELSON, 2007, p. 311).

A proposta do uso de abordagens híbridas não é nova na área de SI. Burns e Dennis (1985) propuseram um modelo no qual projetos de baixa complexidade deveriam ser conduzidos por meio de prototipagem. Goodyear e Nelson (2007, p. 311) argumentam que os projetos de alta complexidade e baixa incerteza deveriam ser conduzidos por meio do ciclo de vida tradicional de desenvolvimento de sistemas, enquanto os projetos de alta complexidade e incerteza deveriam ser tratados por abordagens híbridas.

Entretanto, Goodyear e Nelson (2007, p. 311) argumentam que mesmo as abordagens híbridas usadas em sistemas de porte e complexidade moderados falham ao lidar com os projetos maiores e mais complexos, que têm sido mais frequentes no caso dos projetos de TI do setor público. Os autores concluem que a maioria das técnicas de desenvolvimento de sistemas se adequa melhor à faixa que vai de sistemas grandes e simples a sistemas pequenos e complexos.

Mathiassen e Stage (1992) refinam o modelo Burns e Dennis (1985) propondo o "Princípio da Redução Limitada”. Os autores explicam que o modelo de operação experimental, como por exemplo, o desenvolvimento baseado em prototipagem, reduz a incerteza, mas adiciona novas fontes de complexidade, o que demanda contramedidas analíticas.

Por outro lado, o modelo de operação analítico, baseado em especificações detalhadas, contribui para a redução da complexidade, mas adiciona novas fontes de incerteza, demandando contramedidas experimentais (MATHIASSEN; STAGE, 1992).

Consequentemente, os autores apontam a necessidade de balancear medidas analíticas e experimentais ao realizar certas tarefas, para conseguir lidar efetivamente com a complexidade e a incerteza (MATHIASSEN; STAGE, 1992). 
Em uma crítica ao modelo cascata, DeGrace e Stahl (1990, p. 82) afirmam que esse modelo foi associado com o desenvolvimento de certos softwares que colocavam o computador em uma posição central: folha de pagamentos, sistemas de reservas em aeronaves, sistemas de planejamento, etc. Entretanto, nos últimos anos temos encontrado problemas de natureza diferente, para os quais o computador fornece e organiza a informação, mas o papel central cabe ao ser humano. Segundo os autores, o desenvolvimento de sistemas, atualmente, em razão dessa mudança na natureza dos sistemas, precisa lidar com diversos problemas complexos.

Rittel e Webber (1973) citam a abordagem clássica da Engenharia de Sistemas, segundo a qual é necessário entender o problema, obter informação, analisar a informação, sintetizar a informação, esperar pela intuição criativa e trabalhar a solução. No caso de um problema complexo, não é possível entendê-lo sem entender seu contexto, não faz sentido buscar informação sem ter visão de um espaço de soluções, não é possível usar a visão tradicional de primeiro entender e depois solucionar.

Poppendieck (2002) complementa esse pensamento, explicando que a aplicação de ferramentas mais formais de análise é impossível antes que o problema possa ser articulado de forma concisa, bem delimitada e consensual. Em outras palavras, o problema deve primeiro ser domesticado.

Goodyear e Nelson (2007, p. 311) listam alguns fatores que trazem complexidade ao ambiente de desenvolvimento de sistemas das organizações do setor público:

- Mudanças frequentes devidas à volatilidade da liderança e à interferência externa;

- Prazo que pode demorar anos, com requisitos que mudam constantemente;

- Ser forçado a iniciar o desenvolvimento antes de todos os requisitos serem conhecidos.

Xia e Lee (2004) explicam a complexidade a partir de duas dimensões, cada uma com dois aspectos:

- Organizacional versus Tecnológico;

- $\quad$ Estrutural versus Dinâmico. 
As duas dimensões propostas por Xia e Lee (2004) são combinadas para formar uma taxonomia da complexidade dos projetos de desenvolvimento de sistemas de informação. $\mathrm{O}$ Gráfico 6 apresenta os aspectos que formam a taxonomia de Xia e Lee (2004).

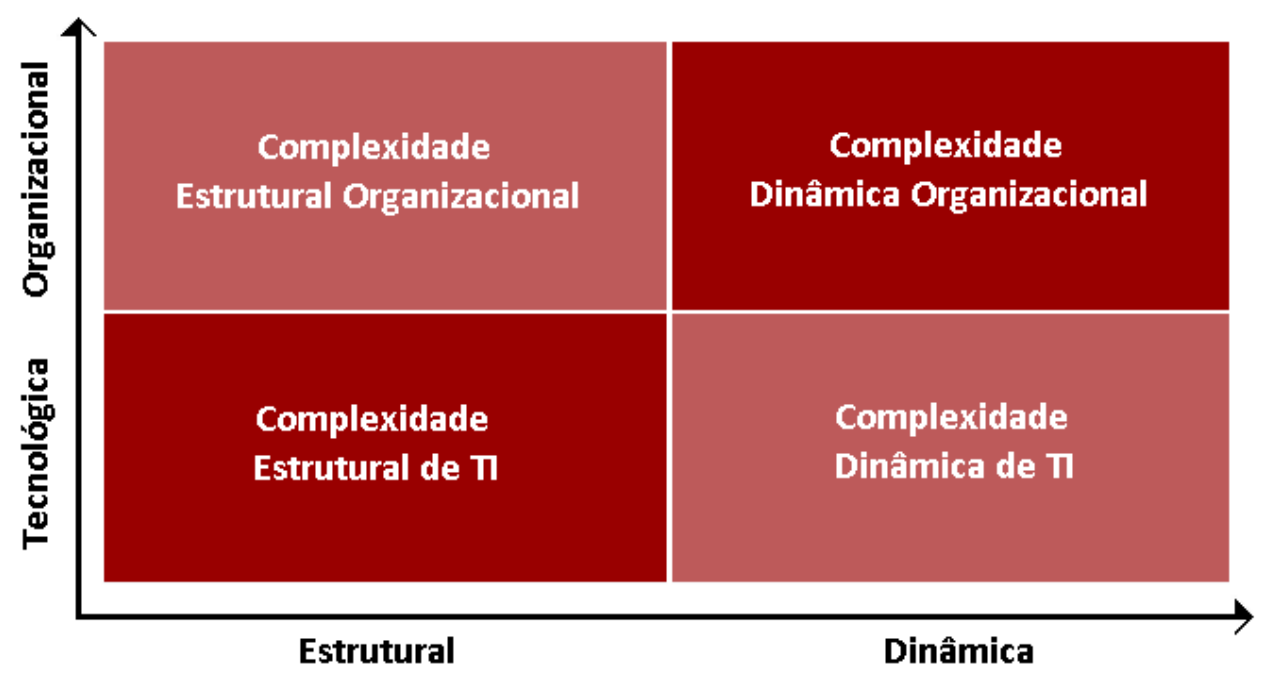

Gráfico 6: Taxonomia da complexidade do desenvolvimento de sistemas de informação Fonte: adaptado de XIA e LEE (2004)

Os elementos da taxonomia proposta por Xia e Lee (2004) são listados a seguir:

- Complexidade estrutural organizacional: reflete a natureza e força das relações entre os elementos no ambiente organizacional, incluindo os recursos do projeto, suporte de usuários e da alta gerência, equipe do projeto, habilidade e nível de proficiência da equipe do projeto;

- Complexidade estrutural de TI: inclui a complexidade do relacionamento entre os elementos de TI, refletindo a diversidade das unidades de negócio dos usuários, os ambientes de software, a natureza do processamento de dados, a variedade de plataformas tecnológicas, a necessidade de integração e a diversidade de fornecedores externos;

- Complexidade dinâmica organizacional: contempla o padrão de mudança no ambiente organizacional dos projetos de desenvolvimento de sistemas de informação, incluindo mudanças nas necessidades de informação dos usuários, processos de negócio e estruturas organizacionais, além dos efeitos do projeto no ambiente organizacional;

- Complexidade dinâmica de TI: mede os padrões e a frequência das mudanças no ambiente do projeto de desenvolvimento de sistemas de informação, incluindo mudanças na infraestrutura de TI, arquitetura e ferramentas de desenvolvimento de software. 
As dimensões de complexidade propostas por Xia e Lee (2004) diferem dos aspectos enfatizados por outros autores que estudam a complexidade dos projetos de desenvolvimento de SI, como, por exemplo, Poppendieck (2002), Schwaber (2004) e Goodyear e Nelson (2007). Consequentemente, é conveniente verificar qual ponto de vista acerca da complexidade descreve melhor o problema do agravamento do comprometimento em projetos de desenvolvimento de SI. 
A literatura de gerenciamento de projetos, incluindo o gerenciamento de projetos no setor público, aponta uma série de obstáculos que atrapalham as organizações na entrega de projetos que contemplem o escopo combinado com a qualidade desejada e respeitem os limites de prazo e orçamento (REMENYI, 1999, p. 59; SMITH, 2001, p. 8; WALLACE; KEIL, 2004; WIRICK, 2009, p. 18-19).

Os obstáculos enfrentados pelos projetos podem levá-los a se tornar projetos problemáticos e, consequentemente, candidatos ao agravamento (KEIL; MANN; RAI, 2000).

A classificação de Staw e Ross (1987) inclui quatro fatores para explicar o agravamento do projeto: as características específicas do projeto, fatores psicológicos, sociais e organizacionais. Ao apresentar seus exemplos, Staw e Ross (1987) concentram as causas que levam um projeto a se tornar problemático nas características específicas do projeto e em alguns fatores organizacionais, enquanto as causas que fazem um projeto problemático ser continuado apesar do feedback negativo são contempladas nos fatores psicológicos, sociais e organizacionais.

As teorias analisadas por Keil, Mann e Rai (2000) também focam as causas que fazem um projeto problemático ser continuado apesar do feedback negativo: Teoria da Autojustificação, Teoria da Perspectiva, Teoria da Agência e Teoria do Afastamento e Aproximação.

O foco desta pesquisa, conforme explicado no objetivo e nas questões de pesquisa, são os riscos que levam um projeto a se tornar problemático, especificamente projetos de TI do setor público.

Em uma pesquisa sobre os riscos em projetos de TI e suas consequências, conduzida em múltiplas indústrias e em projetos gerenciados por membros do PMI, Wallace e Keil (2004) propõem uma classificação que abrange quatro grandes categorias de riscos já mencionadas antes por Keil et al. (1998): (1) mandato do cliente, (2) escopo e requisitos, (3) execução e (4) ambiente. 
Ciborra (2007, p. 31) critica essa classificação, pois, para ele, os autores falham em considerar a literatura comportamental que aponta que essas percepções podem ser fortemente enviesadas e dependentes de uma série de fatores psicológicos e contextuais.

O modelo de referência usado nesta pesquisa tem como ponto de partida a classificação proposta por Wallace e Keil (2004). A opção pelo uso desse modelo como ponto de partida está relacionada à relevância das pesquisas sobre agravamento realizadas por Mark Keil (KEIL, 1995; KEIL; ROBEY, 1999; MONTEALEGRE; KEIL, 2000; KEIL; MANN; RAI, 2000; KEIL et al., 2000; KEIL et al., 2007; FLYNN et al., 2009). Vale ressaltar que a pesquisa realizada neste estudo levou em conta o alerta de Ciborra (2007, p. 31).

Além de serem usadas como ponto de partida para a pesquisa, as conclusões da pesquisa de Wallace e Keil (2004) serão testadas como uma teoria alternativa às explicações propostas no modelo de referência.

No modelo de referência serão usados conceitos relacionados aos chamados problemas complexos (wicked problems) de Rittel e Webber (1973), para selecionar os riscos mais relevantes da classificação de Wallace e Keil (2004).

\subsection{Modelo de Wallace e Keil}

O modelo de Wallace e Keil (2004) é baseado na classificação de Keil et al. (1998) das quatro macrocategorias de risco: (1) mandato do cliente, (2) escopo e requisitos, (3) execução e (4) ambiente. Wallace e Keil (2004) explicam que existe a percepção de que os riscos (2) e (3) estão sob maior controle do gerente do projeto, enquanto os riscos (1) e (4) estão fora do alcance do gerente do projeto.

Wallace e Keil (2004) analisaram o impacto das quatro grandes categorias de risco no processo (se o projeto foi completado no prazo e no orçamento) e no produto (se o produto atende às necessidades que motivaram o projeto). As conclusões da pesquisa foram as seguintes: 
- Para minimizar os impactos no produto, é fundamental gerenciar os riscos dos tipos: (1) mandato do cliente, (2) escopo e requisitos, e (3) execução;

- Para minimizar os impactos no processo, é fundamental gerenciar os riscos dos tipos: (2) escopo e requisitos, e (3) execução;

- Os riscos relacionados do tipo (4) ambiente não tiveram correlação com impactos no produto ou no processo.

Wallace e Keil (2004) argumentam que o risco mais importante está relacionado à execução e que, nos casos em que esse risco é baixo, a boa execução do projeto poderia minimizar os riscos relacionados ao mandato do cliente, escopo e requisitos. Por outro lado, quando o risco de escopo e requisitos é baixo, essa característica apresenta efeitos compensatórios em relação a um alto risco de execução.

Considerando-se os riscos relacionados aos resultados do processo na pesquisa de Wallace e Keil (2004) - (2) riscos relacionados ao escopo e aos requisitos e (3) riscos de execução - no caso de um projeto em que os riscos relacionados a escopo e requisitos sejam altos, caso os riscos relacionados à execução sejam minimizados, os efeitos dos riscos de escopo e requisitos também seriam minimizados. Por outro lado, caso os riscos relacionados à execução sejam altos, esses riscos potencializariam os riscos relacionados a escopo e requisitos. De acordo com os autores, os riscos relacionados a escopo, requisitos e execução, que estão sob o controle do gerente de projetos, são os mais relevantes para o processo e são importantes também para o resultado do produto (WALLACE; KEIL, 2004).

O problema de o projeto entrar em situação de agravamento está mais relacionado às características do processo (se o projeto foi completado no prazo e no orçamento) do que do produto (se o produto atende as necessidades que motivaram o projeto). A proposição principal a ser concluída do modelo de Wallace e Keil (2004) é que um projeto com altos riscos de escopo e requisitos e altos riscos de execução tem maior chance de entrar em situação de agravamento. Essa primeira proposição será formulada da seguinte forma:

P1: Altos riscos de (2) escopo e requisitos, juntamente com altos riscos de (3) execução, contribuem para que um projeto entre em situação de agravamento. 
A segunda proposição está relacionada às duas categorias de risco da classificação de Keil et al. (1998) - (1) mandato do cliente e (4) ambiente - que, segundo Wallace e Keil (2004) não são relevantes para que o projeto seja completado no prazo e no orçamento.

P2: Os riscos de (1) mandato do cliente e (4) ambiente não são relevantes para que um projeto problemático entre em situação de agravamento.

Por outro lado, vários autores citam as mudanças no governo, que ocasionam instabilidades no ambiente organizacional com posterior reestruturação na organização, como causa de problemas em projetos (OECD, 2001; DINIZ et al., 2009; WIRICK, 2009, p. 19). Consequentemente, considerando-se as conclusões de pesquisas especializadas no setor público e levando-se em conta que a pesquisa de Wallace e Keil (2004) foi diversificada em diversos setores, é questionável que a conclusão sobre a irrelevância dos riscos de (1) mandato do cliente e (4) ambiente seja aplicável aos projetos de TI do setor público.

Conforme detalhado no item "4.5 Gerenciamento de Riscos em Projetos de SI" do capítulo "4 Revisão da Literatura", o modelo de Walace e Keil possui um total de 53 riscos distribuídos nos quatro quadrantes.

\subsection{Modelo de Referência}

Para responder à primeira questão de pesquisa, referente a quais são os principais riscos que podem contribuir para que um projeto de TI do setor público chegue à situação de agravamento, serão selecionados os fatores de risco de Wallace e Keil (2004) relacionados à complexidade e ao tamanho do projeto.

Antes de selecionar os riscos que se encaixam na definição de complexidade, o pesquisador realizou duas adaptações no modelo de Wallace e Keil (2004), que contém originalmente 53 riscos.

Primeiramente, foram adicionados dois riscos citados na literatura de gestão de projetos de TI no setor público: 
- Estrutura ineficiente para a tomada de decisão: risco relacionado ao ambiente, proposto a partir da avaliação da importância do comitê do projeto segundo a OGC (2009b);

- Prazo político: risco de execução que costuma afetar projetos do setor público (RAINEY, 1997, p. 168; WIRICK, 2009, p. 89; FURLONG; AL-KARAGHOULI, 2010).

Dessa forma, com essa lista de 55 riscos, foi efetuada pelo pesquisador uma consolidação com o propósito de simplificar a operacionalização da pesquisa e sua posterior análise. Após a consolidação, a lista foi reduzida para 15 riscos. Os Quadros 16, 17, 18 e 19 apresentam a equivalência entre os 15 riscos consolidados e os 55 riscos iniciais, agrupados segundo os quatro quadrantes de Keil et al. (1998).

\section{Quadro 16: Agrupamento dos riscos iniciais do mandato do cliente}

\begin{tabular}{|l|l|l|}
\hline \multicolumn{1}{|c|}{ Riscos Consolidados } & \multicolumn{1}{c|}{ Riscos Iniciais } \\
\hline Falta de participação do usuário. & $\bullet \quad$ Falta de participação do usuário; \\
& $\bullet \quad$ Usuários não comprometidos com o projeto; \\
\hline $\begin{array}{l}\text { Usuários com atitudes negativas em relação ao } \\
\text { projeto. }\end{array}$ & $\bullet \quad \begin{array}{l}\text { Usuários com atitudes negativas em relação ao } \\
\text { projeto; }\end{array}$ \\
\hline Falta de apoio da alta direção ao projeto. & $\bullet \quad \begin{array}{l}\text { Usuários resistentes a mudanças; } \\
\text { Falta de comprometimento ou pouco } \\
\text { comprometimento da organização com o projeto. }\end{array}$ & $\bullet \quad$ Falta de apoio da alta direção ao projeto. \\
\hline
\end{tabular}

Fonte: elaborado pelo autor

\section{Quadro 17: Agrupamento dos riscos iniciais de escopo e requisitos}

\begin{tabular}{|c|c|}
\hline Riscos Consolidados & Riscos Iniciais \\
\hline $\begin{array}{l}\text { Dificuldades no detalhamento e estabilização dos } \\
\text { requisitos. }\end{array}$ & $\begin{array}{l}\text { - } \quad \text { Requisitos de sistema que mudam frequentemente; } \\
\text { - } \quad \text { Requisitos do sistema identificados de forma } \\
\text { inadequada; } \\
\text { - } \quad \text { Requisitos de sistema obscuros (não claros); } \\
\text { - } \quad \text { Requisitos de sistema incorretos; } \\
\text { - } \quad \text { Requisitos de sistema conflitantes; } \\
\text { - } \quad \text { Dificuldade em definir entradas e saídas do sistema. }\end{array}$ \\
\hline Problemas no direcionamento do projeto. & $\begin{array}{l}\text { - } \text { Critério de sucesso do projeto indefinido; } \\
\text { - Metas do projeto mal definidas; } \\
\text { - Objetivos e escopo do projeto que mudam } \\
\text { frequentemente. }\end{array}$ \\
\hline $\begin{array}{l}\text { Falta de entendimento pelos usuários sobre as } \\
\text { capacidades e limitações do sistema. }\end{array}$ & $\begin{array}{l}\text { - Falta de entendimento pelos usuários sobre as } \\
\text { capacidades e limitações do sistema. }\end{array}$ \\
\hline
\end{tabular}


Quadro 18: Agrupamento dos riscos iniciais de execução

\begin{tabular}{|c|c|}
\hline Riscos Consolidados & Riscos Iniciais \\
\hline Dificuldades técnicas. & 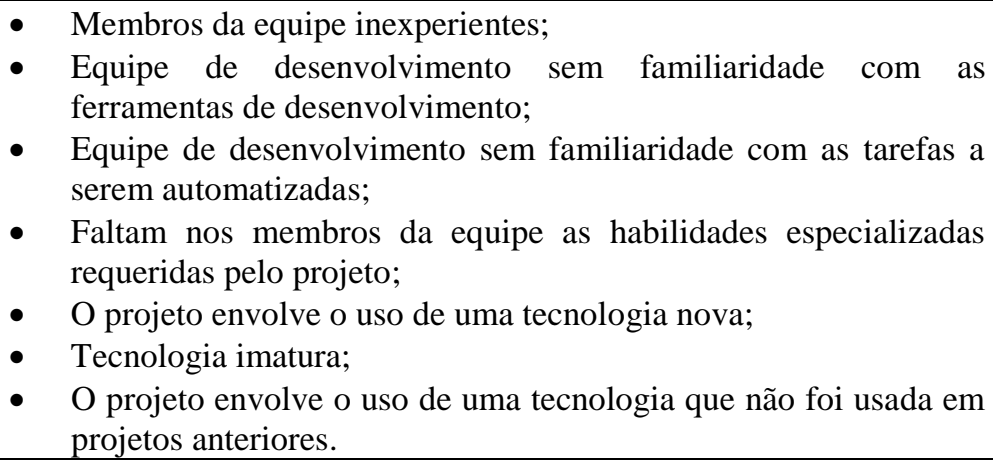 \\
\hline $\begin{array}{l}\text { Complexidade do sistema e } \\
\text { organizacional. }\end{array}$ & $\begin{array}{l}\text { - Alto nível de complexidade técnica; } \\
\text { - A tarefa a ser automatizada é altamente complexa; } \\
\text { - O projeto afeta um grande número de unidades e/ou } \\
\text { departamentos dos usuários; } \\
\text { - Ser um dos maiores projetos já empreendidos pela organização; } \\
\text { - Necessidade de integração com um grande número de sistemas. }\end{array}$ \\
\hline Problemas na gestão do projeto. & $\begin{array}{l}\text { - } \quad \text { Falta de uma metodologia efetiva de gerenciamento de projetos; } \\
\text { - } \quad \text { Estimativa inadequada do cronograma do projeto; } \\
\text { - } \quad \text { Prazo político; } \\
\text { - } \quad \text { Progresso do projeto não monitorado suficientemente de perto; } \\
\text { - } \quad \text { Planejamento precário do projeto; } \\
\text { - } \quad \text { Marcos do projeto não definidos de forma clara; } \\
\text { - } \quad \text { Estimativa inadequada do orçamento do projeto. } \\
\text { - } \quad \text { Gerente do projeto não efetivo; } \\
\text { - } \quad \text { Gerente do projeto inexperiente; } \\
\text { - } \quad \text { Comunicação não efetiva. }\end{array}$ \\
\hline Problemas na gestão da equipe. & $\begin{array}{l}\text { - Membros da equipe de desenvolvimento treinados de forma } \\
\text { inadequada; } \\
\text { - Falta de comprometimento com o projeto por parte dos membros } \\
\text { da equipe; } \\
\text { - Conflitos frequentes na equipe de desenvolvimento; } \\
\text { - Rotatividade frequente dos membros da equipe; } \\
\text { - Atitudes negativas da equipe de desenvolvimento; } \\
\text { - Faltam habilidades de liderança do projeto nas pessoas } \\
\text { - envolvidas; } \\
\text { - Estimativa inadequada dos recursos necessários. }\end{array}$ \\
\hline
\end{tabular}

Fonte: elaborado pelo autor 
Quadro 19: Agrupamento dos riscos iniciais de ambiente

\begin{tabular}{|l|ll|}
\hline \multicolumn{1}{|c|}{ Riscos Consolidados } & \multicolumn{1}{c|}{ Riscos Iniciais } \\
\hline Ambiente organizacional instável. & $\bullet$ & $\begin{array}{l}\text { Recursos deslocados do projeto em razão de mudanças nas } \\
\text { prioridades da organização; }\end{array}$ \\
& $\bullet \quad \begin{array}{l}\text { Ambiente organizacional instável; } \\
\text { Mudança na gestão organizacional durante o projeto; } \\
\text { Organização passando por uma reestruturação durante o projeto. }\end{array}$ \\
\hline $\begin{array}{l}\text { Estrutura ineficiente para a tomada de } \\
\text { decisão. }\end{array}$ & $\bullet$ & Estrutura ineficiente para a tomada de decisão. \\
\hline $\begin{array}{l}\text { Políticas corporativas com efeitos } \\
\text { negativos no projeto. }\end{array}$ & $\bullet$ & Políticas corporativas com efeitos negativos no projeto. \\
\hline $\begin{array}{l}\text { Problemas com fornecedores. } \\
\text { - }\end{array}$ & $\bullet \begin{array}{l}\text { Dependência de um fornecedor externo; } \\
\text { Muitos fornecedores externos envolvidos no desenvolvimento do } \\
\text { projeto. }\end{array}$ \\
\hline
\end{tabular}

Fonte: elaborado pelo autor

A definição de complexidade usada no contexto desta pesquisa contempla aspectos relacionados às seguintes características:

- Dificuldade em definir qual é o problema a ser resolvido (RITTEL; WEBBER, 1973);

- Contribuição para o aumento da incerteza (SCHWABER, 2004, p. 5; RITTEL; WEBBER, 1973), incluindo mudanças frequentes nos requisitos, troca de liderança ou obrigatoriedade de iniciar o desenvolvimento antes de os requisitos serem conhecidos (GOODYEAR; NELSON, 2007, p. 311);

- Dificuldade de obter consenso (SCHWABER, 2004, p. 5; RITTEL; WEBBER, 1973).

Dentre os riscos relacionados à complexidade e incerteza, três se destacam a partir da literatura:

- Riscos de escopo e requisitos (dificuldades no detalhamento e estabilização dos requisitos, problemas no direcionamento do projeto e Falta de entendimento pelos usuários sobre as capacidades e limitações do sistema), pelo grande impacto da dificuldade de definir qual é o problema a ser resolvido e, consequentemente, pelo aumento da incerteza;

- Complexidade do sistema e organizacional;

- Problemas na gestão do projeto, o que evidencia que a abordagem escolhida para lidar com os fatores anteriores foi ineficaz.

Os outros 10 riscos consolidados também ajudam a aumentar a complexidade do projeto, mas se tornam menos importantes caso os cinco riscos referentes aos três fatores citados acima 
estejam bem encaminhados. A Ilustração 2 apresenta o modelo de referência de forma resumida.

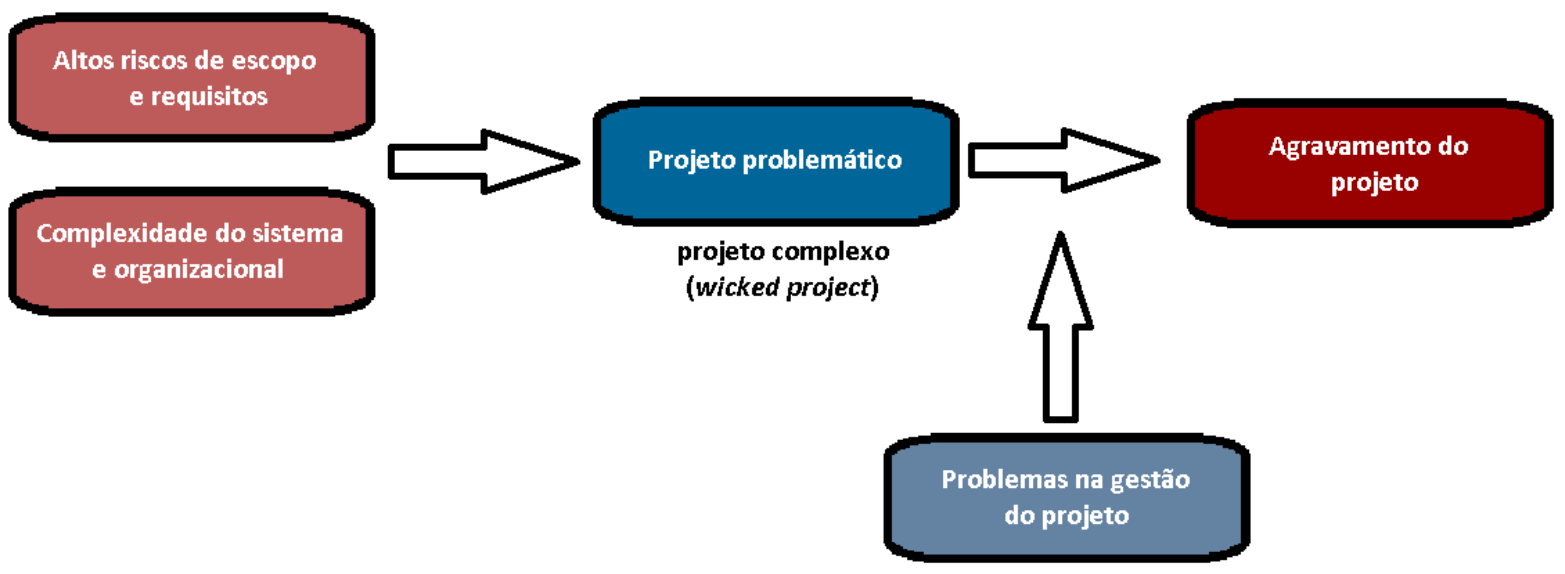

Ilustração 2: Resumo do modelo de referência Fonte: elaborada pelo autor

Dessa forma, a proposição principal derivada do modelo de referência está relacionada ao fato de que projetos problemáticos do setor público que chegaram à situação de agravamento apresentavam inicialmente dificuldades no detalhamento e na estabilização dos requisitos e complexidade do sistema e organizacional. Consequentemente, a seguinte proposição pode ser formulada:

P3: Altos riscos relacionados a escopo e requisitos, juntamente com a complexidade do sistema e organizacional, fazem com que um projeto se torne um projeto complexo (wicked project).

Ao lidar com projetos complexos, Schwaber (2004, p. 5) e Poppendieck (2002) recomendam que os problemas relacionados à sua complexidade sejam resolvidos. Logo, ao se avaliar em retrospectiva um projeto em situação de agravamento, a conclusão provavelmente será de que ocorreram problemas na gestão do projeto. A percepção de problemas na gestão do projeto tende a ocorrer mesmo que alguma metodologia tenha sido aplicada, pois a percepção (em retrospectiva) será de que essa metodologia não foi efetiva. Dessa forma, a seguinte proposição pode ser formulada: 
P4: Projetos em situação de agravamento apresentam altos riscos relacionados a escopo e requisitos, complexidade do sistema e organizacional, e problemas na gestão do projeto.

A alternativa de cancelar ou reorientar o projeto (processo de de-escalation) por causa de seu grau de complexidade (wickedness) também não é simples, pois os envolvidos na tomada de decisão teriam que chegar a um consenso sobre o cancelamento do projeto e provavelmente nem todos concordarão que isso é necessário, em razão de diversos fatores de projeto, psicológicos, sociais e organizacionais, propostos no modelo de Staw e Ross (1987).

Essa natureza complexa da tomada de decisão envolve a gestão do projeto, a prevenção do agravamento, a maneira de contornar o descontrole do escopo e promover o cancelamento ou reorientação de um projeto que está sofrendo de agravamento (o chamado processo de deescalation).

A maneira como um problema é estruturado e interpretado também é um fator a ser considerado. De acordo com a Teoria da Perspectiva (KAHNEMAN; TVERSKY, 1979, TVERSKY; KAHNEMAN, 1981), a curva de valor é geralmente côncava para ganhos e convexa para perdas. Logo, a própria formulação do problema está associada à escolha de um caminho mais avesso ou propenso ao risco.

Keil et al. (2007) explicam que, quando o feedback negativo a respeito do andamento do projeto é ambíguo e a direção a seguir não é clara, os tomadores de decisão podem ser influenciados por vieses cognitivos que prejudicam a interpretação da situação e o reconhecimento do problema, ocasionando o comportamento de agravamento do projeto.

Outro aspecto importante relacionado a um projeto que esteja no espaço de complexidade denominado wicked é sua tendência de entrar em situação de agravamento e se tornar um projeto interminável. Neste caso, a resolução do problema inclui características adicionais de complexidade relacionadas à decisão de cancelar, reorientar ou continuar o projeto. Essas características adicionais de complexidade, segundo a literatura de agravamento de projetos, abrangem as seguintes questões:

- Proximidade de completar o projeto;

- O quão alto é o nível de Sunk Costs; 
- Autojustificação individual e do grupo (tanto psicológica quanto social);

- Existência de feedback negativo e se esse feedback é ambíguo ou inequívoco;

- Existência ou ausência de auditorias periódicas feitas por pessoas externas ao projeto;

- Problemas de agência (pessoas ou grupos que se beneficiem com a continuidade do projeto, mesmo que isso não seja mais vantajoso para a organização);

- Ambiguidade dos custos e recompensas associados ao projeto;

- Falta ou excesso de comprometimento.

Dessa forma, mesmo que uma tentativa de diminuir o nível em um dos eixos seja bemsucedida, ela pode ser insuficiente para tirar o projeto da situação de wickedness.

Em relação à possibilidade de reorientar o projeto para que ele saia da situação de agravamento, a teoria de agravamento baseada na complexidade proposta nesta tese explica o processo de de escalation como a domesticação do projeto.

Xia e Lee (2004) explicam que, para aumentar a taxa de sucesso dos projetos de desenvolvimento de sistemas e seu retorno sobre o investimento, as organizações precisam desenvolver estratégias para gerenciar a complexidade de seus projetos de desenvolvimento de sistemas.

Ou seja, uma reorientação bem-sucedida precisaria resolver os problemas de complexidade do projeto. Dessa maneira, pode-se propor a seguinte proposição:

P5: A reorientação bem-sucedida de um projeto em situação de agravamento envolve aspectos relacionados à diminuição da complexidade do projeto ou à aplicação de técnicas mais adequadas para lidar com a complexidade existente.

Logo, avaliar como os gestores do setor público lidaram com os problemas que propiciaram o agravamento de seus projetos de TI pode ajudar a descobrir técnicas mais adequadas para prevenir e reorientar projetos complexos. 


\subsection{Modelo baseado nos conceitos de Governança de TI}

A necessidade de estabelecer estruturas de governança apropriadas é citada em diferentes estudos de gerenciamento de projetos (OECD, 2001; GILLIES, 2007; ITGI, 2007; PRASSER, 2007; YOUNG, 2007; OGC, 2009b).

Weill e Ross (2006, p. 10) explicam que uma boa governança deve descrever de forma clara quais decisões devem ser tomadas, quem deve tomar cada decisão e como isso será monitorado. Uma boa governança de TI deve incentivar comportamentos desejáveis relacionados à TI.

Gillies (2007) argumenta que os gerentes e executivos de negócio devem ser proprietários da gestão e dos resultados dos projetos de TI, e que devem existir pontos claros de responsabilização das áreas de negócio em projetos estratégicos.

Para Goodyear e Nelson (2007, p. 318), é importante incentivar que os funcionários se sintam donos do projeto (ownership), desenvolver relações de confiança e dar suporte ao aprendizado das pessoas envolvidas.

Weill (2004) e Weill e Ross (2006, p. 11-12) citam alguns arquétipos para a tomada de decisão:

- Monarquia de Negócio: os altos gerentes da organização;

- Monarquia de TI: os especialistas do departamento de TI;

- Feudalismo: de forma relativamente isolada, cada unidade de negócio toma decisões de maneira independente;

- Federalismo: combinação entre o centro corporativo e as unidades de negócio, com ou sem o envolvimento do pessoal de TI;

- Duopólio de TI: o grupo de TI, juntamente com algum outro grupo (a alta gerência ou líderes das unidades de negócio);

- Anarquia: tomada de decisão individual ou por pequenos grupos de modo isolado. 
Weill (2004) e Weill e Ross (2006, p. 62-63) argumentam que a estrutura de governança denominada Federalismo possui uma longa tradição de uso no Setor Público. Arranjos federalistas procuram balancear as responsabilidades entre múltiplos órgãos do governo, alinhando o centro com as pontas. Entretanto, as empresas com desempenho inferior de governança usam principalmente o modelo federalista em sua tomada de decisão (WEILL, 2004).

Uma característica distintiva do modelo federalista é a necessidade de estabelecer consenso entre as partes. Entretanto, existem indícios na literatura sobre Governo Eletrônico da dificuldade em estabelecer consenso. Em um estudo de caso de implementação de Governo Eletrônico, Angelopoulos et al. (2010) explicam que a diferença entre o conselho diretivo e o líder governamental sobre prioridades, juntamente com as tentativas fúteis de atingir consenso, foi responsável pela paralisação permanente do projeto.

Os problemas da estrutura de governança federalista ficam mais evidentes se considerarmos as possíveis relações conflituosas entre as partes interessadas do projeto. Segundo De' (2005), no caso do Setor Público, novos sistemas geralmente acarretam a redistribuição do poder entre os atores-chave, o que potencializa a existência de conflitos e resistência no projeto.

No caso do agravamento de um projeto de TI do Setor Público descrito por Pan et al. (2006), conflitos a respeito do design envolveram o gerente do projeto pela área de sistemas de informação, usuários e o fornecedor, desde os estágios iniciais do projeto.

Wirick (2009, p. 24), referindo-se a projetos do setor público, e Wallace e Keil (2004) mencionando projetos em geral, citam o impacto negativo que a existência de conflitos tem no gerenciamento de projetos.

Dessa forma, considerando-se o exposto acima, uma estrutura de Governança eficaz deveria ter uma estruturação de papéis e responsabilidades que descrevesse de forma clara quais decisões devem ser tomadas, quem deve tomar cada decisão e como isso será monitorado, proporcionando aos administradores assumir a propriedade e responsabilidade por essas decisões. 
Apesar de conhecerem a necessidade de resolver os problemas de governança e eventuais conflitos entre usuários (risco relacionado ao mandato do usuário), ou a instabilidade da organização (risco relacionado ao ambiente), dificilmente os tomadores de decisão do setor público com a responsabilidade de resolver o problema chegarão a um consenso sobre essas necessidades e terão autoridade suficiente para determinar um novo modelo de governança, resolver os conflitos entre as áreas ou estabilizar o ambiente organizacional.

Para operacionalizar a análise do papel da governança, será criada uma categoria de risco para agrupar os riscos de Wallace e Keil (2004) que se enquadrem como riscos de governança. Adicionalmente, foi incluído o risco "Estrutura ineficiente para a tomada de decisão". O Quadro 20 apresenta os riscos selecionados para compor a categoria "riscos de governança".

\section{Quadro 20: Riscos relacionados à Governança de TI}

\begin{tabular}{|c|c|}
\hline Risco & Justificativa \\
\hline Falta de participação do usuário. & $\begin{array}{l}\text { Necessidade de existência pontos claros de responsabilização das áreas de } \\
\text { negócio em projetos estratégicos (GILLIES, 2007). }\end{array}$ \\
\hline Conflitos entre os usuários. & $\begin{array}{l}\text { Relacionado à dificuldade de obtenção de consenso em estruturas } \\
\text { federalistas, comuns no setor público (WEILL, 2004; WEILL; ROSS, } \\
\text { 2006, p. 62-63). }\end{array}$ \\
\hline $\begin{array}{l}\text { Falta de apoio da alta direção ao } \\
\text { projeto. }\end{array}$ & $\begin{array}{l}\text { Gerentes e executivos de negócio devem ser proprietários da gestão e dos } \\
\text { resultados dos projetos de TI (GILLIES, 2007). }\end{array}$ \\
\hline $\begin{array}{l}\text { Falta de comprometimento ou } \\
\text { pouco comprometimento da } \\
\text { organização com o projeto. }\end{array}$ & $\begin{array}{l}\text { Gerentes e executivos de negócio devem ser proprietários da gestão e dos } \\
\text { resultados dos projetos de TI (GILLIES, 2007). }\end{array}$ \\
\hline $\begin{array}{l}\text { O projeto afeta um grande } \\
\text { número de unidades e/ou } \\
\text { departamentos dos usuários. }\end{array}$ & $\begin{array}{l}\text { Relacionado à dificuldade de obtenção de consenso em estruturas } \\
\text { federalistas, comuns no setor público (WEILL, 2004; WEILL; ROSS, } \\
\text { 2006, p. 62-63). }\end{array}$ \\
\hline $\begin{array}{l}\text { Falta de uma metodologia efetiva } \\
\text { de gerenciamento de projetos. }\end{array}$ & $\begin{array}{l}\text { Especificação dos direitos decisórios e do framework de responsabilidades } \\
\text { (WEILL, 2004; WEILL; ROSS, 2006, p. 8). }\end{array}$ \\
\hline $\begin{array}{l}\text { Estrutura ineficiente para a } \\
\text { tomada de decisão. }\end{array}$ & $\begin{array}{l}\text { Pouca separação entre a gestão do projeto e o cliente do projeto, O que } \\
\text { resulta em interferência excessiva no design, orçamento e gestão } \\
\text { (PRASSER, 2007). }\end{array}$ \\
\hline $\begin{array}{l}\text { Mudança na } \quad \text { gestão } \\
\text { organizacional durante o projeto. }\end{array}$ & $\begin{array}{l}\text { Especificação dos direitos decisórios e do framework de responsabilidades } \\
\text { (WEILL, 2004; WEILL; ROSS, 2006, p. 8). }\end{array}$ \\
\hline $\begin{array}{l}\text { Políticas corporativas com efeitos } \\
\text { negativos no projeto. }\end{array}$ & $\begin{array}{l}\text { Estimular comportamentos desejáveis na utilização de TI (WEILL, 2004; } \\
\text { WEILL; ROSS, 2006, p. 8). }\end{array}$ \\
\hline organizacional & $\begin{array}{l}\text { Especificação dos direitos decisórios e do framework de responsabilidades } \\
\text { (WEILL, 2004; WEILL; ROSS, 2006, p. 8). }\end{array}$ \\
\hline $\begin{array}{l}\text { Organização passando por uma } \\
\text { reestruturação durante o projeto. }\end{array}$ & $\begin{array}{l}\text { Especificação dos direitos decisórios e do framework de responsabilidades } \\
\text { (WEILL, 2004; WEILL; ROSS, 2006, p. 8). }\end{array}$ \\
\hline
\end{tabular}

Fonte: elaborado pelo autor

Além dos riscos classificados por Wallace e Keil (2004) e relacionados à Governança de TI, existe uma série de recomendações da literatura sobre agravamento do comprometimento que tangenciam o tema governança: 
- Estabelecer de forma antecipada um limite de investimento e divulgar publicamente esse limite (BROCKNER et al.,1979);

- Estruturar a continuidade do projeto a partir da condição de término automático: o projeto será encerrado, a não ser que uma decisão de continuidade seja tomada (BROCKNER et al.,1979; MONTEALEGRE; KEIL, 2000);

- Substituição dos tomadores de decisão que optaram por um determinado curso de ação (STAW; ROSS, 1987; NEWMAN; SABHERWAL, 1996), como, por exemplo, usar auditores externos em auditorias periódicas (MEREDITH, 1988);

- Estruturar o sistema de recompensas para reduzir as forças que encorajam o agravamento - por exemplo, recompensando a honestidade no reconhecimento da existência de problemas e uma clara avaliação das alternativas (STAW; ROSS, 1987);

- Incentivar um modelo de tomada de decisão mais alinhado com a Teoria Econômica, de forma que os Sunk Costs não interfiram na tomada de decisão;

- Evitar que a informação seja filtrada nos níveis hierárquicos inferiores, antes de chegar aos tomadores de decisão (STAW; ROSS, 1987);

- Evitar contradições entre a direção do feedback e a forma como ele é apresentado, diminuindo a ambiguidade (HENG; TAN; WEI, 2003).

- Desenvolver mecanismos para alinhar o interesse do agente ao do principal, como, por exemplo, tornar a ocorrência de resultados negativos menos ameaçadora aos membros do projeto, conforme sugerido por Newman e Sabherwal (1996) e Montealegre e Keil (2000).

- Estruturar a governança do projeto buscando reduzir a ambiguidade entre os custos e recompensas associados à decisão de continuar ou cancelar o projeto (RUBIN; BROCKNER, 1975).

Existem duas proposições a serem testadas a respeito do relacionamento entre a Governança de TI e o agravamento de projetos:

P6: Altos riscos relacionados à Governança de TI contribuem para que um projeto problemático entre em situação de agravamento.

P7: Altos riscos relacionados à Governança de TI contribuem para que um projeto problemático permaneça em situação de agravamento. 
A proposição P6 corresponde à substituição do fator de risco "Problemas na Gestão do Projeto" pelos elementos da categoria riscos de governança, adaptando-se o modelo de referência conforme apresentado na Ilustração 3.

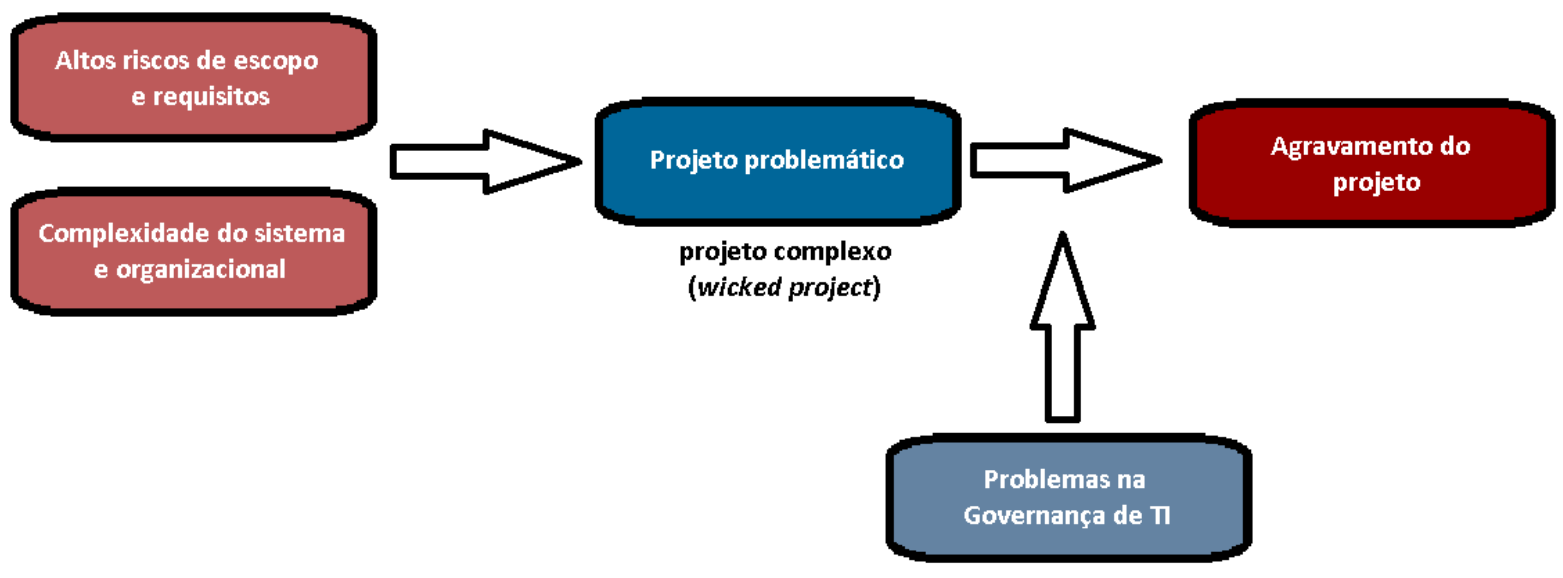

Ilustração 3: Modelo de referência adaptado Fonte: elaborada pelo autor

\subsection{Modelo de Xia e Lee}

Xia e Lee (2004) concluíram em sua pesquisa que a complexidade mais relevante para o desempenho do projeto é a complexidade estrutural organizacional, e que a complexidade estrutural de TI, apesar de apresentar as maiores notas em complexidade, não afetou significativamente o desempenho.

A conclusão de Xia e Lee (2004) contraria o restante da literatura sobre complexidade listada no item referente ao modelo de referência, pois, caso esteja correta, podemos concluir que um projeto em situação de agravamento, que corresponde a um problema extremo de desempenho, deveria apresentar alta complexidade estrutural organizacional, mesmo que outras complexidades não fossem altas.

O Quadro 21 apresenta a comparação entre os elementos que compõem a complexidade estrutural organizacional de Xia e Lee (2004) e os elementos equivalentes no modelo de Wallace e Keil (2004). 
Quadro 21: Comparação do elemento de complexidade estrutural organizacional do modelo de Xia e Lee com os riscos de Wallace e Keil

\begin{tabular}{|l|l|}
\hline \multicolumn{1}{|c|}{ Modelo de Xia e Lee (2004) } & \multicolumn{1}{|c|}{ Fatores de Risco de Wallace e Keil (2004) } \\
\hline $\begin{array}{l}\text { O gerente de projetos não tem controle direto sobre os } \\
\text { recursos do projeto. }\end{array}$ & Falta de cooperação dos usuários. \\
\hline Usuários não ofereceram suporte suficiente. & $\begin{array}{l}\text { Estimativa inadequada dos recursos necessários; } \\
\text { Recursos deslocados do projeto em razão de } \\
\text { mudanças nas prioridades da organização. }\end{array}$ \\
\hline O projeto teve recursos insuficientes. & $\begin{array}{l}\text { Faltam nos membros da equipe as habilidades } \\
\text { especializadas requeridas pelo projeto. }\end{array}$ \\
\hline $\begin{array}{l}\text { A equipe do projeto não possui o conhecimento e a } \\
\text { habilidade necessários. }\end{array}$ & Falta de apoio da alta direção ao projeto. \\
\hline A alta gerência ofereceu suporte insuficiente. & \\
\hline
\end{tabular}

Fonte: elaborado pelo autor

Dessa forma, apesar de a pesquisa de Xia e Lee (2004) ter sido realizada em organizações da América do Norte, sem restrições referentes ao setor público ou privado, convém avaliar sua aplicabilidade a projetos de TI do setor público no Brasil. Consequentemente, mais uma proposição será avaliada neste estudo:

P8: Projetos de TI do setor público em situação de agravamento apresentam alta complexidade estrutural organizacional. 


\section{METODOLOGIA}

O objetivo deste capítulo é descrever, em linhas gerais, os procedimentos metodológicos que direcionaram este estudo em todas as suas fases. Dessa maneira, detalhando-se a postura metodológica adotada durante a pesquisa, bem como os passos seguidos, espera-se garantir a confiabilidade e rigor científico do trabalho, para desenvolver uma teoria consistente na prevenção dos riscos que favorecem o agravamento dos projetos no Setor Público.

De acordo com Myers (2009, p. 22), qualquer projeto de pesquisa deve ser construído com base em uma série de passos que contemplem suas bases filosóficas (epistemologia), o método de pesquisa, as técnicas de coleta de dados, a abordagem para análise dos dados e um relatório escrito.

Existem na literatura algumas classificações das bases filosóficas passíveis de utilização. Guba e Lincoln (2005, p. 192), por exemplo, propõem uma classificação atualizada que contempla os paradigmas do Positivismo, do Pós-Positivismo, da Teoria Crítica, do Construtivismo e o Participativo.

Crotty (1998, p. 3-4) cita quatro elementos que precisam ser contemplados nas pesquisas:

- Métodos: técnicas e procedimentos usados para coletar e analisar os dados relacionados a alguma hipótese ou questão de pesquisa;

- Metodologia: a estratégia ou plano de ação que direciona o uso de um método em particular, e a ligação dessa escolha e uso dos métodos com os resultados desejados;

- Perspectiva teórica: o ponto de vista filosófico que embasa a metodologia e fornece um contexto para o processo. Além disso, também serve de embasamento para a lógica e os critérios usados na pesquisa;

- Epistemologia: a teoria do conhecimento embutida na perspectiva teórica e, consequentemente, na metodologia.

A Ilustração 4 apresenta o modelo de Croty (1998, p. 4), que enfatiza o relacionamento e a influência entre os quatro elementos. 


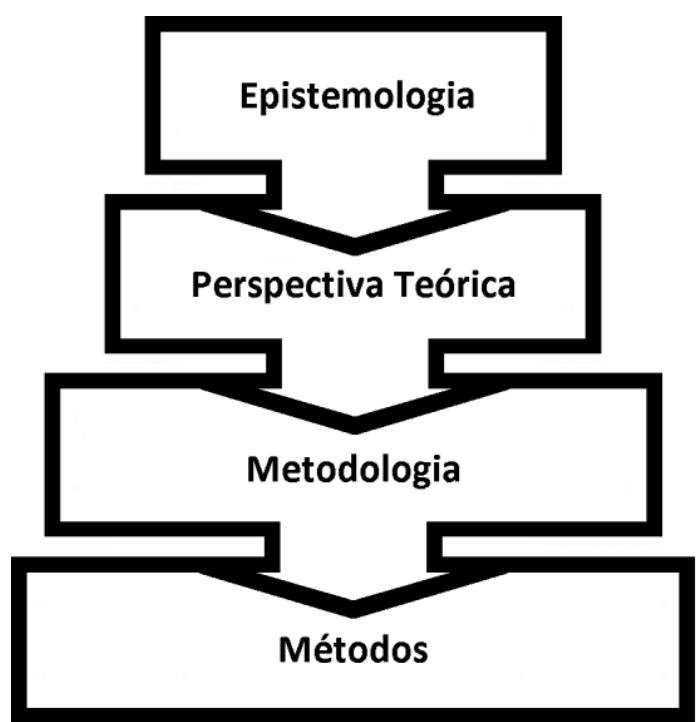

Ilustração 4: Quatro elementos do processo de pesquisa Fonte: adaptada de Crotty (1998, p. 4)

Quanto à epistemologia, esta pesquisa é fundamentada no Objetivismo, que é a visão epistemológica de que os objetos e entidades existem de forma significativa e sua existência independe de alguém ter consciência de sua existência ou de alguém ter tido alguma experiência com o objeto ou entidade (CROTTY, 1998, p. 6).

Quanto à perspectiva teórica, a pesquisa proposta é fundamentada no ponto de vista filosófico Positivista, baseado na premissa da existência de uma realidade objetiva (epistemologia objetivista) que pode ser descrita, medida e que independe do observador (MYERS, 2009, p. 37).

O Positivismo é habitualmente associado ao método científico (CROTTY, 1998, p. 18). Após Popper, o entendimento do método científico mudou de uma visão da ciência como um processo indutivo, para uma visão da ciência como um processo hipotético-dedutivo (CROTTY, 1998, p. 32).

Crotty (1998, p. 32) explica o processo hipotético-dedutivo da seguinte forma:

- Pesquisas científicas são propostas hipoteticamente;

- Proposiçõos são deduzidas dessas teorias;

- As proposições são testadas, ou seja, é feito um grande esforço para provar que as proposições são falsas. 
De acordo com Popper (2002, p.18), teorias não são passíveis de verificação empírica. Dessa forma o critério usado para demarcação das teorias aceitas é a possibilidade de essas teorias serem falseadas. Em um sistema científico deve ser possível refutar uma teoria por meio da experiência. Consequentemente, Crotty (1998, p.32) explica que a falseabilidade é o que separa as teorias científicas das teorias não científicas.

Assim, uma teoria que tenha superado continuamente uma série de testes é "corroborada", ou seja, é tratada como uma verdade provisória, enquanto não for substituída por outra teoria que explique os fenômenos de forma mais completa (POPPER, 2002, p. 264). Consequentemente, quanto mais fácil for testar uma determinada teoria, mas fácil será corroborá-la (POPPER, 2002, p. 271).

Stone (1978, p. 29) explica que um requisito do método científico é o pesquisador testar empiricamente as predições sobre fenômenos do mundo real.

Este texto também adota a visão ontológica exposta por Gregor (2006), de que a teoria possui existência separada do entendimento subjetivo do pesquisador. Em outras palavras, a teoria existe objetivamente no mundo das entidades construídas pelo homem.

Gregor (2006) propõe uma classificação com cinco tipos diferentes de teorias na disciplina Sistemas de Informação:

- Tipo I - Teorias para análise: teorias analíticas analisam “o que", em oposição à explicação de causalidade ou à tentativa de fazer generalizações preditivas;

- Tipo II - Teorias para explicação: explicam primariamente como e por que algum fenômeno ocorre;

- $\quad$ Tipo III - Teorias para predição: buscam fazer predições (o que será), mas não buscam explicar o porquê;

- Tipo IV - Teorias para explicação e predição: explicam "o que”, "como", "quando" e "o que será". Este tipo de teoria implica o entendimento das causas subjacentes, predições e a descrição teórica dos constructos e dos relacionamentos entre eles;

- Tipo V - Teorias para Design e Ação: dizem como fazer algo, incluindo princípios de forma, função, métodos e conhecimento teórico para justificação. 
A pesquisa descrita neste texto se encaixa no Tipo IV, teoria para explicação e predição, pois busca descrever o relacionamento entre os fatores de risco (variáveis) que levam à situação de agravamento, oferecendo a possibilidade de o resultado do projeto ser antecipado a partir das suas condições de risco.

O primeiro passo desta pesquisa, que seguiu o modelo objetivista/positivista, correspondeu à elaboração e refinamento do modelo de referência (explicado no capítulo 3) a partir de uma pesquisa bibliográfica que contemplou o Agravamento de Projetos, a Administração Pública, os Riscos de Projeto de TI, os Projetos de TI na Administração Pública, a Governança de TI e a Complexidade.

O segundo passo desta pesquisa foi deduzir algumas proposições com base no modelo de referência. O objetivo deste passo foi desenvolver proposições testáveis, de forma a viabilizar os testes de falseabilidade da teoria. Complementarmente, foram construídas proposições alternativas para explicação dos fenômenos.

Segundo Gregor (2006), a contribuição de pesquisas do Tipo IV ao avanço do conhecimento está relacionada à construção ou teste de teorias. Em relação a esta pesquisa, serão testadas proposições baseadas na literatura existente, que constitui o teste de teorias obtidas por meio da revisão bibliográfica, e, a partir disso, será proposta uma evolução na teoria sobre agravamento de projetos de TI na Administração Pública, baseada nas proposições do modelo de referência.

Em relação ao terceiro passo, correspondente à execução dos testes, é necessário detalhar os dois elementos restantes no modelo de pesquisa proposto por Crotty (1998, p. 2): a metodologia de pesquisa e o método de pesquisa.

Myers (2009, p. 9) explica que existem vantagens e desvantagens ao se optar por uma pesquisa qualitativa ou quantitativa. De forma geral, a pesquisa quantitativa é mais adequada quando existe uma amostra de tamanho grande e o pesquisador gostaria de generalizar seus resultados para uma grande população. Por outro lado, quando existe uma amostra pequena, como quando se estuda um aspecto em profundidade em uma ou em poucas organizações, a pesquisa qualitativa é mais adequada. 
Dessa forma, em razão da complexidade do assunto estudado e da dificuldade de acesso a uma amostra de tamanho adequado a uma pesquisa quantitativa, a opção foi executar uma pesquisa qualitativa.

Miles e Huberman (1994) explicam que dados qualitativos são frequentemente citados como a melhor estratégia para descoberta, exploração de uma nova área e desenvolvimento de hipóteses. Os autores enfatizam também o forte potencial dos dados qualitativos para testar hipóteses e para suplementar, explicar, iluminar ou reinterpretar dados quantitativos.

\subsection{Método de Pesquisa}

Segundo Myers (2009, p. 73) um estudo de caso na área de Administração é uma pesquisa que usa evidências empíricas de uma ou mais organizações com o objetivo de estudar o assunto dentro de seu contexto e desenvolver uma contribuição original ao conhecimento. Nesse tipo de pesquisa podem ser usadas múltiplas fontes de evidência, apesar de as mais comuns serem entrevistas e documentos.

Benbasat, Goldstein e Mead (1987) justificam que um estudo de caso é uma estratégia viável de pesquisa em SI por possibilitar:

a) Estudar o sistema de informação em seu estado natural, aprender com a prática em "estado da arte" e desenvolver teorias a partir da prática;

b) Entender a natureza e complexidade dos processos para que se responda a questões do tipo "como" e "por que";

c) Pesquisar uma área em que poucos estudos tenham sido empreendidos.

Como a pesquisa desta tese contempla o desenvolvimento de uma teoria que será testada empiricamente, ela se encaixa na definição da justificativa (a).

A característica determinante do modelo de referência proposto é a complexidade existente em um projeto grande e com muitos elementos de risco. Em um projeto com essas características, completá-lo com sucesso torna-se um problema de grande complexidade, e a estratégia de pesquisa baseada em estudos de caso é adequada para analisar essa complexidade, conforme o item (b). 
Além disso, apesar de existirem muitas pesquisas relacionadas aos riscos de projeto, especialmente aqueles relacionados ao seu escopo, e outros estudos relacionados ao agravamento do projeto, eles não foram empreendidos com foco na importância da Governança ou da complexidade (wickedness) para relacionar os riscos de projeto com a situação de agravamento. Dessa forma, este estudo pretende preencher essa lacuna, o que o relaciona à justificativa (c) de Benbasat, Goldstein e Mead (1987).

Lee (1989), Galliers (1991) e Myers (2009, p. 77) apontam o estudo de caso como uma estratégia de pesquisa válida para pesquisas qualitativas alinhadas com a perspectiva teórica positivista.

A escolha do método de pesquisa foi baseada na definição dos elementos do processo de pesquisa, e a opção pelo estudo de caso ocorreu porque essa é uma estratégia que se encaixa na epistemologia objetivista, na perspectiva teórica positivista, e é uma metodologia de pesquisa qualitativa.

Myers (2009, p. 72) argumenta que os estudos de caso podem ser exploratórios, quando o objetivo é a descoberta, ou explanatórios, quando o objetivo está relacionado a testar, relacionar ou comparar. $\mathrm{O}$ estudo de casos previsto nesta pesquisa tem objetivo explanatório, relacionado a testar o modelo de referência proposto e as teorias alternativas nos casos estudados.

Stake (2005, p. 445) classifica o estudo de caso como intrínseco, instrumental ou coletivo/múltiplo:

- Intrínseco: o caso é estudado somente para um maior entendimento do caso em particular;

- Instrumental: o caso é examinado principalmente para fornecer novos insights sobre um assunto ou generalizações;

- Coletivo ou múltiplo: estudo instrumental no qual vários casos são analisados conjuntamente para investigar um fenômeno, população ou condição geral.

Ao avaliar a aplicação da análise de caso em pesquisas no setor público, Behn (1993, p. 50) explica que a análise de caso é baseada na premissa de que, para desenvolver uma teoria sobre a prática efetiva, é necessário entender muitas observações de práticas efetivas. Eisenhardt 
(1989) argumenta que é frequentemente difícil gerar uma teoria muito complexa com menos de 4 casos.

Dessa forma, seguindo a recomendação de Behn (1993, p. 50) e de Eisenhardt (1989), a metodologia de pesquisa empregada é o estudo de caso coletivo ou múltiplo. Entretanto, em razão de restrições de tempo e acesso, foi possível pesquisar um conjunto restrito de três minicasos, que serão usados para testar e avaliar a teoria proposta e as explicações alternativas.

A escolha dos casos foi baseada em uma amostra não aleatória. Os casos que compõem a pesquisa foram selecionados a partir da perspectiva de sua contribuição para que se replique ou se estenda a teoria emergente, conforme explicação de Eisenhardt (1989).

Segundo Stake (2005, p. 451), mesmo em grandes estudos de caso coletivos, o tamanho da amostra é geralmente muito pequeno para uma seleção aleatória. Consequentemente, o autor recomenda que o principal critério de escolha dos casos seja a maior oportunidade de aprendizado.

Considerando-se o critério de oportunidade de aprendizado e possibilidade de acesso, foram selecionados projetos do setor público com as seguintes características:

- Duração igual ou superior a 1 ano;

- Custo estimado superior a R\$1.000.000,00;

- Mais de uma organização governamental envolvida e/ou envolvimento de diferentes departamentos dentro da mesma organização.

Os critérios relacionados à duração e aos custos foram incluídos para aumentar a chance de os projetos escolhidos possuírem maior complexidade. O critério de envolvimento de várias organizações ou departamentos aumenta a chance de existirem dificuldades relacionadas à Governança, além de constituir também um elemento adicional de complexidade.

Inicialmente, dois projetos da Secretaria da Fazenda do Estado de São Paulo que se enquadram nos critérios acima foram selecionados para o estudo de caso: 
- Processo Administrativo Tributário Eletrônico (ePAT): redesenho do processo administrativo tributário eletrônico por meio da tecnologia Business Process Modeling (BPM), com o objetivo de tornar mais ágil o andamento dos processos administrativos tributários e eliminar o uso de papel nos passos intermediários do fluxo de trabalho;

- Nota Fiscal Eletrônica (NF-e): projeto com o propósito de substituir a nota fiscal em papel por um documento eletrônico com finalidade equivalente e com a mesma validade jurídica (SEFAZ, 2006b).

Além desses dois casos, será estudado também o caso de um projeto anônimo, que apresenta grande potencial de aprendizado por causa de sua complexidade. Em razão da extensão do agravamento deste projeto, seu nome, seu objeto e os nomes das instituições governamentais envolvidas permanecerão anônimos, de acordo com os termos em que foi autorizada a pesquisa. Para o propósito desta tese, o projeto anônimo será denominado "Rainha Vermelha".

O autor da pesquisa atuou no projeto ePAT como gerente de projetos no período de abril a julho de 2010 e foi cedido à área de TI do órgão público responsável pelo projeto Rainha Vermelha de setembro de 2010 a maio de 2012, para atuar na equipe de gestão do projeto.

Este estudo se baseia na visão de Eisenhardt (1989) de que o estudo de caso é uma estratégia válida para a criação de teorias e de que é possível fazer generalizações tanto ao estudar um caso isolado quanto ao realizar um estudo de caso coletivo, apesar de outros autores, como Stone (1978, p. 138), defenderem que não é possível testar hipóteses, fazer generalizações ou concluir inferências causais a partir de estudos de caso.

Complementarmente ao exposto por Eisenhardt (1989), Myers (2009, p. 72) argumenta que estudos de caso podem ser usados em estudos exploratórios, com o propósito de descoberta, e em estudos explanatórios, com o propósito de testar, explicar ou comparar.

Eisenhardt e Graebner (2007) explicam que a indução e a generalização podem ser usadas para o desenvolvimento de teorias baseadas em estudos de caso, e enfatizam que estudos de casos múltiplos geralmente originam teorias mais simples do que estudos de caso único, pois os autores do primeiro tipo de estudo enfatizam apenas o que existe de comum entre os casos estudados. 
É relevante destacar que as explicações a respeito da indução e da generalização em Eisenhardt (1989) e em Eisenhardt e Graebner (2007) estão relacionadas à elaboração de teorias e não à sua validação. A crítica de Popper (2002, p. 3-4) ao uso da indução e da generalização está relacionada com a demarcação do que constitui o conhecimento científico válido (validação de teorias) no processo hipotético-dedutivo e não com a forma pela qual teorias são concebidas.

A importância da teoria é enfatizada por Yin, que considera essencial o desenvolvimento de uma teoria na fase de desenho da pesquisa (YIN, 2005, p. 49) e recomenda que a análise de dados seja empreendida com base nas proposições teóricas que levaram ao estudo de caso (YIN, 2005, p. 140).

O desenvolvimento e especificação dos constructos são importantes no contexto geral desta pesquisa, levando-se em conta o passo seguinte, de corroborar a teoria por meio de uma análise cruzada de casos. Eisenhardt (1989) argumenta que a especificação dos constructos antes de a pesquisa ser efetuada pode ajudar em seu desenho inicial e auxilia os pesquisadores na medição desses constructos de forma mais precisa.

Behn (1993, p. 58) argumenta que, no desenvolvimento do conhecimento por meio de análise de casos, os pesquisadores do setor público algumas vezes têm a sensação de não saber o suficiente para fazer predições ou desenvolver modelos. Apesar disso, um dos objetivos desta pesquisa é elaborar um modelo que ajude a prever o agravamento do projeto, permitindo a tomada de ações preventivas por parte da alta administração.

A necessidade de amarração com a literatura (EISENHARDT,1989) e o desenvolvimento de uma teoria na fase de desenho da pesquisa (YIN, 2005, p. 49) estão alinhados à visão de Popper (2002, p. 9), referente à formulação das hipóteses no processo hipotético-dedutivo antes de testar as proposições na busca de seu falseamento.

Yin (2005, p. 55) propõe quatro testes para determinar a qualidade dos estudos de caso:

- Validade do constructo: a medida operacional é correta para o conceito estudado;

- Validade interna: os devidos cuidados são tomados ao se estabelecerem relações de causalidade, evitando-se dessa forma relações espúrias; 
- Validade externa: capacidade de realizar uma generalização analítica, generalizandose os resultados a uma teoria mais abrangente;

- Confiabilidade: demonstrar que a pesquisa poderia ser repetida e apresentar resultados compatíveis.

\subsection{Procedimento de Coleta de Dados}

Remenyi e Williams (1996) sugerem que após o desenvolvimento das questões de pesquisa e da seleção da teoria que será usada na pesquisa, o passo seguinte corresponde à decisão dos tipos de dados que serão coletados e de como eles serão analisados.

Stake (2005, p. 453) enfatiza a importância da utilização de várias fontes de dados, usadas de maneira complementar para viabilizar uma triangulação.

A recomendação da utilização de múltiplas fontes de evidência também é feita por Yin (2005, p. 111), que cita alguns exemplos:

- Documentação;

- Registros em arquivos;

- Entrevistas;

- Observações diretas;

- Observação participante;

- Artefatos físicos.

Dubé e Paré (2003), em uma análise sobre o rigor nos estudos de caso na área de SI, criticam o fato de que $40 \%$ das publicações pesquisadas não mencionaram como foi o procedimento de coleta de dados. Dessa forma, para aumentar a confiabilidade desta pesquisa, o procedimento de coleta de dados será detalhado.

Yin (2005, p. 55) cita as táticas de estudo que podem ser usadas para aumentar a validade do constructo durante a coleta de dados:

- Utilização de múltiplas fontes de evidência;

- Estabelecimento de um encadeamento de evidências. 
Complementarmente, o rascunho de cada estudo de caso foi revisado por informantes-chave, conforme recomendação de Yin (2005, p. 55), para aumentar a validade de constructo.

Entre as fontes de evidência citadas por Yin (2005, p. 111), foram usadas neste estudo: entrevistas e documentação. Além disso, os entrevistados também preencheram um questionário para avaliação dos riscos que levaram o projeto à situação de agravamento. $\mathrm{O}$ Quadro 22 apresenta as fontes de evidência usadas em cada caso.

Quadro 22: Fontes de evidência na coleta de dados

\begin{tabular}{|l|l|l|l|}
\hline Caso & \multicolumn{1}{|c|}{ ePAT } & \multicolumn{1}{c|}{ NF-e } & Rainha Vermelha \\
\hline \multirow{2}{*}{$\begin{array}{l}\text { Fontes de } \\
\text { Evidência }\end{array}$} & Entrevistas & Entrevistas & Entrevistas \\
\cline { 2 - 4 } & Documentos & Documentos & Documentos \\
\cline { 2 - 4 } & Questionário & Questionário & Questionário \\
\hline
\end{tabular}

Fonte: elaborado pelo autor

Os Quadros 23, 24 e 25 apresentam a descrição das entrevistas. São apresentados os papéis desempenhados pelos entrevistados, mas seus nomes são mantidos em sigilo, em respeito aos acordos de confidencialidade feitos com as organizações envolvidas. Todas as entrevistas foram conduzidas nas organizações públicas envolvidas com os respectivos projetos.

Quadro 23: Entrevistas do projeto ePAT

\begin{tabular}{|c|c|c|c|}
\hline Papel do Entrevistado & $\begin{array}{l}\text { Duração da } \\
\text { Entrevista }\end{array}$ & Data & $\begin{array}{c}\text { Ferramenta para documentação da } \\
\text { entrevista }\end{array}$ \\
\hline $\begin{array}{l}\text { Gerente do projeto pela Secretaria da } \\
\text { Fazenda no início do projeto. }\end{array}$ & 66 minutos & 21.09 .2011 & $\begin{array}{l}\text { Entrevista gravada e posteriormente } \\
\text { transcrita. }\end{array}$ \\
\hline $\begin{array}{l}\text { Gerente do projeto pela Secretaria da } \\
\text { Fazenda após a reorientação do } \\
\text { projeto. }\end{array}$ & 51 minutos & 27.10 .2011 & $\begin{array}{l}\text { Entrevista gravada e posteriormente } \\
\text { transcrita. }\end{array}$ \\
\hline $\begin{array}{l}\text { Diretor da principal área cliente - } \\
\text { usuário sênior. }\end{array}$ & 14 minutos & 03.11 .2011 & $\begin{array}{l}\text { Entrevista gravada e posteriormente } \\
\text { transcrita. }\end{array}$ \\
\hline $\begin{array}{l}\text { Usuário - principal responsável pela } \\
\text { especificação do sistema. }\end{array}$ & 52 minutos & 09.11 .2011 & $\begin{array}{l}\text { Entrevista gravada e posteriormente } \\
\text { transcrita. }\end{array}$ \\
\hline Diretor da Consultoria. & 60 minutos & 11.11 .2011 & $\begin{array}{l}\text { Anotações diretamente em um arquivo } \\
\text { do Microsoft Word (o entrevistado não } \\
\text { autorizou a gravação da entrevista). }\end{array}$ \\
\hline
\end{tabular}

Fonte: elaborado pelo autor

Nos projetos ePAT, NF-e e Rainha Vermelha, a seleção dos entrevistados dos projetos ocorreu a partir da avaliação de quanto a entrevista poderia contribuir para o entendimento e a avaliação do caso. No caso específico da NF-e, além do aspecto mencionado acima, também foi relevante o problema de acesso, pois muitos dos executivos envolvidos no projeto não 
estavam mais na Secretaria da Fazenda, uma vez que o projeto se tornou operacional, ainda como um projeto-piloto, em 2006, e saiu da fase de projeto-piloto em 2007.

Quadro 24: Entrevistas do projeto NF-e

\begin{tabular}{|l|c|c|l|}
\hline \multicolumn{1}{|c|}{ Papel do Entrevistado } & $\begin{array}{l}\text { Duração da } \\
\text { Entrevista }\end{array}$ & Data & \multicolumn{1}{|c|}{$\begin{array}{c}\text { Ferramenta para } \\
\text { documentação da } \\
\text { entrevista }\end{array}$} \\
\hline $\begin{array}{l}\text { Administrador de banco de dados (DBA) durante a } \\
\text { transição da versão Oracle para a versão Dot Net. }\end{array}$ & 51 minutos & 14.12 .2011 & $\begin{array}{l}\text { Entrevista gravada e } \\
\text { posteriormente transcrita. }\end{array}$ \\
\hline $\begin{array}{l}\text { Arquiteto e principal desenvolvedor do sistema em } \\
\text { Dot Net (desempenha o papel de líder técnico na } \\
\text { evolução do sistema). }\end{array}$ & 28 minutos & 15.12 .2011 & $\begin{array}{l}\text { Entrevista gravada e } \\
\text { posteriormente transcrita. }\end{array}$ \\
\hline $\begin{array}{l}\text { Desenvolvedor do sistema em Dot Net (atualmente é } \\
\text { Diretor de Desenvolvimento do DTI). }\end{array}$ & 25 minutos & 15.12 .2011 & $\begin{array}{l}\text { Entrevista gravada e } \\
\text { posteriormente transcrita. }\end{array}$ \\
\hline $\begin{array}{l}\text { Usuário sênior - participou do projeto original e, } \\
\text { atualmente, é o líder da área usuária responsável pela } \\
\text { evolução do sistema. }\end{array}$ & 33 minutos & 12.01 .2012 & $\begin{array}{l}\text { Entrevista gravada e } \\
\text { posteriormente transcrita. }\end{array}$ \\
\hline
\end{tabular}

Fonte: elaborado pelo autor

Em relação ao projeto Rainha Vermelha, por causa do acordo de anonimato que foi firmado com o órgão público que autorizou a pesquisa, os dois principais órgãos públicos envolvidos serão denominados de Dispater e Salus. As duas organizações pertencem à mesma esfera de governo. As informações sobre qual esfera de governo (federal, estadual ou municipal) está envolvida, qual o objeto do projeto e quais as instituições envolvidas também foram omitidas. 
Quadro 25: Entrevistas do projeto Rainha Vermelha

\begin{tabular}{|c|c|c|c|}
\hline Papel do Entrevistado & $\begin{array}{l}\text { Duração da } \\
\text { Entrevista }\end{array}$ & Data & $\begin{array}{l}\text { Ferramenta para } \\
\text { documentação da } \\
\text { entrevista }\end{array}$ \\
\hline $\begin{array}{l}\text { Atuação na equipe de gestão do projeto de TI como } \\
\text { representante dos administradores mais seniores da } \\
\text { Dispater. }\end{array}$ & 51 minutos & 04.11 .2011 & $\begin{array}{l}\text { Entrevista gravada e } \\
\text { posteriormente } \\
\text { transcrita. }\end{array}$ \\
\hline $\begin{array}{l}\text { Usuário sênior - diretor de departamento e gestor de } \\
\text { despesas referentes ao contrato. Segundo na hierarquia } \\
\text { da Dispater. }\end{array}$ & 31 minutos & 08.11 .2011 & $\begin{array}{l}\text { Entrevista gravada e } \\
\text { posteriormente } \\
\text { transcrita. }\end{array}$ \\
\hline $\begin{array}{l}\text { Gerente do projeto pelo consórcio Janus, vencedor da } \\
\text { licitação. }\end{array}$ & 59 minutos & 10.11 .2011 & $\begin{array}{l}\text { Entrevista gravada e } \\
\text { posteriormente } \\
\text { transcrita. }\end{array}$ \\
\hline $\begin{array}{l}\text { Usuário } 1 \text { - responsável pela migração de dados. } \\
\text { Funcionário cedido pela empresa pública de } \\
\text { processamento de dados - participou do projeto como } \\
\text { usuário pela Salus, exceto no período de junho de } 2011 \text { a } \\
\text { fevereiro de 2012, quando integrou a equipe de TI da } \\
\text { Dispater. }\end{array}$ & 45 minutos & 28.11 .2011 & $\begin{array}{l}\text { Entrevista gravada e } \\
\text { posteriormente } \\
\text { transcrita. }\end{array}$ \\
\hline $\begin{array}{l}\text { Usuário } 2 \text { - atuação na definição das regras de negócio. } \\
\text { Funcionário cedido pela empresa pública de } \\
\text { processamento de dados - participou do projeto como } \\
\text { usuário pela Salus até junho de } 2011 \text {, quando passou a } \\
\text { integrar a equipe de TI da Dispater. }\end{array}$ & 37 minutos & 28.11 .2011 & $\begin{array}{l}\text { Entrevista gravada e } \\
\text { posteriormente } \\
\text { transcrita. }\end{array}$ \\
\hline $\begin{array}{l}\text { Usuário sênior - diretor técnico e terceiro na hierarquia } \\
\text { da Dispater. }\end{array}$ & 42 minutos & 30.11 .2011 & $\begin{array}{l}\text { Entrevista gravada e } \\
\text { posteriormente } \\
\text { transcrita. }\end{array}$ \\
\hline $\begin{array}{l}\text { Gerente de projeto no departamento de TI que atende a } \\
\text { Dispater até agosto de } 2010 \text {. }\end{array}$ & 40 minutos & 30.11 .2011 & $\begin{array}{l}\text { Entrevista gravada e } \\
\text { posteriormente } \\
\text { transcrita. }\end{array}$ \\
\hline
\end{tabular}

Fonte: elaborado pelo autor

No caso dos projetos ePAT e NF-e, o acesso aos documentos internos foi feito com autorização da Secretaria da Fazenda do Estado de São Paulo, com a restrição de que o estudo não poderia incorrer em quebra de sigilo fiscal do contribuinte. No caso do projeto Rainha Vermelha, o acesso aos documentos internos foi feito com autorização do órgão público responsável, com a ressalva de manter-se sigilo sobre quais esferas de governo (federal, estadual ou municipal) estão envolvidas, qual o objeto do projeto e, também, quais as instituições envolvidas.

A participação na equipe de gestão do projeto ePAT e na equipe de gestão do projeto Rainha Vermelha também facilitou o acesso à documentação interna do projeto. Desses projetos, este estudo usou os seguintes tipos de documentos internos:

- Atas de reunião;

- Planos de projeto;

- Apresentações em Microsoft Power Point; 
- Cronogramas em Microsoft Project.

No caso do projeto NF-e, foi usada como fonte de dados secundários a dissertação de Álvaro Ribeiro Botelho Junqueira (JUNQUEIRA, 2007), ex-diretor do DTI, que efetuou sua pesquisa sobre os fatores de sucesso do projeto da NF-e. Além disso, a lotação funcional do autor desta tese na Secretaria da Fazenda do Estado de São Paulo viabilizou o acesso a documentos internos, disponíveis na Intranet desse órgão, referentes ao projeto da NF-e.

Ainda em relação aos documentos, nos projetos ePAT e NF-e, parte das informações foi retirada do Diário Oficial do Estado de São Paulo e, no caso do projeto Rainha Vermelha, parte das informações foi obtida por meio do Diário Oficial referente à esfera de governo deste projeto.

Finalmente, para complementar a coleta de evidências durante as entrevistas, cada entrevistado preencheu um questionário avaliando quanto os riscos listados influenciaram o projeto e o levaram à situação de agravamento.

O questionário foi construído a partir dos quatro quadrantes de riscos de Keil et al. (1998): mandato do cliente, escopo e requisitos, execução e ambiente, contemplando os 53 riscos propostos por Wallace e Keil (2004) e listados na revisão bibliográfica. Além disso, foram adicionados mais dois riscos a partir da literatura:

- Estrutura ineficiente para a tomada de decisão: risco relacionado ao ambiente, proposto a partir da avaliação da importância do comitê do projeto segundo a OGC (2009b);

- Prazo político: risco de execução que costuma afetar projetos do setor público (RAINEY, 1997, p. 168; WIRICK, 2009, p. 89; FURLONG; AL-KARAGHOULI, 2010).

O questionário de riscos respondido durante as entrevistas será descrito em maiores detalhes no capítulo 6, onde é explicado o modelo de referência. Stone (1978, p. 61) cita os questionários como a forma mais comum de coletar dados em pesquisas sobre comportamento organizacional. 
Em relação ao preenchimento, foi solicitado a cada entrevistado que avaliasse o impacto de cada fator de risco no projeto, usando uma escala Likert de sete valores, onde 1 significa risco muito baixo (muito pouco impacto) e 7 significa risco muito alto (grande impacto).

Convém ressaltar que, no âmbito deste estudo, o questionário busca complementar as informações coletadas por meio de entrevistas, consideradas o principal método de coleta de dados usado nesta tese.

\subsection{Procedimento de Análise dos Dados}

Hoppen e Meirelles (2005) criticam as pesquisas qualitativas realizadas no Brasil entre 1990 e 2003, classificando-as, de maneira geral, como de nível de qualidade médio/baixo. Algumas evidências dessa qualidade média/baixa foram listadas pelos autores:

(a) Somente $25 \%$ dos artigos pesquisados apresentam teorias e conceitos de base aprofundados e conceitos encadeados para uma análise crítica fundamentada;

(b) Apenas $41 \%$ detalham as questões de pesquisa;

(c) Somente $27 \%$ possuem um modelo de pesquisa definido claramente;

(d) Menos de $12 \%$ utilizam dados secundários;

(e) Apenas 39\% têm o protocolo de análise dos dados explicitado;

(f) Somente $59 \%$ apresentam recomendações e limites do estudo.

Dessa forma, a qualidade deste estudo está fundamentada na pesquisa bibliográfica apresentada no capítulo 4, de forma a atender ao item (a); no detalhamento das questões de pesquisa, no capítulo 3, para atender ao item (b); na elaboração do modelo de referência, no capítulo 6, de forma a atender ao item (c). Além disso, são usados dados secundários no estudo de caso da Nota Fiscal Eletrônica, para o qual já existem pesquisas publicadas, atendendo ao item (d). Finalmente, o item (f) é atendido no capítulo 9, como parte da conclusão.

Em relação ao item (e), referente a explicitar o protocolo de análise dos dados, convém detalhar mais esse item, para deixá-lo ajustado ao padrão de qualidade almejado para este estudo. 
Segundo Miles e Huberman (1994; p. 56-57), codificação é parte da análise e códigos são usados para recuperar e organizar pedaços de texto (palavras, frases, sentenças ou um parágrafo inteiro). Os autores classificam os códigos em três tipos:

- Códigos descritivos: atribuição de uma classe de fenômenos a um segmento de texto, com pouca interpretação envolvida;

- Códigos de interpretação: códigos para representar as interpretações que são realizadas pelo pesquisador quando ele adquiriu mais conhecimento sobre o assunto e o contexto;

- Códigos de padrão: apresenta ainda mais poder de inferência e explanação. O trecho recebe um código indicando o tema inferido ou padrão.

Miles e Huberman (1994; p. 58) recomendam que a codificação seja iniciada antes do trabalho de campo e seja baseada no modelo de referência, nas hipóteses, nas áreas de problema e nas variáveis a serem estudadas. No caso deste estudo, o modelo inicial de codificação foi baseado nos constructos do modelo de referência e nos constructos de teorias alternativas para a explicação do fenômeno.

Yin $(2005$, p. 124) recomenda que o pesquisador siga três princípios para maximizar os benefícios de possuir várias fontes de evidências, estabelecer a validade do constructo e aumentar a confiabilidade de um estudo de caso:

- Utilizar várias fontes de evidência, usando a triangulação como fundamento lógico;

- Criar um banco de dados para o estudo de caso: a base comprobatória;

- Manter um encadeamento das evidências.

A codificação das entrevistas e documentos desta pesquisa foi executada por meio do software NVIVO versão 9; dessa forma, foi possível atribuir nomes mais significativos aos códigos. A base comprobatória também foi armazenada no software NVIVO e contempla as fontes de evidência descritas no item 5.2 Procedimento de Coleta de Dados.

Yin (2005, p. 55) explica que o desenvolvimento de um banco de dados para o estudo de caso contribui para o aumento da confiabilidade do estudo.

Yin (2005, p. 140) recomenda três estratégias gerais para a análise dos dados:

- Basear-se nas proposições teóricas; 
- Pensar sobre explanações concorrentes;

- Desenvolver uma descrição de caso.

A estratégia que direcionará esta análise é o embasamento nas proposições teóricas. Dessa forma, serão procurados padrões nos dados codificados, buscando-se evidenciar o relacionamento entre as variáveis independentes e a variável dependente, referente ao agravamento do projeto.

Complementarmente, será usada a técnica específica proposta por Yin (2005, p. 145), denominada "adequação ao padrão", comparando o padrão empírico (oriundo da coleta de dados) com o prognóstico (oriundo do modelo de referência e das explanações concorrentes).

Cook e Campbel (1979, p. 50) explicam que, uma vez estabelecido que duas variáveis apresentem correlação, é preciso decidir se existe qualquer relação causal entre elas. A validade interna de uma pesquisa é descrita por Yin (2005, p. 56) como o estabelecimento de uma relação causal, respeitando-se certas condições para evitar que sejam concluídas relações espúrias entre as variáveis.

Dessa forma, busca-se atender à recomendação de Yin (2005, p. 57) de uso das técnicas de pesquisa para aumentar a validade interna: adequação ao padrão, construção da explanação e estudo de explanações concorrentes. A quarta técnica recomendada por Yin (2005, p. 57), a utilização de modelos lógicos, foi aplicada na descrição dos modelos teóricos testados, mas não foi usada como técnica analítica dos dados coletados.

Finalmente, como cada projeto foi armazenado como um arquivo distinto no software NVIVO, o passo final da análise contempla uma síntese de casos cruzados (YIN, 2005, p. 163) comparando as conclusões dos casos individuais.

Convém explicar as métricas usadas no questionário de riscos. Os constructos usados no questionário são explicados no capítulo sobre o modelo de referência (capítulo 3).

O questionário contém os cinquenta e cinco riscos detalhados, e o cálculo dos quinze riscos consolidados do modelo de referência ocorreu por meio de média aritmética simples. $\mathrm{O}$ cálculo dos riscos de governança do modelo alternativo, juntamente com os riscos de 
complexidade estrutural do modelo de Xia e Lee (2004), também foi realizado por meio de média aritmética simples, considerando-se os fatores detalhados que compõem cada modelo.

\subsection{Resumo da Metodologia Utilizada}

O Quadro 26 apresenta um resumo da metodologia utilizada, baseado no conjunto de informações sugerido por Myers (2009, p. 22), com a adição dos campos epistemologia e metodologia, propostos por Crotty (1998, p. 2-17).

\section{Quadro 26: Resumo da metodologia a ser utilizada}

\begin{tabular}{|l|l|}
\hline Epistemologia & Objetivismo. \\
\hline $\begin{array}{l}\text { Base filosófica } \\
\text { Perspectiva Teórica }\end{array}$ & Positivismo. \\
\hline Metodologia & Pesquisa qualitativa. \\
\hline Método de pesquisa & Estudo explanatório/instrumental considerando casos múltiplos. \\
\hline $\begin{array}{l}\text { Técnicas de coleta de } \\
\text { dados }\end{array}$ & Entrevistas, análise de documentos e questionário. \\
\hline $\begin{array}{l}\text { Abordagem para } \\
\text { análise dos dados }\end{array}$ & $\begin{array}{l}\text { Avaliar a aderência dos dados ao modelo de referência, buscando } \\
\text { sua refutação ou corroboração; } \\
\text { Avaliar a aderência dos dados à literatura prévia referente a } \\
\text { projetos problemáticos e ao agravamento de projetos; } \\
\text { Triangulação entre as diferentes técnicas de coleta de dados; } \\
\text { Triangulação por meio da síntese de casos cruzados. }\end{array}$ \\
\hline Relatório escrito & Tese de Doutorado. \\
\hline
\end{tabular}

Fonte: elaborado pelo autor 


\section{Projeto ePAT}

O Projeto do Processo Administrativo Tributário Eletrônico (ePAT) surgiu da necessidade de modernização do antigo sistema de fluxo de trabalho (workflow), denominado TIT2000, responsável pelo controle do Processo Administrativo Tributário (PAT).

Segundo Di Pietro (2011, p. 625):

“O processo administrativo contencioso é o que se desenvolve perante um órgão cercado de garantias que asseguram sua independência e imparcialidade, com competência para proferir decisões com força de coisa julgada sobre as lides surgidas entre a Administração e o administrado”.

O PAT é um exemplo de processo administrativo contencioso que ocorre no âmbito das administrações tributárias. Ferreira (2009, p. 355) apresenta uma definição desse processo:

\footnotetext{
"Processo administrativo-tributário é o conjunto de atos necessários à solução, na instância administrativa, de questões relativas à aplicação ou interpretação da legislação tributária.

Considera-se processo administrativo-tributário aquele que versa sobre a aplicação ou a interpretação da legislação tributária”.
}

De maneira menos formal, o PAT possibilita que o contribuinte que foi autuado por meio de um Auto de Infração e Imposição de Multa (AIIM) possa contestar o auto de infração no âmbito administrativo (Poder Executivo) antes de uma eventual contestação no âmbito do Poder Judiciário. O Processo Contencioso Administrativo do Estado de São Paulo é baseado na Lei Estadual 13.457/09.

Segundo o documento de Visão do ePAT (SEFAZ, 2010a):

“Todo contribuinte tem o direito de defender-se, caso seja autuado pela fiscalização tributária, sem necessariamente ter que recorrer ao órgão judiciário, podendo fazê-lo de forma administrativa, recorrendo junto às próprias repartições fiscalizadoras".

O TIT2000 havia sido desenvolvido pela Companhia de Processamento de Dados do Estado de São Paulo (PRODESP) com base na tecnologia Oracle Forms. Com a evolução tecnológica na TI, surgiu a expectativa de tornar o processo livre de papel, com a digitalização de 
documentos assinados manualmente e com a utilização de documentos assinados por meio de certificados digitais.

Uma diferença importante do novo sistema a ser desenvolvido em relação ao sistema TIT2000 se refere à maneira como os documentos são gerenciados. No TIT2000, os documentos existiam no formato em papel e o sistema estava integrado ao GDOC, Sistema de Gestão de Documentos da Secretaria da Fazenda, que armazena informações sobre a localização física do documento e a pessoa responsável por sua posse. Dessa forma, enquanto o sistema antigo fornecia a localização física do documento, o novo sistema fornece o próprio documento em formato digital.

O projeto apresentado neste estudo de caso corresponde à terceira tentativa de automatizar o fluxo do PAT. A primeira tentativa chegou à fase de homologação, mas nunca foi aprovada para ser implantada em produção, enquanto a segunda tentativa, que contemplava um fluxo simplificado, com prazo previsto de seis meses, não chegou a ultrapassar o estágio de documentação.

Com a maior automação proporcionada pelo ePAT, a meta passou a ser reduzir o prazo despendido nos processos administrativos, de cerca de 8 anos, para 8 meses, ou um máximo 2 anos em casos mais extremos. Consequentemente, o uso do processo administrativo como forma de protelar o pagamento dos valores relacionados ao auto de infração seria desestimulado (SEFAZ, 2010a).

De acordo com a SEFAZ (2011a):

“O ePAT será utilizado como meio eletrônico na lavratura do auto de infração, na tramitação dos processos administrativos tributários, para a prática e comunicação de atos e para a transmissão de peças processuais".

De acordo com a SEFAZ (2011a), o credenciamento ao ePAT garante uma série de vantagens:

- Realização de atos processuais de qualquer lugar, a partir de qualquer computador conectado à Internet; 
- Horário ampliado para a realização dos atos processuais em relação ao horário dos postos fiscais;

- Segurança por meio do uso de certificado digital;

- Facilidade na consulta ao processo a qualquer tempo e de qualquer lugar, pois não será mais necessário pedir vistas ao processo para acesso aos documentos.

A área usuária responsável pela liderança do projeto ePAT é o Tribunal de Impostos e Taxas (TIT) da Secretaria da Fazenda do Estado de São Paulo. Pelas características do PAT, outras áreas da Secretaria da Fazenda precisaram ser envolvidas na especificação do sistema, pois também participam do fluxo de trabalho do PAT, como, por exemplo, a Diretoria Executiva da Administração Tributária (DEAT) e a Diretoria da Representação Fiscal (DRF) (SEFAZ, 2010a).

Além disso, o sistema ePAT também deveria interagir com a Diretoria de Arrecadação (DA). Entretanto, a especificação da parte da DA foi fornecida pela própria DEAT, por meio da Assistência Fiscal de Informação, Avaliação e Controle (AFIAC).

Um dos entrevistados da área de TI explicou:

"Quem interage com a DA é a AFIAC. E a AFIAC passa pra gente essa interação...

Pra não dar, de novo, conflitos. Porque vai acabar afetando alguma coisa que foi definida pela AFIAC. Então, vocês [DA e AFIAC] discutem, vocês montam o modelo. Traz pra gente e a gente executa".

Além disso, duas áreas da Secretaria da Fazenda relacionadas aos Sistemas de Informação também foram envolvidas: a Diretoria de Informações (DI), responsável pelos sistemas de informações gerenciais e pela especificação e testes dos sistemas da área tributária, e o Departamento de Tecnologia da Informação (DTI), responsável pelo desenvolvimento de sistemas e pela infraestrutura de TI da Secretaria da Fazenda.

Em razão do envolvimento de diversas diretorias subordinadas à Coordenadoria da Administração Tributária (CAT), também foram envolvidos no projeto funcionários do gabinete da CAT. Além das áreas já citadas, convém mencionar a área responsável pelo acompanhamento dos projetos e do planejamento estratégico da Secretaria da Fazenda, 
denominado Departamento de Planejamento e Gestão (DPG). O DTI e o DPG fazem parte da Coordenadoria de Planejamento Estratégico e Modernização Fazendária (CPM).

Pela quantidade de áreas envolvidas, convém apresentar o organograma da Secretaria da Fazenda à época do projeto. O organograma não apresenta todos os departamentos da Secretaria da Fazenda, mas somente aqueles envolvidos com o Projeto ePAT, conforme a Ilustração 5.

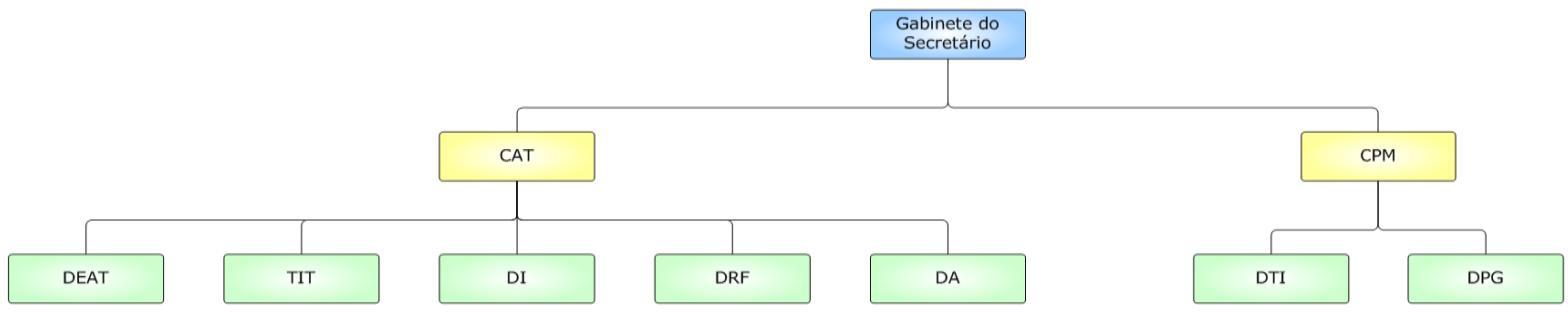

Ilustração 5: Organograma das áreas da Secretaria da Fazenda envolvidas no Projeto ePAT Fonte: elaborada pelo autor

A concepção do projeto foi iniciada em março de 2009. Desde o início existia uma preocupação com o prazo e a intenção de concluir o projeto na mesma gestão administrativa na qual foi iniciado.

Em alguns dos depoimentos, os entrevistados comentam a influência do cenário político na definição do primeiro prazo:

"Porque existia um prazo político para que esse processo entrasse no ar e a consultoria não se sentia resguardada politicamente para tentar este prazo absurdo do ponto de vista político”.

"Tratar a expectativa é muito importante. Expectativa de tempo que existia desde antes de sair o projeto. O projeto começou com uma pressão de tempo. Mesmo antes de saber qual era o conteúdo do projeto".

"O prazo foi um grande vilão. Por causa dele, todas as outras coisas ficavam loucas. A forte pressão sobre o prazo teve desdobramentos nocivos por todo o projeto".

Quando o agravamento se tornou crítico, entretanto, a importância do prazo político se tornou secundária, de acordo com um depoimento referente à reorientação do projeto: 
"O problema não eram questões de prazos ou políticas. O problema era de viabilidade. Tinha comprado um produto. Foi investido numa empresa. Foi substituída uma ideia, foi colocado que não ia funcionar e ia causar um estrago pra gente e pra área-fim, todo mundo participou."

Na visão da área de negócio, apesar da preocupação com a entrega ainda na mesma gestão de governo, o prazo proposto não era político, pois foi aceito pela consultoria após sua análise técnica:

"Se eu definir politicamente o que eu quero. Que o projeto termine em dezembro. É possível? Politicamente eu quero que termine, mas eu pergunto antes, é possível?"

"A área técnica sempre dizia que era possível".

A liderança do projeto do ponto de vista das áreas de negócio cabia ao TIT e do ponto de vista de informática cabia ao DTI. Uma fornecedora do DTI no projeto, denominada, no âmbito deste trabalho, de Consultoria UML, atuou no projeto para desenvolver a especificação do sistema usando a ferramenta-padrão da metodologia aplicada na Secretaria da Fazenda, os casos de uso da UML (BOOCH; RUMBAUGH; JACOBSON, 1999).

Os casos de uso foram construídos com base na Lei Estadual 13.457/09, que descreve os procedimentos do Processo Administrativo Tributário, que os casos de uso buscavam operacionalizar de maneira mais automatizada e com documentos no formato digital. A interpretação da lei e a definição dos requisitos foram realizadas pelos profissionais do TIT, e a elaboração dos casos de uso foi realizada pela Consultoria UML, com a supervisão do DTI. O cronograma referente à elaboração dos casos de uso previa o término dessa etapa ao final de julho de 2009. A elaboração dos casos de uso prosseguiu até o final de agosto de 2009.

Durante o período de especificação, os especialistas do DTI e do TIT buscaram soluções prontas de mercado, avaliando inclusive a solução que automatizara o Poder Judiciário do Estado de Santa Catarina. Entretanto, como o sistema usado em Santa Catarina havia sido construído com tecnologia convencional, sem usar ferramentas de modelagem de processos de negócio (BPM - Business Process Modeling/Management), houve uma avaliação dos técnicos do DTI de que sua customização a um tribunal administrativo e à legislação do Estado de São Paulo e suas posteriores manutenções teriam um custo muito alto, tanto financeiro quanto em relação ao prazo. 
Complementarmente, a consultoria que havia desenvolvido a solução para o Estado de Santa Catarina estimou que a customização de seu produto para atender à primeira instância do Tribunal Administrativo do Estado de São Paulo levaria um ano e seis meses. Apesar de a consultoria de Santa Catarina ter experiência na área jurídica, esse prazo foi considerado demasiadamente extenso pela Secretaria da Fazenda do Estado de São Paulo.

Durante a busca por soluções e com base na consultoria técnica prestada pelo DTI, foi decidido que o projeto seria desenvolvido tendo como base uma ferramenta de BPM (BPM Suite ou BPMS). Baldam et al. (2007, p. 19) explicam que o BPM envolve a descoberta, o projeto (design) e a entrega de processos de negócios, além do controle executivo, administrativo e supervisório desses processos. O BPMS é descrito como uma suíte de produtos de software integrados com a finalidade de habilitar o BPM (BALDAM et al., 2007, p. 111).

Um dos entrevistados explicou como a decisão pelo uso de uma ferramenta de BPM foi tomada:

"Qual era o componente de maior risco? Ter um grupo sem conhecimento jurídico, mas com uma ferramenta de BPM, e do outro lado ter o conhecimento jurídico, mas com uma ferramenta de sistema. Depois de muitas reuniões, optou-se pela ferramenta de BPM, porque se chegou à conclusão, de maneira coletiva, de que o fato de eu ter um fluxo complexo e eu não precisar me preocupar em coordenar de maneira sistêmica esses vários passos era um ganho grande contra o fato de eu ter que ensinar um pouco de juridiquês (SIC) para o grupo de desenvolvedores".

Além disso, em razão do fato de a Secretaria da Fazenda já possuir uma ferramenta de fluxo de trabalho denominada Staffware, concluiu-se que, ao invés de adquirir uma nova ferramenta, seria mais barato fazer uma atualização (upgrade) na ferramenta que estava disponível. Foi emitido um parecer técnico pelo DTI justificando a atualização (SEFAZ, 2009a).

O autor do parecer (SEFAZ, 2009a) explicou em entrevista que:

"No momento que eles falaram 'nós vamos fazer o upgrade do Staffware'. Na hora da concorrênciapreço, não havia condições de a Oracle concorrer, porque era menos de 50\% do preço da Oracle, o preço do BPM da TIBCO, por ser o upgrade". 
A partir do parecer favorável à atualização da ferramenta de workflow, em 22 de julho de 2009 foi publicado um edital de licitação (SEFAZ, 2009b, 2009c) na modalidade pregão para: atualização das licenças do Staffware 9.0 para BPMS TIBCO iProcess Suite v. 11 da TIBCO International Inc., aquisição de um banco de horas com 30.000 horas de consultoria para desenvolvimento de soluções e treinamento para os fazendários responsáveis pela manutenção dos fluxos de trabalho a serem implantados. O resultado do pregão foi publicado no Diário Oficial do Estado de São Paulo em 11 de agosto de 2009.

Consequentemente, a empresa vencedora da licitação assumiria a responsabilidade pelo desenvolvimento do projeto ePAT a partir da especificação que havia sido construída pela Consultoria UML. A empresa vencedora da licitação será denominada Consultoria BPM no restante deste trabalho.

\subsection{Primeira Fase do Projeto de BPM: Agravamento}

A Consultoria BPM começou a desenvolver o projeto no início de setembro de 2009. A data de início que consta do cronograma original é 08 de setembro, com implantação prevista para $1^{\circ}$ de julho de 2010, totalizando um prazo aproximado de dez meses e atendendo ao direcionamento de implantar a solução ainda no mesmo mandato político.

Logo no início do projeto, as especificações que haviam sido desenvolvidas pela Consultoria UML foram descartadas sob a alegação de que a forma de especificar um projeto de BPM difere da especificação tradicional de um projeto de desenvolvimento de sistemas. Segundo a Consultoria BPM, a especificação funcional por meio de casos de uso não era adequada para o projeto. Um dos entrevistados explicou:

\footnotetext{
"Mas o resultado que nós tivemos em mãos, que foi o caso de uso, ele foi literalmente engavetado, porque quando a equipe da BPM TIBCO chegou através de uma consultoria, nós entregamos todos os casos de uso pra eles, mas eles praticamente começaram a fazer um levantamento do zero, porque aí eles começaram a fazer um levantamento de fluxo, um levantamento de cada passo que iria acontecer".
}

O descarte da especificação construída em UML foi um fator de insatisfação para os usuários, pois a especificação teve que ser refeita e os usuários tiveram que explicar duas vezes os 
mesmos processos para consultorias diferentes. Um dos entrevistados do Departamento de TI explicou:

"Uma das coisas que a gente mais ouvia nessas entrevistas era a frase: Mas nós falamos isso pro pessoal da [Nome da Consultoria UML]. Então o fato de o pessoal da [Nome da Consultoria UML] ter feito o pré-levantamento, acabou causando um problema para o segundo levantamento porque sempre que era feita uma pergunta, ou era colocada uma dúvida a respeito da questão, sempre tínhamos que ouvir: Mas isto já foi explicado para a [Nome da Consultoria UML]."

A estimativa em relação ao escopo do projeto também foi um fator problemático. Inicialmente, a previsão era de que o projeto consumiria entre 10.000 e 15.000 horas de esforço. Entretanto, durante a execução do projeto, o escopo demonstrou ser relativamente maior do que o previsto inicialmente pela equipe de TI. Do ponto de vista da área usuária principal, entretanto, o escopo era considerado muito mais estável do que do ponto de vista da área de TI.

Alguns depoimentos da equipe de TI indicam problemas relacionados a escopo e requisitos:

\begin{abstract}
"Nós percebemos que aqueles 33 estados que aquela consultoria de fluxo havia colocado como sendo realmente o estado da coisa... Nós percebemos que aqueles 33 estados viraram, de uma hora pra outra, 80 estados, porque à medida que nós íamos fazendo perguntas, as pessoas iam dando cada vez mais detalhes do processo e esses detalhes iam tornando o fluxo em si mais complexo".
\end{abstract}

"Um fluxo que de 33 estados já estava com 80 , de repente se viu com mais alguns estados, tanto préjulgamento quanto pós-julgamento, porque outras áreas começaram a perceber que era uma grande oportunidade, de elas também automatizarem seus fluxos. Então isso gerou um risco enorme, porque o escopo começou a crescer."

"Com esse escopo delimitado, nós percebemos que aquelas 13000 horas eram uma fantasia, porque o escopo cresceu, o escopo se acomodou e à medida que nós conversávamos com as pessoas, nós víamos que o processo ficava cada vez mais detalhado, cada vez mais complexo, cada vez mais cheio de ramos. Ou seja, existiam muitas situações especiais que exigiam um entrelaçamento de etapas que naquele primeiro esboço simples e limpo não transparecia”.

"Quando você entra em um projeto, você conhece as fronteiras do processo, mas você não conhece o conteúdo daquela fronteira, são cinco ou seis etapas, mas você não conhece os detalhes daquela etapa. 
Isso inclui tanto a equipe técnica como o demandante/usuário. Desconhecimento do conteúdo, da fronteira do projeto".

"É importante e toma um tempo danado: a falta de definição por parte do interlocutor da área. Várias indefinições ao longo do projeto tornam o problema crítico".

O texto abaixo, extraído da ata de uma reunião datada de 23 de abril de 2010, demonstra o ponto de vista da Consultoria BPM a respeito da estabilização do escopo (SEFAZ, 2010b):

"[Consultoria BPM] alega que o último documento enviado contraria o escopo que havia sido combinado em janeiro deste ano, pois acrescenta escopo que havia sido excluído nessa data".

Por outro lado, a área de negócio entendia que o escopo estava bem delimitado, mas a área de TI do projeto estava com dificuldades na compreensão e documentação dos requisitos, conforme o depoimento abaixo:

\footnotetext{
"Do ponto de vista dos requisitos e do negócio, nós tínhamos um bom andamento, mas na hora de concretizar em termos de desenvolvimento do sistema, a coisa não acontecia. Também na parte de requisitos mesmo, nós passávamos com o pessoal de TI as regras que precisavam ter e havia uma falta de sintonia com o que a gente precisava e o que eles conseguiam registrar como requisito. A gente ia ver os requisitos e esqueceram muitas das regras que tinham que ter."
}

Além dos problemas relacionados a escopo e requisitos, outro fator de risco considerado importante diz respeito à migração da base de dados do sistema legado, o TIT2000, que tinha um conteúdo muito menor do que o conteúdo do sistema novo, mesmo se considerarmos somente o conteúdo mínimo do sistema novo. Além disso, as etapas do fluxo construído no TIT2000 não eram equivalentes às etapas do novo fluxo e não existiam regras suficientemente bem definidas para viabilizar essa migração de maneira automática. Por outro lado, a quantidade de processos, na casa dos milhares, inviabilizava uma migração manual.

Complementarmente, a estratégia de implantação previa que seria feita uma implantação de grandes módulos do projeto, de forma que quando um grande módulo fosse implantado, ocorreria a migração de todos os dados do TIT2000 correspondentes àquela etapa e esse pedaço do TIT2000 seria desligado. Dessa forma, até a data de implantação do grande módulo 
os processos seriam controlados pelo TIT2000, e a partir dessa data todos os processos seriam controlados no ePAT.

Os depoimentos dos entrevistados da área de TI explicam esses dois problemas, que estão relacionados:

\footnotetext{
"Além de nós estarmos preocupados com o desenvolvimento do novo, nós éramos, em todas as reuniões, acossados por esse grande fantasma que é o legado".

"A estratégia de implantação prevista inicialmente seria uma loucura. Com uma implantação de uma só vez, com migração".
}

Em abril de 2010, a apresentação executiva apontava o prazo de 30 de julho de 2010 (SEFAZ, 2010c). Vale a pena ressaltar que, até abril de 2010, as entregas realizadas pela consultoria contemplavam somente protótipos e documentação, sem nenhuma entrega de sistema pronto para ser homologado (SEFAZ, 2010c).

Em abril de 2010 ocorreu uma mudança na condução do projeto pela área de TI da Secretaria da Fazenda. Após o ingresso de novos funcionários aprovados em concurso público, o DTI passou a ter um quadro maior e mais diversificado de profissionais e passou a escalar uma equipe maior para o acompanhamento do projeto, incluindo profissionais do Centro de Gestão de Projetos, Processos e Relacionamento (CPPR).

Esse acompanhamento mais próximo e a dificuldade da consultoria em entregar módulos do sistema em condições de serem homologados contribuíram para ressaltar os problemas do projeto. Um dos entrevistados explicou que:

\footnotetext{
"A equipe contratada, ela trabalhava praticamente, diretamente, com o cliente. O DTI não tinha, na época, pessoas pra trabalhar junto com a consultoria, junto ao cliente. Então, isto gerou um mal-estar muito grande, porque a consultoria, ela via as coisas crescendo e ela não tinha poderes políticos de barrar este crescimento."
}

O acompanhamento do projeto por parte das áreas de negócio ocorria por meio de uma apresentação ao comitê executivo do projeto, composto de representantes de todas as áreas da Secretaria da Fazenda envolvidas no projeto, inclusive o gabinete da CAT, conforme o 
organograma apresentado na Ilustração 5. As apresentações do status do projeto para o comitê executivo ocorriam semanalmente.

A Ilustração 6 apresenta os principais marcos previstos na primeira apresentação conduzida pela nova equipe, que passou a acompanhar o projeto a partir de abril de 2010. Entre as duas primeiras apresentações, ocorridas em 28 de abril (SEFAZ, 2010c) e em 5 de maio (SEFAZ, 2010d), foi incluída a previsão do subsistema de voto eletrônico, que estava fora do escopo original e foi planejado para entrega em 21 de setembro de 2010.

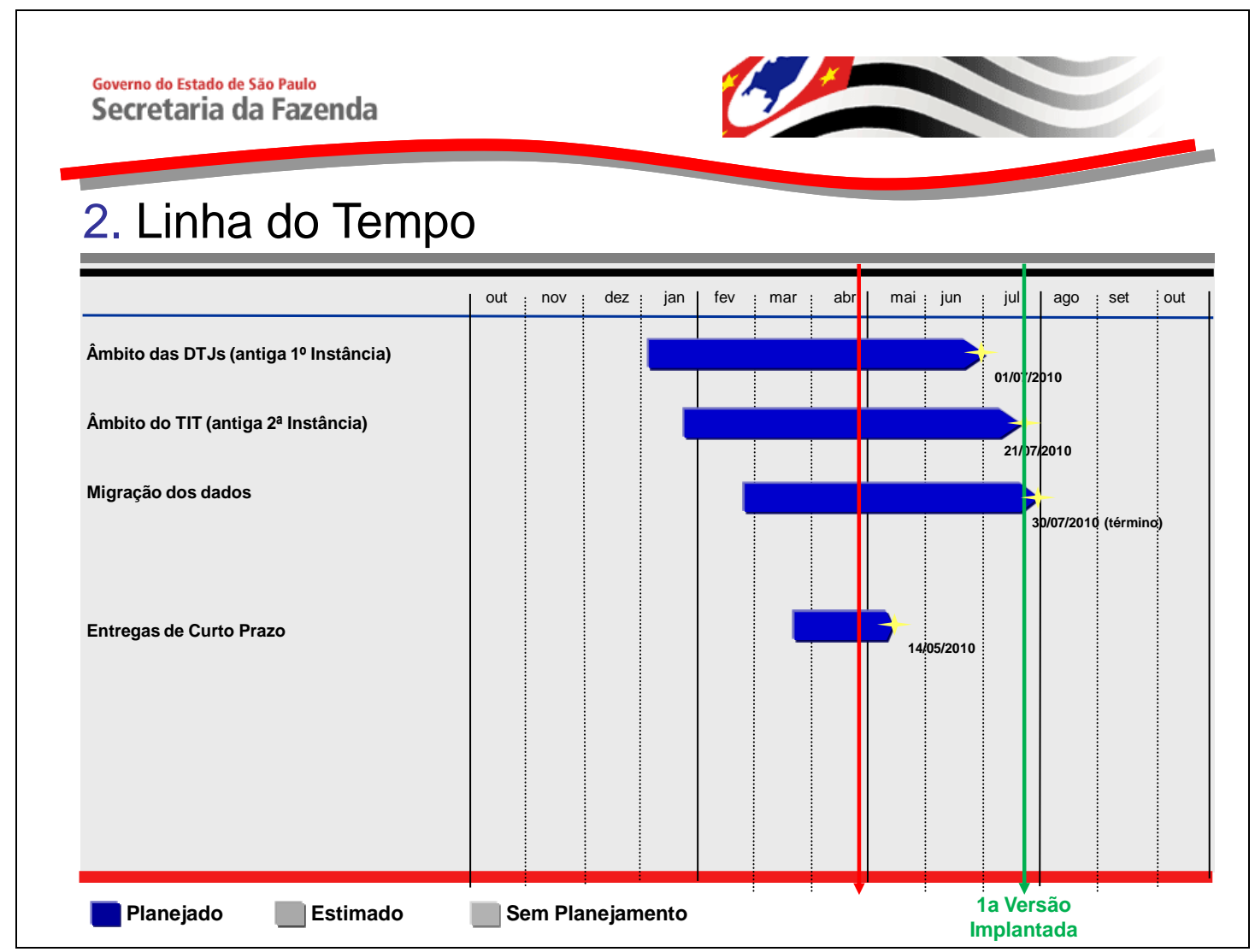

Ilustração 6: Linha do tempo do projeto ePAT - versão de 28/04/2010 Fonte: SEFAZ (2010c)

Além disso, outro item do escopo sobre o qual havia disputa sobre seu entendimento, referente à forma de paginação das peças anexadas ao processo e a consequente reorganização das peças, foi planejado para ser entregue em duas versões, com sua versão final apenas em 13 de agosto de 2010 (SEFAZ, 2010d). Durante essa fase do projeto, ocorreram diversas alterações no cronograma, pois a consultoria tinha dificuldades com suas entregas e o clima de trabalho começava a se deteriorar. 
A apresentação de 12 de maio de 2010 (SEFAZ, 2010e) apontava problemas na homologação iniciada em 10 de maio. As dificuldades com as homologações juntamente com as integrações com sistemas legados e a migração dos dados do sistema que seria substituído, o TIT2000, prosseguiram até que em 09 de junho de 2010 foi apresentada uma nova previsão para o término do projeto (SEFAZ, 2010i).

A área cliente continuava insatisfeita com as entregas, e as dificuldades com a homologação persistiam. Consequentemente, no dia 07 de julho de 2011 foi repactuado um novo cronograma, com previsão para término do projeto em 03 de novembro de 2011 (SEFAZ, 2010m).

Na apresentação seguinte, em 14 de julho de 2010 (SEFAZ, 2010n), não existia mais previsão de entrega, pois o cronograma estava em situação de replanejamento. Na apresentação de 21 de julho de 2010, foram apresentadas as novas datas previstas para o término do projeto (SEFAZ, 2010o):

- Versão sem migração dos dados do sistema antigo:

○ $1^{a}$ Instância: $29 / 11 / 2010$

○ $\quad 2^{a}$ Instância: $17 / 01 / 2011$

- Versão com migração:

○ $\quad 1^{\text {a }}$ Instância: $11 / 04 / 2011$

○ $\quad 2^{a}$ Instância: 13/06/2011

O Quadro 27 apresenta as alterações de cronograma ocorridas no período de abril a julho de 2010. 
Quadro 27: Alterações de cronograma ocorridas no Projeto ePAT, no período de abril a julho de 2010

\begin{tabular}{|c|c|c|c|c|c|}
\hline $\begin{array}{c}\text { Data da } \\
\text { apresentação } \\
\text { ao comitê } \\
\text { executivo }\end{array}$ & $\begin{array}{c}\text { Entrega } \\
\text { prevista da } \\
\text { Primeira } \\
\text { Instância }\end{array}$ & $\begin{array}{c}\text { Entrega } \\
\text { prevista da } \\
\text { Segunda } \\
\text { Instância }\end{array}$ & $\begin{array}{c}\text { Conclusão } \\
\text { prevista para a } \\
\text { Migração dos } \\
\text { dados }\end{array}$ & $\begin{array}{c}\text { Entrega } \\
\text { prevista da } \\
\text { Reorganização } \\
\text { das Peças }\end{array}$ & $\begin{array}{c}\text { Entrega } \\
\text { prevista do } \\
\text { Voto } \\
\text { Eletrônico }\end{array}$ \\
\hline $28 / 04 / 2010$ & $01 / 07 / 2010$ & $21 / 07 / 2010$ & $30 / 07 / 2010$ & $13 / 08 / 2010$ & $21 / 09 / 2010$ \\
\hline $19 / 05 / 2010$ & $01 / 07 / 2010$ & $21 / 07 / 2010$ & $30 / 07 / 2010$ & $13 / 08 / 2010$ & A definir \\
\hline $02 / 06 / 2010$ & $01 / 07 / 2010$ & $21 / 07 / 2010$ & $30 / 07 / 2010$ & $13 / 08 / 2010$ & $\begin{array}{r}21 / 07 / 2010 \\
\text { (antecipado) }\end{array}$ \\
\hline $09 / 06 / 2010$ & $08 / 07 / 2010$ & $13 / 08 / 2010$ & 17/09/2010 & $\begin{array}{r}13 / 08 / 2010 \\
\text { (incluído no } \\
\text { escopo da } \\
\text { segunda } \\
\text { instância) }\end{array}$ & $21 / 07 / 2010$ \\
\hline $16 / 06 / 2010$ & $16 / 07 / 2010$ & $20 / 08 / 2010$ & 17/09/2010 & --- & $28 / 07 / 2010$ \\
\hline $30 / 06 / 2010$ & $28 / 07 / 2010$ & $20 / 08 / 2010$ & $17 / 09 / 2010$ & --- & $28 / 07 / 2010$ \\
\hline $07 / 07 / 2011$ & $31 / 08 / 2010$ & $03 / 11 / 2010$ & $01 / 11 / 2010$ & -- & $28 / 07 / 2010$ \\
\hline $21 / 07 / 2010$ & $29 / 11 / 2010$ & $11 / 04 / 2011$ & $13 / 06 / 2011$ & --- & --- \\
\hline
\end{tabular}

Fonte: elaborado pelo autor a partir de SEFAZ (2010c, 2010d, 2010e, 2010f, 2010g, 2010h, 2020i, 2010j, 2010k, 20101, 2010m, 2010n, 2010o)

No mês de julho de 2011, o comitê executivo concluiu que não seria mais viável implantar o projeto conforme o prazo apresentado pela consultoria, e foi tomada a decisão de cancelamento. O Gráfico 7 mostra a evolução da data de término prevista para o projeto.

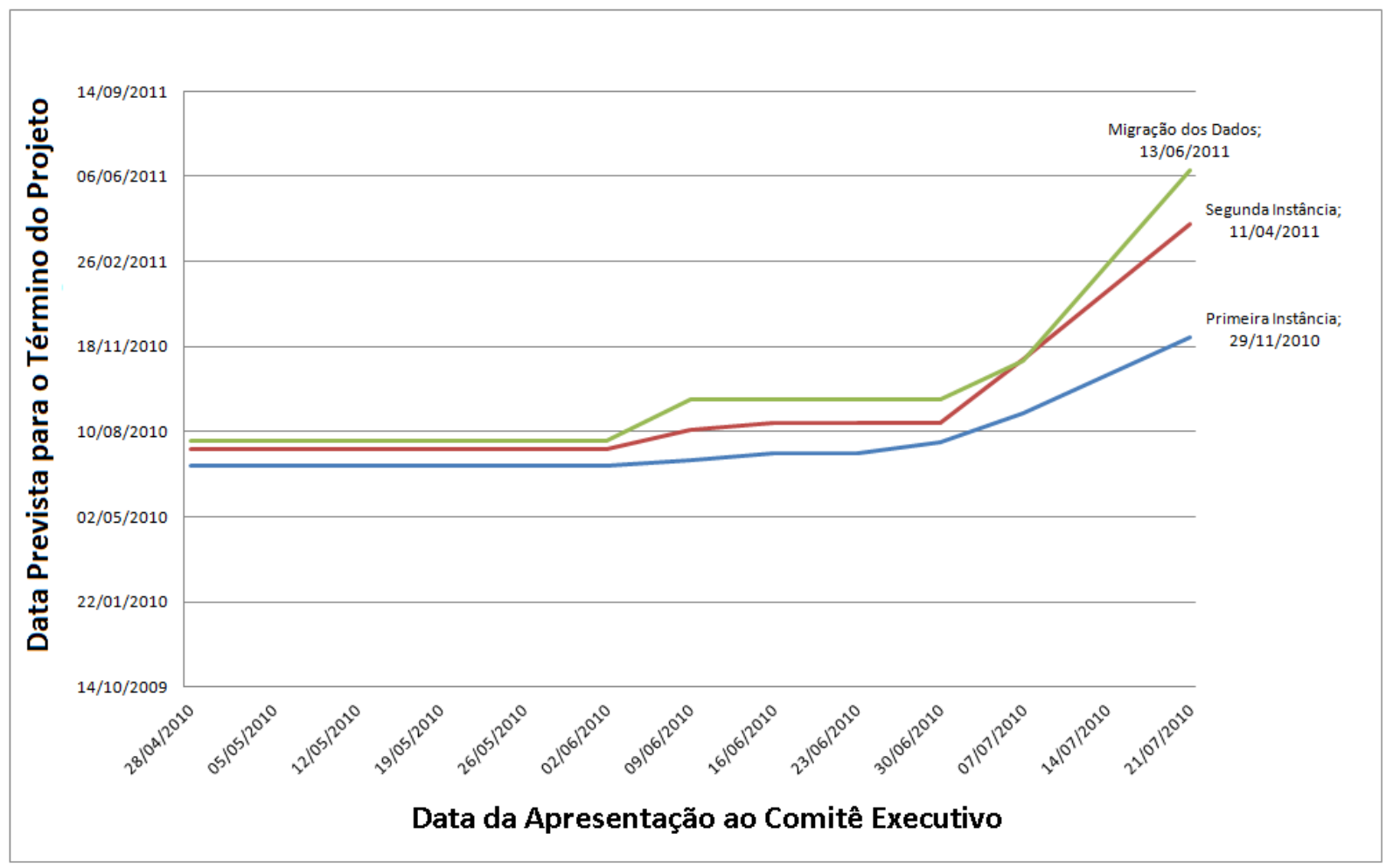

Gráfico 7: Evolução da data de término prevista para o projeto ePAT

Fonte: elaborado pelo autor a partir de SEFAZ (2010c, 2010d, 2010e, 2010f, 2010g, 2010h, 2020i, 2010j, 2010k, 20101, 2010m, 2010n, 2010o) 
Posteriormente, a decisão de cancelamento foi alterada para uma reorientação do projeto, que foi colocada em prática com as seguintes características:

- Gestão do projeto pela equipe do DTI;

- Uso de metodologia ágil de desenvolvimento de sistemas baseada no framework Scrum;

- Levantamento de requisitos realizado pelos Agentes Fiscais de Renda do DTI;

- Desenvolvimento realizado pela equipe do DTI, reforçada por profissionais da consultoria.

A Consultoria BPM listou alguns dos problemas e riscos principais enfrentados no projeto ePAT:

"Falta de habilidade em lidar com o governo. A dinâmica em projetos de governo é diferente. A forma de cobrar a área usuária. A forma de conduzir o projeto. A forma de se relacionar com o servidor público.

Pegada de empresa privada na condução de um projeto em uma empresa pública.

Falta de patente para questionar os usuários mais seniores.

Prazo. Falta de conhecimento do problema. Indefinições".

Os cinco entrevistados explicaram as consequências de afastar a Consultoria BPM da condução do projeto:

"A consultoria deixaria de entrar em contato direto com o cliente, que a consultoria não mais iria responder por cronogramas, por metas e por objetivos e a consultoria deixava de fazer o levantamento de requisitos. Então foi uma solução drástica que, para o bem do projeto, deu certo, porque, apesar de hoje estarmos totalmente fora do prazo político, totalmente fora do prazo das 13000 horas, a gente está com o projeto sendo entregue passo a passo".

"A consultoria estava na gestão do projeto, pelo menos na parte do TI, de desenvolvimento. E ali que a coisa não funcionou".

"Acho que o risco foi a parte de gerenciamento mesmo. Ou pelo menos a gente não tinha essa... Talvez ter mais visibilidade dos resultados que eles estão alcançando".

“A gestão do projeto passada para o DTI resolveu o problema da patente. Como todos puderam perceber, os prazos iniciais eram inatingíveis. Mesmo com o DTI assumindo a condução do negócio, naqueles prazos, o projeto jamais seria entregue". 
"A principal questão foi alinhar primeiro a parte de comunicação, pra poder não ter identificadores falsos. E também definir um processo de trabalho. Fazer com que todo mundo tivesse seus papéis bem claros, o que era responsabilidade do DTI, o que era responsabilidade de negócio".

\subsection{Segunda Fase do Projeto de BPM: Reorientação}

A segunda fase do projeto, iniciada no mês de agosto de 2010, começou com um levantamento dos principais problemas do desenvolvimento. Todos os envolvidos no projeto foram entrevistados e alguns problemas, como as dificuldades de comunicação, foram detectados. Além do levantamento das principais dificuldades, logo no início da segunda fase foi implantado um novo método de trabalho, baseado em princípios ágeis e influenciado pelo framework Scrum.

Uma grande mudança na forma de trabalho relacionou-se com prazos mais curtos entre as entregas, que possibilitaram regularidade na entrega de produtos para avaliação pelos usuários. Com os prazos longos entre a especificação e a homologação, como ocorreu na primeira fase do projeto, em muitos casos, durante a homologação, os usuários não estavam mais familiarizados com o que havia sido pedido, e solicitavam muitas mudanças durante a homologação. Com prazos mais curtos, a validação ocorria em um momento mais próximo à especificação e os usuários lembravam com mais clareza o que haviam pedido.

Outra alteração que reduziu a complexidade do projeto foi relacionada à estratégia de condução do projeto. Um sistema de workflow possui uma sequência de passos ou etapas que devem ser seguidos. Informações coletadas no projeto evidenciam que, na tentativa de atender ao prazo solicitado pelo cliente, a empresa Consultoria BPM elaborou o cronograma com um alto paralelismo entre as várias etapas do processo. Complementarmente, como as áreas clientes forneciam os requisitos em velocidades diferentes, era comum que uma área tivesse que definir uma etapa sem que as etapas anteriores estivessem definidas. Essa abordagem causava alguns problemas:

- O desenvolvimento de cada etapa do processo ocorria de forma menos intuitiva, pois os usuários eram levados a especificar uma etapa de forma isolada do resto do contexto do fluxo de processos e sem detalhamento das etapas anteriores;

- Dificuldade de integração entre as etapas após seu desenvolvimento;

- Dificuldade na montagem da massa de testes para validar cada etapa. 
A consultoria explica que preferiria usar um ciclo de vida iterativo e incremental, mas que a busca pelo cumprimento do prazo os teria induzido ao paralelismo:

"No caso do ePAT, foi tentado esse caminho (quebrar em pedaços menores). Até foi dividido um pouco. Entretanto, foi feito um paralelismo para atingir os prazos. A abordagem de paralelismo, tentada para atingir os prazos, inviabilizou uma abordagem iterativa e incremental".

Na segunda fase do projeto, ocorreu a opção pelo desenvolvimento sequencial, priorizando-se a ordem na qual os processos seriam executados na prática, o que soluiconou os problemas descritos acima, diminuindo a complexidade do projeto. A percepção de que era necessário diminuir essa complexidade pode ser vista no texto abaixo, extraído de uma das entrevistas:

\footnotetext{
"Então, não foi uma mudança de gestão, não se trocou simplesmente a figura de uma pessoa que estava tomando conta do processo por outra pessoa que passou a tomar conta do processo. Houve uma modificação estrutural na forma de conduzir o processo e houve também uma mudança de postura do cliente, porque na hora que houve a ruptura ideológica, vamos dizer assim, dentro do DTI, o cliente se apercebeu de que realmente o problema era muito grande."
}

“As regras (de negócios) são bem complexas. Assim, não tem tantas regras, mas a interação entre elas é que complica demais".

\subsection{Análise dos Fatores de Risco do Projeto ePAT}

Considerando-se a classificação de riscos do modelo de referência, composta de 15 fatores, os principais fatores (citados por três ou mais pessoas dentre os cinco entrevistados) mencionados durante as entrevistas para explicar o problema de agravamento no projeto ePAT foram os seguintes:

- Dificuldades com escopo e requisitos;

- Complexidade do sistema e organizacional;

- Problemas na gestão do projeto;

- Problemas com fornecedores.

As evidências obtidas a partir das entrevistas mostram que os problemas com fornecedores estão relacionados ao fato de o fornecedor atuar na gestão do projeto e não especificamente em problemas relacionados ao processo de contratação. 
Com menor ênfase (citados apenas uma vez), foram também mencionados os seguintes problemas:

- Conflitos entre os usuários (problema consolidado como parte de "usuários com atitudes negativas em relação ao projeto");

- Equipe de desenvolvimento sem familiaridade com as ferramentas de desenvolvimento (problema consolidado como parte de "dificuldades técnicas"), tratando-se não da equipe do projeto, mas dos novos profissionais, recém-chegados à Secretaria da Fazenda.

Em relação ao questionário respondido, os Quadros 28 e 29 apresentam os fatores de riscos consolidados, referentes ao quadrante do mandato do cliente, da classificação de Keil et al. (1998).

Quadro 28: Riscos consolidados do mandato do cliente no projeto ePAT

\begin{tabular}{|l|c|c|c|c|c|}
\hline \multicolumn{1}{|c|}{ Risco Consolidado } & \multicolumn{4}{|c|}{ Entrevistados } \\
\cline { 2 - 5 } & $\mathbf{1}$ & $\mathbf{2}$ & $\mathbf{3}$ & $\mathbf{4}$ & $\mathbf{5}$ \\
\hline Falta de participação do usuário (consolidado - valores médios). & 1,0 & 5,3 & 3,0 & 1,0 & 1,3 \\
\hline Falta de participação do usuário. & 1,0 & 6,0 & 3,0 & 1,0 & 1,0 \\
\hline Usuários não comprometidos com o projeto. & 1,0 & 4,0 & 3,0 & 1,0 & 2,0 \\
\hline Falta de cooperação dos usuários. & 1,0 & 6,0 & 3,0 & 1,0 & 1,0 \\
\hline $\begin{array}{l}\text { Usuários com atitudes negativas em relação ao projeto (consolidado - } \\
\text { valores médios). }\end{array}$ & 1,3 & 6,0 & 3,7 & 1,0 & 3,0 \\
\hline Usuários com atitudes negativas em relação ao projeto. & 1,0 & 7,0 & 3,0 & 1,0 & 2,0 \\
\hline Usuários resistentes a mudanças. & 1,0 & 6,0 & 4,0 & 1,0 & 4,0 \\
\hline Conflitos entre os usuários. & 2,0 & 5,0 & 4,0 & 1,0 & 3,0 \\
\hline Falta de apoio da alta direção ao projeto. & 1,0 & 1,0 & 1,0 & 1,0 & 1,0 \\
\hline $\begin{array}{l}\text { Falta de comprometimento ou pouco comprometimento da organização } \\
\text { com o projeto. }\end{array}$ & 1,0 & 2,0 & 1,0 & 1,0 & 1,0 \\
\hline
\end{tabular}

Fonte: elaborado pelo autor

Os dados obtidos por meio do questionário estão alinhados com as respostas obtidas por meio das entrevistas, segundo as quais os riscos relacionados ao mandato do cliente não foram significativos para que o projeto entrasse em situação de agravamento.

O fator de risco relacionado a usuários com atitudes negativas em relação ao projeto, que foi citado apenas por um dos entrevistados, obteve uma pontuação um pouco maior do que a dos outros itens, sem, no entanto, chegar ao ponto médio da escala Likert de sete valores. 
Quadro 29: Médias dos riscos consolidados do mandato do cliente no projeto ePAT

\begin{tabular}{|c|c|c|c|}
\hline Risco Consolidado & Média & $\begin{array}{l}\text { Maior } \\
\text { Valor }\end{array}$ & $\begin{array}{l}\text { Menor } \\
\text { Valor }\end{array}$ \\
\hline $\begin{array}{l}\text { Falta de participação do usuário (consolidado - valores } \\
\text { médios). }\end{array}$ & 2,3 & 5,3 & 1,0 \\
\hline Falta de participação do usuário & 2,4 & 6,0 & 1,0 \\
\hline Usuários não comprometidos com o projeto. & 2,2 & 4,0 & 1,0 \\
\hline Falta de cooperação dos usuários. & 2,4 & 6,0 & 1,0 \\
\hline $\begin{array}{l}\text { Usuários com atitudes negativas em relação ao projeto } \\
\text { (consolidado - valores médios). }\end{array}$ & 3,0 & 6,0 & 1,0 \\
\hline Usuários com atitudes negativas em relação ao projeto. & 2,8 & 7,0 & 1,0 \\
\hline Usuários resistentes a mudanças. & 3,2 & 6,0 & 1,0 \\
\hline Conflitos entre os usuários. & 3,0 & 5,0 & 1,0 \\
\hline Falta de apoio da alta direção ao projeto. & 1,0 & 1,0 & 1,0 \\
\hline $\begin{array}{l}\text { Falta de comprometimento ou pouco comprometimento da } \\
\text { organização com o projeto. }\end{array}$ & 1,2 & 2,0 & 1,0 \\
\hline
\end{tabular}

Fonte: elaborado pelo autor

Em relação aos riscos de escopo e requisitos da classificação de Keil et al. (1998), os Quadros 30 e 31 apresentam os fatores consolidados de acordo com o modelo de referência.

\section{Quadro 30: Riscos consolidados de escopo e requisitos no projeto ePAT}

\begin{tabular}{|c|c|c|c|c|c|}
\hline \multirow{2}{*}{ Risco Consolidado } & \multicolumn{5}{|c|}{ Entrevistados } \\
\hline & 1 & 2 & 3 & 4 & 5 \\
\hline $\begin{array}{l}\text { Dificuldades no detalhamento e estabilização dos requisitos (consolidado - } \\
\text { valores médios). }\end{array}$ & 3,2 & 3,8 & 3,0 & 1,2 & 5,0 \\
\hline Requisitos de sistema que mudam frequentemente; & 5,0 & 4,0 & 3,0 & 2,0 & 7,0 \\
\hline Requisitos do sistema identificados de forma inadequada; & 3,0 & 7,0 & 4,0 & 1,0 & 5,0 \\
\hline Requisitos de sistema obscuros (não claros); & 3,0 & 7,0 & 4,0 & 1,0 & 6,0 \\
\hline Requisitos de sistema incorretos; & 4,0 & 1,0 & 2,0 & 1,0 & 6,0 \\
\hline Requisitos de sistema conflitantes; & 2,0 & 3,0 & 3,0 & 1,0 & 5,0 \\
\hline Dificuldade em definir entradas e saídas do sistema. & 2,0 & 1,0 & 2,0 & 1,0 & 1,0 \\
\hline Problemas no direcionamento do projeto (consolidado - valores médios). & 3,3 & 5,3 & 3,7 & 1,0 & 6,3 \\
\hline Critério de sucesso do projeto indefinido; & 1,0 & 7,0 & 6,0 & 1,0 & 6,0 \\
\hline Metas do projeto mal definidas; & 5,0 & 5,0 & 2,0 & 1,0 & 6,0 \\
\hline Objetivos e escopo do projeto que mudam frequentemente. & 4,0 & 4,0 & 3,0 & 1,0 & 7,0 \\
\hline $\begin{array}{l}\text { Falta de entendimento pelos usuários sobre as capacidades e limitações do } \\
\text { sistema. }\end{array}$ & 2,0 & 3,0 & 5,0 & 1,0 & 5,0 \\
\hline
\end{tabular}

Fonte: elaborado pelo autor 
Quadro 31: Médias dos riscos consolidados de escopo e requisitos no projeto ePAT

\begin{tabular}{|l|r|r|r|}
\hline \multicolumn{1}{|c|}{ Risco Consolidado } & Média & \multicolumn{1}{c|}{$\begin{array}{c}\text { Maior } \\
\text { Valor }\end{array}$} & \multicolumn{1}{c|}{$\begin{array}{c}\text { Menor } \\
\text { Valor }\end{array}$} \\
\hline $\begin{array}{l}\text { Dificuldades no detalhamento e estabilização dos requisitos } \\
\text { (consolidado - valores médios). }\end{array}$ & 3,2 & 5,0 & 1,2 \\
\hline $\begin{array}{l}\text { Requisitos de sistema que mudam frequentemente; } \\
\text { Requisitos do sistema identificados de forma } \\
\text { inadequada; }\end{array}$ & 4,2 & 7,0 & 2,0 \\
\hline Requisitos de sistema obscuros (não claros); & 4,2 & 7,0 & 1,0 \\
\hline Requisitos de sistema incorretos; & 2,8 & 6,0 & 1,0 \\
\hline $\begin{array}{l}\text { Requisitos de sistema conflitantes; } \\
\text { Dificuldade em definir entradas e saídas do sistema. }\end{array}$ & 1,4 & 5,0 & 1,0 \\
\hline $\begin{array}{l}\text { Problemas no direcionamento do projeto (consolidado - } \\
\text { valores médios). }\end{array}$ & 4,9 & 6,3 & 1,0 \\
\hline $\begin{array}{l}\text { Critério de sucesso do projeto indefinido; } \\
\text { Metas do projeto mal definidas; }\end{array}$ & 3,0 & 7,0 \\
\hline $\begin{array}{l}\text { Objetivos e escopo do projeto que mudam } \\
\text { frequentemente. }\end{array}$ & 3,8 & 7,0 & 1,0 \\
\hline $\begin{array}{l}\text { Falta de entendimento pelos usuários sobre as capacidades e } \\
\text { limitações do sistema. }\end{array}$ & 3,2 & 5,0 & 1,0 \\
\hline
\end{tabular}

Fonte: elaborado pelo autor

A avaliação dos fatores de risco de escopo e requisitos por meio de questionário apresentou uma polarização análoga à dos dados da entrevista, com a área técnica de TI (entrevistas 2, $3 \mathrm{e}$ 5) entendendo que ocorreu uma dificuldade em estabilizar o escopo, e a área de negócio (entrevistas 1 e 4 ) entendendo que o escopo estava claro e fechado desde o início.

Podemos concluir, a partir das entrevistas e dos questionários, que existiram problemas nos três fatores de risco que compõem os riscos de escopo e requisitos, mas que não houve consenso entre os entrevistados sobre a intensidade desses problemas e sua importância para o agravamento do projeto.

Quanto aos riscos de execução da classificação de Keil et al. (1998), os Quadros 32 e 33 apresentam os fatores consolidados segundo o modelo de referência. 
Quadro 32: Riscos consolidados de execução no projeto ePAT

\begin{tabular}{|c|c|c|c|c|c|}
\hline \multirow{2}{*}{ Risco Consolidado } & \multicolumn{5}{|c|}{ Entrevistados } \\
\hline & 1 & 2 & 3 & 4 & 5 \\
\hline Dificuldades técnicas (consolidado - valores médios). & 2,7 & 3,5 & 4,4 & 5,0 & 3,7 \\
\hline Membros da equipe inexperientes. & 3,0 & 2,0 & 3,0 & 5,0 & 5,0 \\
\hline $\begin{array}{l}\text { Equipe de desenvolvimento sem familiaridade com as ferramentas } \\
\text { de desenvolvimento. }\end{array}$ & 5,0 & 3,0 & 2,0 & 2,0 & 2,0 \\
\hline $\begin{array}{l}\text { Equipe de desenvolvimento sem familiaridade com as tarefas a } \\
\text { serem automatizadas. }\end{array}$ & 1,0 & 3,0 & 6,0 & 7,0 & 6,0 \\
\hline $\begin{array}{l}\text { Faltam nos membros da equipe as habilidades especializadas } \\
\text { requeridas pelo projeto. }\end{array}$ & 1,0 & 2,0 & 5,0 & 5,0 & 3,0 \\
\hline O projeto envolve o uso de uma tecnologia nova. & 4,0 & 6,0 & 6,0 & 7,0 & 3,0 \\
\hline Tecnologia imatura. & 2,0 & 3,0 & NA & 4,0 & 4,0 \\
\hline $\begin{array}{l}\text { O projeto envolve o uso de uma tecnologia que não foi usada em } \\
\text { projetos anteriores. }\end{array}$ & 1,0 & 5,0 & 6,0 & 7,0 & 5,0 \\
\hline Complexidade do sistema e organizacional (consolidado - valores médios). & 6,8 & 6,8 & 5,2 & 7,0 & 6,0 \\
\hline Alto nível de complexidade técnica. & 6,0 & 6,0 & 4,0 & 7,0 & 5,0 \\
\hline A tarefa a ser automatizada é altamente complexa. & 7,0 & 7,0 & 6,0 & 7,0 & 6,0 \\
\hline $\begin{array}{l}\text { O projeto afeta um grande número de unidades e/ou departamentos } \\
\text { dos usuários. }\end{array}$ & 7,0 & 7,0 & 5,0 & 7,0 & 7,0 \\
\hline Ser um dos maiores projetos já empreendidos pela organização. & 7,0 & 7,0 & 5,0 & 7,0 & 7,0 \\
\hline Necessidade de integração com um grande número de sistemas. & 7,0 & 7,0 & 6,0 & 7,0 & 5,0 \\
\hline Problemas na gestão do projeto (consolidado - valores médios). & 3,9 & 5,4 & 5,6 & 3,9 & 5,4 \\
\hline Falta de uma metodologia efetiva de gerenciamento de projetos. & 5,0 & 7,0 & 6,0 & 6,0 & 7,0 \\
\hline Estimativa inadequada do cronograma do projeto. & 7,0 & 5,0 & 7,0 & 5,0 & 7,0 \\
\hline Prazo político. & 1,0 & 4,0 & 3,0 & 6,0 & 7,0 \\
\hline Progresso do projeto não monitorado suficientemente de perto. & 4,0 & 3,0 & 5,0 & 1,0 & 3,0 \\
\hline Planejamento precário do projeto. & 4,0 & 6,0 & 6,0 & 1,0 & 6,0 \\
\hline Marcos do projeto não definidos de forma clara. & 4,0 & 5,0 & 4,0 & 1,0 & 4,0 \\
\hline Estimativa inadequada do orçamento do projeto. & 3,0 & 3,0 & NA & 1,0 & 5,0 \\
\hline Gerente do projeto não efetivo. & 4,0 & 7,0 & 7,0 & 6,0 & 6,0 \\
\hline Gerente do projeto inexperiente. & 2,0 & 7,0 & 7,0 & 6,0 & 6,0 \\
\hline Comunicação não efetiva. & 5,0 & 7,0 & 5,0 & 6,0 & 3,0 \\
\hline Problemas na gestão da equipe (consolidado - valores médios). & 2,6 & 3,1 & 5,6 & 5,6 & 4,3 \\
\hline $\begin{array}{l}\text { Membros da equipe de desenvolvimento treinados de forma } \\
\text { inadequada. }\end{array}$ & 4,0 & 4,0 & 5,0 & 7,0 & 3,0 \\
\hline $\begin{array}{l}\text { Falta de comprometimento com o projeto por parte dos membros da } \\
\text { equipe. }\end{array}$ & 1,0 & 4,0 & 5,0 & 6,0 & 5,0 \\
\hline Conflitos frequentes na equipe de desenvolvimento. & 2,0 & 2,0 & 4,0 & 6,0 & 2,0 \\
\hline Rotatividade frequente dos membros da equipe. & 5,0 & 2,0 & 6,0 & 5,0 & 4,0 \\
\hline Atitudes negativas da equipe de desenvolvimento. & 2,0 & 2,0 & 7,0 & 5,0 & 5,0 \\
\hline Faltam habilidades de liderança do projeto nas pessoas envolvidas. & 3,0 & 5,0 & 6,0 & 6,0 & 6,0 \\
\hline Estimativa inadequada dos recursos necessários. & 1,0 & 3,0 & 6,0 & 4,0 & 5,0 \\
\hline
\end{tabular}

Fonte: elaborado pelo autor 
Quadro 33: Médias dos riscos consolidados de execução no projeto ePAT

\begin{tabular}{|c|c|c|c|}
\hline Risco Consolidado & Média & $\begin{array}{l}\text { Maior } \\
\text { Valor }\end{array}$ & $\begin{array}{l}\text { Menor } \\
\text { Valor }\end{array}$ \\
\hline Dificuldades técnicas (consolidado - valores médios). & 3,9 & 5,0 & 2,7 \\
\hline Membros da equipe inexperientes. & 3,6 & 5,0 & 2,0 \\
\hline $\begin{array}{l}\text { Equipe de desenvolvimento sem familiaridade com as } \\
\text { ferramentas de desenvolvimento. }\end{array}$ & 2,8 & 5,0 & 2,0 \\
\hline $\begin{array}{l}\text { Equipe de desenvolvimento sem familiaridade com as } \\
\text { tarefas a serem automatizadas. }\end{array}$ & 4,6 & 7,0 & 1,0 \\
\hline $\begin{array}{l}\text { Faltam nos membros da equipe as habilidades } \\
\text { especializadas requeridas pelo projeto. }\end{array}$ & 3,2 & 5,0 & 1,0 \\
\hline O projeto envolve o uso de uma tecnologia nova. & 5,2 & 7,0 & 3,0 \\
\hline Tecnologia imatura. & 3,3 & 4,0 & 2,0 \\
\hline $\begin{array}{l}\text { O projeto envolve o uso de uma tecnologia que não foi } \\
\text { usada em projetos anteriores. }\end{array}$ & 4,8 & 7,0 & 1,0 \\
\hline $\begin{array}{l}\text { Complexidade do sistema e organizacional (consolidado - } \\
\text { valores médios). }\end{array}$ & 6,4 & 7,0 & 5,2 \\
\hline Alto nível de complexidade técnica. & 5,6 & 7,0 & 4,0 \\
\hline A tarefa a ser automatizada é altamente complexa. & 6,6 & 7,0 & 6,0 \\
\hline $\begin{array}{l}\text { O projeto afeta um grande número de unidades e/ou } \\
\text { departamentos dos usuários. }\end{array}$ & 6,6 & 7,0 & 5,0 \\
\hline $\begin{array}{l}\text { Ser um dos maiores projetos já empreendidos pela } \\
\text { organização. }\end{array}$ & 6,6 & 7,0 & 5,0 \\
\hline $\begin{array}{l}\text { Necessidade de integração com um grande número de } \\
\text { sistemas. }\end{array}$ & 6,4 & 7,0 & 6,0 \\
\hline Problemas na gestão do projeto (consolidado - valores médios). & 4,8 & 5,6 & 3,9 \\
\hline $\begin{array}{l}\text { Falta de uma metodologia efetiva de gerenciamento de } \\
\text { projetos. }\end{array}$ & 6,2 & 7,0 & 5,0 \\
\hline Estimativa inadequada do cronograma do projeto. & 6,2 & 7,0 & 5,0 \\
\hline Prazo político. & 4,2 & 7,0 & 1,0 \\
\hline $\begin{array}{l}\text { Progresso do projeto não monitorado suficientemente de } \\
\text { perto. }\end{array}$ & 3,2 & 5,0 & 1,0 \\
\hline Planejamento precário do projeto. & 4,6 & 6,0 & 1,0 \\
\hline Marcos do projeto não definidos de forma clara. & 3,6 & 5,0 & 1,0 \\
\hline Estimativa inadequada do orçamento do projeto. & 3,0 & 5,0 & 1,0 \\
\hline Gerente do projeto não efetivo. & 6,0 & 7,0 & 4,0 \\
\hline Gerente do projeto inexperiente. & 5,6 & 7,0 & 2,0 \\
\hline Comunicação não efetiva. & 5,2 & 7,0 & 3,0 \\
\hline Problemas na gestão da equipe (consolidado - valores médios). & 4,2 & 5,6 & 2,6 \\
\hline $\begin{array}{l}\text { Membros da equipe de desenvolvimento treinados de } \\
\text { forma inadequada. }\end{array}$ & 4,6 & 7,0 & 3,0 \\
\hline $\begin{array}{l}\text { Falta de comprometimento com o projeto por parte dos } \\
\text { membros da equipe. }\end{array}$ & 4,2 & 6,0 & 1,0 \\
\hline Conflitos frequentes na equipe de desenvolvimento. & 3,2 & 6,0 & 2,0 \\
\hline Rotatividade frequente dos membros da equipe. & 4,4 & 6,0 & 2,0 \\
\hline Atitudes negativas da equipe de desenvolvimento. & 4,2 & 7,0 & 2,0 \\
\hline $\begin{array}{l}\text { Faltam habilidades de liderança do projeto nas pessoas } \\
\text { envolvidas. }\end{array}$ & 5,2 & 6,0 & 3,0 \\
\hline Estimativa inadequada dos recursos necessários. & 3,8 & 6,0 & 1,0 \\
\hline
\end{tabular}

Fonte: elaborado pelo autor

Em relação aos riscos de complexidade do sistema e organizacional e problemas na gestão do projeto, os dados obtidos por meio do questionário estão alinhados com as entrevistas quanto à importância desses fatores para compreender o agravamento do projeto ePAT. 
Entre os riscos relacionados às dificuldades técnicas, somente um deles foi mencionado nas entrevistas e, mesmo assim, de maneira restrita os novos profissionais, recém-chegados à Secretaria da Fazenda. Em relação ao questionário, tanto os riscos relacionados às dificuldades técnicas quanto os riscos relacionados à gestão da equipe tiveram alta pontuação, apesar de apresentarem uma pontuação menor do que dos outros dois fatores de risco de execução.

Finalmente, os Quadros 34 e 35 apresentam os fatores de risco consolidados, referentes ao quadrante do ambiente da classificação de Keil et al. (1998).

Quadro 34: Riscos consolidados de ambiente no projeto ePAT

\begin{tabular}{|c|r|c|c|c|c|}
\hline \multicolumn{1}{|c|}{ Risco Consolidado } & \multicolumn{3}{|c|}{ Entrevistados } \\
\cline { 2 - 5 } & $\mathbf{1}$ & $\mathbf{2}$ & $\mathbf{3}$ & $\mathbf{4}$ & $\mathbf{5}$ \\
\hline Ambiente organizacional instável (consolidado - valores médios). & 1,5 & 1,0 & 3,0 & 1,0 & 1,8 \\
\hline $\begin{array}{l}\text { Recursos deslocados do projeto em razão de mudanças nas } \\
\text { prioridades da organização. }\end{array}$ & 1,0 & 1,0 & 5,0 & 1,0 & 2,0 \\
\hline Ambiente organizacional instável. & 1,0 & 1,0 & 3,0 & 1,0 & 1,0 \\
\hline Mudança na gestão organizacional durante o projeto. & 3,0 & 1,0 & 3,0 & 1,0 & 2,0 \\
\hline Organização passando por uma reestruturação durante o projeto. & 1,0 & 1,0 & 1,0 & 1,0 & 2,0 \\
\hline Políticas corporativas com efeitos negativos no projeto. & 4,0 & 1,0 & 3,0 & 1,0 & 2,0 \\
\hline Estrutura ineficiente para a tomada de decisão. & 3,0 & 7,0 & 2,0 & 1,0 & 4,0 \\
\hline Problemas com fornecedores (consolidado - valores médios). & 4,0 & 6,0 & 6,0 & 6,5 & 7,0 \\
\hline Dependência de um fornecedor externo. & 6,0 & 5,0 & 7,0 & 7,0 & 7,0 \\
\hline $\begin{array}{l}\text { Muitos fornecedores externos envolvidos no desenvolvimento do } \\
\text { projeto. }\end{array}$ & 2,0 & 7,0 & 5,0 & 6,0 & 7,0 \\
\hline
\end{tabular}

Fonte: elaborado pelo autor

Quadro 35: Médias dos riscos consolidados de ambiente no projeto ePAT

\begin{tabular}{|c|c|c|c|}
\hline Risco Consolidado & Média & $\begin{array}{l}\text { Maior } \\
\text { Valor }\end{array}$ & $\begin{array}{l}\text { Menor } \\
\text { Valor }\end{array}$ \\
\hline $\begin{array}{l}\text { Ambiente organizacional instável (consolidado - valores } \\
\text { médios). }\end{array}$ & 1,7 & 3,0 & 1,0 \\
\hline $\begin{array}{l}\text { Recursos deslocados do projeto em razão de mudanças } \\
\text { nas prioridades da organização. }\end{array}$ & 2,0 & 5,0 & 1,0 \\
\hline Ambiente organizacional instável. & 1,4 & 3,0 & 1,0 \\
\hline Mudança na gestão organizacional durante o projeto. & 2,0 & 3,0 & 1,0 \\
\hline $\begin{array}{l}\text { Organização passando por uma reestruturação durante } \\
\text { o projeto. }\end{array}$ & 1,2 & 2,0 & 1,0 \\
\hline Políticas corporativas com efeitos negativos no projeto. & 2,2 & 4,0 & 1,0 \\
\hline Estrutura ineficiente para a tomada de decisão. & 3,4 & 7,0 & 1,0 \\
\hline Problemas com fornecedores (consolidado - valores médios). & 5,9 & 7,0 & 4,0 \\
\hline Dependência de um fornecedor externo. & 6,4 & 7,0 & 5,0 \\
\hline $\begin{array}{lcc}\text { Muitos fornecedores externos envolvidos no } \\
\text { desenvolvimento do projeto. }\end{array}$ & 5,4 & 7,0 & 2,0 \\
\hline
\end{tabular}


Novamente, os resultados do questionário estão alinhados com as entrevistas no que se refere aos problemas com fornecedores, que tiveram uma alta pontuação. Adicionalmente, o risco de uma estrutura ineficiente para a tomada de decisão teve uma pontuação média.

Complementarmente à análise dos riscos de acordo com o modelo de referência, é importante apresentar a análise referente aos modelos alternativos propostos. Os Quadros 36 e 37 apresentam os riscos associados a problemas na Governança de TI.

\section{Quadro 36: Riscos de Governança de TI no projeto ePAT}

\begin{tabular}{|c|c|c|c|c|c|}
\hline \multirow{2}{*}{ Risco } & \multicolumn{5}{|c|}{ Entrevistados } \\
\hline & 1 & 2 & 3 & 4 & 5 \\
\hline Falta de participação dos usuários. & 1,0 & 6,0 & 3,0 & 1,0 & 1,0 \\
\hline Conflitos entre os usuários. & 2,0 & 5,0 & 4,0 & 1,0 & 3,0 \\
\hline Falta de apoio da alta direção ao projeto. & 1,0 & 1,0 & 1,0 & 1,0 & 1,0 \\
\hline $\begin{array}{l}\text { Falta de comprometimento ou pouco comprometimento da organização com } \\
\text { o projeto. }\end{array}$ & 1,0 & 2,0 & 1,0 & 1,0 & 1,0 \\
\hline $\begin{array}{l}\text { O projeto afeta um grande número de unidades e/ou departamentos dos } \\
\text { usuários. }\end{array}$ & 7,0 & 7,0 & 5,0 & 7,0 & 7,0 \\
\hline Falta de uma metodologia efetiva de gerenciamento de projetos. & 5,0 & 7,0 & 6,0 & 6,0 & 7,0 \\
\hline Estrutura ineficiente para a tomada de decisão. & 3,0 & 7,0 & 2,0 & 1,0 & 4,0 \\
\hline Mudança na gestão organizacional durante o projeto. & 3,0 & 1,0 & 3,0 & 1,0 & 2,0 \\
\hline Políticas corporativas com efeitos negativos no projeto. & 4,0 & 1,0 & 3,0 & 1,0 & 2,0 \\
\hline Ambiente organizacional instável. & 1,0 & 1,0 & 3,0 & 1,0 & 1,0 \\
\hline Organização passando por uma reestruturação durante o projeto. & 1,0 & 1,0 & 1,0 & 1,0 & 2,0 \\
\hline
\end{tabular}

Fonte: elaborado pelo autor

Quadro 37: Médias dos riscos de Governança de TI no projeto ePAT

\begin{tabular}{|c|c|c|c|}
\hline Risco & Média & $\begin{array}{l}\text { Maior } \\
\text { Valor }\end{array}$ & $\begin{array}{l}\text { Menor } \\
\text { Valor }\end{array}$ \\
\hline Falta de participação dos usuários. & 2,4 & 6,0 & 1,0 \\
\hline Conflitos entre os usuários. & 3,0 & 5,0 & 1,0 \\
\hline Falta de apoio da alta direção ao projeto. & 1,0 & 1,0 & 1,0 \\
\hline $\begin{array}{l}\text { Falta de comprometimento ou pouco comprometimento da } \\
\text { organização com o projeto. }\end{array}$ & 1,2 & 2,0 & 1,0 \\
\hline $\begin{array}{l}\text { O projeto afeta um grande número de unidades e/ou } \\
\text { departamentos dos usuários. }\end{array}$ & 6,6 & 7,0 & 5,0 \\
\hline $\begin{array}{l}\text { Falta de uma metodologia efetiva de gerenciamento de } \\
\text { projetos. }\end{array}$ & 6,2 & 7,0 & 5,0 \\
\hline Estrutura ineficiente para a tomada de decisão. & 3,4 & 7,0 & 1,0 \\
\hline Mudança na gestão organizacional durante o projeto. & 2,0 & 3,0 & 1,0 \\
\hline Políticas corporativas com efeitos negativos no projeto. & 2,2 & 4,0 & 1,0 \\
\hline Ambiente organizacional instável. & 1,4 & 3,0 & 1,0 \\
\hline $\begin{array}{l}\text { Organização passando por uma reestruturação durante o } \\
\text { projeto. }\end{array}$ & 1,2 & 2,0 & 1,0 \\
\hline
\end{tabular}


Dentre os riscos de Governança de TI, os riscos com maior pontuação foram justamente aqueles relacionados à complexidade e ao uso de metodologia de gerenciamento de projetos no modelo de referência. Consequentemente, o agrupamento dos riscos por esse critério apresentou mais valores baixos (abaixo de 4) do que valores altos (acima de 4), com uma média de 2,8 .

Os Quadros 38 e 39 apresentam os elementos relacionados à complexidade estrutural do modelo de Xia e Lee (2004).

Quadro 38: Riscos de complexidade estrutural do modelo de Xia e Lee no projeto ePAT

\begin{tabular}{|c|c|c|c|c|c|}
\hline \multirow{2}{*}{ Risco } & \multicolumn{5}{|c|}{ Entrevistados } \\
\hline & $\mathbf{1}$ & 2 & 3 & 4 & 5 \\
\hline Falta de cooperação dos usuários. & 1,0 & 6,0 & 3,0 & 1,0 & 1,0 \\
\hline Estimativa inadequada dos recursos necessários. & 1,0 & 3,0 & 6,0 & 4,0 & 5,0 \\
\hline $\begin{array}{l}\text { Recursos deslocados do projeto em razão de mudanças nas prioridades da } \\
\text { organização. }\end{array}$ & 1,0 & 1,0 & 5,0 & 1,0 & 2,0 \\
\hline $\begin{array}{l}\text { Faltam nos membros da equipe as habilidades especializadas requeridas } \\
\text { pelo projeto. }\end{array}$ & 1,0 & 2,0 & 5,0 & 5,0 & 3,0 \\
\hline Falta de apoio da alta direção ao projeto. & 1,0 & 1,0 & 1,0 & 1,0 & 1,0 \\
\hline
\end{tabular}

Fonte: elaborado pelo autor

Quadro 39: Médias dos riscos de complexidade estrutural do modelo de Xia e Lee no projeto ePAT

\begin{tabular}{|l|r|r|r|}
\hline \multicolumn{1}{|c|}{ Risco Consolidado } & Média & \multicolumn{1}{c|}{$\begin{array}{c}\text { Maior } \\
\text { Valor }\end{array}$} & $\begin{array}{c}\text { Menor } \\
\text { Valor }\end{array}$ \\
\hline Falta de cooperação dos usuários. & 2,4 & 6,0 & 1,0 \\
\hline Estimativa inadequada dos recursos necessários. & 3,8 & 6,0 & 1,0 \\
\hline $\begin{array}{l}\text { Recursos deslocados do projeto em razão de mudanças nas } \\
\text { prioridades da organização. }\end{array}$ & 2,0 & 5,0 & 1,0 \\
\hline $\begin{array}{l}\text { Faltam nos membros da equipe as habilidades especializadas } \\
\text { requeridas pelo projeto. }\end{array}$ & 3,2 & 5,0 & 1,0 \\
\hline Falta de apoio da alta direção ao projeto. & 1,0 & 1,0 & 1,0 \\
\hline
\end{tabular}

Fonte: elaborado pelo autor

O agrupamento dos riscos pelo critério de complexidade estrutural do modelo de Xia e Lee (2004) apresentou mais valores baixos (abaixo de 4,0) do que valores altos (acima de 4,0). Todos os fatores apresentaram média inferior a 4,0, e a média contemplando todos os fatores agregados foi de 2,5 . 


\section{$5.4 \quad$ Aderência dos Resultados às Teorias}

O projeto ePAT enfrentou a situação de agravamento até o momento em que foi reorientado. Consequentemente, as proposições apresentadas no capítulo 3, que contempla o modelo de referência e as teorias alternativas, os dados coletados na análise do ePAT permitiram as seguintes conclusões:

Em relação à primeira proposição:

P1: Altos riscos de (2) escopo e requisitos, juntamente com altos riscos de (3) execução, contribuem para que um projeto entre em situação de agravamento.

Os dados apresentados nos Quadros 29, 30, 31 e 32 demonstram alto risco de execução e um risco médio relacionado a escopo e requisitos. Complementarmente, os dados qualitativos obtidos por meio das entrevistas enfatizam problemas nesses dois quadrantes. Consequentemente, podemos concluir que os dados obtidos se comportam de acordo com a proposição P1.

Em relação à segunda proposição:

P2: Os riscos de (1) mandato do cliente e (4) ambiente não são relevantes para que um projeto problemático entre em situação de agravamento.

Conforme pode ser visto nos Quadros 33 e 34, em relação aos dados dos fatores de risco relacionados ao ambiente, somente o fator de problemas com fornecedores teve alta pontuação. Quanto aos fatores de risco relacionados ao mandato do cliente, apresentados nos Quadros 27 e 28, esses riscos tiveram pontuação baixa.

Dessa forma, podemos concluir que os riscos do mandato do cliente e do ambiente não foram relevantes para que o projeto entrasse em situação de agravamento, conforme a proposição $\mathrm{P} 2$.

As proposição P3 e P4 serão avaliadas conjuntamente: 
P3: Altos riscos relacionados a escopo e requisitos, juntamente com a complexidade do sistema e organizacional, fazem com que um projeto se torne um projeto complexo (wicked project).

P4: Projetos em situação de agravamento apresentam altos riscos relacionados a escopo e requisitos, complexidade do sistema e organizacional, e problemas na gestão do projeto.

Os fatores de risco apontados nas proposições P3 e P4, juntamente com os problemas com os fornecedores, foram os mais críticos segundo as entrevistas. Além disso, o risco relacionado à complexidade do sistema e organizacional foi o que obteve a maior pontuação entre todos os riscos do questionário (média de 6,4), seguido pelo fator relacionado a riscos com fornecedores (média de 5,9) e problemas na gestão do projeto (média de 4,8).

Entretanto, ao considerarmos os 15 fatores de risco, alguns riscos tiveram pontuação relativa mais alta em relação a problemas no escopo e requisitos, conforme podemos ver no Gráfico 8.

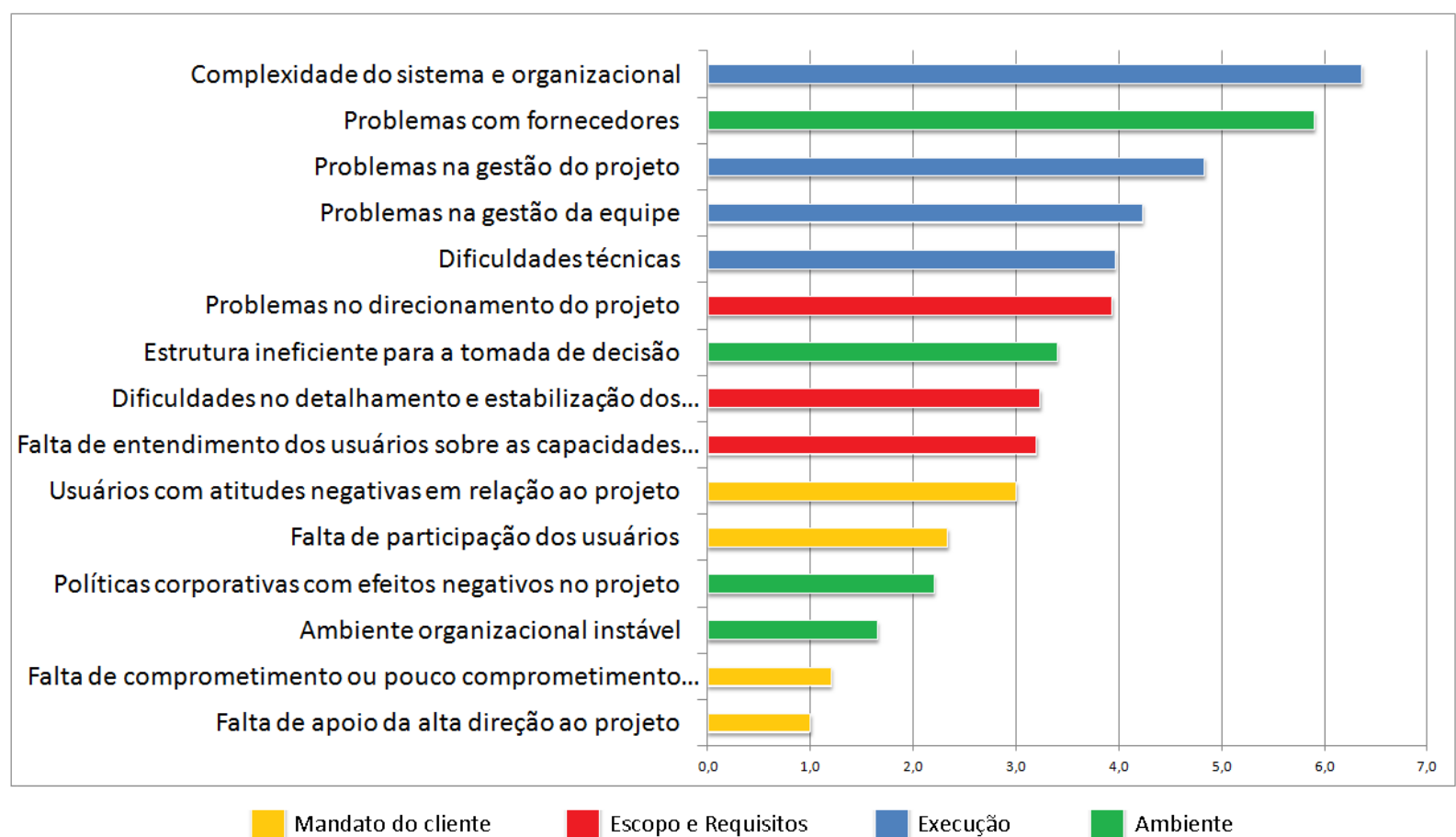

Gráfico 8: Riscos consolidados do projeto ePAT Fonte: elaborado pelo autor 
Dessa forma, ao considerarmos o modelo de referência, uma explicação possível é que quando se tem um projeto com alta complexidade do sistema e organizacional, até mesmo uma incerteza moderada em relação a escopo e requisitos é suficiente para tornar o projeto wicked.

A conclusão, considerando os dados das entrevistas, é de que o caso do projeto ePAT se comporta de acordo com o modelo. Entretanto, ao fazermos a triangulação com os dados do questionário, o alinhamento ao modelo se torna menos evidente, apresentando indícios de que a complexidade pode ser um fator de risco mais relevante do que a incerteza.

Quanto à proposição P5:

P5: A reorientação bem-sucedida de um projeto em situação de agravamento envolve aspectos relacionados à diminuição da complexidade do projeto ou à aplicação de técnicas mais adequadas para lidar com a complexidade existente.

A solução aplicada na reorientação do projeto ePAT, que foi bem-sucedida no propósito de corrigir o problema do agravamento, envolveu o uso de uma estratégia iterativa e incremental, bem documentada na literatura, para resolver problemas relacionados especialmente à incerteza, mas também à complexidade.

A redução da complexidade pelo uso de um modelo iterativo e incremental também está relacionada a um risco descrito por Smith $(2001$, p. 18,19), referente à falha do comprador em quebrar um projeto complexo em fases ou projetos menores.

Além da utilização de uma metodologia iterativa e incremental, outros elementos de risco foram reduzidos por meio das seguintes ações:

- Maior força política do gestor do projeto para lidar com a área usuária;

- O prazo passou a ser calculado com maior influência técnica e menor influência política;

- Os processos passaram a ser desenvolvidos de acordo com a mesma sequência na qual serão usados na prática, o que facilitou sua compreensão por todos os envolvidos e diminuiu drasticamente o custo e o prazo da construção da massa de testes; 
- A migração dos dados do sistema legado foi excluída do projeto;

- Entregas em produção que contribuíram para o retorno da confiança na viabilidade do projeto.

Consequentemente, a redução da complexidade pelo uso de uma metodologia iterativa e incremental, juntamente com a eliminação de outros elementos de complexidade listados acima, estão alinhadas com a proposição P5.

As proposições P6 e P7 serão tratadas de forma conjunta:

P6: Altos riscos relacionados à Governança de TI contribuem para que um projeto problemático entre em situação de agravamento.

P7: Altos riscos relacionados à Governança de TI contribuem para que um projeto problemático permaneça em situação de agravamento.

As proposições P6 e P7 não foram validadas a partir dos dados obtidos no caso do projeto ePAT, pois o agrupamento dos riscos pelo critério de governança apresentou mais valores baixos (abaixo de 4) do que valores altos (acima de 4), com uma média de 2,8.

Em relação à última proposição:

P8: Projetos de TI do setor público em situação de agravamento apresentam alta complexidade estrutural organizacional.

A proposição P8 também não foi validada a partir dos dados obtidos, pois o agrupamento dos riscos pelo critério de complexidade estrutural do modelo de Xia e Lee (2004) apresentou mais valores baixos (abaixo de 4) do que valores altos (acima de 4), com uma média de 2,5.

O primeiro caso estudado foi consistente com as proposições P1 e P2, relativas ao modelo de Wallace e Keil (2004), e com as proposições P3, P4 e P5, relativas ao modelo de referência. 
Em relação às proposições P6 e P7, referentes ao modelo baseado na Governança de TI e à proposição P8, referente ao modelo de Xia e Lee (2004), houve corroboração pelas evidências do caso estudado.

O Quadro 40 apresenta um resumo da avaliação das proposições e de sua aderência às teorias:

Quadro 40: Avaliação do caso do projeto ePAT em relação às proposições e teorias

\begin{tabular}{|l|l|l|}
\hline \multicolumn{1}{|c|}{ Teoria } & \multicolumn{1}{|c|}{ Proposição } & \multicolumn{1}{|c|}{$\begin{array}{c}\text { Caso } \\
\text { Alinhado à } \\
\text { Teoria }\end{array}$} \\
\hline $\begin{array}{l}\text { Wallace e } \\
\text { Keil (2004) }\end{array}$ & $\begin{array}{l}\text { P1: Altos riscos de (2) escopo e requisitos, juntamente com altos riscos de (3) } \\
\text { execução, contribuem para que um projeto entre em situação de agravamento. }\end{array}$ & Sim \\
\cline { 2 - 4 } & $\begin{array}{l}\text { P2: Os riscos de (1) mandato do cliente e (4) ambiente não são relevantes para } \\
\text { que um projeto problemático entre em situação de agravamento. }\end{array}$ & Sim \\
\hline $\begin{array}{l}\text { Modelo de } \\
\text { referência }\end{array}$ & $\begin{array}{l}\text { P3: Altos riscos relacionados a escopo e requisitos, juntamente com a } \\
\text { complexidade do sistema e organizacional, fazem com que um projeto se } \\
\text { torne um projeto complexo (wicked project). }\end{array}$ & Sim \\
\cline { 2 - 4 } & $\begin{array}{l}\text { P4: Projetos em situação de agravamento apresentam altos riscos relacionados } \\
\text { a escopo e requisitos, complexidade do sistema e organizacional, e problemas } \\
\text { na gestão do projeto. }\end{array}$ & Sim \\
\cline { 2 - 4 } & $\begin{array}{l}\text { P5: A reorientação bem-sucedida de um projeto em situação de agravamento } \\
\text { envolve aspectos relacionados à diminuição da complexidade do projeto ou à } \\
\text { aplicação de técnicas mais adequadas para lidar com a complexidade } \\
\text { existente. }\end{array}$ & Sim \\
\hline $\begin{array}{l}\text { Governança } \\
\text { de TI }\end{array}$ & $\begin{array}{l}\text { P6: Altos riscos relacionados à Governança de TI contribuem para que um } \\
\text { projeto problemático entre em situação de agravamento. }\end{array}$ & Não \\
\cline { 2 - 4 } & $\begin{array}{l}\text { P7: Altos riscos relacionados à Governança de TI contribuem para que um } \\
\text { projeto problemático permaneça em situação de agravamento. }\end{array}$ & Não \\
\hline $\begin{array}{l}\text { Xia e Lee } \\
\text { (2004) }\end{array}$ & $\begin{array}{l}\text { P8: Projetos de TI do setor público em situação de agravamento apresentam } \\
\text { alta complexidade estrutural organizacional. }\end{array}$ & Não \\
\hline
\end{tabular}

Fonte: elaborado pelo autor 


\section{$6 \quad$ Projeto Nota Fiscal Eletrônica}

De acordo com o sítio institucional da Secretaria da Fazenda do Estado de São Paulo, o desenvolvimento do conceito que serviu como base para a Nota Fiscal Eletrônica (NF-e) ocorreu durante o $1^{\circ}$ Encontro Nacional de Administradores Tributários (ENAT), que ocorreu entre 15 e 17 de julho de 2004, em Salvador, Bahia, reunindo os titulares das Administrações Tributárias das três esferas de governo: federal, estadual e municipal, esta última representada apenas pelas capitais. Como resultado do ENAT, ocorreu a aprovação de dois protocolos de cooperação técnica nas áreas do cadastramento (Cadastro Sincronizado) e Nota Fiscal Eletrônica (SEFAZ, 2011b).

Em fevereiro de 2005 a Secretaria da Fazenda do Estado de São Paulo iniciou um projeto com o propósito de substituir a nota fiscal em papel por um documento eletrônico com finalidade equivalente e com a mesma validade jurídica (SEFAZ, 2006b).

Em março de 2005, uma comitiva formada por profissionais do Rio Grande do Sul e de São Paulo foi ao Chile para conhecer o projeto da "Fatura Electrónica". Os representantes que participaram dessa visita consideraram esse momento um marco importante do projeto, pois o projeto brasileiro foi em grande parte baseado no modelo chileno (JUNQUEIRA, 2007, p. 108).

Em 27 de abril de 2005, em São Paulo, SP, foi realizada uma Reunião Técnica do ENAT/ENCAT, com o propósito de unificar os diferentes projetos em andamento no âmbito das Administrações Tributárias e alinhar as diretrizes do projeto, iniciado pelo ENAT, com o fórum de discussão dos Coordenadores e Administradores Tributários Estaduais - ENCAT (SEFAZ, 2011b).

A opção por um modelo único de documento eletrônico com validade nacional influenciou a Receita Federal que iniciava um projeto de escrituração digital denominado Sistema Público de Escrituração Digital (SPED), composto de três subprojetos: escrituração contábil, escrituração fiscal e a nota fiscal eletrônica. Em razão da influência do projeto de nota fiscal eletrônica, a Receita Federal inverteu a ordem dos subprojetos do SPED e a nota fiscal eletrônica que deveria ser a última passou a ser a primeira (SEFAZ, 2006b). 
Durante a Reunião Técnica do ENAT/ENCAT, foram definidas algumas das principais diretrizes do projeto, que permaneceram até sua implantação: uso da Extensible Markup Language (XML) e de certificação digital, envio de arquivo para a Secretaria da Fazenda da jurisdição do emissor da nota fiscal antes da circulação da mercadoria, bem como a validade jurídica do arquivo digital (JUNQUEIRA, 2007, p.109).

A justificativa do projeto está relacionada a benefícios tanto para os contribuintes quanto para a Administração Tributária. Para os contribuintes, o projeto da NF-e colaborou na redução dos seguintes custos (SEFAZ, 2006b):

- Custo de emissão de notas fiscais, incluindo o custo de aquisição do talonário, papel carbono, tinta para impressão e custo de mão de obra para manusear talões e notas;

- Custo de armazenamento das notas fiscais, inclusive a guarda dos documentos fiscais pelo período mínimo de cinco anos;

- Custo de digitar novamente as informações constantes nos documentos fiscais, com a possibilidade de ocorrência de erros humanos;

- Custos devido ao tempo de parada de caminhões nos postos de fronteira para digitação das notas fiscais.

Além dos benefícios para os contribuintes, havia benefícios para as Administrações Tributárias, que passariam a superar as seguintes dificuldades (SEFAZ, 2006b):

- Impossibilidade de acompanhar as operações comerciais em tempo real, pois a Administração Tributária era informada da emissão das notas somente a posteriori;

- Foco reativo e, consequentemente, repressivo da atuação da Administração Tributária, como consequência do processo de emissão dos documentos fiscais;

- Conferência manual das notas fiscais;

- Dificuldade de cruzamento das informações;

- Dificuldade de compartilhamento das informações entre as diferentes Administrações Tributárias.

De abril a julho de 2005 foram realizadas novas reuniões técnicas, com o objetivo de detalhar o modelo conceitual, e em agosto de 2005 foi realizado o II ENAT, no qual as administrações 
tributárias se comprometeram a seguir as seguintes diretrizes no projeto NF-e (JUNQUEIRA, 2007, p. 109, 110):

- Substituir as notas fiscais em papel por documentos eletrônicos;

- Os documentos digitais deveriam ter validade jurídica;

- A NF-e deveria ser padronizada nacionalmente;

- Deveria ocorrer uma interferência mínima do ambiente operacional do contribuinte;

- As NF-es deveriam ser compartilhadas entre as administrações tributárias;

- Preservação do sigilo fiscal, conforme já previsto no Código Tributário Nacional $(\mathrm{CTN})$.

O projeto da NF-e na Secretaria da Fazenda do Estado de São Paulo foi conduzido no âmbito do Programa de Fortalecimento da Gestão Fiscal do Estado de São Paulo - PROFFIS, com financiamento a partir de recursos do Tesouro e do Banco Interamericano de Desenvolvimento (BID), e é considerado um projeto estratégico pelo Governo do Estado (SEFAZ, 2006b).

Durante o PROFFIS, a gestão do programa estava a cargo da Unidade de Execução de Programa (UEP), órgão ligado à Coordenadoria de Planejamento Estratégico e Modernização Fazendária (CPM). Especificamente para os projetos da Coordenadoria da Administração Tributária (CAT), a gestão era feita pelo Coordenador do Programa, que tinha como suporte uma unidade de apoio denominada Unidade de Controle de Programa (UCP) (JUNQUEIRA, 2007, p.106).

O projeto da NF-e foi iniciado oficialmente em fevereiro de 2005 , e o investimento inicial da Secretaria da Fazenda de São Paulo na implantação da NF-e, considerando-se a aquisição de infraestrutura para recepção das notas fiscais e desenvolvimento do sistema, foi estimado em 15 milhões de reais (SEFAZ, 2006b).

No âmbito da Secretaria da Fazenda do Estado de São Paulo, foi montada uma equipe de 25 pessoas, composta de representantes das diretorias envolvidas e alguns membros convidados pelo líder do projeto. A meta inicialmente solicitada pelo Secretário da Fazenda era implantar o sistema no início do segundo semestre de 2005, mas a própria equipe considerava essa meta não realista (JUNQUEIRA, 2007, p. 124). 
O projeto da NF-e teve diversas atividades preparatórias antes de chegar à fase préoperacional, também chamada de piloto. Entre abril e julho de 2005, por exemplo, ocorreu a definição do modelo operacional da NF-e para operação em âmbito nacional. Além disso, após a definição do modelo, foram executadas diversas atividades com o propósito de oficializar as decisões técnicas tomadas pelos especialistas (área de negócio) das Administrações Tributárias (SEFAZ, 2006b). O Quadro 41 contém a lista dessas atividades.

Quadro 41: Atividades preparatórias do projeto NF-e

\begin{tabular}{|c|c|c|}
\hline Data & Atividade & Descrição \\
\hline $\begin{array}{l}\text { Abril a julho de } \\
2005\end{array}$ & $\begin{array}{l}\text { Definição do modelo } \\
\text { operacional da NF-e. }\end{array}$ & \\
\hline Agosto de 2005 & $\begin{array}{lr}\text { Aprovação } & \text { do } \\
\text { protocolo } & \text { ENAT } \\
03 / 2005 & \end{array}$ & $\begin{array}{l}\text { Todos os estados, Receita Federal e representantes da Associação } \\
\text { Brasileira dos Secretários de Finanças dos Municípios das Capitais } \\
\text { (ABRASF) assinam o protocolo, viabilizando o projeto em âmbito } \\
\text { nacional e atribuindo sua coordenação ao ENCAT. }\end{array}$ \\
\hline $\begin{array}{l}\text { Setembro de } \\
2005\end{array}$ & $\begin{array}{l}\text { Aprovação do ajuste } \\
\text { SINIEF 07/2005. }\end{array}$ & $\begin{array}{l}\text { Implantação da NF-e e do Documento Auxiliar da NF-e (DANFE) } \\
\text { na legislação nacional por meio do Sistema Nacional de } \\
\text { Informações Econômicas e Fiscais - SINIEF. }\end{array}$ \\
\hline $\begin{array}{l}\text { Dezembro de } \\
2005\end{array}$ & $\begin{array}{l}\text { Aprovação do Ato } \\
\text { COTEPE 72/2005. }\end{array}$ & $\begin{array}{l}\text { Formalização das definições técnicas do projeto por meio da } \\
\text { Comissão Técnica Permanente do Imposto sobre Operações } \\
\text { Relativas à Circulação de Mercadorias e sobre Prestações de } \\
\text { Serviços de Transporte Interestadual e Intermunicipal e de } \\
\text { Comunicação-COTEPE. }\end{array}$ \\
\hline
\end{tabular}

Fonte: elaborado pelo autor a partir de dados da SEFAZ (2006a)

Em julho de 2005 foi feita uma apresentação em São Paulo para 42 empresas, escolhidas por meio de critérios tais como representatividade no segmento, alto volume de arrecadação, bom relacionamento com a Secretaria da Fazenda e grande quantidade de operações. Dessas empresas, 19 entraram com pedido de credenciamento para a fase piloto do projeto e em outubro de 2005 foi realizada a primeira reunião de trabalho com elas (JUNQUEIRA, 2007, p. 112).

Um ponto importante do projeto foi o grande investimento no modelo conceitual antes de dar início à parte de TI do projeto. Um dos desenvolvedores envolvidos no projeto explicou que:

"Na verdade, o que aconteceu, a documentação dele demorou quase dois anos para.,. Em reuniões em Brasília com representantes de todos os estados, para chegar a ficar madura. Quando ela veio para a gente, ela veio muito redonda." 


\subsection{Primeira Fase do Projeto NF-e: Piloto (Fase Pré-operacional)}

O projeto piloto nacional, denominado fase pré-operacional, foi iniciado com a participação de seis estados: São Paulo, Bahia, Rio Grande do Sul, Maranhão, Goiás e Santa Catarina. Além disso, participaram também a Superintendência da Zona Franca de Manaus (SUFRAMA), a Receita Federal e a Coordenação Nacional do ENCAT (SEFAZ, 2006b).

A primeira versão do sistema NF-e no Estado de São Paulo foi desenvolvida pela Diretoria de Informações (DI) da Coordenadoria da Administração Tributária (CAT), com a participação da Companhia de Processamento de Dados do Estado de São Paulo (Prodesp), usando a tecnologia Java e o Banco de Dados Oracle, ambos baseados em servidores Linux. Foi usada também a tecnologia Real Application Clusters (RAC) da Oracle, por meio da qual dois ou mais computadores podem fazer acessos simultâneos a uma base de dados única.

O início da construção (desenvolvimento) do sistema ocorreu em janeiro de 2006. Antes disso, já havia sido realizado trabalho de infraestrutura e concepção inicial da parte técnica, por intermédio da elaboração dos documentos de casos de uso com a especificação das funcionalidades. A elaboração dos casos de uso era de responsabilidade da DI, na qual havia uma pessoa dedicada ao projeto. A construção de documentos, programas de computador e cronogramas ficou a cargo da Prodesp. O Departamento de Tecnologia da Informação era responsável pela infraestrutura (SEFAZ, 2006c apud JUNQUEIRA, 2007, p. 126).

Convém apresentar o organograma da Secretaria da Fazenda à época do projeto, restrito às diretorias envolvidas com o Projeto NF-e, juntamente com a Prodesp, conforme a Ilustração 7. 


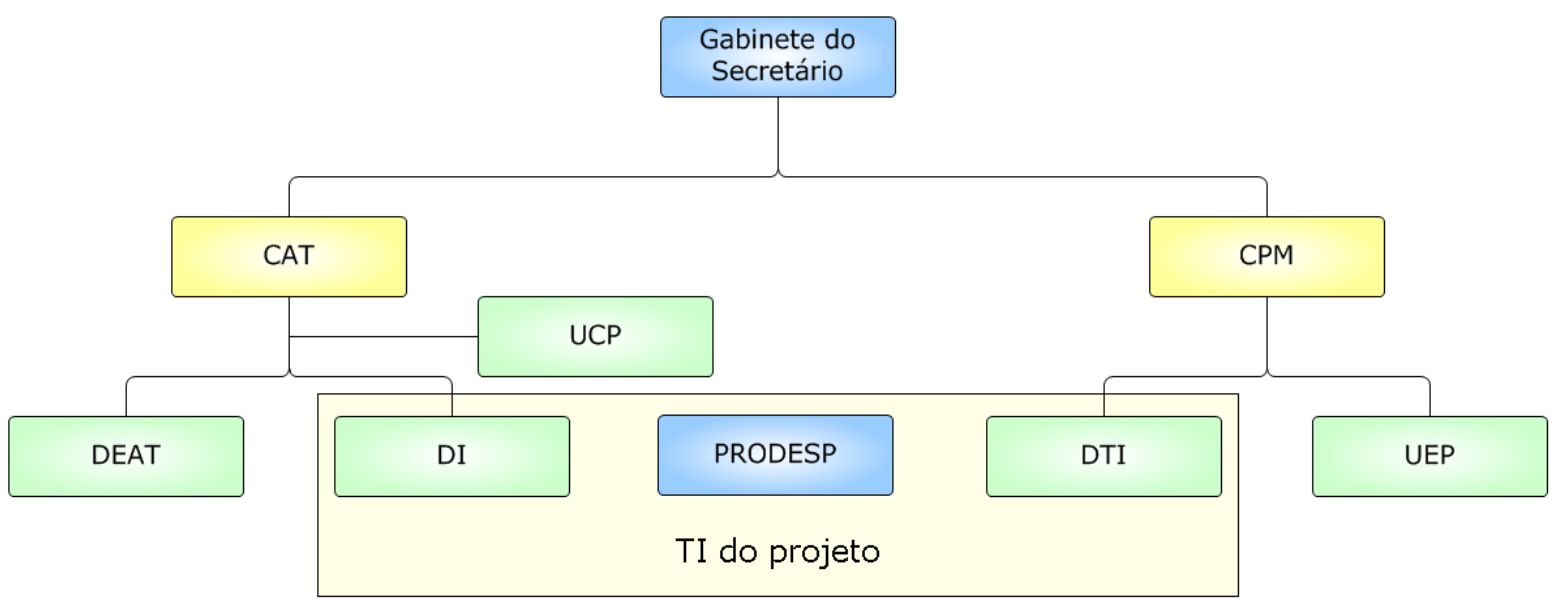

Ilustração 7: Organograma das áreas da Secretaria da Fazenda envolvidas no Projeto NF-e Fonte: elaborada pelo autor

Segundo Junqueira (2007, p. 127), a metodologia de desenvolvimento de sistemas usada no projeto foi baseada no Processo Unificado (JACOBSON; BOOBK; RUMBAUGH, 1999). Além disso, o projeto foi dividido em três fases principais:

- Primeira fase: 9 casos de uso e foco nas atividades necessárias para o desenvolvimento da fase pré-operacional;

- Segunda fase: 14 casos de uso e foco nas funcionalidades complementares, necessárias para que o sistema pudesse ser implantado no ambiente de produção;

- Terceira fase: 8 casos de uso, contemplando as demais funcionalidades do sistema.

A capacidade de recepção das notas fiscais eletrônicas foi prevista para ser incrementada da seguinte forma (SEFAZ, 2006b):

- Primeiro semestre de 2006: recepção de 340 mil notas fiscais por mês;

- Segundo semestre de 2006: recepção de 3 milhões de notas fiscais por mês;

- Primeiro semestre de 2007: recepção de 10 milhões de notas fiscais por mês;

- Segundo semestre de 2007: recepção de 30 milhões de notas fiscais por mês (equivalente a $50 \%$ do total de notas fiscais modelo "1/1 A" emitidas por mês em São Paulo).

O início do recebimento das notas fiscais eletrônicas, ainda sem validade jurídica e de forma paralela à emissão das notas fiscais em papel, ocorreu a partir de 3 de abril de 2006 (JUNQUEIRA, 2007, p. 127). O início em produção (com validade jurídica) ocorreu em 15 de 
setembro de 2006, com as empresas Wickbold e Volkswagen, que emitiram no primeiro mês 3.954 notas fiscais eletrônicas (SEFAZ, 2006a).

Uma semana após a entrada em produção do sistema, foi publicada uma portaria para o credenciamento de novas empresas, dando-se início à segunda fase do projeto. Nessa fase, foram escolhidas mais 50 empresas para participar do processo, para se tornarem emissoras efetivas a partir de abril de 2007 (JUNQUEIRA, 2007, p. 127).

\subsection{Segunda Fase do Projeto NF-e: Operacional}

Durante a segunda fase do projeto, a solução desenvolvida na plataforma Java/Oracle começou a apresentar problemas de desempenho. Um dos responsáveis pelo desenvolvimento da solução da NF-e que está em operação atualmente explicou que:

“A DI juntamente com a Prodesp tinham desenvolvido um sistema em Java e esse sistema não era escalável. Estava em uma fase de piloto, ainda só com cinquenta empresas e o sistema já apresentava sinais... sinais de problemas de performance... Com esse número reduzido.”

Em razão dos problemas de desempenho que o sistema desenvolvido na plataforma Java/Oracle apresentava, foi necessária uma reformulação na parte tecnológica. Nessa época, algumas alternativas foram avaliadas e a Secretaria da Fazenda optou por reformular o sistema. As entrevistas com pessoas envolvidas na área de desenvolvimento e infraestrutura do projeto fornecem uma explicação sobre as decisões tomadas:

"Entre gastar tempo, dinheiro e esforço tentando corrigir isso em Java... é... Ou criar um sistema novo, já com uma filosofia e tal, que seria uma solução definitiva, eles optaram por essa segunda opção.”

“A gente conversou com a DEAT, explicou qual era o direcionamento, então a DI não ia mais investir tempo e dinheiro naquele sistema e ia fazer um sistema novo."

"Na verdade, tinha uma tentativa em Oracle com Java, que não chegou a decolar. Não chegou a escalar. Ficou presa no período de cinquenta empresas só. E... e que sofreu uma mudança de tecnologia. Ele mudou para Dot Net com SQL Server. Por quê? Foi uma coisa muito pontual no momento. Java é uma excelente linguagem. Oracle é um excelente gerenciador de banco de dados, mas a mão de obra que trabalhava não era capacitada o suficiente e a gente, que tinha mão de obra boa, bem qualificada, a 
gente tinha se especializado em Dot Net com SQL. Então o que definiu a mudança foi mais o material humano do que outra coisa."

“Com essa equipe de desenvolvimento, com esse nosso... essa nossa pouca experiência em ambiente RAC. Nós tivemos alguns tropeços no começo. Mas a solução tecnológica, ela era muito forte. Muito boa. Eu acho que... Muitas vezes, o que faltou foi um apoio maior do fornecedor. Não só na questão do... Do processo de banco de dados, de arquitetura. Porque arquitetura teoricamente era muito simples. O que foi implementado no mundo SQL Server que vive hoje a nota fiscal eletrônica é exatamente o que foi implementado no Oracle naquela época."

O sucesso do projeto sob o ponto de vista técnico deveu-se também a um arquiteto talentoso, o que está alinhado às conclusões de Curtis, Krasner e Iscoe (1988), que atribuem o sucesso em projetos grandes ao trabalho de um grande arquiteto/designer. O projeto foi conduzido na parte de desenvolvimento por apenas duas pessoas: um arquiteto/desenvolvedor e um desenvolvedor. O profissional que atuou apenas com desenvolvimento explicou:

\footnotetext{
"Porque ele deu a solução e eu fui ajudando ele na parte braçal. Quer dizer, se não tivesse o [nome do arquiteto], eu não sei com é que sairia. Eu te digo por quê. Antes disso, foi feita uma consulta à Prodesp. Para ela... Se ela poderia fazer em Dot Net e SQL Server. A proposta da Prodesp foi três equipes de seis pessoas, quer dizer, dezoito pessoas trabalhando por seis meses para poder fazer. Simplesmente, a gente não tinha esse time e tinha um mês para fazer isso."
}

Complementarmente, ao comentar com o entrevistado da área de negócio a respeito da existência de um competente arquiteto atuando com a TI, o entrevistado comentou que existiu também um profissional excepcional atuando com a equipe de negócio, que foi o responsável pela elaboração das últimas versões do manual de integração do contribuinte (ENCAT, 2006) e simplificou a complexidade inerente ao projeto.

Em relação à estratégia evolutiva, o projeto foi gerenciado não apenas como um projeto de TI, mas incluindo uma evolução gradual dos setores da economia que eram obrigados a usar a nota fiscal em formato eletrônico.

Junqueira (2007, p. 130) explicou o papel positivo que os aspectos políticos tiveram sobre o projeto, argumentando que a grande exposição na mídia viabilizou um círculo virtuoso de apoio institucional e priorização, que contribuíram para a superação dos obstáculos em razão do apoio dos altos executivos políticos. 
A versão do projeto construída em Dot Net, denominada versão 1.0, foi implantada em produção em 2007 para substituir a versão em Oracle, e posteriormente foi evoluindo até a versão 1.10. A versão 2.0 da NF-e, também desenvolvida na plataforma Dot Net, mas totalmente reconstruída, entrou em produção em abril de 2011.

\subsection{Análise dos Fatores de Risco do Projeto NF-e}

O primeiro aspecto a ser considerado na análise dos fatores de risco do projeto NF-e está relacionado ao fato de que ele não chegou à condição de agravamento e que o risco relacionado ao desempenho, que se manifestou no início da fase operacional, foi superado com a reformulação do sistema realizada por meio da mudança de plataforma tecnológica.

O sucesso do projeto NF-e no Estado de São Paulo foi avaliado em outra pesquisa, onde Junqueira (2007, p. 186) enumera os fatores de sucesso, obtidos a partir de entrevistas com atores relevantes do projeto:

- Apoio da alta administração;

- Relacionamento de confiança;

- Envolvimento das empresas (contribuintes);

- Capacidade das equipes;

- Escopo bem definido e viável;

- Utilização de padrões abertos.

A partir dessa constatação do sucesso do projeto, a análise de seus fatores de risco foi realizada considerando-se a classificação do modelo de referência, composta de 15 fatores. Em relação às entrevistas, os profissionais das áreas técnicas consideraram o escopo estável e a complexidade baixa, enquanto o profissional da área de negócio explicou que existia alguma complexidade, que foi simplificada pela atuação da equipe de negócio.

Um dos entrevistados citou a falta de apoio do fornecedor do Sistema Gerenciador de Banco de Dados como um fator de risco, que foi solucionado pela mudança de plataforma e o consequente apoio do novo fornecedor. 
Em relação ao prazo, todos os entrevistados consideraram que o prazo foi muito mais técnico do que político. O depoimento de um dos entrevistados esclarece a natureza dos prazos do projeto NF-e:

"Os projetos da NF-e, como envolvem todas as UFs, eles têm os prazos factíveis justamente porque o sistema novo tem que entrar no ar pra todo mundo no mesmo dia, então não chega a ser um risco, não.”

Um dos entrevistados explicou que o único prazo político ocorreu na transição da plataforma tecnológica Oracle para Dot Net e SQL Server, quando foi necessário provar, em um prazo curto, que a nova plataforma era adequada. O sucesso da prova de conceito, dentro de um prazo politicamente curto, viabilizou uma economia aos cofres públicos referente ao que não se precisaria gastar para comprar as licenças de uso dos softwares da Oracle.

Em relação ao questionário, os Quadros 42 e 43 apresentam os fatores de riscos consolidados, referentes ao quadrante do mandato do cliente da classificação de Keil et al. (1998).

\section{Quadro 42: Riscos consolidados do mandato do cliente no projeto NF-e}

\begin{tabular}{|c|c|c|c|c|}
\hline \multirow{2}{*}{ Risco Consolidado } & \multicolumn{4}{|c|}{ Entrevistados } \\
\hline & 1 & 2 & 3 & 4 \\
\hline Falta de participação do usuário (consolidado - valores médios). & 1,7 & 3,7 & 1,0 & 1,0 \\
\hline Falta de participação do usuário. & 2,0 & 4,0 & 1,0 & 1,0 \\
\hline Usuários não comprometidos com o projeto. & 1,0 & 4,0 & 1,0 & 1,0 \\
\hline Falta de cooperação dos usuários. & 2,0 & 3,0 & 1,0 & 1,0 \\
\hline $\begin{array}{l}\text { Usuários com atitudes negativas em relação ao projeto (consolidado - valores } \\
\text { médios). }\end{array}$ & 2,0 & 4,3 & 1,0 & 1,0 \\
\hline Usuários com atitudes negativas em relação ao projeto. & 3,0 & 6,0 & 1,0 & 1,0 \\
\hline Usuários resistentes a mudanças. & 1,0 & 6,0 & 1,0 & 1,0 \\
\hline Conflitos entre os usuários. & 2,0 & 1,0 & 1,0 & 1,0 \\
\hline Falta de apoio da alta direção ao projeto. & 2,0 & 1,0 & 1,0 & 1,0 \\
\hline $\begin{array}{l}\text { Falta de comprometimento ou pouco comprometimento da organização com o } \\
\text { projeto. }\end{array}$ & 1,0 & 1,0 & 1,0 & 1,0 \\
\hline
\end{tabular}


Quadro 43: Médias dos riscos consolidados do mandato do cliente no projeto NF-e

\begin{tabular}{|c|c|c|c|}
\hline Risco Consolidado & Média & $\begin{array}{l}\text { Maior } \\
\text { Valor }\end{array}$ & $\begin{array}{l}\text { Menor } \\
\text { Valor }\end{array}$ \\
\hline $\begin{array}{l}\text { Falta de participação do usuário (consolidado - valores } \\
\text { médios). }\end{array}$ & 1,8 & 3,7 & 1,0 \\
\hline Falta de participação do usuário. & 2,0 & 4,0 & 1,0 \\
\hline Usuários não comprometidos com o projeto. & 1,8 & 4,0 & 1,0 \\
\hline Falta de cooperação dos usuários. & 1,8 & 3,0 & 1,0 \\
\hline $\begin{array}{l}\text { Usuários com atitudes negativas em relação ao projeto } \\
\text { (consolidado - valores médios). }\end{array}$ & 2,1 & 4,3 & 1,0 \\
\hline Usuários com atitudes negativas em relação ao projeto. & 2,8 & 6,0 & 1,0 \\
\hline Usuários resistentes a mudanças. & 2,3 & 6,0 & 1,0 \\
\hline Conflitos entre os usuários. & 1,3 & 2,0 & 1,0 \\
\hline Falta de apoio da alta direção ao projeto. & 1,3 & 2,0 & 1,0 \\
\hline $\begin{array}{l}\text { Falta de comprometimento ou pouco comprometimento da } \\
\text { organização com o projeto. }\end{array}$ & 1,0 & 1,0 & 1,0 \\
\hline
\end{tabular}

Fonte: elaborado pelo autor

No caso dos riscos do mandato do cliente, os dados obtidos por meio do questionário estão alinhados com as respostas obtidas por meio das entrevistas, ou seja, os riscos relacionados ao mandato do cliente não foram significativos para que o projeto entrasse em situação de agravamento.

Ocorreu uma variação maior nos riscos relacionados à falta de participação dos usuários e usuários com atitudes negativas em relação ao projeto. $\mathrm{O}$ entrevistado que atribuiu maior risco a esses fatores explicou que sua análise contemplou tanto os usuários da Secretaria da Fazenda quanto as empresas/contribuintes. A pesquisa de Junqueira (2007, p. 112) explica que existia uma preocupação inicial das empresas com relação às intenções dos órgãos fazendários.

Em relação aos riscos de escopo e requisitos da classificação de Keil et al. (1998), os Quadros 44 e 45 apresentam os fatores consolidados de acordo com o modelo de referência. 
Quadro 44: Riscos consolidados de escopo e requisitos no projeto NF-e

\begin{tabular}{|c|c|c|c|c|}
\hline \multirow{2}{*}{ Risco Consolidado } & \multicolumn{4}{|c|}{ Entrevistados } \\
\hline & 1 & 2 & 3 & 4 \\
\hline $\begin{array}{l}\text { Dificuldades no detalhamento e estabilização dos requisitos (consolidado - valores } \\
\text { médios). }\end{array}$ & 3,8 & 1,3 & 1,0 & 2,0 \\
\hline Requisitos de sistema que mudam frequentemente; & 4,0 & 1,0 & 1,0 & 3,0 \\
\hline Requisitos do sistema identificados de forma inadequada; & 4,0 & 2,0 & 1,0 & 1,0 \\
\hline Requisitos de sistema obscuros (não claros); & NA & 1,0 & 1,0 & 1,0 \\
\hline Requisitos de sistema incorretos; & 4,0 & 1,0 & 1,0 & 3,0 \\
\hline Requisitos de sistema conflitantes; & NA & 2,0 & 1,0 & 3,0 \\
\hline Dificuldade em definir entradas e saídas do sistema. & 3,0 & 1,0 & 1,0 & 1,0 \\
\hline Problemas no direcionamento do projeto (consolidado - valores médios). & 2,7 & 1,0 & 1,0 & 1,3 \\
\hline Critério de sucesso do projeto indefinido; & 3,0 & 1,0 & 1,0 & 1,0 \\
\hline Metas do projeto mal definidas; & 4,0 & 1,0 & 1,0 & 2,0 \\
\hline Objetivos e escopo do projeto que mudam frequentemente. & 1,0 & 1,0 & 1,0 & 1,0 \\
\hline Falta de entendimento pelos usuários sobre as capacidades e limitações do sistema. & 4,0 & 3,0 & 1,0 & 2,0 \\
\hline
\end{tabular}

Fonte: elaborado pelo autor

Quadro 45: Médias dos riscos consolidados de escopo e requisitos no projeto NF-e

\begin{tabular}{|c|c|c|c|}
\hline Risco Consolidado & Média & $\begin{array}{l}\text { Maior } \\
\text { Valor }\end{array}$ & $\begin{array}{l}\text { Menor } \\
\text { Valor }\end{array}$ \\
\hline $\begin{array}{l}\text { Dificuldades no detalhamento e estabilização dos requisitos } \\
\text { (consolidado - valores médios). }\end{array}$ & 1,8 & 3,8 & 1,0 \\
\hline Requisitos de sistema que mudam frequentemente; & 2,3 & 4,0 & 1,0 \\
\hline $\begin{array}{l}\text { Requisitos do sistema identificados de forma } \\
\text { inadequada; }\end{array}$ & 2,0 & 4,0 & 1,0 \\
\hline Requisitos de sistema obscuros (não claros); & 1,0 & 1,0 & 1,0 \\
\hline Requisitos de sistema incorretos; & 2,3 & 4,0 & 1,0 \\
\hline Requisitos de sistema conflitantes; & 2,0 & 3,0 & 1,0 \\
\hline Dificuldade em definir entradas e saídas do sistema. & 1,5 & 3,0 & 1,0 \\
\hline $\begin{array}{l}\text { Problemas no direcionamento do projeto (consolidado - } \\
\text { valores médios). }\end{array}$ & 1,5 & 2,7 & 1,0 \\
\hline Critério de sucesso do projeto indefinido; & 1,5 & 3,0 & 1,0 \\
\hline Metas do projeto mal definidas; & 2,0 & 4,0 & 1,0 \\
\hline $\begin{array}{l}\text { Objetivos e escopo do projeto que mudam } \\
\text { frequentemente. }\end{array}$ & 1,0 & 1,0 & 1,0 \\
\hline $\begin{array}{l}\text { Falta de entendimento pelos usuários sobre as capacidades e } \\
\text { limitações do sistema. }\end{array}$ & 2,5 & 4,0 & 1,0 \\
\hline
\end{tabular}

Fonte: elaborado pelo autor

No caso dos riscos de escopo e requisitos, os dados obtidos por meio do questionário estão alinhados com as respostas obtidas por meio das entrevistas. Conforme os depoimentos, o período de aproximadamente dois anos de especificação resultou em um conjunto relativamente estável de requisitos, e as poucas mudanças, como, por exemplo, as alterações em leiautes de arquivos, foram tratadas de forma satisfatória pela equipe técnica, conforme explicado no depoimento abaixo: 
“O que mudava de uma versão e a outra desse sistema eram os schemas do XML. Os schemas novos vinham com informações novas. E do jeito que o [nome do arquiteto/designer] projetou a solução... A solução, ela podia conviver com vários schemas diferentes. Até com data de validade para determinado schema."

Quanto aos riscos de execução da classificação de Keil et al. (1998), os Quadros 46 e 47 apresentam os fatores de risco do projeto NF-e consolidados segundo o modelo de referência.

Quadro 46: Riscos consolidados de execução no projeto NF-e

\begin{tabular}{|c|c|c|c|c|}
\hline \multirow{2}{*}{ Risco Consolidado } & \multicolumn{4}{|c|}{ Entrevistados } \\
\hline & 1 & 2 & 3 & 4 \\
\hline Dificuldades técnicas (consolidado - valores médios). & 4,3 & 3,3 & 1,1 & 3,3 \\
\hline Membros da equipe inexperientes. & 5,0 & 3,0 & 1,0 & 3,0 \\
\hline $\begin{array}{l}\text { Equipe de desenvolvimento sem familiaridade com as ferramentas de } \\
\text { desenvolvimento. }\end{array}$ & 4,0 & 3,0 & 1,0 & 2,0 \\
\hline $\begin{array}{l}\text { Equipe de desenvolvimento sem familiaridade com as tarefas a serem } \\
\text { automatizadas. }\end{array}$ & 5,0 & 3,0 & 1,0 & 1,0 \\
\hline $\begin{array}{l}\text { Faltam nos membros da equipe as habilidades especializadas requeridas } \\
\text { pelo projeto. }\end{array}$ & 4,0 & 3,0 & 2,0 & 1,0 \\
\hline O projeto envolve o uso de uma tecnologia nova. & 4,0 & 4,0 & 1,0 & 5,0 \\
\hline Tecnologia imatura. & 3,0 & 4,0 & 1,0 & 4,0 \\
\hline $\begin{array}{l}\text { O projeto envolve o uso de uma tecnologia que não foi usada em projetos } \\
\text { anteriores. }\end{array}$ & 5,0 & 3,0 & 1,0 & 7,0 \\
\hline Complexidade do sistema e organizacional (consolidado - valores médios). & 3,0 & 3,8 & 3,4 & 4,6 \\
\hline Alto nível de complexidade técnica. & 3,0 & 2,0 & 1,0 & 6,0 \\
\hline A tarefa a ser automatizada é altamente complexa. & 4,0 & 1,0 & 1,0 & 4,0 \\
\hline $\begin{array}{l}\text { O projeto afeta um grande número de unidades e/ou departamentos dos } \\
\text { usuários. }\end{array}$ & 2,0 & 7,0 & 1,0 & 4,0 \\
\hline Ser um dos maiores projetos já empreendidos pela organização. & 4,0 & 6,0 & 7,0 & 5,0 \\
\hline Necessidade de integração com um grande número de sistemas. & 2,0 & 3,0 & 7,0 & 4,0 \\
\hline Problemas na gestão do projeto (consolidado - valores médios). & 3,3 & 2,1 & 1,4 & 1,3 \\
\hline Falta de uma metodologia efetiva de gerenciamento de projetos. & 4,0 & 1,0 & 4,0 & 1,0 \\
\hline Estimativa inadequada do cronograma do projeto. & 4,0 & 2,0 & 1,0 & 2,0 \\
\hline Prazo político. & 3,0 & 2,0 & 1,0 & 1,0 \\
\hline Progresso do projeto não monitorado suficientemente de perto. & 4,0 & 1,0 & 1,0 & 1,0 \\
\hline Planejamento precário do projeto. & 2,0 & 2,0 & 1,0 & 1,0 \\
\hline Marcos do projeto não definidos de forma clara. & 3,0 & 2,0 & 1,0 & 1,0 \\
\hline Estimativa inadequada do orçamento do projeto. & 1,0 & 4,0 & 1,0 & 1,0 \\
\hline Gerente do projeto não efetivo. & 4,0 & 4,0 & NA & 1,0 \\
\hline Gerente do projeto inexperiente. & 5,0 & 2,0 & NA & 1,0 \\
\hline Comunicação não efetiva. & 3,0 & 1,0 & 1,0 & 3,0 \\
\hline Problemas na gestão da equipe (consolidado - valores médios). & 3,4 & 1,9 & 1,0 & 1,6 \\
\hline Membros da equipe de desenvolvimento treinados de forma inadequada. & 4,0 & 1,0 & 1,0 & 3,0 \\
\hline Falta de comprometimento com o projeto por parte dos membros da equipe. & 2,0 & 1,0 & 1,0 & 1,0 \\
\hline Conflitos frequentes na equipe de desenvolvimento. & 3,0 & 1,0 & 1,0 & 1,0 \\
\hline Rotatividade frequente dos membros da equipe. & 3,0 & 3,0 & 1,0 & 2,0 \\
\hline Atitudes negativas da equipe de desenvolvimento. & 2,0 & 1,0 & 1,0 & 2,0 \\
\hline Faltam habilidades de liderança do projeto nas pessoas envolvidas. & 5,0 & 3,0 & 1,0 & 1,0 \\
\hline Estimativa inadequada dos recursos necessários. & 5,0 & 3,0 & 1,0 & 1,0 \\
\hline
\end{tabular}

Fonte: elaborado pelo autor 
Quadro 47: Médias dos riscos consolidados de execução no projeto NF-e

\begin{tabular}{|c|c|c|c|}
\hline Risco Consolidado & Média & $\begin{array}{l}\text { Maior } \\
\text { Valor }\end{array}$ & $\begin{array}{l}\text { Menor } \\
\text { Valor }\end{array}$ \\
\hline Dificuldades técnicas (consolidado - valores médios). & 3,0 & 4,3 & 1,1 \\
\hline Membros da equipe inexperientes. & 3,0 & 5,0 & 1,0 \\
\hline $\begin{array}{l}\text { Equipe de desenvolvimento sem familiaridade com as } \\
\text { ferramentas de desenvolvimento. }\end{array}$ & 2,5 & 4,0 & 1,0 \\
\hline $\begin{array}{l}\text { Equipe de desenvolvimento sem familiaridade com as } \\
\text { tarefas a serem automatizadas. }\end{array}$ & 2,5 & 5,0 & 1,0 \\
\hline $\begin{array}{l}\text { Faltam nos membros da equipe as habilidades } \\
\text { especializadas requeridas pelo projeto. }\end{array}$ & 2,5 & 4,0 & 1,0 \\
\hline O projeto envolve o uso de uma tecnologia nova. & 3,5 & 5,0 & 1,0 \\
\hline Tecnologia imatura. & 3,0 & 4,0 & 1,0 \\
\hline $\begin{array}{l}\text { O projeto envolve o uso de uma tecnologia que não foi } \\
\text { usada em projetos anteriores. }\end{array}$ & 4,0 & 7,0 & 1,0 \\
\hline $\begin{array}{l}\text { Complexidade do sistema e organizacional (consolidado - } \\
\text { valores médios). }\end{array}$ & 3,7 & 4,6 & 3,0 \\
\hline Alto nível de complexidade técnica. & 3,0 & 6,0 & 1,0 \\
\hline A tarefa a ser automatizada é altamente complexa. & 2,5 & 4,0 & 1,0 \\
\hline $\begin{array}{l}\text { O projeto afeta um grande número de unidades e/ou } \\
\text { departamentos dos usuários. }\end{array}$ & 3,5 & 7,0 & 1,0 \\
\hline $\begin{array}{l}\text { Ser um dos maiores projetos já empreendidos pela } \\
\text { organização. }\end{array}$ & 5,5 & 7,0 & 4,0 \\
\hline $\begin{array}{l}\text { Necessidade de integração com um grande número de } \\
\text { sistemas. }\end{array}$ & 4,0 & 7,0 & 2,0 \\
\hline $\begin{array}{l}\text { Problemas na gestão do projeto (consolidado - valores } \\
\text { médios). }\end{array}$ & 2,1 & 3,3 & 1,3 \\
\hline $\begin{array}{l}\text { Falta de uma metodologia efetiva de gerenciamento de } \\
\text { projetos. }\end{array}$ & 2,5 & 4,0 & 1,0 \\
\hline Estimativa inadequada do cronograma do projeto. & 2,3 & 4,0 & 1,0 \\
\hline Prazo político. & 1,8 & 3,0 & 1,0 \\
\hline $\begin{array}{l}\text { Progresso do projeto não monitorado suficientemente } \\
\text { de perto. }\end{array}$ & 1,8 & 4,0 & 1,0 \\
\hline Planejamento precário do projeto. & 1,5 & 2,0 & 1,0 \\
\hline Marcos do projeto não definidos de forma clara. & 1,8 & 3,0 & 1,0 \\
\hline Estimativa inadequada do orçamento do projeto. & 1,8 & 4,0 & 1,0 \\
\hline Gerente do projeto não efetivo. & 3,0 & 4,0 & 1,0 \\
\hline Gerente do projeto inexperiente. & 2,7 & 5,0 & 1,0 \\
\hline Comunicação não efetiva. & 2,0 & 3,0 & 1,0 \\
\hline $\begin{array}{l}\text { Problemas na gestão da equipe (consolidado - valores } \\
\text { médios). }\end{array}$ & 2,0 & 3,4 & 1,0 \\
\hline $\begin{array}{l}\text { Membros da equipe de desenvolvimento treinados de } \\
\text { forma inadequada. }\end{array}$ & 2,3 & 4,0 & 1,0 \\
\hline $\begin{array}{l}\text { Falta de comprometimento com o projeto por parte dos } \\
\text { membros da equipe. }\end{array}$ & 1,3 & 2,0 & 1,0 \\
\hline Conflitos frequentes na equipe de desenvolvimento. & 1,5 & 3,0 & 1,0 \\
\hline Rotatividade frequente dos membros da equipe. & 2,3 & 3,0 & 1,0 \\
\hline Atitudes negativas da equipe de desenvolvimento. & 1,5 & 2,0 & 1,0 \\
\hline $\begin{array}{l}\text { Faltam habilidades de liderança do projeto nas pessoas } \\
\text { envolvidas. }\end{array}$ & 2,5 & 5,0 & 1,0 \\
\hline Estimativa inadequada dos recursos necessários. & 2,5 & 5,0 & 1,0 \\
\hline
\end{tabular}

Fonte: elaborado pelo autor

Em relação aos riscos de complexidade do sistema e organizacional e problemas na gestão do projeto, os dados obtidos por meio do questionário estão alinhados com as entrevistas, no 
sentido de que existia certa complexidade no projeto (por isso a nota 3,7). Essa complexidade, no entanto, foi gerenciada satisfatoriamente pela equipe do projeto.

Entre os riscos relacionados às dificuldades técnicas, foram mencionados riscos na plataforma que foi substituída, e um dos entrevistados mencionou riscos relacionados ao uso das tecnologias de certificação digital e XML, que eram novidade na Secretaria da Fazenda em 2006. Entretanto, mesmo o entrevistado que mencionou esse risco explicou que ele foi bem gerenciado.

No caso da gestão do projeto, não existiu uma gestão formal do projeto sob o ponto de vista de TI. Os dois desenvolvedores precisavam atender à gestão do projeto corporativo. A parte técnica foi conduzida pelos dois desenvolvedores, sem a aplicação de qualquer metodologia de gestão de projetos e isso não teve impacto negativo no projeto.

Os Quadros 48 e 49 apresentam os fatores de riscos consolidados, referentes ao quadrante do ambiente da classificação de Keil et al. (1998).

Quadro 48: Riscos consolidados de ambiente no projeto NF-e

\begin{tabular}{|c|c|c|c|c|}
\hline \multirow{2}{*}{ Risco Consolidado } & \multicolumn{4}{|c|}{ Entrevistados } \\
\hline & 1 & 2 & 3 & 4 \\
\hline Ambiente organizacional instável (consolidado - valores médios). & 1,3 & 4,8 & 2,3 & 3,3 \\
\hline $\begin{array}{l}\text { Recursos deslocados do projeto em razão de mudanças nas prioridades da } \\
\text { organização. }\end{array}$ & 1,0 & 6,0 & 1,0 & 4,0 \\
\hline Ambiente organizacional instável. & 2,0 & 3,0 & 6,0 & 1,0 \\
\hline Mudança na gestão organizacional durante o projeto. & 1,0 & 6,0 & 1,0 & 4,0 \\
\hline Organização passando por uma reestruturação durante o projeto. & 1,0 & 4,0 & 1,0 & 4,0 \\
\hline Políticas corporativas com efeitos negativos no projeto. & 1,0 & 4,0 & 4,0 & 1,0 \\
\hline Estrutura ineficiente para a tomada de decisão. & 2,0 & 1,0 & 6,0 & 1,0 \\
\hline Problemas com fornecedores (consolidado - valores médios). & 4,0 & 1,0 & 1,0 & 1,0 \\
\hline Dependência de um fornecedor externo. & 5,0 & 1,0 & 1,0 & 1,0 \\
\hline Muitos fornecedores externos envolvidos no desenvolvimento do projeto. & 3,0 & 1,0 & 1,0 & 1,0 \\
\hline
\end{tabular}


Quadro 49: Médias dos riscos consolidados de ambiente no projeto NF-e

\begin{tabular}{|c|c|c|c|}
\hline Risco Consolidado & Média & $\begin{array}{l}\text { Maior } \\
\text { Valor }\end{array}$ & $\begin{array}{l}\text { Menor } \\
\text { Valor }\end{array}$ \\
\hline $\begin{array}{l}\text { Ambiente organizacional instável (consolidado }- \text { valores } \\
\text { médios). }\end{array}$ & 2,9 & 4,8 & 1,3 \\
\hline $\begin{array}{l}\text { Recursos deslocados do projeto em razão de mudanças } \\
\text { nas prioridades da organização. }\end{array}$ & 3,0 & 6,0 & 1,0 \\
\hline Ambiente organizacional instável. & 3,0 & 6,0 & 1,0 \\
\hline Mudança na gestão organizacional durante o projeto. & 3,0 & 6,0 & 1,0 \\
\hline $\begin{array}{l}\text { Organização passando por uma reestruturação durante } \\
\text { o projeto. }\end{array}$ & 2,5 & 4,0 & 1,0 \\
\hline Políticas corporativas com efeitos negativos no projeto. & 2,5 & 4,0 & 1,0 \\
\hline Estrutura ineficiente para a tomada de decisão. & 2,5 & 6,0 & 1,0 \\
\hline Problemas com fornecedores (consolidado - valores médios). & 1,8 & 4,0 & 1,0 \\
\hline Dependência de um fornecedor externo. & 2,0 & 5,0 & 1,0 \\
\hline 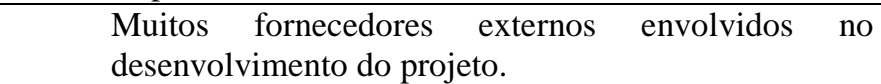 & 1,5 & 3,0 & 1,0 \\
\hline
\end{tabular}

Fonte: elaborado pelo autor

Novamente, os resultados do questionário estão alinhados com as entrevistas no caso dos riscos de ambiente, que foram pouco enfatizados nas entrevistas. Em relação aos problemas com fornecedores, eles ocorreram no início do projeto, mas foram resolvidos com a troca de plataforma tecnológica.

Complementarmente à análise dos riscos de acordo com o modelo de referência, é importante apresentar a análise referente aos modelos alternativos propostos. Os Quadros 50 e 51 apresentam os riscos associados a problemas na Governança de TI.

Quadro 50: Riscos de Governança de TI no projeto NF-e

\begin{tabular}{|c|c|c|c|c|}
\hline \multirow{2}{*}{ Risco } & \multicolumn{4}{|c|}{ Entrevistados } \\
\hline & 1 & 2 & 3 & 4 \\
\hline Falta de participação dos usuários. & 2,0 & 4,0 & 1,0 & 1,0 \\
\hline Conflitos entre os usuários. & 2,0 & 1,0 & 1,0 & 1,0 \\
\hline Falta de apoio da alta direção ao projeto. & 2,0 & 1,0 & 1,0 & 1,0 \\
\hline $\begin{array}{l}\text { Falta de comprometimento ou pouco comprometimento da organização com o } \\
\text { projeto. }\end{array}$ & 1,0 & 1,0 & 1,0 & 1,0 \\
\hline O projeto afeta um grande número de unidades e/ou departamentos dos usuários. & 2,0 & 7,0 & 1,0 & 4,0 \\
\hline Falta de uma metodologia efetiva de gerenciamento de projetos. & 4,0 & 1,0 & 4,0 & 1,0 \\
\hline Estrutura ineficiente para a tomada de decisão. & 2,0 & 1,0 & 6,0 & 1,0 \\
\hline Mudança na gestão organizacional durante o projeto. & 1,0 & 6,0 & 1,0 & 4,0 \\
\hline Políticas corporativas com efeitos negativos no projeto. & 1,0 & 4,0 & 4,0 & 1,0 \\
\hline Ambiente organizacional instável. & 2,0 & 3,0 & 6,0 & 1,0 \\
\hline Organização passando por uma reestruturação durante o projeto. & 1,0 & 4,0 & 1,0 & 4,0 \\
\hline
\end{tabular}


Quadro 51: Médias dos riscos de Governança de TI no projeto NF-e

\begin{tabular}{|l|r|r|r|}
\hline \multicolumn{1}{|c|}{ Risco } & \multicolumn{1}{|c|}{ Média } & \multicolumn{1}{c|}{$\begin{array}{c}\text { Maior } \\
\text { Valor }\end{array}$} & \multicolumn{1}{c|}{$\begin{array}{c}\text { Menor } \\
\text { Valor }\end{array}$} \\
\hline Falta de participação dos usuários. & 2,0 & 4,0 & 1,0 \\
\hline Conflitos entre os usuários. & 1,3 & 2,0 & 1,0 \\
\hline Falta de apoio da alta direção ao projeto. & 1,3 & 2,0 & 1,0 \\
\hline $\begin{array}{l}\text { Falta de comprometimento ou pouco comprometimento da } \\
\text { organização com o projeto. }\end{array}$ & 1,0 & 1,0 & 1,0 \\
\hline $\begin{array}{l}\text { O projeto afeta um grande número de unidades e/ou } \\
\text { departamentos dos usuários. }\end{array}$ & 3,5 & 7,0 & 1,0 \\
\hline $\begin{array}{l}\text { Falta de uma metodologia efetiva de gerenciamento de } \\
\text { projetos. }\end{array}$ & 2,5 & 4,0 & 1,0 \\
\hline Estrutura ineficiente para a tomada de decisão. & 2,5 & 6,0 & 1,0 \\
\hline Mudança na gestão organizacional durante o projeto. & 3,0 & 6,0 & 1,0 \\
\hline Políticas corporativas com efeitos negativos no projeto. & 2,5 & 4,0 & 1,0 \\
\hline Ambiente organizacional instável. & 3,0 & 6,0 & 1,0 \\
\hline $\begin{array}{l}\text { Organização passando por uma reestruturação durante o } \\
\text { projeto. }\end{array}$ & 2,5 & 4,0 & 1,0 \\
\hline
\end{tabular}

Fonte: elaborado pelo autor

O agrupamento dos riscos de Governança de TI apresentou todos os valores médios abaixo de 4,0, com uma média de 2,3. Logo, os fatores de risco relacionados à Governança de TI não foram relevantes no projeto NF-e.

Os Quadros 52 e 53 apresentam os elementos relacionados à complexidade estrutural do modelo de Xia e Lee (2004) no projeto NF-e.

Quadro 52: Riscos de complexidade estrutural do modelo de Xia e Lee no projeto NF-e

\begin{tabular}{|c|c|c|c|c|}
\hline \multirow{2}{*}{ Risco } & \multicolumn{4}{|c|}{ Entrevistados } \\
\hline & 1 & 2 & 3 & 4 \\
\hline Falta de cooperação dos usuários. & 2,0 & 3,0 & 1,0 & 1,0 \\
\hline Estimativa inadequada dos recursos necessários; & 5,0 & 3,0 & 1,0 & 1,0 \\
\hline $\begin{array}{l}\text { Recursos deslocados do projeto em razão de mudanças nas prioridades da } \\
\text { organização. }\end{array}$ & 1,0 & 6,0 & 1,0 & 4,0 \\
\hline $\begin{array}{l}\text { Faltam nos membros da equipe as habilidades especializadas requeridas pelo } \\
\text { projeto. }\end{array}$ & 4,0 & 3,0 & 2,0 & 1,0 \\
\hline Falta de apoio da alta direção ao projeto. & 2,0 & 1,0 & 1,0 & 1,0 \\
\hline
\end{tabular}

Fonte: elaborado pelo autor 
Quadro 53: Médias dos riscos de complexidade estrutural do modelo de Xia e Lee no projeto NF-e

\begin{tabular}{|l|r|r|r|}
\hline \multicolumn{1}{|c|}{ Risco } & Média & \multicolumn{1}{|c|}{$\begin{array}{c}\text { Maior } \\
\text { Valor }\end{array}$} & \multicolumn{1}{|c|}{$\begin{array}{c}\text { Menor } \\
\text { Valor }\end{array}$} \\
\hline Falta de cooperação dos usuários. & 1,8 & 3,0 & 1,0 \\
\hline Estimativa inadequada dos recursos necessários; & 2,5 & 5,0 & 1,0 \\
\hline $\begin{array}{l}\text { Recursos deslocados do projeto em razão de mudanças nas } \\
\text { prioridades da organização. }\end{array}$ & 3,0 & 6,0 & 1,0 \\
\hline $\begin{array}{l}\text { Faltam nos membros da equipe as habilidades } \\
\text { especializadas requeridas pelo projeto. }\end{array}$ & 2,5 & 4,0 & 1,0 \\
\hline Falta de apoio da alta direção ao projeto. & 1,3 & 2,0 & 1,0 \\
\hline
\end{tabular}

Fonte: elaborado pelo autor

O agrupamento dos riscos pelo critério de complexidade estrutural do modelo de Xia e Lee (2004) apresentou todos os valores médios abaixo de 4,0, com média geral de 2,2. Logo, os fatores de risco relacionados à complexidade estrutural não foram relevantes no projeto NF-e.

\subsection{Aderência dos Resultados às Teorias}

O projeto NF-e, conforme o que foi pesquisado e apresentado, não enfrentou a situação de agravamento. Sobre as proposições apresentadas no capítulo 3, que contemplou o modelo de referência e as teorias alternativas, os dados coletados na análise do NF-e permitiram as seguintes conclusões:

Em relação à primeira proposição:

P1: Altos riscos de (2) escopo e requisitos, juntamente com altos riscos de (3) execução, contribuem para que um projeto entre em situação de agravamento.

Os dados apresentados nos Quadros 43, 44, 45 e 46 demonstram riscos baixos de execução e escopo e requisitos. Complementarmente, os dados qualitativos obtidos por meio das entrevistas também não enfatizam problemas nesses dois quadrantes. Consequentemente, levando-se em conta que o projeto NF-e não entrou em situação de agravamento, podemos concluir que os dados obtidos não contrariam a proposição P1. 
Em relação à segunda proposição:

P2: Os riscos de (1) mandato do cliente e (4) ambiente não são relevantes para que um projeto problemático entre em situação de agravamento.

Conforme pode ser visto nos Quadros 47 e 48, em relação aos dados dos fatores de risco relacionados ao ambiente, nenhum deles apresentou alta pontuação. Quanto aos fatores de risco relacionados ao mandato do cliente, apresentados nos Quadros 41 e 42, esses riscos tiveram pontuação baixa.

Consequentemente, levando-se em conta que o projeto NF-e não entrou em situação de agravamento, podemos concluir que os dados obtidos não contrariam a proposição $\mathrm{P} 2$.

As proposições P3 e P4 serão avaliadas conjuntamente:

P3: Altos riscos relacionados a escopo e requisitos, juntamente com a complexidade do sistema e organizacional, fazem com que um projeto se torne um projeto complexo (wicked project).

P4: Projetos em situação de agravamento apresentam altos riscos relacionados a escopo e requisitos, complexidade do sistema e organizacional, e problemas na gestão do projeto.

Os fatores de risco apontados nas proposições P3 e P4 não foram considerados relevantes para o projeto NF-e. Logo, considerando-se que o projeto não entrou em agravamento, os dados novamente não contrariam essas duas proposições.

De maneira geral, de acordo com as entrevistas e os questionários, os riscos do projeto não contribuíram para o projeto entrar em situação de agravamento e o projeto, realmente, não chegou à essa situação. O Gráfico 9 apresenta esses riscos consolidados. 


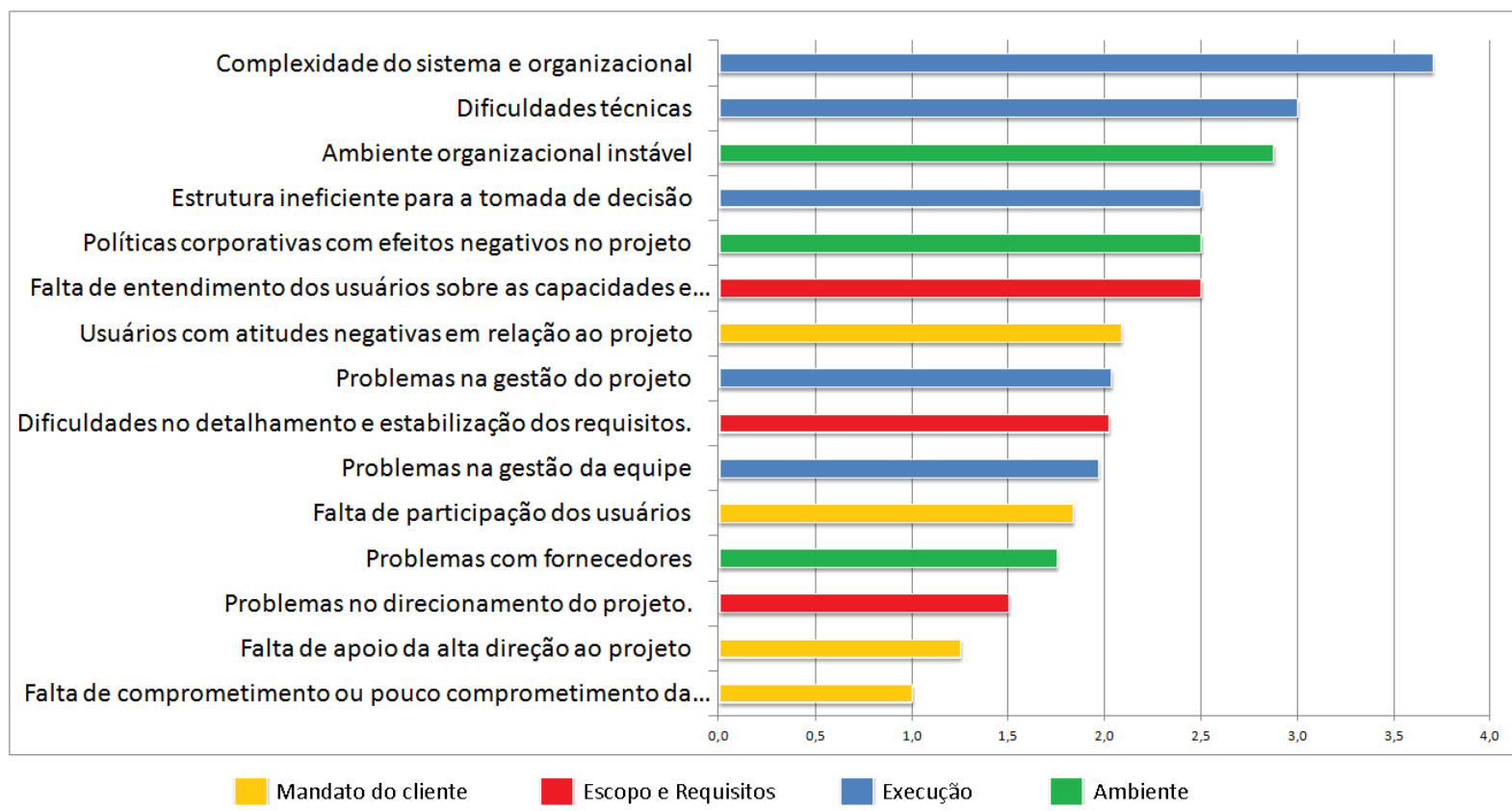

Gráfico 9: Riscos consolidados do projeto NF-e Fonte: elaborado pelo autor

Quanto à proposição $\mathrm{P} 5$ :

P5: A reorientação bem-sucedida de um projeto em situação de agravamento envolve aspectos relacionados à diminuição da complexidade do projeto ou à aplicação de técnicas mais adequadas para lidar com a complexidade existente.

Como o projeto NF-e não entrou em situação de agravamento, não é possível avaliar a proposição P5. Entretanto, os entrevistados mencionaram a redução da complexidade anterior ao desenvolvimento por meio de um grande período de especificação de requisitos, que, além de simplificar o problema a ser resolvido pela área de TI, também entregou requisitos mais estáveis.

Outro fator de risco que evoluiu de forma benéfica ao projeto foi a parte política, que proporcionou o círculo virtuoso de apoio institucional e priorização citado por Junqueira (2007, p. 130).

Em relação à proposição P6: 
P6: Altos riscos relacionados à Governança de TI contribuem para que um projeto problemático entre em situação de agravamento.

O projeto não entrou em situação de agravamento e não apresentou valores altos nos fatores de risco, conforme previa a teoria. A média dos riscos de Governança de TI, considerando todos os fatores de risco classificados nessa categoria, foi de 2,3.

Quanto à proposição P7:

P7: Altos riscos relacionados à Governança de TI contribuem para que um projeto problemático permaneça em situação de agravamento.

Não foi possível avaliar a proposição $\mathrm{P} 7$, pois o projeto não entrou em situação de agravamento.

Em relação à última proposição:

P8: Projetos de TI do setor público em situação de agravamento apresentam alta complexidade estrutural organizacional.

O projeto não entrou em situação de agravamento e não apresentou valores altos nos fatores de risco de complexidade estrutural do modelo de Xia e Lee (2004), conforme previa a teoria. O agrupamento dos riscos pelo critério de complexidade estrutural do modelo de Xia e Lee (2004), considerando todos os fatores de risco classificados nessa categoria, foi 2,2.

O segundo caso estudado foi consistente com as proposições P1 e P2, relativas ao modelo de Wallace e Keil (2004), e com as proposições P3 e P4, relativas ao modelo de referência.

Em relação às proposições P6, referente ao modelo baseado na Governança de TI, e P8, referente ao modelo de Xia e Lee (2004), as evidências do caso da NF-e estão alinhadas com as duas teorias.

Não foi possível avaliar as proposições P5 e P7, pois o projeto não entrou em situação de agravamento. 
O Quadro 54 apresenta um resumo da avaliação das proposições e das teorias:

Quadro 54: Avaliação do caso do projeto NF-e em relação às proposições e teorias

\begin{tabular}{|c|c|c|}
\hline Teoria & Proposição & $\begin{array}{c}\text { Caso } \\
\text { Alinhado à } \\
\text { Teoria } \\
\end{array}$ \\
\hline \multirow[t]{2}{*}{$\begin{array}{l}\text { Wallace e } \\
\text { Keil (2004) }\end{array}$} & $\begin{array}{l}\text { P1: Altos riscos de (2) escopo e requisitos, juntamente com altos riscos de (3) } \\
\text { execução, contribuem para que um projeto entre em situação de agravamento. }\end{array}$ & Sim \\
\hline & $\begin{array}{l}\text { P2: Os riscos de (1) mandato do cliente e (4) ambiente não são relevantes para } \\
\text { que um projeto problemático entre em situação de agravamento. }\end{array}$ & Sim \\
\hline \multirow[t]{3}{*}{$\begin{array}{l}\text { Modelo de } \\
\text { referência }\end{array}$} & $\begin{array}{l}\text { P3: Altos riscos relacionados a escopo e requisitos, juntamente com a } \\
\text { complexidade do sistema e organizacional, fazem com que um projeto se } \\
\text { torne um projeto complexo (wicked project). }\end{array}$ & Sim \\
\hline & $\begin{array}{l}\text { P4: Projetos em situação de agravamento apresentam altos riscos relacionados } \\
\text { a escopo e requisitos, complexidade do sistema e organizacional, e problemas } \\
\text { na gestão do projeto. }\end{array}$ & Sim \\
\hline & $\begin{array}{l}\text { P5: A reorientação bem-sucedida de um projeto em situação de agravamento } \\
\text { envolve aspectos relacionados à diminuição da complexidade do projeto ou à } \\
\text { aplicação de técnicas mais adequadas para lidar com a complexidade } \\
\text { existente. }\end{array}$ & $\begin{array}{l}\text { Não foi } \\
\text { possível } \\
\text { avaliar. }\end{array}$ \\
\hline \multirow[t]{2}{*}{$\begin{array}{l}\text { Governança } \\
\text { de TI }\end{array}$} & $\begin{array}{l}\text { P6: Altos riscos relacionados à Governança de TI contribuem para que um } \\
\text { projeto problemático entre em situação de agravamento. }\end{array}$ & Sim \\
\hline & $\begin{array}{l}\text { P7: Altos riscos relacionados à Governança de TI contribuem para que um } \\
\text { projeto problemático permaneça em situação de agravamento. }\end{array}$ & $\begin{array}{l}\text { Não foi } \\
\text { possível } \\
\text { avaliar. }\end{array}$ \\
\hline $\begin{array}{l}\text { Xia e Lee } \\
(2004)\end{array}$ & $\begin{array}{l}\text { P8: Projetos de TI do setor público em situação de agravamento apresentam } \\
\text { alta complexidade estrutural organizacional. }\end{array}$ & Sim \\
\hline
\end{tabular}

Fonte: elaborado pelo autor 


\section{$7 \quad$ Projeto Rainha Vermelha}

"E naquele mesmo momento, não sei como, elas começaram a correr.

Alice nunca pôde esclarecer, quando, mais tarde, pensava nisso, de que modo tinham começado: só o que lembrava é que corriam de mãos dadas, e que a Rainha ia tão depressa que ela mal podia se manter ao seu lado. E, ainda assim a Rainha ia sempre gritando: 'Mais depressa! Mais depressa!'

E Alice via que não podia correr mais, mas nem fôlego tinha para dizer isso.

Mas o mais curioso era que as árvores, e as outras coisas ao redor delas, não mudavam de lugar: por mais que corressem, parecia que não passavam adiante de coisa alguma.

A Rainha encostou-a a uma árvore, e disse com ar bondoso:

- Agora pode descansar um pouco.

A menina olhou em roda, muito surpreendida.

- Mas... creio que estive sempre debaixo desta árvore! Tudo aqui está bem como era!

- Pois sem dúvida que está! Como queria que estivesse?

- É que na minha terra - disse Alice, ainda ofegante -, quando a gente corre como nós corremos agora, acha sempre alguma coisa diferente.

- É uma espécie de terra muito vagarosa! - disse a Rainha. - Agora você já viu que, para ficar no mesmo lugar, é preciso correr a bom correr, como você fez. E se quiser mudar de lugar é necessário correr duas vezes mais depressa do que aquilo!"

Carroll (2008, p. 37-39)

A concepção do projeto Rainha Vermelha ocorreu a partir do cancelamento de dois projetos executados em dois órgãos públicos diferentes, denominados Dispater e Salus. As duas organizações pertencem à mesma esfera de governo e estava previsto que os sistemas resultantes dos dois projetos deveriam ter algum nível de integração.

As informações sobre qual esfera de governo (federal, estadual ou municipal), qual o objeto dos projetos e quais as instituições envolvidas foram omitidas em razão do acordo de anonimato firmado com o órgão público que autorizou a pesquisa.

Existia um consenso de que esses projetos cancelados apresentavam nível razoável de complexidade. O projeto da Dispater contemplava o desenvolvimento de um novo sistema em tecnologia Web para modernizar o sistema legado que havia sido baseado em tecnologia mainframe, e estava em operação desde dezembro de 1984. Tanto o sistema em operação quanto o sistema em desenvolvimento estavam sob a responsabilidade da empresa de processamento de dados que atende àquela esfera de governo. 
O prazo do projeto da Dispater foi inicialmente estimado em um ano e meio (de julho de 2006 a dezembro de 2007) e posteriormente expandido em seis meses, para julho de 2008, em razão de uma solicitação de mudança aprovada pelo cliente. Ao final de 2008, com aproximadamente seis meses de atraso, a empresa de processamento de dados informou à Dispater que seriam necessários mais dois anos para a conclusão do projeto, com término previsto para dezembro de 2010. Em virtude desse atraso no término do projeto, o administrador público responsável pela Dispater optou por seu cancelamento, que foi oficializado em julho de 2009.

As razões oficiais para o cancelamento do projeto da Dispater foram baseadas nas ocorrências que comprometeram o desenvolvimento do projeto no prazo combinado, como, por exemplo, o tamanho reduzido da equipe de TI com conhecimento das regras de negócio, concorrência do projeto pelos recursos que atuavam na manutenção do sistema que estava em produção, necessidade de manutenção do sistema em produção e de retrabalho no projeto em razão de mudanças na legislação que se refletiram nas regras de negócio.

Em abril de 2008, ainda antes do cancelamento do projeto da Dispater, foi criado um projeto para automatizar os processos da Salus, com impacto em todos os órgãos públicos da administração direta e autarquias daquela esfera de governo. O projeto também estava sob a responsabilidade da mesma empresa de processamento de dados do projeto da Dispater. $\mathrm{O}$ projeto original para automação dos processos da Salus teve uma primeira fase, restrita ao planejamento, executada em seis meses.

Em virtude da necessidade de integração do resultado do projeto da Salus com o resultado do projeto da Dispater, que havia sido cancelado, a Dispater propôs um projeto de aquisição de uma solução de mercado (de prateleira) capaz de suportar as necessidades combinadas das duas instituições, como forma de atender às suas necessidades com maior celeridade. A partir desse entendimento, foi tomada a decisão de cancelar também o projeto da Salus e empreender o projeto conjunto, denominado de Rainha Vermelha. O projeto da Salus foi cancelado logo após o término de sua fase de planejamento.

Apesar de o cancelamento oficial do projeto da Dispater ter ocorrido somente em julho de 2009, já em abril do mesmo ano foi formado um grupo de trabalho com técnicos da Dispater e da Salus para o desenvolvimento, gerenciamento e implantação do projeto Rainha Vermelha. 
Um dos entrevistados apontou como principais fatores de risco desse projeto alguns fatos descritos anteriormente e ocorridos antes mesmo da aquisição da solução:

- O projeto ter sido uma imposição da Dispater à Salus;

- O projeto envolver dois órgãos públicos distintos: Dispater e Salus;

- O não envolvimento no projeto da companhia de processamento de dados daquela esfera de governo, que conhecia as regras de negócio do sistema a ser substituído.

\subsection{Aquisição da Solução}

A aquisição da solução foi baseada na Lei 8.666/93, que rege as licitações públicas no Brasil. O processo de concorrência ocorreu na modalidade menor preço, por meio de um pregão eletrônico. Nesse caso, segundo Di Pietro (2001, p. 403), o critério de seleção da proposta mais vantajosa para a Administração corresponde à proposta de menor preço, desde que ela esteja de acordo com as especificações do edital ou convite.

O edital contemplava o seguinte escopo (DISPATER, 2009):

- Licença de uso em caráter definitivo do software objeto da contratação;

- Requisitos funcionais equivalentes aos do antigo projeto da Salus;

- Requisitos funcionais equivalentes aos do antigo projeto da Dispater;

- Requisitos funcionais de caráter geral;

- Instalação do sistema correspondente à solução;

- Treinamento;

- Customização e parametrização do software adquirido;

- Migração dos dados;

- Integração com outros sistemas da mesma esfera de governo;

- Garantia, suporte técnico e manutenção;

- Implantação para os órgãos públicos envolvidos, contemplando a Dispater, a Salus e outros órgãos e autarquias da mesma esfera de governo;

- Fornecimento do hardware necessário ao processamento da solução nos três ambientes operacionais (desenvolvimento, homologação e produção);

- Fornecimento da aplicação e outros softwares aplicativos e ferramentas necessárias para o funcionamento da solução, como, por exemplo, sistema operacional, sistema gerenciador de banco de dados e ferramentas para a geração de relatórios. 
O edital previa também a adequação da solução à legislação vigente. Vale ressaltar que, nessa esfera de governo, as regras de negócio estavam codificadas na forma de leis e não havia a expectativa de mudar essas leis. Consequentemente, o projeto considerava que a ferramenta a ser adquirida deveria ser aderente às regras de negócio, e não fazia parte do projeto a alteração ou simplificação da legislação. Durante a fase de licitação, existia a expectativa de que a customização no sistema seria inferior a $20 \%$.

No edital, as entregas foram separadas em quinze produtos. A organização em partes menores viabilizava um maior paralelismo e permitia que o vencedor do edital, qualquer que fosse, pudesse planejar melhor o andamento das entregas e seu fluxo de caixa, permitindo, por exemplo, o pagamento dos produtos intermediários.

O edital já estipulava as principais datas de entrega (marcos) do sistema, conforme apresentado nas ilustrações 8 e 9. Consequentemente, o prazo desejado previa a implantação em produção da primeira etapa do sistema na mesma gestão política que promoveu a licitação. 


\begin{tabular}{|c|c|c|c|c|}
\hline Nome da tarefa & Duração & Início & Término & 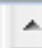 \\
\hline - Projeto Rainha Vermelha - Edital & 1286 dias & Sex 25/09/09 & Qui 25/09/14 & \\
\hline Assinatura do Contrato & 0 dias & Sex $25 / 09 / 09$ & Sex $25 / 09 / 09$ & \\
\hline Produto 1 & 15 diasd & Sex $25 / 09 / 09$ & Sáb 10/10/09 & \\
\hline Produto 2 & 31,5 mesesd & Sáb 10/10/09 & Sáb $12 / 05 / 12$ & \\
\hline - Etapa 1 & 321 dias & Sex $25 / 09 / 09$ & Dom 19/12/10 & \\
\hline Produto 3 & 45 diasd & Sex $25 / 09 / 09$ & Seg 09/11/09 & \\
\hline Produto 4 & 60 diasd & $\operatorname{Sex} 25 / 09 / 09$ & Ter $24 / 11 / 09$ & \\
\hline Produto 5 & 5 mesesd & Seg 09/11/09 & Qui 08/04/10 & \\
\hline Produto 6 & 5 mesesd & Qui 08/04/10 & Dom 05/09/10 & \\
\hline Produto 7 & 5 mesesd & Seg 09/11/09 & Qui 08/04/10 & \\
\hline Produto 8 & 3,5 mesesd & Qui 08/04/10 & Qui $22 / 07 / 10$ & \\
\hline Produto 9 & 3,5 mesesd & Dom 05/09/10 & Dom 19/12/10 & \\
\hline Implantação da Primeira Etapa & 0 dias & Dom 19/12/10 & Dom $19 / 12 / 10$ & \\
\hline - Etapa 2 & 365 dias & Dom 19/12/10 & Sáb 12/05/12 & \\
\hline Produto 10 & 5 mesesd & Dom $19 / 12 / 10$ & Qua $18 / 05 / 11$ & \\
\hline Produto 11 & 12 mesesd & Qua $18 / 05 / 11$ & Sáb 12/05/12 & \\
\hline Produto 12 & 12 mesesd & Qua $18 / 05 / 11$ & Sáb 12/05/12 & \\
\hline Implantação da Segunda Etapa & 0 dias & Sáb 12/05/12 & Sáb 12/05/12 & \\
\hline Produto 13 & 8 mesesd & Sex $25 / 09 / 09$ & Dom 23/05/10 & \\
\hline Produto 14 & 28 mesesd & Sáb 12/05/12 & Qui 25/09/14 & \\
\hline Produto 15 & 60 mesesd & Sex $25 / 09 / 09$ & Qui 25/09/14 & \\
\hline Término do Contrato & 0 dias & Sáb 30/08/14 & Qui 25/09/14 & \\
\hline
\end{tabular}

Ilustração 8: Cronograma tabular construído a partir do edital

Fonte: elaborada pelo autor a partir de dados de DISPATER (2009)

Os entrevistados explicaram que:

"Quando se tencionou buscar um projeto pronto, comercial, pra fazer o [Objeto do Projeto], acredito que não houve tempo suficiente. Eu não participei dessa fase, participei só no fim. Eu acredito que não houve tempo suficiente pra fazer uma análise mais profunda do nível que esse sistema poderia atender às necessidades do [nome da esfera de governo]."

"Quando eu cheguei aqui, o projeto já tinha começado. E ele deu início na gestão [nome do administrador público/político], [cargo do administrador público/político], e a exigência dele era que fosse um projeto rápido, ele queria que o sistema tivesse sido implantado já durante a gestão dele. Então o prazo foi extremamente curto já de cara, mesmo com o alerta do pessoal interno que já era responsável."

"O formato do edital foi nesse sentido, de ter alguma coisa mais ou menos pronta pra já facilitar a implantação. Então, não teria que ser desenvolvido do zero, visando já essa velocidade de implantação.” 
“Os prazos colocados no edital eram prazos impossíveis de serem concluídos, de tal forma que o projeto já iniciou fadado ao fracasso, porque o prazo pra conclusão era impossível de ser atingido.”

“É um prazo que, na minha opinião, não seria capaz de ser executado.”

Além das entrevistas, as respostas do questionário também apontam um consenso de que o prazo da primeira etapa era político e não técnico. Dos sete entrevistados, todos atribuíram a nota máxima de 7,0 ao risco de prazo político.

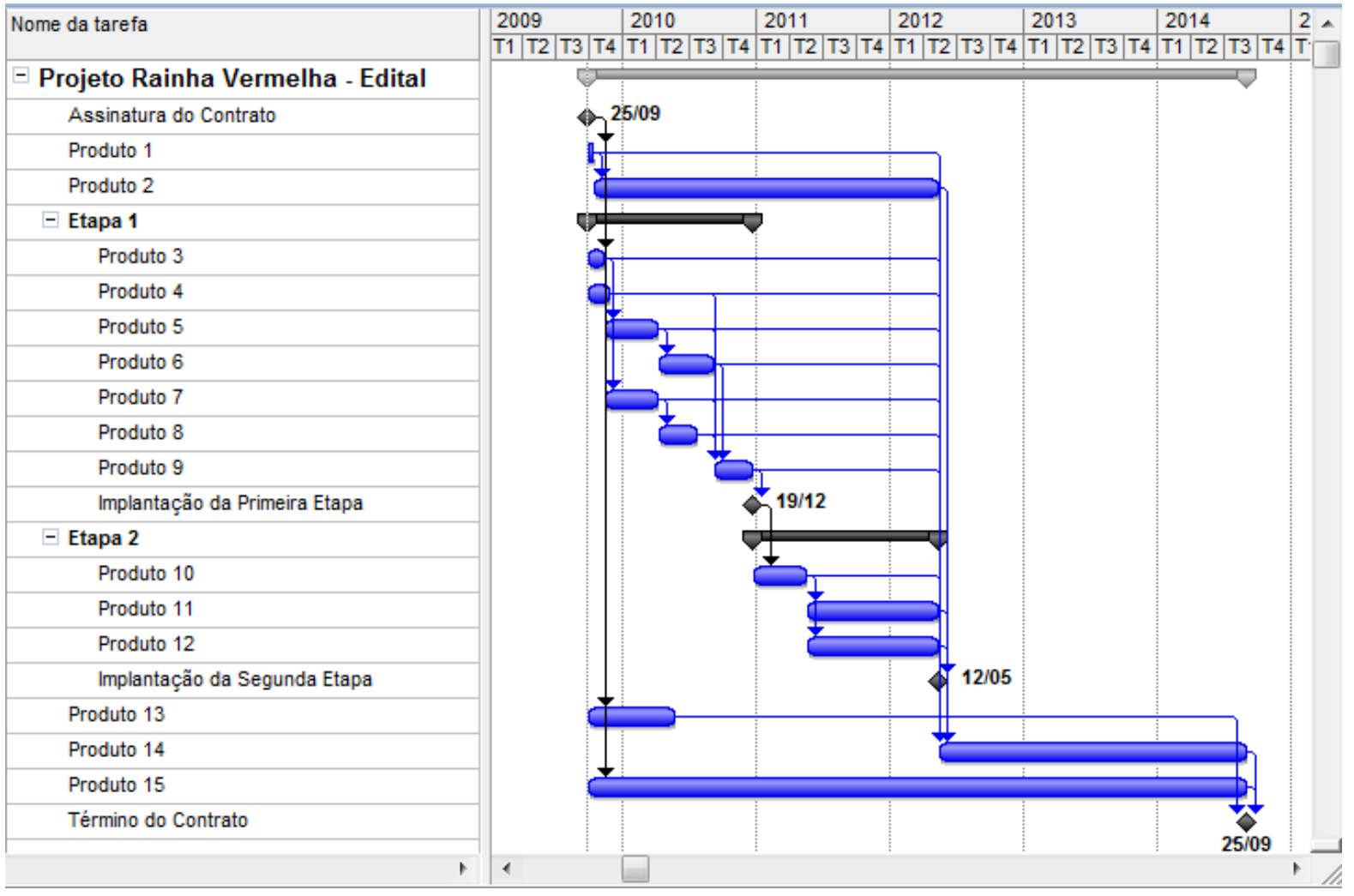

Ilustração 9: Cronograma construído a partir do edital

Fonte: elaborada pelo autor a partir de dados de DISPATER (2009)

Para manter o anonimato, o consórcio vencedor da licitação será denominado Janus. A explicação da primeira fase do projeto, na qual o consórcio Janus tenta cumprir o prazo político previsto no edital, será apresentada no próximo item.

\subsection{Primeira Fase do Projeto Rainha Vermelha: Paralelismo}

Logo após a adjudicação e assinatura do contrato, a primeira fase do projeto Rainha Vermelha foi marcada pela expectativa de implantar rapidamente o sistema, com o mínimo de 
customizações, buscando cumprir o cronograma com o qual o consórcio Janus estava amarrado tanto pelo edital (DISPATER, 2009) quanto pelo contrato (DISPATER; JANUS, 2009).

O primeiro cronograma elaborado pelo consórcio Janus previa muitas parametrizações no sistema e poucas customizações. A Ilustração 10 mostra o primeiro cronograma apresentado.

\begin{tabular}{|c|c|c|c|c|c|c|}
\hline \multirow{2}{*}{ id } & \multirow{2}{*}{ Name do tarefa } & \multirow{2}{*}{ Inicio } & \multirow{2}{*}{ Término } & \multirow{2}{*}{ Duraçனo } & \multicolumn{2}{|r|}{2010} \\
\hline & & & & & \begin{tabular}{|l|l|l|} 
out & now & der \\
\end{tabular} & \begin{tabular}{|l|l|l|l|l|l|l|l|l|l|l|l|}
$j a r$ & fev & mar & abr & moi & jur & jul & ago & set & out & nov & dez \\
\end{tabular} \\
\hline 1 & Planejamento Inicial & $01 / 10 / 2009$ & $13 / 11 / 2009$ & $32 d$ & & \\
\hline 2 & Levantamento de Requisitos & $16 / 11 / 2009$ & $30 / 09 / 2010$ & $229 d$ & & \\
\hline 3 & $\begin{array}{l}\text { Adaptaços no SIstema } \\
\text { (Customizaç̋es) } \\
\end{array}$ & $01 / 01 / 2010$ & $31 / 08 / 2010$ & $173 d$ & & \\
\hline 4 & Parametrizaçāo do Sistema & $01 / 02 / 2010$ & $30 / 09 / 2010$ & $174 d$ & & \\
\hline s & Migraçio de Dados & $01 / 03 / 2010$ & $30 / 09 / 2010$ & $154 d$ & & \\
\hline 6 & Testes e Paralelos & $01 / 06 / 2010$ & $29 / 10 / 2010$ & $109 d$ & & \\
\hline 7 & Entrada em Produção & $01 / 11 / 2010$ & $31 / 12 / 2010$ & $45 d$ & & \\
\hline
\end{tabular}

Ilustração 10: Primeiro cronograma elaborado pelo consórcio Janus, referente à primeira etapa do projeto Fonte: JANUS (2011)

Ao explicar os motivos pelos quais não foi possível cumprir o que estava previsto no edital, o consórcio Janus afirmou que as seguintes premissas deveriam ter sido atendidas (JANUS, 2011):

- Documentação prévia, sistematizando as leis, normas, práticas e procedimentos de forma detalhada;

- Alto nível de integração entre as equipes de trabalho;

- Alto grau de paralelismo;

- Baixo volume de customizações.

Em relação ao excesso de paralelismo, os entrevistados disseram o seguinte:

"No início teve uma tentativa de cumprir aquele prazo do edital. Mas insano. Todo mundo sabia, querendo ou não, só que as partes envolvidas não quiseram admitir formalmente. Mas, no final, todo mundo sabia que o prazo não ia ser cumprido, por paralelismo, sem paralelismo, não ia funcionar."

“Devido à pressa da época, da contratação, já foi direto tocando pau na máquina. Não sentaram e analisaram o edital item a item pra ver se todos os itens solicitados... Como que seria feito pra ser atendido pela empresa, pelo sistema, o nível de customização, o escopo também não foi analisado e detalhado." 
"O que se tentou fazer foi tratar todas as frentes e todos os assuntos que tinha no projeto, tudo em paralelo. Só que os assuntos tinham relação com uma equipe de trabalho, que cuidava de um determinado assunto, com equipe de trabalho de um outro assunto. Então, quer dizer, as pessoas estavam caminhando todas mais ou menos na mesma direção, mas sem saber o que um e o outro estavam fazendo, e quando chegou um determinado momento você viu que as coisas não se casavam.”

Ao justificar o não atendimento do prazo previsto no edital e no primeiro cronograma, o consórcio Janus (2011) apresentou os seguintes problemas, relacionados à gestão e à complexidade do projeto:

- Prazo inicial exíguo;

- Dificuldade inicial de integração entre as três equipes (Janus x Dispater x Salus);

- Dificuldades no comprometimento dos demais órgãos da administração pública envolvidos com o projeto;

- Grande demanda por customizações no sistema;

- Grande quantidade de integrações;

- Não participação da empresa de processamento de dados daquela esfera de governo (responsável pelos antigos projetos, que haviam sido cancelados) como co-gestora da implantação, juntamente com a Dispater e a Salus.

A respeito dos problemas existentes no início da execução do projeto, os entrevistados explicaram o seguinte:

"Problemas como falta de integração entre as equipes, como a falta de um plano de comunicação, como a falta de um planejamento efetivo geral do projeto, seja de execução de trabalho, seja de gerenciamento, aí entrando mais em detalhes. Na minha visão faltava uma etapa de levantamento de requisitos, definição de escopo, definições de papéis e responsabilidades claras do projeto, a própria definição de uma estrutura organizacional no projeto, enfim então tudo muito incipiente e aí de riscos diversos. E todos levando ao único ponto de que o projeto não ia dar certo".

"Eu acredito que o principal risco foi não conhecer a extensão do trabalho que tinha que ser feito e falta de planejamento. Eles chegaram pensando que aqui, que esse projeto era equivalente a outros projetos que eles trabalharam".

O consórcio Janus adotou uma estratégia inicial para entregar o produto dentro do prazo político, baseada na premissa de que seu produto já atenderia em grande parte às necessidades da Dispater e da Salus. Entretanto, ao contrário da maioria das implantações anteriores 
realizadas pelo consórcio Janus, no caso do projeto Rainha Vermelha, os clientes já possuíam um sistema de informação de grande complexidade que estava implantado e estável, mas que precisava evoluir. Ao compararem o sistema Rainha Vermelha com o legado, houve um consenso na Dispater e na Salus de que o sistema novo ainda estava aquém do sistema legado em vários aspectos e que, sem esses ajustes, a implantação não seria viável. Consequentemente, a estratégia inicial de implantar rapidamente a versão-padrão do sistema e depois evoluir não foi bem-sucedida, conforme os depoimentos abaixo:

“A estratégia era impor o que tem pronto, mexer o mínimo possível, e depois, com o tempo, com mais calma, ir arrumando os ponteiros, acertando todos os detalhes, até ficar um sistema adequado pro uso".

"Houve uma reunião inicial, nessa reunião inicial juntou-se todo mundo, eles conversaram a respeito do projeto e infelizmente os técnicos participantes do projeto já sentiam que aquela condução não seria mais adequada porque a empresa chegou impondo e ela impunha mudança de paradigma dentro dos serviços que são executados dentro do [nome da esfera de governo], mudança de conceitos, mudança de forma de trabalho. Era um sistema que, em vez de agregar, ele impunha uma nova forma de trabalho. Por conta disso, inicialmente houve resistência”.

"Então, quando eles viram o sistema novo, falaram: "não, isso daqui tá muito pior do que o que a gente já tem". E isso impediu a implantação imediata do pacote já imposto pelo [consórcio Janus]. A gente não vai aceitar um nível que seja pior do que o atual. A administração não deixou usar essa tática inicial de acertar depois da implantação".

A estratégia adotada de implantar o que já estava pronto para depois evoluir teve consequências no levantamento de requisitos:

\footnotetext{
"Não tinha essa etapa de levantamento de requisito. O que acontecia na época, logo no início, é que a forma de trabalho que foi definida foi a seguinte. A forma de trabalho da época era: O [consórcio Janus] solicitava um determinado levantamento pra área usuária sobre um determinado assunto, sem definir um formato-padrão único de como receber essas informações... A área usuária entregava do jeito que que achava que tinha que entregar pra [Janus]. O que, pros consultores, era péssimo, porque existe uma expectativa de receber de um jeito, só que não existia uma comunicação, uma integração, então não... Era uma reclamação vazia que existia. E, em função disso, toda essa etapa de entendimento das necessidades começou totalmente prejudicada, sem resultado prático”.
}

O entrevistado complementa, explicando que a indefinição dos requisitos inviabilizou o desenvolvimento de estimativas confiáveis: 
"Esse foi outro problema no projeto: que a gente não tem nem escopo definido. A gente não tem nem como fazer um trabalho de estimativa, ou seja, qualquer estimativa que se faça, ela com certeza vai furar. Na minha visão, em função disso, qualquer gestão em cima disso é ineficaz”.

A primeira fase teve a duração de aproximadamente 10 meses e nenhum produto foi homologado. Os envolvidos (consórcio Janus, área de negócio da Dispater, área de TI da Dispater e área de negócio da Salus) concluíram que o produto adquirido não seria aceito sem uma grande quantidade de customizações e que seria necessário investir mais tempo no levantamento de requisitos. Consequentemente, todo o trabalho anterior não foi usado diretamente, servindo apenas como base para essa especificação mais detalhada dos requisitos.

Em razão dos problemas já mencionados, em julho de 2010 foi tomada a decisão de efetuar um novo planejamento do projeto. No total, foram executadas duas tentativas de reorientar o projeto, que serão explicadas no item a seguir.

\subsection{Segunda Fase do Projeto Rainha Vermelha: Tentativas de Reorientação}

Durante a primeira tentativa de reorientação, o consórcio Janus desenvolveu um novo cronograma, ainda com pouca participação das outras áreas envolvidas. Esse cronograma incluía um processo de levantamento de requisitos, iniciado em agosto de 2010. Um problema inicial foi a definição dos prazos para as atividades, que ocorreu sem a participação das áreas clientes, incluindo as atividades sob responsabilidade do cliente. Dessa maneira, mais tarde, quando os prazos não foram cumpridos, essa forma de estabelecer prazos foi apontada como uma das causas da falha da primeira tentativa de reorientação.

Um dos entrevistados mencionou:

"Ele [o gerente de projetos do consórcio Janus] criou uma atividade que chamou de regras e critérios de validação, que no final acabou se tornando uma atividade de levantamento de requisitos ou próximo a isso. O que era necessário para o projeto, e isso foi bom. Mas, por uma questão de falta de planejamento e organização, de novo o projeto começou a descambar”. 
Com a intenção de viabilizar o novo cronograma, o consórcio Janus duplicou o tamanho de sua equipe de consultores. O término do projeto foi previsto para julho de 2011, representando um atraso de seis meses em relação ao término previsto no primeiro cronograma, em dezembro de 2010. A Ilustração 11 apresenta a comparação do segundo cronograma com o cronograma original (JANUS, 2011).

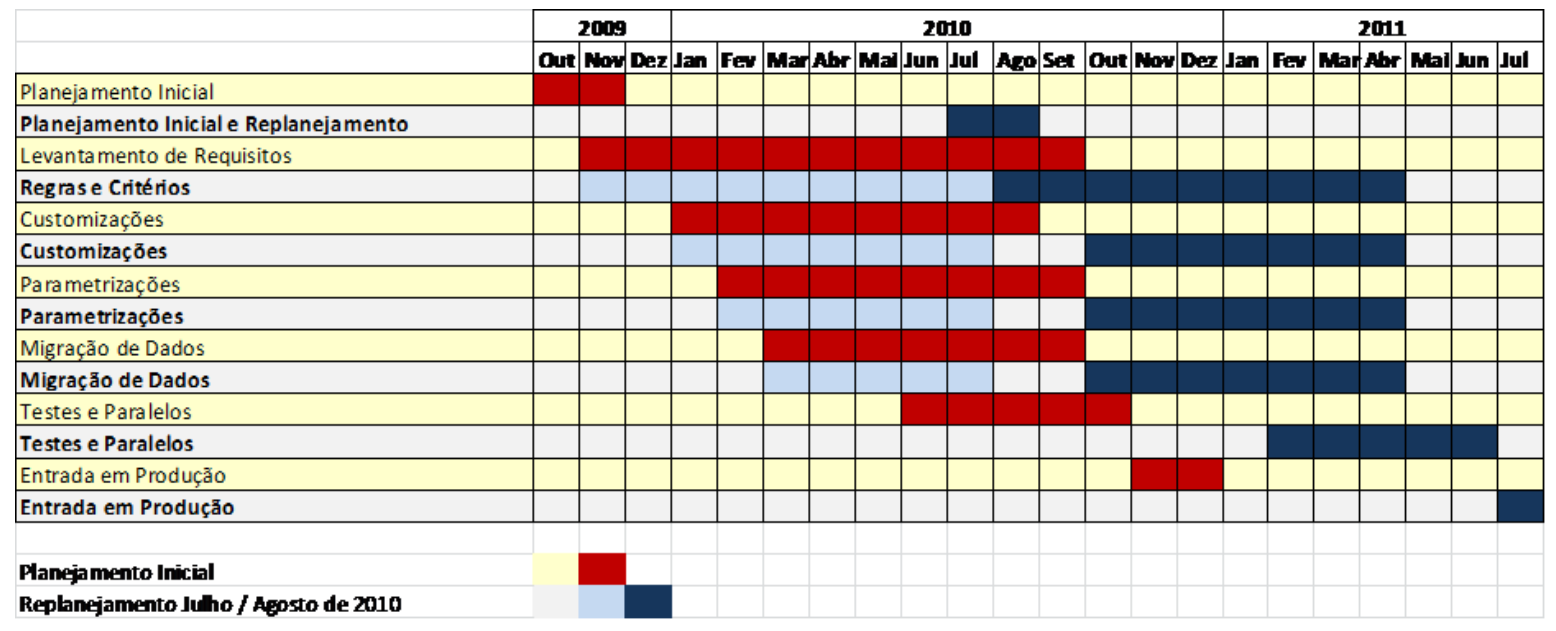

Ilustração 11: Comparação entre o primeiro e o segundo cronogramas Fonte: JANUS (2011)

Durante a primeira tentativa de reorientação, vários dos problemas apresentados no cronograma original se repetiram, como, por exemplo, o alto grau de paralelismo e o cronograma construído a partir de bases irrealistas.

Novamente, um problema relacionado a escopo e levantamento de requisitos inviabilizou o cronograma da primeira tentativa de reorientação, pois o prazo para as tarefas de levantamento de requisitos mostrou-se insuficiente e a quantidade de customizações permaneceu maior do que era esperado pela equipe que estava conduzindo o projeto.

Ao justificar o não atendimento do prazo previsto na primeira reorientação do projeto, o consórcio Janus (2011) apresentou os seguintes problemas:

- Prazos estipulados pelo consórcio Janus e não pelos grupos de trabalho que atuavam na especificação dos requisitos;

- Prazo curto face à serialização do trabalho: especificação de requisitos é gargalo para o andamento das demais atividades;

- Ferramentas inadequadas de gerenciamento do andamento do projeto; 
- Paralelismo fazia com que houvesse diversas frentes de trabalho iniciadas, mas não concluídas. Isso causava a dificuldade de saber em que ponto a implantação estava.

Alguns entrevistados explicaram por que essa reorientação não foi bem-sucedida:

\begin{abstract}
"Basicamente pelos mesmos problemas: falta de integração, falta de priorização, falta de uma atividade que definisse o escopo de trabalho, mesmo que fosse algo parcial, que dividisse o projeto em fases, por exemplo, pra gente visualizar o que deveria ser feito no projeto."

"Então, mesmo naquele momento do projeto em que aconteceu o primeiro replanejamento as coisas não foram feitas, no meu entendimento, conforme deveriam ter sido feitas, conforme boas práticas de mercado, conforme o PMBOK ou qualquer outro processo formal de mercado."

"Então, a gente parou o dia inteiro pra rever, pra replanejar e, de novo, nós erramos. Porque a gente fez o mesmo... A gente elaborou o novo cronograma da mesma forma com que ele foi elaborado quando do edital, de trás pra frente. Eles definiram a data que deveria ser entregue e, a partir dali, foram definidas, foram sendo definidas datas pra término de partes do projeto. Só que esses prazos eram impossíveis de serem concluídos. Sentamos, revimos tudo, pra sair de lá apenas com a sensação de que replanejamos, mas sabíamos que de novo não daria certo."
\end{abstract}

Nos últimos meses de 2010, quando as várias pessoas envolvidas passaram a não acreditar mais no prazo de julho de 2011, foi iniciada a segunda tentativa de reorientação, concluída em fevereiro de 2011. Nessa segunda tentativa, cada grupo envolvido (consórcio Janus, área de negócio da Dispater, área de TI da Dispater e área de negócio da Salus) seria responsável pelas estimativas de suas atividades (JANUS, 2011).

Além disso, o paralelismo foi diminuído e foram aplicados mecanismos de estimativa de prazo e de acompanhamento de projeto alinhados com as recomendações do PMI (2008). O consórcio Janus contratou um especialista em gestão de projetos certificado e tentou aplicar a técnica PERT (Program Evaluation and Review Technique) para fazer as estimativas e a análise de valor agregado para fazer o acompanhamento.

Ocorreram dois problemas durante essa fase que prejudicaram a elaboração do cronograma:

- Resistência das áreas de negócio em aplicar a técnica PERT para estimar os prazos do levantamento de requisitos;

- Compressão excessiva dos prazos de customização pela direção do consórcio Janus. 
A primeira versão do cronograma da segunda reorientação, desenvolvido no final de 2010 , apontava o término do projeto para 2013. Entretanto, como esse prazo causou desconforto na direção da Dispater, a direção do consórcio Janus comprimiu os prazos de customização e justificou a compressão pela adição de novos desenvolvedores à equipe.

$\mathrm{Na}$ versão final do cronograma elaborado em fevereiro de 2011, o prazo para o término da primeira fase do projeto Rainha Vermelha era 31 de julho de 2012. A Ilustração 12 apresenta o terceiro cronograma oficial do projeto.

\begin{tabular}{|c|c|c|c|c|c|c|}
\hline \multirow{2}{*}{ Id } & \multirow{2}{*}{ Nome da tarefa } & \multirow{2}{*}{ Início } & \multirow{2}{*}{ Término } & \multirow{2}{*}{ Duração } & 2011 & 2012 \\
\hline & & & & & \begin{tabular}{|l|l|l|l|l|l|l|l|l|l} 
mar & abr & mai & jun & jul & ago & set & out & nov & dez
\end{tabular} & \begin{tabular}{|l|l|l|l|l|l|l|} 
jan & fev & mar & abr & mai & jun & jul \\
\end{tabular} \\
\hline 1 & Regras e Critérios & $01 / 03 / 2011$ & $27 / 04 / 2012$ & $304 d$ & & 7 \\
\hline 3 & Levantamentos & $01 / 03 / 2011$ & $21 / 03 / 2011$ & $15 d$ & 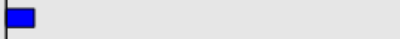 & \\
\hline 4 & Customizações & $10 / 03 / 2011$ & $31 / 03 / 2011$ & $16 \mathrm{~d}$ & $\square$ & \\
\hline 6 & Migração & $21 / 03 / 2011$ & $31 / 03 / 2011$ & $9 d$ & $\square$ & \\
\hline 7 & Módulo 2 & $01 / 04 / 2011$ & $29 / 04 / 2011$ & $21 d$ & $\boldsymbol{z}$ & \\
\hline 8 & Levantamentos & $01 / 04 / 2011$ & $21 / 04 / 2011$ & $15 d$ & $\square$ & \\
\hline 9 & Customizaçōes & $11 / 04 / 2011$ & $29 / 04 / 2011$ & $15 \mathrm{~d}$ & $\square$ & \\
\hline 13 & Ciclos de Migração & $21 / 03 / 2011$ & $31 / 05 / 2012$ & $314 d$ & & 7 \\
\hline 14 & Testes e Paralelos & $01 / 08 / 2011$ & $29 / 06 / 2012$ & $240 d$ & $\gamma$ & 7 \\
\hline 15 & Entrada em Produção & $02 / 07 / 2012$ & $31 / 07 / 2012$ & $22 d$ & & \\
\hline
\end{tabular}

Ilustração 12: Terceiro cronograma oficial do projeto Rainha Vermelha Fonte: JANUS (2011)

Novamente, durante essa fase ocorreram problemas referentes aos requisitos e à qualidade do produto resultante do projeto. Quando o consórcio Janus apresentou o primeiro módulo customizado para homologação, em maio de 2011, com aproximadamente dois meses de atraso, a homologação apontou 223 não conformidades. Uma das reclamações mais comuns dos usuários em relação às não conformidades referia-se à validação dos campos, considerada fundamental por Salus e Dispater, mas que não era atendida adequadamente pela versão original do produto adquirido.

Um dos entrevistados deu o seguinte depoimento a respeito da primeira tentativa de homologação: 
“Uma decepção, uma decepção. Por quê? Porque nós achávamos que se nós já estávamos indo pra um aspecto de homologação aquilo deveria funcionar, e qual foi a nossa surpresa? Que nada estava funcionando."

As áreas usuárias também demonstravam insatisfação com o fluxo de trabalho do novo produto, e muitas customizações foram solicitadas para que o sistema se adequasse ao modelo de trabalho usado naquela esfera de governo. Uma consequência disso foi, novamente, o excesso de customizações, que foi apontado como uma das causas de o projeto entrar em situação de agravamento, pois a expectativa inicial de $20 \%$ de customização não havia sido atendida. No primeiro módulo, os técnicos do consórcio Janus comentavam que o nível de customização havia chegado a aproximadamente $95 \%$.

Em razão dos problemas ocorridos durante a homologação, especialmente o problema com as validações e o comportamento do sistema, oito versões do documento de especificação do primeiro módulo foram construídas entre dezembro de 2010 e outubro de 2011. Em cada versão, algumas alterações correspondiam a mudanças nos requisitos, mas a maior parte das mudanças no documento contemplava detalhamentos de requisitos que não haviam sido atendidos ou que não haviam sido interpretados corretamente pelo consórcio Janus, segundo o ponto de vista da Dispater e da Salus.

Um dos entrevistados explicou como isso aconteceu e qual foi a consequência disso para o projeto:

"Da forma como foi conduzida, não tinha como ter previsibilidade, porque o escopo nunca era definido, era totalmente livre de controle. Na reunião, eles podiam se lembrar de um detalhe que não foi discutido: 'Ah não, vamos... então vamos marcar uma reunião mais pra frente pra tratar desse detalhe que não foi fechado lá atrás'. Isso... esse processo de trabalho acho que foi a principal causa de ter descarrilado a partir desse segundo planejamento. Ter um cronograma, porém a metodologia de trabalho ser livre assim da... livre vontade do analista de negócio."

As entrevistas apontaram também diversos problemas durante todo o projeto referentes à necessidade de customizações no sistema:

"E o mais que nos deixa, vamos dizer assim, perplexos é que determinadas coisas que já deveriam fazer parte do produto, como foi anunciado, não fazem, temos que construir do zero". 
“O fornecedor não atende às necessidades do [Nome da esfera de governo], ou seja, o produto que ele nos deu não atende às nossas necessidades. Então, as customizações que a gente tem que fazer... Nós estamos construindo um novo projeto, essa é a grande verdade. É um novo sistema. Estamos aproveitando o que ele nos deu, vamos dizer assim, ou seja, descaracterizando totalmente o produto de quem nos forneceu. É a criação de um novo produto".

"Quando nós começamos a falar de planejamento, nós fomos descobrindo que o produto que nos foi oferecido nós é que estávamos construindo, quando na realidade tinha que ser, vamos dizer, o contrário. Eu tinha que rechear uma determinada estrutura e não é o que aconteceu, nós acabamos levantando um sistema do nada, construindo um sistema praticamente da sua base, da sua origem.”

“A customização, pelo que eles [consórcio Janus] colocam, é em torno de 95\%. Então, quer dizer... Se você tem um sistema que você tem que customizar $95 \%$, significa que você desenvolveu um sistema novo".

Conforme mencionado na revisão bibliográfica, ao implantar um ERP, é necessário balancear as customizações no pacote com os ajustes nos processos da empresa, para se adequar ao pacote (ZWICKER; SOUZA, 2003, p. 69). Apesar de o software do consórcio Janus não se enquadrar em todas as características de um ERP, esse software é claramente um pacote de mercado, e a necessidade de customizações no sistema ou ajustes nos processos ocorre de forma análoga ao de uma implantação de ERP.

Em relação às mudanças que um ERP pode trazer aos processos de trabalho (SACCOL; MACADDAR; SOARES, 2003, p. 178), o caso do projeto Rainha Vermelha apresentava uma restrição importante: seus processos de trabalho e processos de negócio estavam especificados em leis. Por isso, mesmo que as leis fossem alteradas, existiria um legado que precisaria necessariamente ser gerenciado a partir da legislação antiga, pois essas leis não poderiam ser aplicadas de forma retroativa. Logo, a grande dificuldade de alteração das leis e a ineficácia das potenciais novas leis em relação ao legado inviabilizaram os ajustes na própria organização e direcionaram a estratégia de condução do projeto para um excesso de customizações.

Após o fracasso da primeira tentativa de homologação, em razão do excesso de não conformidades, a área de TI da Dispater determinou que os testes que o consórcio Janus alegava ter executado eram insuficientes. Inicialmente, a área de TI da Dispater desenvolveu uma metodologia para os testes baseada em padrões de mercado e solicitou que o consórcio 
Janus incluísse esses testes em seu cronograma e apresentasse evidências de sua execução. Entretanto, como o consórcio Janus alegou não ter disponibilidade de mão de obra habilitada para realizar os testes, estes ficaram sob responsabilidade do próprio departamento de desenvolvimento de sistemas da Dispater.

Os testes foram executados inicialmente pelos funcionários de carreira da Dispater, a partir da metodologia que havia sido proposta para o consórcio Janus. Posteriormente, foi contratada uma equipe de testes de uma consultoria externa que já prestava serviços para a Dispater e que passou a aplicar os testes de acordo com a orientação dos funcionários de carreira da Dispater.

Com a inclusão da etapa de testes, várias versões do primeiro módulo foram entregues para testes, até que, em dezembro de 2011, a área de TI da Dispater, juntamente com o consórcio Janus, considerou que o primeiro módulo estava em condições de ser homologado pelas áreas usuárias. Dessa forma, o período de correção das não conformidades do primeiro módulo durou de maio a dezembro de 2011.

Paralelamente aos testes e às correções das não conformidades, o consórcio Janus solicitou em setembro de 2011 uma reestruturação do contrato, alegando desequilíbrio econômicofinanceiro, pois, com a dificuldade em conseguir homologar as entregas realizadas, o projeto passou a não fornecer receita à empresa. Essa solicitação foi recusada pela Dispater, responsável pela gestão do contrato, pois esta considerou que não existia um cronograma confiável de entregas, nem garantias de que o consórcio Janus teria condições de concluir o projeto no prazo contratual, mesmo com a prorrogação do prazo pelo período de um ano, conforme o limite estipulado na lei 8.666/93. O Gráfico 10, mostrado a seguir, apresenta a evolução da data prevista da primeira etapa do projeto, considerando como última data o término do contrato original. O contrato original, além da primeira etapa, considerava também a segunda etapa, contemplando a administração indireta, além do período de garantia. 


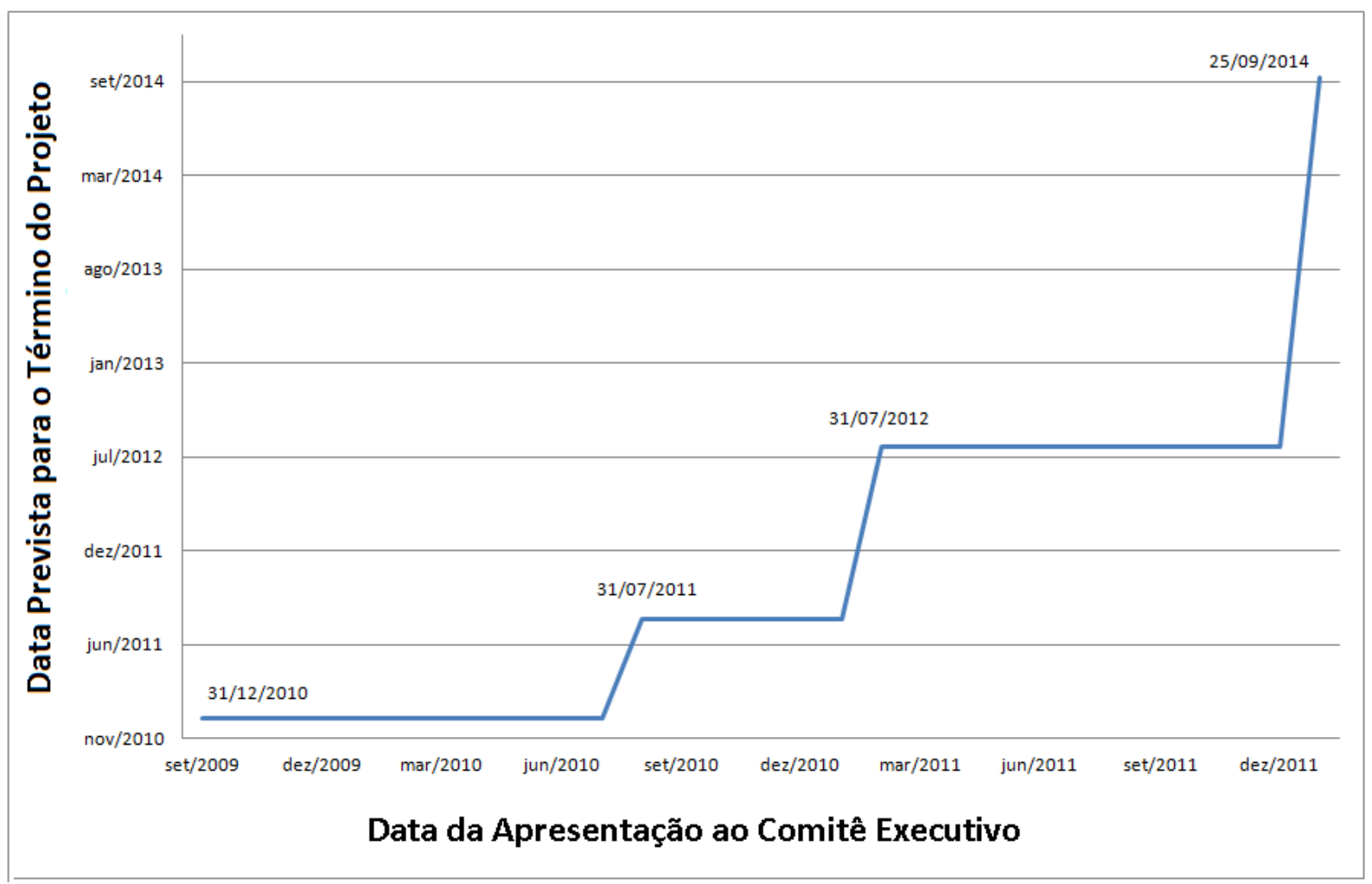

Gráfico 10: Evolução da data de término prevista para o projeto Rainha Vermelha Fonte: elaborado pelo autor a partir de Dispater e Janus (2009) e Janus (2011)

Consequentemente, o projeto foi paralisado em dezembro de 2011 e, em janeiro de 2012, a Dispater e a Salus concordaram que o consórcio Janus não tinha condições para desenvolver e entregar a parte do sistema referente à Salus. O desenvolvimento dessa parte do projeto, estimada em $70 \%$ do escopo total, passou então a ser de responsabilidade da equipe de desenvolvimento de sistemas da Dispater. Logo, a área de TI da Dispater assumiu a responsabilidade de desenvolver a parte do sistema referente à Salus, que, após a implantação, passaria a ser administrada pela empresa de processamento de dados daquela esfera de governo.

O novo sistema a ser desenvolvido para a Salus pela área de TI da Dispater foi projetado para usar tecnologia Dot Net na parte de interface com os usuários, e tecnologia Oracle na parte de banco de dados. A metodologia de desenvolvimento usada na Dispater é baseada em conceitos de agilidade e é influenciada pela metodologia Scrum.

Em relação à parte do sistema referente à Dispater, que ainda caberia ao consórcio Janus, o projeto foi oficialmente paralisado em fevereiro de 2012, com a concordância do consórcio 
Janus, para que uma consultoria de mercado contratada pela Dispater, denominada Minerva, fizesse um diagnóstico do projeto, avaliando as seguintes possibilidades:

- Desenvolvimento completo da solução com mão de obra interna, contemplando o departamento de TI da Dispater, com o suporte da companhia de processamento de dados daquela esfera de governo;

- Desenvolvimento da parte do sistema referente à Salus pelo departamento de TI da Dispater, com o suporte da companhia de processamento de dados daquela esfera de governo. O desenvolvimento da parte do projeto referente à área de negócio da Dispater continuaria sob a responsabilidade do consórcio Janus;

- Manutenção do consórcio Janus como responsável por todo o projeto.

Ao explicar por que foi tão difícil cancelar o projeto, um dos entrevistados disse:

"A preocupação de não causar um rompimento de contrato muito doloroso é que levou, foi levando esse projeto adiante."

A contratação da Minerva ocorreu em razão da necessidade dos administradores públicos de terem o aval de especialistas para endossar sua tomada de decisão. O diagnóstico fornecido pela consultoria deve servir de evidência no caso de uma auditoria pelo Tribunal de Contas daquela esfera de governo.

Entre as recomendações da consultoria Minerva, podemos destacar (MINERVA, 2012):

- No caso da aquisição de um pacote para atender às necessidades combinadas da Salus e Dispater:

○ Minimizar as divergências (gaps) funcionais;

- Evitar modificações do produto (customizações);

○ Gerenciamento de riscos rigoroso.

- No caso do desenvolvimento interno:

- Simplificar processos e requisitos antes do desenvolvimento;

- Gestão rigorosa de mudança de requisitos;

○ Gerenciamento de riscos rigoroso.

A consultoria Minerva (2012) também recomendou a reorganização do projeto como um programa composto de vários projetos. O PMI (2008, p. 9) define programa como "um grupo 
de projetos relacionados, gerenciados de modo coordenado para a obtenção de benefícios e controle que não estariam disponíveis se eles fossem gerenciados individualmente". Consequentemente, a recomendação da consultoria Minerva (2012) implica no aumento da camada de gestão do projeto para tratar melhor sua complexidade.

\subsection{Análise dos Fatores de Risco do Projeto Rainha Vermelha}

De maneira geral, os entrevistados explicaram as razões para o agravamento mediante justificativas relacionadas ao seu tamanho e complexidade, além de problemas relacionados à gestão do projeto:

"Eles [o consórcio Janus] acreditavam ter uma visão do todo, mas, infelizmente, o que eles achavam que era real não era. Quando eles viram a extensão do [nome da esfera de governo], o [nome da esfera de governo] era mais extenso que os outros entes públicos com os quais eles haviam trabalhado e, não só mais extenso, como também mais complexo. Haviam muitos detalhes que eles não tinham a menor ideia que aqui existiam, era um terreno cheio de pedras que eles pensaram que era um terreno fácil de ser perfurado."

"Ainda mais um projeto dessa dimensão, que, na época, talvez eu nem tivesse essa noção de tamanho do projeto, mas de importância com certeza eu sabia, porque eu sabia que era um projeto do [nome da esfera de governo]."

"Primeiro, a questão de planejamento, já esbarramos nesse problema. Nós não tivemos um planejamento que nos desse uma diretiva das etapas que nós tínhamos que cumprir, os prazos já previamente fixados. Então, vamos dizer assim, tudo ficou, de uma certa forma, largado, essa é a expressão, largado."

“É um projeto complexo que está sendo mal administrado na parte de gerenciamento."

Em relação à gestão do projeto, esse fator está fortemente relacionado aos problemas com o fornecedor, pois a gestão do projeto, ou seja, a responsabilidade pela elaboração dos planos e cronogramas, por exemplo, coube ao fornecedor. Alguns depoimentos explicam os problemas relacionados ao fornecedor: 


\begin{abstract}
“O que aconteceu no início? Não foi disponibilizada uma equipe grande por parte [do consórcio Janus], acho que, se eu não me engano, eram quatro ou cinco consultores só, nessa fase de conhecimento, e eles tocariam o levantamento de escopo."
\end{abstract}

"Primeiro fator que eu vejo como importante foi a questão de que a empresa não entende do nosso negócio. Então, o produto que ela tem a nos oferecer, ele não atende às nossas necessidades, tanto no aspecto tecnológico como também nos resultados que a gente... que nós já alcançamos e que a gente tem que expandir. Então, é nesse sentido que a gente... que cresce a nossa preocupação, que a gente acaba constatando que realmente a empresa não tem o know-how que nós esperávamos que ela tivesse.”

"Então a gente não tinha uma gerência de projetos. Quem na realidade, quem tinha que dar essas diretivas era a própria empresa. Ela que deveria começar a traçar as metas e os objetivos que nós deveríamos atingir."

Durante a descrição do caso, muitos itens relacionados ao escopo e à estabilização dos requisitos foram levantados, destacando-se principalmente os problemas relacionados ao excesso de customizações no sistema. Vários dos depoimentos já apresentados exemplificam os problemas relacionados ao escopo e à estabilização dos requisitos.

Em relação ao excesso de customizações, Moreno, Gobbo Jr. e Cavenaghi (2007) citaram esse problema no caso da implantação de um ERP em uma prefeitura municipal. Apesar de esses autores considerarem o excesso de customizações como um fator de risco importante, esse risco não é contemplado no modelo de Wallace e Keil (2004).

Além dos problemas já mencionados, vários outros fatores não descritos no modelo de Wallace e Keil (2004) foram citados pelos entrevistados, como, por exemplo:

- Desmotivação;

- Não acreditar na viabilidade do projeto;

- Falta de confiança;

- Atitudes defensivas por parte de todos os envolvidos;

- Falta de integração entre as equipes;

- Falta de autoridade para questionar as áreas de negócio;

- Ociosidade da área de negócio em razão do pequeno tamanho da equipe da consultoria;

- Problemas de governança. 
Os problemas de governança foram muito enfatizados em uma das entrevistas, cujo entrevistado possuía um embasamento mais técnico da área de TI. Os problemas de governança mencionados foram os seguintes:

- Falta de definições de papéis e responsabilidades claras no projeto;

- Falta de definição de uma estrutura organizacional no projeto;

- Falta de estrutura clara para tomada de decisão;

- Falta de um plano de escalação.

Em relação ao questionário respondido, os Quadros 55 e 56 apresentam os fatores de riscos consolidados, referentes ao quadrante do mandato do cliente da classificação de Keil et al. (1998).

Quadro 55: Riscos consolidados do mandato do cliente no projeto Rainha Vermelha

\begin{tabular}{|l|r|r|r|r|r|c|c|}
\hline \multicolumn{1}{|c|}{ Risco Consolidado } & \multicolumn{5}{|c|}{ Entrevistados } \\
\cline { 2 - 6 } & $\mathbf{1}$ & $\mathbf{2}$ & $\mathbf{3}$ & $\mathbf{4}$ & $\mathbf{5}$ & $\mathbf{6}$ & $\mathbf{7}$ \\
\hline $\begin{array}{l}\text { Falta de participação do usuário (consolidado - valores } \\
\text { médios). }\end{array}$ & 5,3 & 2,7 & 5,3 & 1,0 & 3,3 & 1,0 & 1,0 \\
\hline Falta de participação do usuário. & 6,0 & 5,0 & 6,0 & 1,0 & 2,0 & 1,0 & 1,0 \\
\hline Usuários não comprometidos com o projeto. & 6,0 & 2,0 & 4,0 & 1,0 & 4,0 & 1,0 & 1,0 \\
\hline Falta de cooperação dos usuários. & 4,0 & 1,0 & 6,0 & 1,0 & 4,0 & 1,0 & 1,0 \\
\hline $\begin{array}{l}\text { Usuários com atitudes negativas em relação ao projeto } \\
\text { (consolidado - valores médios). }\end{array}$ & 6,3 & 3,0 & 5,3 & 2,3 & 4,0 & 1,0 & 5,0 \\
\hline Usuários com atitudes negativas em relação ao projeto. & 6,0 & 3,0 & 6,0 & 3,0 & 5,0 & 1,0 & 5,0 \\
\hline Usuários resistentes a mudanças. & 7,0 & 4,0 & 4,0 & 3,0 & 5,0 & 1,0 & 4,0 \\
\hline Conflitos entre os usuários. & 6,0 & 2,0 & 6,0 & 1,0 & 2,0 & 1,0 & 6,0 \\
\hline Falta de apoio da alta direção ao projeto. & 4,0 & 1,0 & 7,0 & 1,0 & 2,0 & 1,0 & 2,0 \\
\hline $\begin{array}{l}\text { Falta de comprometimento ou pouco comprometimento da } \\
\text { organização com o projeto. }\end{array}$ & 4,0 & 1,0 & 4,0 & 1,0 & 5,0 & 2,0 & 3,0 \\
\hline
\end{tabular}


Quadro 56: Médias dos riscos consolidados do mandato do cliente no projeto Rainha Vermelha

\begin{tabular}{|c|c|c|c|}
\hline Risco Consolidado & Média & $\begin{array}{l}\text { Maior } \\
\text { Valor }\end{array}$ & $\begin{array}{c}\text { Menor } \\
\text { Valor }\end{array}$ \\
\hline $\begin{array}{l}\text { Falta de participação do usuário (consolidado - valores } \\
\text { médios). }\end{array}$ & 2,8 & 5,3 & 1,0 \\
\hline Falta de participação do usuário. & 3,1 & 6,0 & 1,0 \\
\hline Usuários não comprometidos com o projeto. & 2,7 & 6,0 & 1,0 \\
\hline Falta de cooperação dos usuários. & 2,6 & 6,0 & 1,0 \\
\hline $\begin{array}{l}\text { Usuários com atitudes negativas em relação ao projeto } \\
\text { (consolidado - valores médios). }\end{array}$ & 3,9 & 6,3 & 1,0 \\
\hline $\begin{array}{l}\text { Usuários com atitudes negativas em relação ao } \\
\text { projeto. }\end{array}$ & 4,1 & 6,0 & 1,0 \\
\hline Usuários resistentes a mudanças. & 4,0 & 7,0 & 1,0 \\
\hline Conflitos entre os usuários. & 3,4 & 6,0 & 1,0 \\
\hline Falta de apoio da alta direção ao projeto. & 2,6 & 7,0 & 1,0 \\
\hline $\begin{array}{l}\text { Falta de comprometimento ou pouco } \\
\text { comprometimento da organização com o projeto. }\end{array}$ & 2,9 & 5,0 & 1,0 \\
\hline
\end{tabular}

Fonte: elaborado pelo autor

Os dados obtidos por meio do questionário estão alinhados com as respostas obtidas por meio das entrevistas. O fator de risco com maior pontuação está relacionado a usuários com atitudes negativas em relação ao projeto. Esse fator também foi citado por quatro fontes diferentes nas entrevistas. Os depoimentos mais relevantes foram os seguintes:

“No início, a divisão desses grupos [várias áreas de negócio e várias ares de TI] era muito nítida e muito prejudicial ao projeto."

"Então existia uma... Vamos dizer... Desconfiança mútua. Assim, cada grupo era muito fechado no seu umbigo, vamos dizer assim, não tinha uma integração forte. Na verdade, a meu ver, o que causou isso? Um prazo muito curto e a desconfiança do produto. Como nasceu já com essa expectativa de não dar certo, um projeto num prazo tão curto, a preocupação das equipes foi, 'não vamos deixar brecha pra não jogar a culpa pra mim'."

Em relação aos riscos de escopo e requisitos da classificação de Keil et al. (1998), os Quadros 57 e 58 apresentam os fatores consolidados de acordo com o modelo de referência. 
Quadro 57: Riscos consolidados de escopo e requisitos no projeto Rainha Vermelha

\begin{tabular}{|c|c|c|c|c|c|c|c|}
\hline \multirow{2}{*}{ Risco Consolidado } & \multicolumn{7}{|c|}{ Entrevistados } \\
\hline & 1 & 2 & 3 & 4 & 5 & 6 & 7 \\
\hline $\begin{array}{l}\text { Dificuldades no detalhamento e estabilização dos requisitos } \\
\text { (consolidado - valores médios). }\end{array}$ & 5,7 & 5,0 & 6,3 & 3,5 & 3,7 & 2,8 & 2,5 \\
\hline Requisitos de sistema que mudam frequentemente; & 7,0 & 7,0 & 5,0 & 4,0 & 6,0 & 4,0 & 6,0 \\
\hline $\begin{array}{l}\text { Requisitos do sistema } \\
\text { inadequada; }\end{array}$ & 7,0 & 7,0 & 7,0 & 2,0 & 4,0 & 2,0 & 1,0 \\
\hline Requisitos de sistema obscuros (não claros); & 7,0 & 7,0 & 7,0 & 2,0 & 4,0 & 2,0 & 1,0 \\
\hline Requisitos de sistema incorretos; & 4,0 & 4,0 & 7,0 & 2,0 & 4,0 & 2,0 & 1,0 \\
\hline Requisitos de sistema conflitantes; & 5,0 & 4,0 & 5,0 & 4,0 & 2,0 & 2,0 & 1,0 \\
\hline Dificuldade em definir entradas e saídas do sistema. & 4,0 & 1,0 & 7,0 & 7,0 & 2,0 & 5,0 & 5,0 \\
\hline $\begin{array}{l}\text { Problemas no direcionamento do projeto (consolidado - valores } \\
\text { médios). }\end{array}$ & 6,0 & 4,3 & 6,3 & 3,7 & 5,7 & 3,7 & 3,7 \\
\hline Critério de sucesso do projeto indefinido; & 7,0 & 5,0 & 7,0 & 6,0 & 7,0 & 3,0 & 7,0 \\
\hline Metas do projeto mal definidas; & 4,0 & 1,0 & 7,0 & 2,0 & 7,0 & 4,0 & 1,0 \\
\hline $\begin{array}{l}\text { Objetivos e escopo do projeto que mudam } \\
\text { frequentemente. }\end{array}$ & 7,0 & 7,0 & 5,0 & 3,0 & 3,0 & 4,0 & 3,0 \\
\hline $\begin{array}{l}\text { Falta de entendimento pelos usuários sobre as capacidades e } \\
\text { limitações do sistema. }\end{array}$ & 6,0 & 3,0 & 7,0 & 7,0 & 7,0 & 6,0 & 5,0 \\
\hline
\end{tabular}

Fonte: elaborado pelo autor

Quadro 58: Médias dos riscos consolidados de escopo e requisitos no projeto Rainha Vermelha

\begin{tabular}{|c|c|c|c|}
\hline Risco Consolidado & Média & $\begin{array}{l}\text { Maior } \\
\text { Valor }\end{array}$ & $\begin{array}{l}\text { Menor } \\
\text { Valor }\end{array}$ \\
\hline $\begin{array}{l}\text { Dificuldades no detalhamento e estabilização dos requisitos } \\
\text { (consolidado - valores médios). }\end{array}$ & 4,2 & 6,3 & 2,5 \\
\hline Requisitos de sistema que mudam frequentemente; & 5,6 & 7,0 & 4,0 \\
\hline $\begin{array}{l}\text { Requisitos do sistema identificados de forma } \\
\text { inadequada; }\end{array}$ & 4,3 & 7,0 & 1,0 \\
\hline Requisitos de sistema obscuros (não claros); & 4,3 & 7,0 & 1,0 \\
\hline Requisitos de sistema incorretos; & 3,4 & 7,0 & 1,0 \\
\hline Requisitos de sistema conflitantes; & 3,3 & 5,0 & 1,0 \\
\hline Dificuldade em definir entradas e saídas do sistema. & 4,4 & 7,0 & 1,0 \\
\hline $\begin{array}{l}\text { Problemas no direcionamento do projeto (consolidado - } \\
\text { valores médios). }\end{array}$ & 4,8 & 6,3 & 3,7 \\
\hline Critério de sucesso do projeto indefinido; & 6,0 & 7,0 & 3,0 \\
\hline Metas do projeto mal definidas; & 3,7 & 7,0 & 1,0 \\
\hline $\begin{array}{l}\text { Objetivos e escopo do projeto que mudam } \\
\text { frequentemente. }\end{array}$ & 4,6 & 7,0 & 3,0 \\
\hline $\begin{array}{l}\text { Falta de entendimento pelos usuários sobre as capacidades e } \\
\text { limitações do sistema. }\end{array}$ & 5,9 & 7,0 & 3,0 \\
\hline
\end{tabular}

Fonte: elaborado pelo autor

Podemos concluir, a partir dos questionários, que existiram problemas nos três fatores de risco que compõem os riscos de escopo e requisitos. Os problemas relacionados a escopo e requisitos foram corroborados também pelas entrevistas e também pelos documentos, se levarmos em conta a quantidade de versões assinadas da especificação do primeiro módulo do 
sistema. Como já foi mencionado anteriormente, foram emitidas e assinadas oito versões diferentes do documento de especificação do primeiro módulo, no prazo de dez meses.

Quanto aos riscos de execução da classificação de Keil et al. (1998), os Quadros 59 e 60 apresentam os fatores consolidados segundo o modelo de referência. 
Quadro 59: Riscos consolidados de execução no projeto Rainha Vermelha

\begin{tabular}{|c|c|c|c|c|c|c|c|}
\hline \multirow{2}{*}{ Risco Consolidado } & \multicolumn{7}{|c|}{ Entrevistados } \\
\hline & 1 & 2 & 3 & 4 & 5 & 6 & 7 \\
\hline Dificuldades técnicas (consolidado - valores médios). & 4,0 & 3,9 & 1,3 & 4,4 & 3,9 & 4,6 & 1,4 \\
\hline Membros da equipe inexperientes. & 3,0 & 5,0 & 1,0 & 6,0 & 6,0 & 2,0 & 1,0 \\
\hline $\begin{array}{l}\text { Equipe de desenvolvimento sem familiaridade com as } \\
\text { ferramentas de desenvolvimento. }\end{array}$ & 3,0 & 3,0 & 1,0 & 3,0 & 2,0 & 6,0 & 1,0 \\
\hline $\begin{array}{l}\text { Equipe de desenvolvimento sem familiaridade com as } \\
\text { tarefas a serem automatizadas. }\end{array}$ & 4,0 & 5,0 & 1,0 & 6,0 & 7,0 & 6,0 & 1,0 \\
\hline $\begin{array}{l}\text { Faltam nos membros da equipe as habilidades } \\
\text { especializadas requeridas pelo projeto. }\end{array}$ & 3,0 & 5,0 & 2,0 & 4,0 & 6,0 & 6,0 & 2,0 \\
\hline O projeto envolve o uso de uma tecnologia nova. & 6,0 & 5,0 & 1,0 & 2,0 & 2,0 & 3,0 & 1,0 \\
\hline Tecnologia imatura. & 3,0 & 2,0 & 1,0 & 6,0 & 2,0 & 7,0 & 1,0 \\
\hline $\begin{array}{l}\text { O projeto envolve o uso de uma tecnologia que não foi } \\
\text { usada em projetos anteriores. }\end{array}$ & 6,0 & 2,0 & 2,0 & 4,0 & 2,0 & 2,0 & 3,0 \\
\hline $\begin{array}{l}\text { Complexidade do sistema e organizacional (consolidado - } \\
\text { valores médios). }\end{array}$ & 4,8 & 6,6 & 5,2 & 7,0 & 6,6 & 6,8 & 7,0 \\
\hline Alto nível de complexidade técnica. & 6,0 & 6,0 & 3,0 & 7,0 & 6,0 & 6,0 & 7,0 \\
\hline A tarefa a ser automatizada é altamente complexa. & 3,0 & 6,0 & 2,0 & 7,0 & 7,0 & 7,0 & 7,0 \\
\hline $\begin{array}{l}\text { O projeto afeta um grande número de unidades e/ou } \\
\text { departamentos dos usuários. }\end{array}$ & 3,0 & 7,0 & 7,0 & 7,0 & 7,0 & 7,0 & 7,0 \\
\hline $\begin{array}{l}\text { Ser um dos maiores projetos já empreendidos pela } \\
\text { organização. }\end{array}$ & 5,0 & 7,0 & 7,0 & 7,0 & 7,0 & 7,0 & 7,0 \\
\hline $\begin{array}{l}\text { Necessidade de integração com um grande número de } \\
\text { sistemas. }\end{array}$ & 7,0 & 7,0 & 7,0 & 7,0 & 6,0 & 7,0 & 7,0 \\
\hline Problemas na gestão do projeto (consolidado - valores médios). & 4,8 & 5,0 & 6,0 & 6,4 & 4,6 & 6,5 & 6,1 \\
\hline $\begin{array}{l}\text { Falta de uma metodologia efetiva de gerenciamento de } \\
\text { projetos. }\end{array}$ & 6,0 & 7,0 & 7,0 & 7,0 & 3,0 & 7,0 & 7,0 \\
\hline Estimativa inadequada do cronograma do projeto. & 7,0 & 7,0 & 7,0 & 7,0 & 7,0 & 7,0 & 7,0 \\
\hline Prazo político. & 7,0 & 7,0 & 7,0 & 7,0 & 7,0 & 7,0 & 7,0 \\
\hline $\begin{array}{l}\text { Progresso do projeto não monitorado suficientemente de } \\
\text { perto. }\end{array}$ & 3,0 & 6,0 & 7,0 & 7,0 & 6,0 & 7,0 & 7,0 \\
\hline Planejamento precário do projeto. & 6,0 & 6,0 & 7,0 & 7,0 & 5,0 & 7,0 & 7,0 \\
\hline Marcos do projeto não definidos de forma clara. & 7,0 & 2,0 & 6,0 & 7,0 & 3,0 & 7,0 & 7,0 \\
\hline Estimativa inadequada do orçamento do projeto. & 2,0 & 2,0 & 7,0 & 1,0 & 2,0 & 4,0 & 2,0 \\
\hline Gerente do projeto não efetivo. & 3,0 & 4,0 & 5,0 & 7,0 & 5,0 & 7,0 & 5,0 \\
\hline Gerente do projeto inexperiente. & 3,0 & 4,0 & 2,0 & 7,0 & 2,0 & 7,0 & 7,0 \\
\hline Comunicação não efetiva. & 4,0 & 5,0 & 6,0 & 7,0 & 6,0 & 5,0 & 5,0 \\
\hline Problemas na gestão da equipe (consolidado - valores médios). & 4,1 & 4,4 & 3,1 & 6,3 & 3,1 & 3,1 & 2,9 \\
\hline $\begin{array}{l}\text { Membros da equipe de desenvolvimento treinados de } \\
\text { forma inadequada. }\end{array}$ & 5,0 & 4,0 & 2,0 & 6,0 & 2,0 & 7,0 & 1,0 \\
\hline $\begin{array}{l}\text { Falta de comprometimento com o projeto por parte dos } \\
\text { membros da equipe. }\end{array}$ & 3,0 & 5,0 & 3,0 & 6,0 & 2,0 & 1,0 & 1,0 \\
\hline Conflitos frequentes na equipe de desenvolvimento. & 4,0 & 4,0 & 3,0 & 6,0 & 2,0 & 2,0 & 4,0 \\
\hline Rotatividade frequente dos membros da equipe. & 3,0 & 3,0 & 1,0 & 6,0 & 4,0 & 1,0 & 3,0 \\
\hline Atitudes negativas da equipe de desenvolvimento. & 3,0 & 3,0 & 4,0 & 6,0 & 3,0 & 2,0 & 4,0 \\
\hline $\begin{array}{l}\text { Faltam habilidades de liderança do projeto nas pessoas } \\
\text { envolvidas. }\end{array}$ & 6,0 & 6,0 & 2,0 & 7,0 & 4,0 & 2,0 & 6,0 \\
\hline Estimativa inadequada dos recursos necessários. & 5,0 & 6,0 & 7,0 & 7,0 & 5,0 & 7,0 & 1,0 \\
\hline
\end{tabular}

Fonte: elaborado pelo autor 
Quadro 60: Médias dos riscos consolidados de execução no projeto Rainha Vermelha

\begin{tabular}{|c|c|c|c|}
\hline Risco Consolidado & Média & $\begin{array}{l}\text { Maior } \\
\text { Valor }\end{array}$ & $\begin{array}{l}\text { Menor } \\
\text { Valor }\end{array}$ \\
\hline Dificuldades técnicas (consolidado - valores médios). & 3,3 & 4,6 & 1,3 \\
\hline Membros da equipe inexperientes. & 3,4 & 6,0 & 1,0 \\
\hline $\begin{array}{l}\text { Equipe de desenvolvimento sem familiaridade com as } \\
\text { ferramentas de desenvolvimento. }\end{array}$ & 2,7 & 6,0 & 1,0 \\
\hline $\begin{array}{l}\text { Equipe de desenvolvimento sem familiaridade com as } \\
\text { tarefas a serem automatizadas. }\end{array}$ & 4,3 & 7,0 & 1,0 \\
\hline $\begin{array}{l}\text { Faltam nos membros da equipe as habilidades } \\
\text { especializadas requeridas pelo projeto. }\end{array}$ & 4,0 & 6,0 & 2,0 \\
\hline O projeto envolve o uso de uma tecnologia nova. & 2,9 & 6,0 & 1,0 \\
\hline Tecnologia imatura. & 3,1 & 7,0 & 1,0 \\
\hline $\begin{array}{l}\text { O projeto envolve o uso de uma tecnologia que não foi } \\
\text { usada em projetos anteriores. }\end{array}$ & 3,0 & 6,0 & 2,0 \\
\hline $\begin{array}{l}\text { Complexidade do sistema e organizacional (consolidado - } \\
\text { valores médios). }\end{array}$ & 6,3 & 7,0 & 4,8 \\
\hline Alto nível de complexidade técnica. & 5,9 & 7,0 & 3,0 \\
\hline A tarefa a ser automatizada é altamente complexa. & 5,6 & 7,0 & 2,0 \\
\hline $\begin{array}{l}\text { O projeto afeta um grande número de unidades e/ou } \\
\text { departamentos dos usuários. }\end{array}$ & 6,4 & 7,0 & 3,0 \\
\hline $\begin{array}{l}\text { Ser um dos maiores projetos já empreendidos pela } \\
\text { organização. }\end{array}$ & 6,7 & 7,0 & 5,0 \\
\hline $\begin{array}{l}\text { Necessidade de integração com um grande número de } \\
\text { sistemas. }\end{array}$ & 6,9 & 7,0 & 6,0 \\
\hline $\begin{array}{l}\text { Problemas na gestão do projeto (consolidado - valores } \\
\text { médios). }\end{array}$ & 5,6 & 6,5 & 4,6 \\
\hline $\begin{array}{l}\text { Falta de uma metodologia efetiva de gerenciamento de } \\
\text { projetos. }\end{array}$ & 6,3 & 7,0 & 3,0 \\
\hline Estimativa inadequada do cronograma do projeto. & 7,0 & 7,0 & 7,0 \\
\hline Prazo político. & 7,0 & 7,0 & 7,0 \\
\hline $\begin{array}{l}\text { Progresso do projeto não monitorado suficientemente } \\
\text { de perto. }\end{array}$ & 6,1 & 7,0 & 3,0 \\
\hline Planejamento precário do projeto. & 6,4 & 7,0 & 5,0 \\
\hline Marcos do projeto não definidos de forma clara. & 5,6 & 7,0 & 2,0 \\
\hline Estimativa inadequada do orçamento do projeto. & 2,9 & 7,0 & 1,0 \\
\hline Gerente do projeto não efetivo. & 5,1 & 7,0 & 3,0 \\
\hline Gerente do projeto inexperiente. & 4,6 & 7,0 & 2,0 \\
\hline Comunicação não efetiva. & 5,4 & 7,0 & 4,0 \\
\hline $\begin{array}{l}\text { Problemas na gestão da equipe (consolidado - valores } \\
\text { médios). }\end{array}$ & 3,9 & 6,3 & 3,1 \\
\hline $\begin{array}{l}\text { Membros da equipe de desenvolvimento treinados de } \\
\text { forma inadequada. }\end{array}$ & 3,9 & 7,0 & 1,0 \\
\hline $\begin{array}{l}\text { Falta de comprometimento com o projeto por parte dos } \\
\text { membros da equipe. }\end{array}$ & 3,0 & 6,0 & 1,0 \\
\hline Conflitos frequentes na equipe de desenvolvimento. & 3,6 & 6,0 & 2,0 \\
\hline Rotatividade frequente dos membros da equipe. & 3,0 & 6,0 & 1,0 \\
\hline Atitudes negativas da equipe de desenvolvimento. & 3,6 & 6,0 & 2,0 \\
\hline $\begin{array}{l}\text { Faltam habilidades de liderança do projeto nas pessoas } \\
\text { envolvidas. }\end{array}$ & 4,7 & 7,0 & 2,0 \\
\hline Estimativa inadequada dos recursos necessários. & 5,4 & 7,0 & 1,0 \\
\hline
\end{tabular}

Fonte: elaborado pelo autor 
Quanto aos riscos de complexidade do sistema e organizacional e problemas na gestão do projeto, os dados obtidos por meio do questionário estão alinhados com as entrevistas. Existe uma convergência entre essas fontes de evidência quanto ao fato de esses fatores terem sido relevantes, na evolução do projeto Rainha Vermelha, para a condição de agravamento.

Dentre os riscos relacionados à gestão da equipe, a falta de conhecimento do sistema por pessoas da equipe de levantamento de requisitos do consórcio Janus recebeu algumas críticas durante as entrevistas. Em relação ao questionário, tanto os riscos relacionados às dificuldades técnicas quanto os riscos relacionados à gestão da equipe tiveram alta pontuação, apesar de apresentarem uma pontuação menor do que a dos outros dois fatores de risco de execução.

Finalmente, os Quadros 61 e 62 apresentam os fatores de risco consolidados, referentes ao quadrante do ambiente da classificação de Keil et al. (1998).

Quadro 61: Riscos consolidados de ambiente no projeto Rainha Vermelha

\begin{tabular}{|l|r|r|r|r|r|r|c|}
\hline Risco Consolidado & \multicolumn{5}{|c|}{ Entrevistados } \\
\cline { 2 - 6 } & $\mathbf{1}$ & $\mathbf{2}$ & $\mathbf{3}$ & $\mathbf{4}$ & $\mathbf{5}$ & $\mathbf{6}$ & $\mathbf{7}$ \\
\hline $\begin{array}{l}\text { Ambiente organizacional instável (consolidado - valores } \\
\text { médios). }\end{array}$ & 5,0 & 2,3 & 2,8 & 1,0 & 1,5 & 1,5 & 1,3 \\
\hline $\begin{array}{l}\text { Recursos deslocados do projeto em razão de mudanças } \\
\text { nas prioridades da organização. }\end{array}$ & 3,0 & 3,0 & 2,0 & 1,0 & 1,0 & 1,0 & 1,0 \\
\hline Ambiente organizacional instável. & 5,0 & 1,0 & 2,0 & 1,0 & 2,0 & 1,0 & 2,0 \\
\hline Mudança na gestão organizacional durante o projeto. & 6,0 & 4,0 & 5,0 & 1,0 & 1,0 & 3,0 & 1,0 \\
\hline $\begin{array}{l}\text { Organização passando por uma reestruturação durante o } \\
\text { projeto. }\end{array}$ & 6,0 & 1,0 & 2,0 & 1,0 & 2,0 & 1,0 & 1,0 \\
\hline Políticas corporativas com efeitos negativos no projeto. & 4,0 & 3,0 & 5,0 & 1,0 & 2,0 & 1,0 & 3,0 \\
\hline Estrutura ineficiente para a tomada de decisão. & 7,0 & 1,0 & 5,0 & 2,0 & 2,0 & 1,0 & 2,0 \\
\hline Problemas com fornecedores (consolidado - valores médios). & 4,5 & 4,5 & 4,0 & 4,5 & 5,0 & 7,0 & 3,5 \\
\hline $\begin{array}{l}\text { Dependência de um fornecedor externo. } \\
\text { Muitos fornecedores externos envolvidos no } \\
\text { desenvolvimento do projeto. }\end{array}$ & 2,0 & 5,0 & 4,0 & 7,0 & 6,0 & 7,0 & 6,0 \\
\hline & 4,0 & 2,0 & 4,0 & 7,0 & 1,0 \\
\hline
\end{tabular}


Quadro 62: Médias dos riscos consolidados de ambiente no projeto Rainha Vermelha

\begin{tabular}{|c|c|c|c|}
\hline Risco Consolidado & Média & $\begin{array}{l}\text { Maior } \\
\text { Valor }\end{array}$ & $\begin{array}{l}\text { Menor } \\
\text { Valor }\end{array}$ \\
\hline $\begin{array}{l}\text { Ambiente organizacional instável (consolidado - valores } \\
\text { médios). }\end{array}$ & 2,2 & 5,0 & 1,0 \\
\hline $\begin{array}{l}\text { Recursos deslocados do projeto em razão de mudanças } \\
\text { nas prioridades da organização. }\end{array}$ & 1,7 & 3,0 & 1,0 \\
\hline Ambiente organizacional instável. & 2,0 & 5,0 & 1,0 \\
\hline Mudança na gestão organizacional durante o projeto. & 3,0 & 6,0 & 1,0 \\
\hline $\begin{array}{l}\text { Organização passando por uma reestruturação durante } \\
\text { o projeto. }\end{array}$ & 2,0 & 6,0 & 1,0 \\
\hline Políticas corporativas com efeitos negativos no projeto. & 2,7 & 5,0 & 1,0 \\
\hline Estrutura ineficiente para a tomada de decisão. & 2,9 & 7,0 & 1,0 \\
\hline Problemas com fornecedores (consolidado - valores médios). & 4,7 & 7,0 & 3,5 \\
\hline Dependência de um fornecedor externo. & 6,0 & 7,0 & 4,0 \\
\hline $\begin{array}{lccc}\text { Muitos fornecedores externos } & \text { envolvidos } & \text { no } \\
\text { desenvolvimento do projeto. } & & \\
\end{array}$ & 3,4 & 7,0 & 1,0 \\
\hline
\end{tabular}

Fonte: elaborado pelo autor

Novamente os resultados do questionário estão alinhados com as entrevistas no caso dos problemas com fornecedores, que tiveram uma alta pontuação. Essa pontuação é ainda mais alta se considerarmos apenas o fator "dependência de um fornecedor externo". Neste caso, a média é 6,0. O problema com o fornecedor está relacionado tanto com a gestão do projeto quanto com as características técnicas de sua equipe.

Adicionalmente, o risco de uma estrutura ineficiente para a tomada de decisão teve uma pontuação média. Além disso, assim como nas entrevistas, a equipe mais técnica e as equipes de negócio chegaram a conclusões diferentes a respeito da contribuição desse fator para o agravamento do projeto. Os técnicos em gestão de projetos avaliaram que esse risco foi relevante, enquanto os especialistas de outras áreas não consideraram esse fator como importante no agravamento do projeto.

Os outros dois riscos, além da pontuação média-baixa na consolidação das respostas ao questionário, também não foram citados nas entrevistas como fatores relevantes para o agravamento do projeto.

Complementarmente à análise dos riscos de acordo com o modelo de referência, é importante apresentar a análise referente aos modelos alternativos propostos. Os Quadros 63 e 64 apresentam a avaliação dos riscos associados a problemas relacionados à Governança de TI no projeto Rainha Vermelha. 
Quadro 63: Riscos de Governança de TI no projeto Rainha Vermelha

\begin{tabular}{|l|c|c|c|c|c|c|c|}
\hline \multicolumn{1}{|c|}{ Risco } & \multicolumn{5}{c|}{ Entrevistados } \\
\cline { 2 - 7 } & $\mathbf{1}$ & $\mathbf{2}$ & $\mathbf{3}$ & $\mathbf{4}$ & $\mathbf{5}$ & $\mathbf{6}$ & $\mathbf{7}$ \\
\hline Falta de participação dos usuários. & 6,0 & 5,0 & 6,0 & 1,0 & 2,0 & 1,0 & 1,0 \\
\hline Conflitos entre os usuários. & 6,0 & 2,0 & 6,0 & 1,0 & 2,0 & 1,0 & 6,0 \\
\hline Falta de apoio da alta direção ao projeto. & 4,0 & 1,0 & 7,0 & 1,0 & 2,0 & 1,0 & 2,0 \\
\hline $\begin{array}{l}\text { Falta de comprometimento ou pouco comprometimento da } \\
\text { organização com o projeto. }\end{array}$ & 4,0 & 1,0 & 4,0 & 1,0 & 5,0 & 2,0 & 3,0 \\
\hline $\begin{array}{l}\text { O projeto afeta um grande número de unidades e/ou } \\
\text { departamentos dos usuários. }\end{array}$ & 3,0 & 7,0 & 7,0 & 7,0 & 7,0 & 7,0 & 7,0 \\
\hline Falta de uma metodologia efetiva de gerenciamento de projetos. & 6,0 & 7,0 & 7,0 & 7,0 & 3,0 & 7,0 & 7,0 \\
\hline Estrutura ineficiente para a tomada de decisão. & 7,0 & 1,0 & 5,0 & 2,0 & 2,0 & 1,0 & 2,0 \\
\hline Mudança na gestão organizacional durante o projeto. & 6,0 & 4,0 & 5,0 & 1,0 & 1,0 & 3,0 & 1,0 \\
\hline Políticas corporativas com efeitos negativos no projeto. & 4,0 & 3,0 & 5,0 & 1,0 & 2,0 & 1,0 & 3,0 \\
\hline Ambiente organizacional instável. & 5,0 & 1,0 & 2,0 & 1,0 & 2,0 & 1,0 & 2,0 \\
\hline $\begin{array}{l}\text { Organização passando por uma reestruturação durante o } \\
\text { projeto. }\end{array}$ & 6,0 & 1,0 & 2,0 & 1,0 & 2,0 & 1,0 & 1,0 \\
\hline
\end{tabular}

Fonte: elaborado pelo autor

Quadro 64: Médias dos riscos de Governança de TI no projeto Rainha Vermelha

\begin{tabular}{|l|r|r|r|}
\hline \multicolumn{1}{|c|}{ Risco } & Média & \multicolumn{1}{|c|}{$\begin{array}{c}\text { Maior } \\
\text { Valor }\end{array}$} & \multicolumn{1}{|c|}{$\begin{array}{c}\text { Menor } \\
\text { Valor }\end{array}$} \\
\hline Falta de participação dos usuários. & 3,1 & 6,0 & 1,0 \\
\hline Conflitos entre os usuários. & 3,4 & 6,0 & 1,0 \\
\hline Falta de apoio da alta direção ao projeto. & 2,6 & 7,0 & 1,0 \\
\hline $\begin{array}{l}\text { Falta de comprometimento ou pouco comprometimento da } \\
\text { organização com o projeto. }\end{array}$ & 2,9 & 5,0 & 1,0 \\
\hline $\begin{array}{l}\text { O projeto afeta um grande número de unidades e/ou } \\
\text { departamentos dos usuários. }\end{array}$ & 6,4 & 7,0 & 3,0 \\
\hline $\begin{array}{l}\text { Falta de uma metodologia efetiva de gerenciamento de } \\
\text { projetos. }\end{array}$ & 6,3 & 7,0 & 3,0 \\
\hline Estrutura ineficiente para a tomada de decisão. & 2,9 & 7,0 & 1,0 \\
\hline Mudança na gestão organizacional durante o projeto. & 2,0 & 6,0 & 1,0 \\
\hline Políticas corporativas com efeitos negativos no projeto. & 2,0 & 5,0 & 1,0 \\
\hline Ambiente organizacional instável. & 2,0 & 6,0 & 1,0 \\
\hline $\begin{array}{l}\text { Organização passando por uma reestruturação durante o } \\
\text { projeto. }\end{array}$ & & 1,0 \\
\hline
\end{tabular}

Fonte: elaborado pelo autor

Dentre os riscos de Governança de TI, os riscos com pontuação acima de 4,0 foram justamente aqueles relacionados à complexidade e ao uso de metodologia de gerenciamento de projetos, que fazem parte do modelo de referência. Consequentemente, o agrupamento dos riscos por esse critério apresentou mais valores baixos (abaixo de 4,0) do que valores altos (acima de 4,0), com uma média de 3,4.

Os Quadros 65 e 66 apresentam os elementos relacionados à complexidade estrutural do modelo de Xia e Lee (2004). 
Quadro 65: Riscos de complexidade estrutural do modelo de Xia e Lee no projeto Rainha Vermelha

\begin{tabular}{|l|c|c|c|c|c|c|c|}
\hline \multicolumn{1}{|c|}{ Risco } & \multicolumn{5}{c|}{ Entrevistados } \\
\cline { 2 - 7 } & $\mathbf{1}$ & $\mathbf{2}$ & $\mathbf{3}$ & $\mathbf{4}$ & $\mathbf{5}$ & $\mathbf{6}$ & $\mathbf{7}$ \\
\hline Falta de cooperação dos usuários. & 4,0 & 1,0 & 6,0 & 1,0 & 4,0 & 1,0 & 1,0 \\
\hline Estimativa inadequada dos recursos necessários; & 5,0 & 6,0 & 7,0 & 7,0 & 5,0 & 7,0 & 1,0 \\
\hline $\begin{array}{l}\text { Recursos deslocados do projeto em razão de mudanças nas } \\
\text { prioridades da organização. }\end{array}$ & 3,0 & 3,0 & 2,0 & 1,0 & 1,0 & 1,0 & 1,0 \\
\hline $\begin{array}{l}\text { Faltam nos membros da equipe as habilidades especializadas } \\
\text { requeridas pelo projeto. }\end{array}$ & 3,0 & 5,0 & 2,0 & 4,0 & 6,0 & 6,0 & 2,0 \\
\hline Falta de apoio da alta direção ao projeto. & 4,0 & 1,0 & 7,0 & 1,0 & 2,0 & 1,0 & 2,0 \\
\hline
\end{tabular}

Fonte: elaborado pelo autor

Quadro 66: Médias dos riscos de complexidade estrutural do modelo de Xia e Lee no projeto Rainha Vermelha

\begin{tabular}{|l|r|r|r|}
\hline \multicolumn{1}{|c|}{ Risco } & \multicolumn{1}{|c|}{ Média } & \multicolumn{1}{|c|}{$\begin{array}{c}\text { Maior } \\
\text { Valor }\end{array}$} & \multicolumn{1}{c|}{$\begin{array}{c}\text { Menor } \\
\text { Valor }\end{array}$} \\
\hline Falta de cooperação dos usuários. & 2,6 & 6,0 & 1,0 \\
\hline Estimativa inadequada dos recursos necessários; & 6,0 & 7,0 & 1,0 \\
\hline $\begin{array}{l}\text { Recursos deslocados do projeto em razão de mudanças nas } \\
\text { prioridades da organização. }\end{array}$ & 2,0 & 3,0 & 1,0 \\
\hline $\begin{array}{l}\text { Faltam nos membros da equipe as habilidades especializadas } \\
\text { requeridas pelo projeto. }\end{array}$ & 4,0 & 6,0 & 2,0 \\
\hline Falta de apoio da alta direção ao projeto. & 3,0 & 7,0 & 1,0 \\
\hline
\end{tabular}

Fonte: elaborado pelo autor

O agrupamento dos riscos pelo critério de complexidade estrutural do modelo de Xia e Lee (2004) apresentou mais valores baixos (abaixo de 4,0) do que valores altos (acima de 4,0), com uma média de 3,5.

Nos fatores de risco de Xia e Lee (2004), dois fatores se destacam com avaliação média acima ou igual a 4,0 :

- Estimativa inadequada dos recursos necessários;

- Faltam nos membros da equipe as habilidades especializadas requeridas pelo projeto.

\subsection{Aderência dos Resultados às Teorias}

O projeto Rainha Vermelha enfrentou a situação de agravamento pelo menos até o momento de sua paralisação de fato, em dezembro de 2011. Apesar de a parte da reorientação referente ao departamento de TI da Dispater focar na redução da complexidade, ainda não há evidências suficientes de que esse redirecionamento foi bem-sucedido. Considerando que ainda não se pode concluir que a reorientação desse projeto foi bem-sucedida, e levando em 
conta os dados coletados no projeto Rainha Vermelha e as proposições desenvolvidas no capítulo 3, pode-se desenvolver as seguintes conclusões:

Em relação à primeira proposição:

P1: Altos riscos de (2) escopo e requisitos, juntamente com altos riscos de (3) execução, contribuem para que um projeto entre em situação de agravamento.

Os dados apresentados nos Quadros 57, 58, 59 e 60 demonstram alto risco de execução e um risco médio-alto relacionado a escopo e requisitos. Complementarmente, os dados qualitativos obtidos por meio das entrevistas enfatizam problemas nesses dois quadrantes. Dessa maneira, podemos concluir que os dados obtidos se comportam de acordo com a proposição P1.

Em relação à segunda proposição:

P2: Os riscos de (1) mandato do cliente e (4) ambiente não são relevantes para que um projeto problemático entre em situação de agravamento.

Da mesma forma que no caso do ePAT, conforme pode ser visto nos Quadros 61 e 62, em relação aos dados dos fatores de risco relacionados ao ambiente, somente o fator problemas com fornecedores teve alta pontuação. Os fatores de risco relacionados ao mandato do cliente, apresentados nos Quadros 55 e 56, também tiveram pontuação baixa.

Dessa forma, podemos concluir que os riscos do mandato do cliente e do ambiente não foram relevantes para que o projeto entrasse em situação de agravamento, conforme a proposição $\mathrm{P} 2$.

As proposições P3 e P4 serão avaliadas conjuntamente:

P3: Altos riscos relacionados a escopo e requisitos, juntamente com a complexidade do sistema e organizacional, fazem com que um projeto se torne um projeto complexo (wicked project). 
P4: Projetos em situação de agravamento apresentam altos riscos relacionados a escopo e requisitos, complexidade do sistema e organizacional, e problemas na gestão do projeto.

De forma análoga à do caso do projeto ePAT, os fatores de risco apontados nas proposições P3 e P4, juntamente com os problemas com os fornecedores, foram os mais críticos segundo as entrevistas do projeto Rainha Vermelha. Além disso, o risco relacionado à complexidade do sistema e organizacional foi o que obteve a maior pontuação dentre todos os riscos do questionário (média de 6,3), seguido pelo fator relacionado à falta de entendimento dos usuários sobre as capacidades e limitações do sistema (média de 5,9) e pelos problemas na gestão do projeto (média de 5,6).

Quando são considerados os 15 fatores de risco, os riscos relacionados a escopo e requisitos (em vermelho) ficaram intercalados com os riscos de execução que compõem a proposição P1 e o risco relacionado a fornecedores, conforme podemos ver no Gráfico 11.

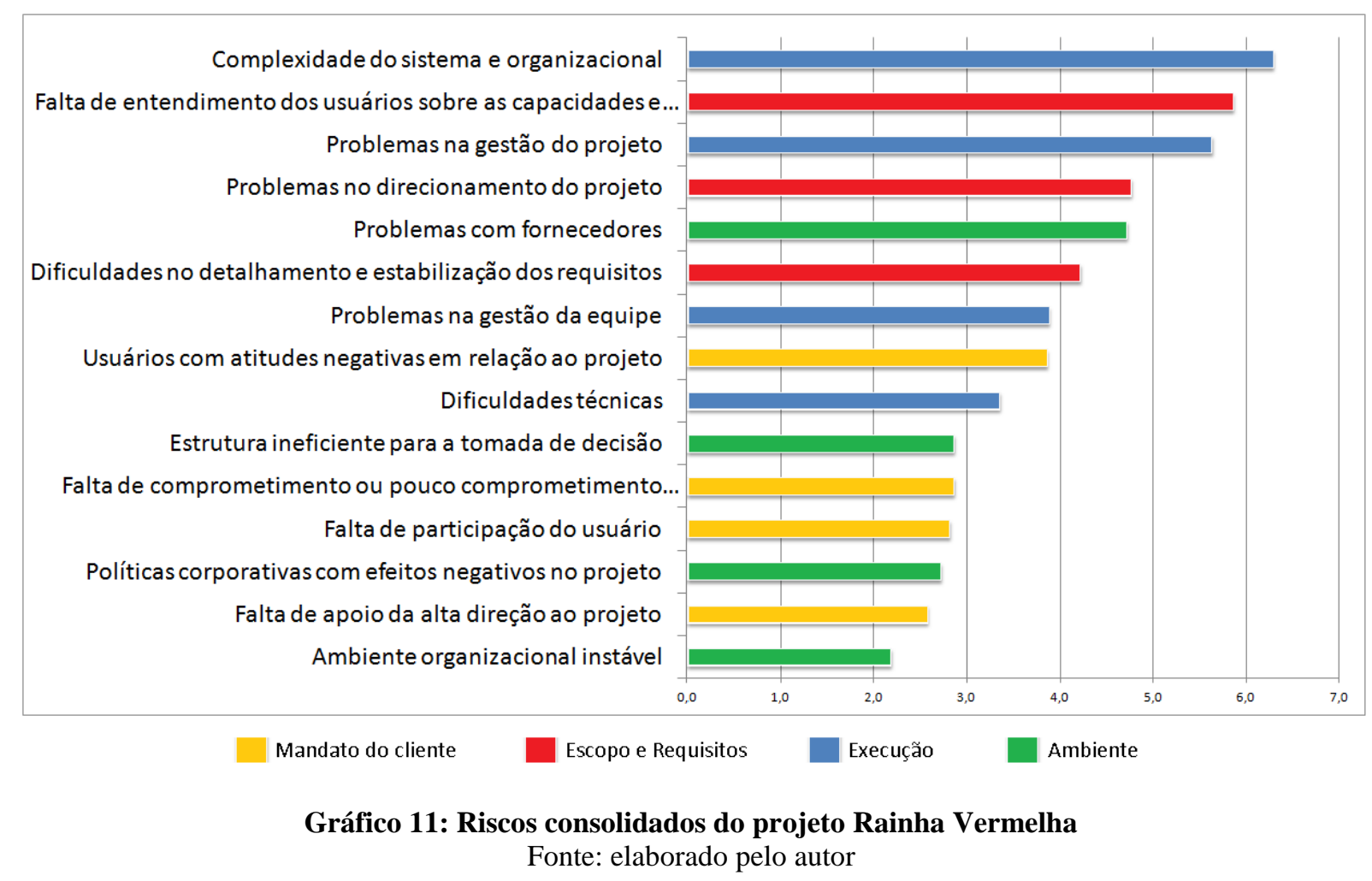

No caso do projeto Rainha Vermelha, os riscos relacionados a escopo e requisitos apresentam indícios de serem mais graves do que no caso do ePAT. Essa característica é consistente com o fato de que o agravamento no projeto Rainha Vermelha foi mais severo do que o 
agravamento no projeto ePAT. Além disso, no projeto NF-e, que não apresentou agravamento, os riscos relacionados a escopo e requisitos não foram considerados relevantes na opinião dos entrevistados, com médias iguais ou inferiores a 2,5.

A conclusão, considerando-se os dados das entrevistas, é de que o caso do projeto Rainha Vermelha se comportou até o momento de acordo com o modelo. Novamente, a triangulação com os dados do questionário apresenta indícios de que a complexidade pode ser um fator de risco mais relevante do que a incerteza.

Quanto à proposição P5:

P5: A reorientação bem-sucedida de um projeto em situação de agravamento envolve aspectos relacionados à diminuição da complexidade do projeto ou à aplicação de técnicas mais adequadas para lidar com a complexidade existente.

A solução aplicada na última reorientação do projeto Rainha Vermelha ainda é muito recente para que seja possível avaliar sua efetividade. Consequentemente, não será possível avaliar a proposição P5.

As proposições P6 e P7 serão tratadas de forma conjunta:

P6: Altos riscos relacionados à Governança de TI contribuem para que um projeto problemático entre em situação de agravamento.

P7: Altos riscos relacionados à Governança de TI contribuem para que um projeto problemático permaneça em situação de agravamento.

As proposições P6 e P7 não foram validadas a partir dos dados obtidos no caso do projeto Rainha Vermelha, pois o agrupamento dos riscos pelo critério de governança apresentou mais valores baixos (abaixo de 4) do que valores altos (acima de 4), com uma média de 3,4.

Em relação à última proposição: 
P8: Projetos de TI do setor público em situação de agravamento apresentam alta complexidade estrutural organizacional.

A proposição P8 também não foi validada a partir dos dados obtidos, pois o agrupamento dos riscos pelo critério de complexidade estrutural do modelo de Xia e Lee (2004) apresentou mais valores baixos (abaixo de 4) do que valores altos (acima de 4), com uma média de 3,5.

O terceiro caso estudado foi consistente com as proposições P1 e P2, relativas ao modelo de Wallace e Keil (2004), e com as proposições P3 e P4, relativas ao modelo de referência. Não foi possível avaliar a proposição P5, pois o projeto ainda não apresentou indícios de uma reorientação bem-sucedida.

As proposições P6 e P7, referentes ao modelo baseado na Governança de TI, e a proposição P8, referente ao modelo de Xia e Lee (2004), não foram corroboradas pelas evidências do caso estudado.

O Quadro 67 apresenta um resumo da avaliação das proposições e de sua aderência às teorias:

Quadro 67: Avaliação do caso do projeto Rainha Vermelha em relação às proposições e teorias

\begin{tabular}{|c|c|c|}
\hline Teoria & Proposição & $\begin{array}{c}\text { Caso } \\
\text { Alinhado à } \\
\text { Teoria }\end{array}$ \\
\hline \multirow[t]{2}{*}{$\begin{array}{l}\text { Wallace e } \\
\text { Keil (2004) }\end{array}$} & $\begin{array}{l}\text { P1: Altos riscos de (2) escopo e requisitos, juntamente com altos riscos de (3) } \\
\text { execução, contribuem para que um projeto entre em situação de agravamento. }\end{array}$ & Sim \\
\hline & $\begin{array}{l}\text { P2: Os riscos de (1) mandato do cliente e (4) ambiente não são relevantes para } \\
\text { que um projeto problemático entre em situação de agravamento. }\end{array}$ & $\mathrm{Sim}$ \\
\hline \multirow[t]{3}{*}{$\begin{array}{l}\text { Modelo de } \\
\text { referência }\end{array}$} & $\begin{array}{l}\text { P3: Altos riscos relacionados a escopo e requisitos, juntamente com a } \\
\text { complexidade do sistema e organizacional, fazem com que um projeto se } \\
\text { torne um projeto complexo (wicked project). }\end{array}$ & Sim \\
\hline & $\begin{array}{l}\text { P4: Projetos em situação de agravamento apresentam altos riscos relacionados } \\
\text { a escopo e requisitos, complexidade do sistema e organizacional, e problemas } \\
\text { na gestão do projeto. }\end{array}$ & $\mathrm{Sim}$ \\
\hline & $\begin{array}{l}\text { P5: A reorientação bem-sucedida de um projeto em situação de agravamento } \\
\text { envolve aspectos relacionados à diminuição da complexidade do projeto ou à } \\
\text { aplicação de técnicas mais adequadas para lidar com a complexidade } \\
\text { existente. }\end{array}$ & $\begin{array}{l}\text { Não foi } \\
\text { possível } \\
\text { avaliar. }\end{array}$ \\
\hline \multirow[t]{2}{*}{$\begin{array}{l}\text { Governança } \\
\text { de TI }\end{array}$} & $\begin{array}{l}\text { P6: Altos riscos relacionados à Governança de TI contribuem para que um } \\
\text { projeto problemático entre em situação de agravamento. }\end{array}$ & Não \\
\hline & $\begin{array}{l}\text { P7: Altos riscos relacionados à Governança de TI contribuem para que um } \\
\text { projeto problemático permaneça em situação de agravamento. }\end{array}$ & Não \\
\hline $\begin{array}{l}\text { Xia e Lee } \\
(2004)\end{array}$ & $\begin{array}{l}\text { P8: Projetos de TI do setor público em situação de agravamento apresentam } \\
\text { alta complexidade estrutural organizacional. }\end{array}$ & Não \\
\hline
\end{tabular}




\section{ANÁLISE CRUZADA DOS CASOS}

Ao se elaborar a análise cruzada dos dados, nota-se, que de forma geral, os três casos pesquisados se alinharam à teoria proposta no modelo de referência e também ao modelo de Wallace e Keil (2004) no que diz respeito aos fatores que contribuem para que um projeto de TI entre em situação de agravamento.

Basicamente, o agravamento, nos casos pesquisados, esteve ligado a uma alta complexidade, constatada nas quatro fontes de evidência usadas: entrevistas, questionário e documentação. Os dois projetos que enfrentaram agravamento, o ePAT e o Rainha Vermelha, apresentaram evidências de alta complexidade por meio de todas as fontes de dados usadas.

Além disso, quanto aos riscos relacionados a escopo e requisitos, no caso do ePAT, os questionários e a documentação apontavam problemas relacionados a esses. No caso das entrevistas, os usuários consideraram que a falha relativa ao escopo e requisitos era devida à atuação da equipe de TI da consultoria enquanto os profissionais de TI atribuíram os problemas às mudanças de requisito solicitadas pelos usuários.

No projeto Rainha Vermelha, que apresentou o agravamento mais severo, todas as fontes de evidência apontaram problemas relacionados a escopo e requisitos.

Por outro lado, o projeto NF-e apresentava uma pontuação baixa em sua análise dos fatores de risco relacionados à complexidade do projeto e ao escopo e requisitos. De forma alinhada ao modelo de referência, esse projeto não enfrentou a situação de agravamento.

Em relação à metodologia de gestão de projetos, em conformidade com o modelo de referência, ela apenas foi considerada problemática nos projetos que apresentaram agravamento. O projeto NF-e, apesar de não possuir uma gestão de projeto formalizada no âmbito da TI, não apresentou problemas nessa categoria. Por outro lado, nos projetos que enfrentaram o agravamento, a gestão do projeto foi percebida como ineficaz, apesar do fato de várias alternativas terem sido buscadas no decorrer do projeto, até mesmo a de aplicar técnicas consagradas pelo mercado (melhores práticas), que não surtiram o efeito desejado. 
Os três casos também se comportaram de forma alinhada à teoria de Wallace e Keil (2004). Entretanto, o modelo de referência explica o problema a partir de um conjunto menor de fatores, facilitando uma detecção precoce dele.

Em relação à proposição de que a reorientação bem-sucedida de um projeto em situação de agravamento envolve aspectos relacionados à diminuição da complexidade do projeto ou à aplicação de técnicas mais adequadas para lidar com a complexidade existente, o único projeto que passou pelo processo de redirecionamento, o ePAT, comportou-se de acordo com essa proposição. Além disso, o projeto NF-e, que não passou pela situação de agravamento, teve sua complexidade reduzida antes do início do projeto em razão de um longo período de especificação e uma busca consciente de redução da complexidade, com o propósito de viabilizar os projetos de nota fiscal eletrônica em todos os Estados da federação, mesmo naqueles com menos recursos.

O Quadro 68 apresenta um quadro consolidado que contempla a avaliação das proposições e de sua aderência às teorias: 
Quadro 68: Avaliação das proposições e teorias em relação aos casos estudados

\begin{tabular}{|c|c|c|c|c|c|}
\hline \multirow[t]{2}{*}{ Teoria } & \multirow[t]{2}{*}{ Proposição } & \multicolumn{3}{|c|}{$\begin{array}{c}\text { Alinhamento dos Casos à } \\
\text { Teoria }\end{array}$} & \multirow{2}{*}{$\begin{array}{l}\text { Alinhamento } \\
\text { à Teoria } \\
\text { (consolidado) }\end{array}$} \\
\hline & & ePAT & NF-e & $\begin{array}{c}\text { Rainha } \\
\text { Vermelha }\end{array}$ & \\
\hline \multirow[t]{2}{*}{$\begin{array}{l}\text { Wallace e } \\
\text { Keil (2004) }\end{array}$} & $\begin{array}{l}\text { P1: Altos riscos de (2) escopo e } \\
\text { requisitos, juntamente com altos riscos } \\
\text { de (3) execução, contribuem para que um } \\
\text { projeto entre em situação de } \\
\text { agravamento. }\end{array}$ & Sim & Sim & Sim & Sim \\
\hline & $\begin{array}{l}\text { P2: Os riscos de (1) mandato do cliente e } \\
\text { (4) ambiente não são relevantes para que } \\
\text { um projeto problemático entre em } \\
\text { situação de agravamento. }\end{array}$ & Sim & Sim & Sim & Sim \\
\hline \multirow[t]{3}{*}{$\begin{array}{l}\text { Modelo de } \\
\text { referência }\end{array}$} & $\begin{array}{l}\text { P3: Altos riscos relacionados a escopo e } \\
\text { requisitos, juntamente com a } \\
\text { complexidade do sistema e } \\
\text { organizacional, fazem com que um } \\
\text { projeto se torne um projeto complexo } \\
\text { (wicked project). }\end{array}$ & Sim & Sim & Sim & Sim \\
\hline & $\begin{array}{l}\text { P4: Projetos em situação de agravamento } \\
\text { apresentam altos riscos relacionados a } \\
\text { escopo e requisitos, complexidade do } \\
\text { sistema e organizacional, e problemas na } \\
\text { gestão do projeto. }\end{array}$ & Sim & Sim & Sim & Sim \\
\hline & $\begin{array}{l}\text { P5: A reorientação bem-sucedida de um } \\
\text { projeto em situação de agravamento } \\
\text { envolve aspectos relacionados à } \\
\text { diminuição da complexidade do projeto } \\
\text { ou à aplicação de técnicas mais } \\
\text { adequadas para lidar com a } \\
\text { complexidade existente. }\end{array}$ & Sim & $\begin{array}{l}\text { Não foi } \\
\text { possível } \\
\text { avaliar. }\end{array}$ & $\begin{array}{l}\text { Não foi } \\
\text { possível } \\
\text { avaliar. }\end{array}$ & $\begin{array}{l}\text { Sim (no caso } \\
\text { em que foi } \\
\text { possível } \\
\text { avaliar) }\end{array}$ \\
\hline \multirow[t]{2}{*}{$\begin{array}{l}\text { Governança } \\
\text { de TI }\end{array}$} & $\begin{array}{l}\text { P6: Altos riscos relacionados à } \\
\text { Governança de TI contribuem para que } \\
\text { um projeto problemático entre em } \\
\text { situação de agravamento. }\end{array}$ & Não & Sim & Não & $\begin{array}{l}\text { Não (nos } \\
\text { casos de } \\
\text { agravamento) }\end{array}$ \\
\hline & $\begin{array}{l}\text { P7: Altos riscos relacionados à } \\
\text { Governança de TI contribuem para que } \\
\text { um projeto problemático permaneça em } \\
\text { situação de agravamento. }\end{array}$ & Não & $\begin{array}{l}\text { Não foi } \\
\text { possível } \\
\text { avaliar. }\end{array}$ & Não & $\begin{array}{l}\text { Não (onde foi } \\
\text { possível } \\
\text { avaliar) }\end{array}$ \\
\hline $\begin{array}{l}\text { Xia e Lee } \\
(2004)\end{array}$ & $\begin{array}{l}\text { P8: Projetos de TI do setor público em } \\
\text { situação de agravamento apresentam alta } \\
\text { complexidade estrutural organizacional. }\end{array}$ & Não & Sim & Não & $\begin{array}{l}\text { Não (nos } \\
\text { casos de } \\
\text { agravamento) }\end{array}$ \\
\hline
\end{tabular}

Fonte: elaborado pelo autor

Um fator isolado que apresentou grande correlação com a intensidade do agravamento foi a existência de um prazo político. A existência de um prazo político foi inicialmente classificada como uma característica da gestão de projetos. Entretanto, o impacto percebido da existência de prazo político na contribuição para o agravamento apresenta indícios de que esse fator não apenas dificulta a gestão da complexidade, como o restante dos fatores que compõem os riscos de Gestão de Projetos, mas também traz consequências diretas no aumento da complexidade. 
Durante as entrevistas, os envolvidos nos projetos que entraram em situação de agravamento explicaram que o prazo político exerceu pressão na equipe do projeto, levando-a a assumir mais riscos e aumentar o paralelismo, que, em retrospectiva, mostrou-se excessivo.

Esse aumento do risco pode ser considerado paradoxal ao se levar em conta a literatura sobre gestão de projetos na área pública, que explica a menor propensão a risco dos funcionários públicos. Os funcionários públicos privilegiam a conformidade em detrimento do desempenho (WIRICK, 2009, p. 19) e são mais avessos ao risco em razão doos diversos mecanismos de vigilância e das punições previstas (WIRICK, 2009, p. 3).

Por conseguinte, essa situação leva a dois paradoxos:

1. Os projetos maiores e mais complexos, apesar de serem naturalmente mais arriscados, são os que sofrem mais pressão pela redução de prazo e, consequentemente, por causa dos esforços para reduzir os prazos, tornam-se ainda mais arriscados.

2. Apesar de os funcionários públicos serem mais avessos ao risco (WIRICK, 2009, p. 3), a existência de prazos políticos leva esses indivíduos a assumirem mais riscos.

Os entrevistados nos projetos ePAT e Rainha Vermelha explicaram que a pressão existente devido ao prazo político levou os gestores de projetos a fazerem apostas arriscadas e a aumentarem o paralelismo no projeto. A literatura sobre gestão de projetos baseada no Guia PMBOK (PMI, 2008, p. 157) explica que o paralelismo aumenta o risco do projeto e a possibilidade de que ocorra o retrabalho. Além desse problema, os entrevistados também descreveram dificuldades na integração do escopo entre as frentes de trabalho paralelas.

Quando os riscos inerentes ao paralelismo se manifestaram, com o previsível retrabalho e as dificuldades de integração, esses problemas abalaram a autoconfiança das pessoas envolvidas com o projeto e minaram a credibilidade de seus gestores, contribuindo fortemente para seu insucesso. No caso do ePAT, no qual o redirecionamento do projeto pôde ser constatado, parte da solução de redução da complexidade envolveu a diminuição do paralelismo e a adoção de uma estratégia de condução do projeto que entregava os módulos do fluxo de trabalho na sequência em que eles seriam executados no mundo real. Essa estratégia só foi 
possível porque a alta administração priorizou a necessidade de entregar o projeto em detrimento da necessidade de cumprir o prazo político.

A priorização da conformidade em detrimento do desempenho (WIRICK, 2009, p. 19) também contribuiu para a manutenção do projeto em situação de agravamento. Cancelar um projeto no setor público não é tão simples quanto cancelar um projeto em uma empresa privada, em razão dos mecanismos de vigilância. Especialmente no caso de projetos terceirizados, há ainda a possibilidade de questionamento judicial.

No caso do ePAT, as dificuldades em cancelar o projeto levaram à busca de uma solução alternativa, que culminou no redirecionamento bem-sucedido do projeto. No caso do projeto Rainha Vermelha, os gestores precisaram contratar uma consultoria externa para embasar sua tomada de decisão, pois qualquer das alternativas precisaria ser fundamentada no caso de um possível questionamento pelo tribunal de contas.

Esse cenário de priorização da conformidade leva a um terceiro paradoxo. Na literatura prescritiva de gerenciamento de projetos, uma das estratégias recomendadas para lidar com riscos negativos é transferir o risco para uma terceira parte (PMI, 2008, p. 303). Entretanto, principalmente no setor público, essa estratégia cria o risco secundário de que, caso o fornecedor não consiga terminar o projeto, torne-se muito trabalhoso conseguir formalizar o rompimento do contrato. O paradoxo, neste caso, é que o impacto dessa dificuldade em formalizar o rompimento do contrato pode ser significativamente maior do que o impacto de cancelar um projeto de desenvolvimento interno. Dessa forma, apesar da transferência do risco para o fornecedor, o risco do projeto aumentou, pois o risco secundário mostrou-se mais intenso do que o risco original.

Em uma análise de riscos rigorosa, segundo as premissas da gestão de riscos, tanto o risco primário quanto o secundário deveriam ser avaliados. Neste caso, a conclusão de que o risco secundário é mais intenso ou ameaçador do que o risco primário deveria levar o tomador de decisão a não transferir o risco para uma terceira parte. Seria importante avaliar o processo decisório (a decisão de fazer ou comprar) no caso de projetos do setor público para verificar o se os riscos secundários são seriamente considerados durante a análise de fazer ou comprar. 
A Teoria dos Custos de Transação (COASE; 1937) apresenta outra explicação acerca da melhor opção para a decisão de fazer ou comprar no caso de projetos complexos. De acordo com Müller (2011, p. 302), estruturas mais ou menos complexas são necessárias para economizar nos custos de transação, dependendo da complexidade do projeto. Portanto, no caso de projetos de maior complexidade, especificidade e incerteza, seria mais adequado executar o projeto internamente (estrutura mais complexa), ao invés de adquiri-lo no mercado (estrutura menos complexa).

As conclusões desta tese acerca da decisão dos gestores públicos sobre desenvolver internamente ou terceirizar projetos complexos de TI no setor público está mais alinhada às recomendações da Teoria dos Custos de Transação do que às recomendações da literatura prescritiva de gerenciamento de projetos.

\subsection{Aderência dos Casos à Literatura Prévia}

Em relação aos fatores psicológicos, sociais e organizacionais, os casos estudados apresentaram características alinhadas à literatura de agravamento de projetos. Conforme previsto na literatura sobre projetos que entraram na situação de agravamento, os três casos estudados não apresentam as características preventivas relacionadas à Teoria da Autojustificação, descritas a seguir:

- Estabelecimento antecipado e divulgação de um limite de investimento, conforme a sugestão de Brockner et al. (1979);

- Condição de término automático: o projeto será encerrado, a não ser que uma decisão de continuidade seja tomada (BROCKNER et al.,1979; MONTEALEGRE; KEIL, 2000);

- Sistema de recompensas estruturado para reduzir as forças que encorajam o agravamento, recompensando, por exemplo, a honestidade no reconhecimento da existência de problemas e uma clara avaliação das alternativas (STAW; ROSS, 1987).

No caso da reavaliação do projeto ePAT, que sofreu reorientação, e do projeto Rainha Vermelha, que foi paralisado, apesar de os responsáveis pela decisão de continuar, reorientar ou cancelar o projeto serem os mesmos que aprovaram inicialmente o projeto, a equipe de gestão foi alterada e a nova equipe de gestão foi capaz de apontar os problemas no andamento 
do projeto. A mudança dos tomadores de decisão é citada por Staw e Ross (1987) e Newman e Sabherwal (1996) como um fator que facilita o cancelamento ou a reorientação de um projeto em situação de agravamento.

Em relação aos fatores de agravamento previstos pela Teoria da Perspectiva, nos casos em que ocorreu agravamento os Sunk Costs foram considerados na tomada de decisão e a informação foi filtrada e apresentada sob uma perspectiva positiva, principalmente quando as apresentações eram realizadas pelos fornecedores.

Complementarmente, em relação aos conceitos da Teoria da Agência, por se tratarem de projetos do setor público, os efeitos de agência foram amplificados pelos mecanismos de Governança. No caso do ePAT, caso a opção de reorientação não tivesse sido escolhida, o cancelamento do projeto, mesmo que justificado, teria ocasionado um processo administrativo. No caso do projeto Rainha Vermelha, os tomadores de decisão optaram pela contratação de um diagnóstico por uma consultoria externa para garantir que sua decisão fosse embasada na opinião de especialistas.

Dessa forma, nos casos em que ocorreu agravamento, mesmo que a decisão de cancelar ou reorientar fosse a mais adequada, os gestores públicos tiveram sua ação limitada pelas características dos mecanismos de governança, que possuem um viés pela continuidade dos projetos. Consequentemente, essa característica no mecanismo de governança para projetos adquiridos externamente apresenta indícios de favorecimento à situação de agravamento.

Finalmente, em relação à Teoria do Afastamento e Aproximação, os projetos estudados que enfrentaram a situação de agravamento apresentaram pouca evolução e criaram, nas partes envolvidas, a sensação de proximidade com o objetivo. Logo, esse aspecto da Teoria do Afastamento e Aproximação não pôde ser avaliado. Um possível indício da aplicabilidade dessa teoria foi o aumento da motivação dos participantes quando percebiam que estavam mais distantes de seu objetivo, situação comumente ressaltada durante as tentativas de reorientação. Entretanto, esse indício é insuficiente para avaliar a aderência ou não dos casos à Teoria do Afastamento e Aproximação. 


\subsection{Respostas às Questões de Pesquisa}

As questões de pesquisa que motivaram o desenvolvimento deste estudo e a elaboração desta tese foram respondidas de forma satisfatória. A primeira questão de pesquisa é:

- Quais são os principais riscos que podem contribuir para que um projeto de TI do setor público chegue à situação de agravamento?

Os casos estudados apresentam indícios de que o principal fator que mais contribui para que um projeto do setor público entre em situação de agravamento é a complexidade, que contempla os seguintes aspectos:

- Alto nível de complexidade técnica;

- A tarefa a ser automatizada é altamente complexa;

- O projeto afeta um grande número de unidades e/ou departamentos dos usuários;

- Ser um dos maiores projetos já empreendidos pela organização;

- Necessidade de integração com um grande número de sistemas.

Complementarmente à complexidade, mas menos evidentes, os riscos relacionados a escopo e requisitos também contribuem para que um projeto do setor público entre em situação de agravamento:

- Dificuldades no detalhamento e estabilização dos requisitos:

- Requisitos de sistema que mudam frequentemente;

- Requisitos do sistema identificados de forma inadequada;

- Requisitos de sistema obscuros (não claros);

- Requisitos de sistema incorretos;

○ Requisitos de sistema conflitantes;

○ Dificuldade em definir entradas e saídas do sistema.

- Problemas no direcionamento do projeto:

- Critério de sucesso do projeto indefinido;

- Metas do projeto mal definidas;

- Objetivos e escopo do projeto que mudam frequentemente.

- Falta de entendimento pelos usuários sobre as capacidades e limitações do sistema. 
De acordo com o modelo de referência, projetos que apresentem as características de complexidade e instabilidade dos requisitos descritas acima são sérios candidatos à situação de agravamento. A gestão de projetos complexos demanda uma metodologia robusta para que os problemas causados pela complexidade e a instabilidade dos requisitos sejam superados (POPPENDIECK, 2002).

Quanto aos fatores relacionados à metodologia, a existência de prazo político ou de pressão política excessiva nos prazos demonstrou ser um fator de risco muito relevante, obtendo a maior pontuação dentre os riscos detalhados.

Os outros fatores de gestão de projetos que também contribuem para o agravamento são os seguintes:

- Falta de uma metodologia efetiva de gerenciamento de projetos;

- Estimativa inadequada do cronograma do projeto;

- Progresso do projeto não monitorado suficientemente de perto;

- Planejamento precário do projeto;

- Marcos do projeto não definidos de forma clara;

- Estimativa inadequada do orçamento do projeto.

- Gerente do projeto não efetivo;

- Gerente do projeto inexperiente;

- Comunicação não efetiva.

A segunda questão de pesquisa é:

- Quais estratégias poderiam ser usadas para superar os problemas que promovem o agravamento de projetos de TI do setor público?

Os casos estudados levaram a três sugestões sobre como superar o problema do agravamento em projetos:

- Simplificar os requisitos;

- Adotar uma metodologia mais adequada às características do projeto;

- Proteger o projeto da interferência excessiva de prazos políticos. 
Indícios de que a simplificação dos requisitos contribui significativamente para o sucesso do projeto foram encontrados nos casos referentes aos projetos ePAT e NF-e. No caso do projeto ePAT, alguns requisitos, como a migração do legado, foram excluídos e contribuíram para a diminuição da complexidade do projeto. Além disso, a metodologia de desenvolvimento utilizada, baseada no Scrum, tem como premissa que os requisitos sejam priorizados. Logo, o escopo como um todo é simplificado, pois os requisitos de menor prioridade são atendidos somente nas fases finais da implementação ou são eventualmente excluídos.

No projeto NF-e, os requisitos foram sistematicamente simplificados em um longo período, que durou aproximadamente dois anos, de especificação anterior ao desenvolvimento, com o propósito de viabilizar a implantação da NF-e mesmo nos estados menos desenvolvidos.

Além de favorecer o bom andamento do projeto NF-e e contribuir para a reorientação bemsucedida do projeto ePAT, a simplificação dos requisitos também foi recomendada pela consultoria Minerva (2012) para o projeto Rainha Vermelha. Outra recomendação, relacionada à adoção de uma metodologia mais adequada, corresponde à reorganização do projeto como um programa. Entretanto, no atual estágio do projeto Rainha Vermelha, ainda não é possível avaliar a efetividade dessas recomendações.

O projeto ePAT também apresentou indícios de que a aplicação de uma metodologia ágil baseada no Scrum foi efetiva ao lidar com as dificuldades relacionadas a escopo e requisitos, além de apresentar agilidade suficiente para tratar da complexidade do projeto. Um aspecto importante da aplicação dessa metodologia é a utilização de um ciclo de vida iterativo e incremental, que simplifica o desenvolvimento ao adotar uma abordagem por fases ao invés da abordagem Big Bang. 


\section{CONCLUSÃO}

A pesquisa descrita nesta tese apresenta um conjunto de conclusões para a prevenção do agravamento em projetos de TI do setor público. A primeira contribuição refere-se à identificação dos fatores de projeto que favorecem o agravamento, a partir dos quais é possível avaliar a propensão de um projeto ao agravamento e tomar decisões mais informadas sobre iniciar, desenvolver interna ou externamente, continuar ou encerrar projetos.

A segunda contribuição está relacionada à forma de condução do projeto, caso ele apresente as características de complexidade e instabilidade de requisitos descritas no modelo conceitual. Os casos estudados apresentam evidências de que, em projetos que apresentem essas características, a chance de sucesso do projeto aumenta significativamente com a simplificação dos requisitos e com a adoção de uma metodologia de gestão adequada à complexidade do projeto.

A terceira contribuição relaciona-se com o processo decisório de conduzir interna ou externamente um projeto complexo de TI no setor público. Esse processo decisório deveria basear-se em uma análise rigorosa dos riscos, contemplando inclusive os riscos secundários, ou seja, os riscos decorrentes da opção de transferir o projeto para uma terceira parte. Apesar de a pesquisa não ter sido focada na análise desse processo, o insucesso dos fornecedores nos casos analisados e a dificuldade adicional de cancelar os projetos em razão das características do processo de contratação da administração pública fornecem indícios de que esses riscos secundários não foram considerados com todas as suas implicações.

Dessa forma, em razão do impacto do risco de "problemas com fornecedores", o modelo de referência pode ser ajustado com a adição desse risco, de forma análoga ao risco "problemas na gestão do projeto", pois a presença de fornecedores dificulta o cancelamento de um projeto problemático, favorecendo, dessa forma, seu agravamento.

Conforme constatou-se na análise cruzada dos casos, as conclusões referentes aos três projetos pesquisados se alinharam à teoria proposta no modelo de referência e também ao modelo de Wallace e Keil (2004) no que diz respeito aos fatores que influenciam um projeto de TI para a ocorrência de agravamento. Dessa forma, outra contribuição desta tese se refere à 
redução da quantidade de fatores de riscos a serem monitorados para avaliar a propensão do projeto ao agravamento. No modelo de Wallace e Keil (2004), os fatores de risco considerados mais relevantes são os 10 relacionados a escopo e requisitos e os 28 riscos de execução. No modelo de referência, além dos 10 riscos de escopo e requisitos, basta avaliarmos os 5 riscos relacionados à complexidade juntamente com o risco de prazo político.

O risco de existência de prazo político, apesar de ter sido classificado inicialmente como parte dos riscos de gestão de projetos, demonstrou ser muito relevante para que um projeto se torne problemático e entre em situação de agravamento. Consequentemente, a partir das evidências coletadas, o modelo de referência pode ser atualizado com a incorporação do risco de "prazo político" como um fator que favorece que um projeto se torne problemático.

Considerando o risco de prazo político e o risco de problemas com fornecedores, que não estavam presentes no modelo de referência original, mas se mostraram relevantes na pesquisa, um modelo atualizado é proposto como resultado deste estudo, conforme apresentado na ilustração 13.

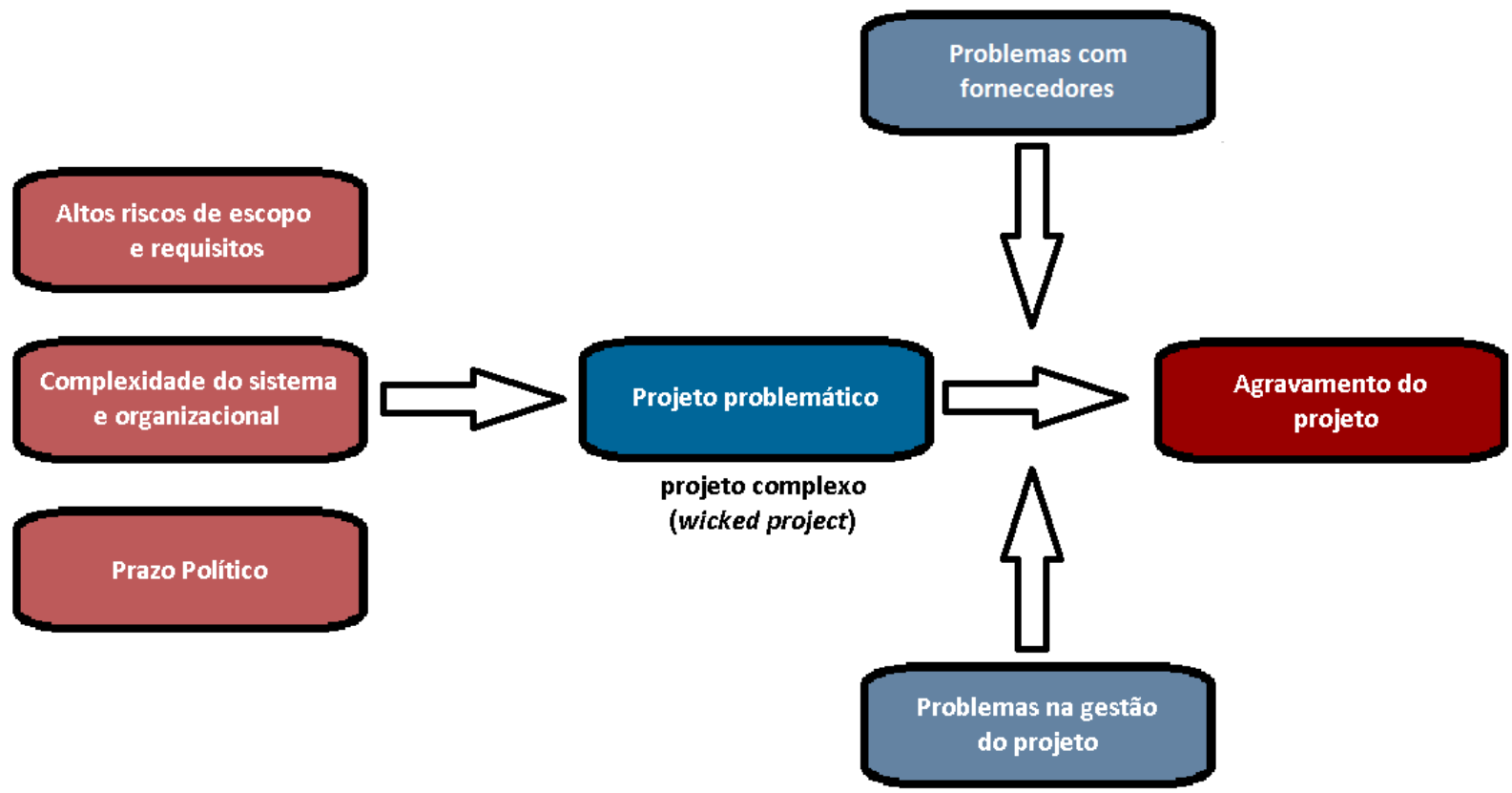

Ilustração 13: Modelo de referência atualizado Fonte: elaborada pelo autor 


\subsection{Recomendações para a Prática}

A primeira recomendação para a prática está relacionada à avaliação dos fatores de risco do projeto. Em projetos de TI de alta complexidade e dificuldades relacionadas a escopo e requisitos é fundamental aplicar uma metodologia adequada para lidar com a complexidade do projeto. A decomposição do projeto por meio do uso de ciclos de vida iterativos e incrementais e/ou a adoção de modelos de governança que organizem melhor a condução do trabalho são fundamentais para viabilizar o sucesso de projetos complexos de TI.

A segunda recomendação está relacionada à existência de prazo político em um projeto complexo. O prazo político aumenta a chance de o projeto fracassar, pois os executores do projeto tendem a aumentar sua exposição ao risco para cumprir o prazo político. Com a concretização dos eventos de risco, potencializados pelo prazo político, ocorrem fatores como aumento do retrabalho, diminuição da credibilidade do projeto e diminuição da motivação da equipe. Logo, é primordial gerenciar a ansiedade das partes interessadas que têm papéis políticos e proteger o projeto de interferências excessivas do aspecto político.

A terceira recomendação prática diz respeito à análise de fazer ou comprar e aos riscos secundários. Ao avaliarem a possibilidade de adquirir um projeto complexo de TI externamente, é importante que os gestores:

- Considerem profundamente os riscos secundários decorrentes da opção de transferir o risco de um projeto complexo de TI do setor público para um fornecedor;

- Analisem o nível de especificidade do produto do projeto e sigam a recomendação da Teoria dos Custos de Transação, segundo a qual, no caso de um produto de alta especificidade, o clã tende a ser mais adequado que a hierarquia e a hierarquia tende a ser mais adequada do que o mercado (OUCHI, 1980).

A quarta recomendação prática está relacionada à aplicação de uma metodologia adequada às características de complexidade do projeto e estabilidade de seus requisitos. Vale ressaltar que não há metodologia ou framework que seja o mais indicado para qualquer tipo de projeto. Consequentemente, os gestores devem selecionar as recomendações mais adequadas e customizar a metodologia caso a caso. 
Finalmente, a última recomendação prática se refere à necessidade de simplificar e priorizar os requisitos. Os dois projetos que foram bem sucedidos dentre os três estudados nesta tese usaram a simplificação dos requisitos para viabilizar seu sucesso. Essa simplificação pode ocorrer antes do desenvolvimento, como no caso do projeto NF-e, ou durante o desenvolvimento, como no caso do projeto ePAT. Além disso, no caso do projeto Rainha Vermelha, a simplificação dos requisitos foi recomendada como forma de aumentar as chances de sucesso do projeto. Complementarmente, técnicas como o Product Backlog do framework Scrum ou a análise MoSCoW (must have, should have, could have e won't have for now) usada na metodologia Prince2 (OGC, 2009a, p. 51, 93; 2009b, p. 43) podem ajudar a priorizar os requisitos, postergando a implementação dos requisitos menos importantes para os usuários.

\subsection{Limitações do Estudo}

As limitações deste estudo estão relacionadas ao fato de que esta tese se refere a uma pesquisa qualitativa e baseada em um estudo de casos múltiplos. Logo, as limitações inerentes a esse tipo de pesquisa se fazem naturalmente presentes.

Primeiramente, apesar da perspectiva de generalização analítica e da possibilidade de expandirem a teoria, as conclusões obtidas por meio de estudos de caso devem passar por mais testes para aumentar a confiança em sua validade. Por se tratar de uma pesquisa positivista, não há a intenção de provar a teoria, mas sim a de corroborá-la, ou seja, torná-la provisoriamente aceita, caso ela supere os testes empíricos. Consequentemente, a pequena quantidade de casos, restrita a três projetos, limita a corroboração da teoria.

O questionário usado mostrou-se muito extenso e essa característica dificultou a análise, em razão da necessidade de agregação dos dados em um conjunto menor de constructos. Avaliando-se em retrospectiva, teria sido mais apropriado usar um questionário com os quinze itens consolidados, apresentados no Quadro 21 do capítulo 3.2, denominado Modelo de Referência.

Finalmente, em razão do foco positivista da pesquisa, aspectos mais subjetivos e interpretativos, principalmente relacionados a disputas de poder e fatores políticos, foram 
intencionalmente deixados de lado. A opção do estudo pelo foco em fatores estruturais está relacionada à dificuldade de obter autorização para pesquisar aspectos tão sensíveis e sujeitos a julgamentos de valor, como problemas de agência, disputas de poder, aspectos políticos e relações interpessoais no ambiente do setor público. Apesar de se tratar de uma escolha consciente, essa opção limitou a abrangência da pesquisa.

\subsection{Sugestões de Pesquisas Futuras}

As sugestões de pesquisas futuras são baseadas principalmente nas limitações desta pesquisa e em aspectos abordados na revisão bibliográfica que não puderam ser estudados em mais profundidade por restrições de tempo e escopo. Para amadurecer os resultados, é recomendável que mais pesquisas abordem os fatores de projeto que podem levar ao agravamento. Em razão da característica de singularidade inerente à definição de projeto, o estudo de caso é uma opção interessante para novas pesquisas e conta com respaldo na literatura de agravamento, como, por exemplo, na recomendação de Drummond e Hogdson (2011, p. 6), que consideram essa técnica adequada por sua aproximação ao ambiente real.

Outra sugestão de pesquisa está relacionada à compreensão de como é conduzida na prática a decisão de fazer ou comprar, juntamente com a avaliação dos riscos no caso de projetos de TI do setor público. O insucesso das consultorias estudadas nesta tese pode ser um indício de que esse processo não levou em consideração os riscos secundários. É importante que mais pesquisas sejam empreendidas, com o objetivo de investigar o processo de avaliação dos riscos durante a análise de fazer ou comprar.

Por fim, sugere-se a replicação no Brasil de experimentos nos quais as variáveis possam ser mais controladas, como nos experimentos de Rubin e Brockner (1975), Staw e Ross (1978), Brockner, Shaw e Rubin (1979), Northcraft e Wolf (1984), Whyte (1986), Garland et al. (1990), Brockner (1992), Conlon e Garland (1993), Harrison e Harrell (1993), Whyte (1993), Harrell e Harrison (1994) e Garland e Conlon (1998).

A compreensão dos fatores que levam ao agravamento de projetos de TI no setor público também pode se beneficiar de estudos mais interpretativistas ou críticos, que abordem temas 
que foram excluídos da análise desenvolvida neste texto, mas que podem complementar seu entendimento. 
ACEVES, René Méndez; DÍAZ, Cindy R. Pérez; LUNA-REYES, Luis F. Portales de Gobierno Estatal en México: El caso del Portal del Gobierno del Estado de Puebla. In: ANNUAL INTERNATIONAL CONFERENCE ON DIGITAL GOVERNMENT RESEARCH, 11 ${ }^{\text {th }}, 2010$, Puebla, México. Proceedings... Puebla, México: ACM, 2010. p. 183-192.

AICHHOLZER, Georg; SCHMUTZER, Rupert. Organisational Challenges to the Development of Electronic Government. In: INTERNATIONAL WORKSHOP ON DATABASE AND EXPERT SYSTEMS APPLICATIONS, 11 ${ }^{\text {th }}, 2000$, Los Alamitos, California. Proceedings... Los Alamitos, California: IEEE Computer Society, 2000.

ALBERTIN, Alberto Luiz. Valor Estratégico dos Projetos de Tecnologia de Informação. Revista de Administração de Empresas - RAE, São Paulo, v. 41, n. 3, p. 42-50, 0709/2001.

ANGELOPOULOS, Spyros; KITSIOS, Fotis; KOFAKIS, Petros; PAPADOPOULOS, Thanos. Emerging Barriers in E-Government Implementation. In: INTERNATIONAL IFIP EGOV CONFERENCE, 9 ${ }^{\text {th }}$, 2010, Lausanne, Switzerland. Proceedings... Lausanne, Switzerland: Springer Lecture Notes in Computer Science, 2010, p. 226-237.

BALDAM, Roquemar de Lima; VALLE, Rogério de Aragão Bastos do; PEREIRA, Humberto Rubens Maciel; HILST, Sérgio de Mattos; ABREU, Maurício Pereira de; SOBRAL, Valmir Santos. Gerenciamento de Processos de Negócio. São Paulo: Érica, 2007.

BEHN, Robert D. Case-Analysis Research and Managerial Effectiveness: Learning How to Lead Organizations Up Sand Dunes. In: BOZEMAN, Barry (Org.). Public Management: The State of Art. San Francisco: Jossey-Bass Publishers, 1993. (The Jossey-Bass Public Administration Series). 
BENBASAT, Izak; GOLDSTEIN, David K.; MEAD, Melissa. The Case Research Strategy in Studies of Information Systems. MIS Quarterly, Minneapolis, v. 11, n. 3, p. 369-386, 09/1987.

BOOCH, Grady; RUMBAUGH, James; JACOBSON, Ivar. The Unified Modeling Language User Guide. Boston: Addison-Wesley, 1999. (Object Technology Series).

BOWEN, Michael G. The Escalation Phenomenon Reconsidered: Decision Dilemmas or Decision Errors. The Academy of Management Review, v. 12, n. 1, p. 52-66, 01/1987.

BOYACIGILLER, Nakiye Avdan; ADLER, Nancy J. The Parochial Dinosaur: Organizational Science in a Global Context. Academy of Management Review, v. 16, n. 2, p. 262-90, 04/1991.

BROCKNER, Joel. The Escalation of Commitment to a Failing Course of Action: Toward Theoretical Progress. The Academy of Management Review, v. 17, n. 1, p. 39-61, 01/1992.

BROCKNER, Joel; SHAW, Myril C.; RUBIN. Jeffrey Z. Factors Affecting Withdrawal from an Escalating Conflict: Quitting Before It's Too Late. Journal of Experimental Social Psychology, Minneapolis, v. 15, n. 5, p. 492-503, 09/1979.

BROWN, Tom. Modernisation or Failure? IT Development Projects in the UK Public Sector. Financial Accountability\&Management, v. 17, n. 4, p. 363-381, 11/ 2001.

BURNS, Richard N.; DENNIS, Alan Robert. Selecting the Appropriate Application Development Methodology. ACM SIGMIS Database, v. 17, n. 1, p. 19-23, 09/1985.

CARNEIRO, Margareth Fabíola dos Santos. Gerenciamento de Portfólio, Programas e Projetos. In: CARNEIRO, Margareth Fabíola dos Santos (Org.). Gestão Pública: O papel do Planejamento Estratégico, Gerenciamento de Portfólio, Programas e Projetos e dos Escritórios de Projetos na Modernização da Gestão Pública”. Rio de Janeiro: Brasport, 2010, p. 102-245.

CARROL, Lewis. Alice no País dos Espelhos. 2. ed. Trad. Pepita de Leão. São Paulo: Martin Claret, 2008. (A Obra Prima de Cada Autor). 
CAVALCANTI, Bianor Scelza. O Gerente Equalizador: Estratégias de Gestão no Setor Público. Rio de Janeiro: FGV Editora, 2005.

CHAPMAN, Chris; WARD, Stephen. Project risk Management: Processes, Techniques and Insights. West Sussex, England: John Willey \& Sons, Ltd., 1997.

CHINESE CULTURE CONNECTION, The. Chinese Values and the Search of Culture-Free Dimensions of Culture. Journal of Cross-Cultural Psychology, Western Washington University, v. 18, n. 2, p. 143-64, 06/1987.

CHOW, Chee W.; HARRISON, Paul; LINDQUIST, Timothy; WU, Anne. Escalating Commitment to Unprofitable Projects: Replication and Cross-Cultural Extension. Management Accounting Research, v. 8, n. 3, p. 347-361, 09/1997.

CIBORRA, Claudio U. Teams, Markets and Systems: Business Innovation and Information Technology. Cambridge University Press, 1993.

CIBORRA, Claudio U. Digital Technologies and Risk: a critical review. In: HANSETH, Ole; CIBORRA, Claudio U. (Eds.). Risk, Complexity and ICT. Cheltenham, UK: Edward Elgar, 2007, p. 23-45,

COASE, Ronald. The Nature of the Firm, Economica, New Series, v. 4, n. 16, p. 387-405, $11 / 1937$.

CONLON, Donald E.; GARLAND, Howard. The Role of Project Completion Information in Resource Allocation Decisions. Academy of Management Journal, v. 36, n. 2, p. 402-413, 04/1993.

COOK, Thomas D.; CAMPBELL, Donald T. Quasi-Experimentation: Design \& analysis issues for field settings. Boston: Houghton Mifflin Company, 1979.

CROTTY, Michael. The Foundations of Social Research: Meaning and Perspective in the Research Process. Lodon: Sage, 1998. 
CURTIS, Bill; KRASNER, Herb; ISCOE, Neil. A Field Study of the Software Design Process for Large Systems. Communications of the ACM. New York, v. 31, n. 11, p. 1268-1287, 11/1988.

DE', Rahul. E-Government Systems in Developing Countries: Stakeholders and Conflict. INTERNATIONAL IFIP EGOV CONFERENCE, $4^{\text {th }}, 2005$, Berlin, Germany. Proceedings... Berlin, Germany: Springer Lecture Notes in Computer Science, 2005, p. 26-37.

DE', Rahul; SARKAR, Sandeep. Rituals in e-Government Implementation: An Analysis of Failure. In: INTERNATIONAL IFIP EGOV CONFERENCE, 9 ${ }^{\text {th }}$ 2010, Lausanne, Switzerland. Proceedings... Lausanne, Switzerland: Springer Lecture Notes in Computer Science, 2010, p. 226-237.

DEEPHOUSE, Christopher; MUKHOPADHYAY, Tridas; GOLDENSON, Denis R.; KELLNER, Marc I. Software Process and Project Performance. Journal of Management Information Systems, v. 12, n. 3, p. 185-203, Winter 1996.

DEGRACE, Peter; STAHL, Leslie Hulet. Wicked Problems, Righteous Solutions: A catalogue of modern Software Engineering Paradigms. Upper Saddle River, NJ: Prentice Hall, 1990. (Yourdon Press Computing Series).

DINIZ, Eduardo Henrique; BARBOSA, Alexandre Fernandes; JUNQUEIRA, Álvaro R. B.; PRADO, Otavio. O Governo Eletrônico no Brasil: Perspectiva Histórica a partir de um Modelo Estruturado de Análise. Revista de Administração Pública - RAP, Rio de Janeiro, v. 43, n. 1, p. 23-48, 02/2009.

DI PIETRO, Maria Sylvia Zanella. Direito Administrativo. 24. ed. São Paulo: Editora Atlas, 2011.

DRUMMOND, Helga. Escalation in Decision Making: The tragedy of Taurus. New York: Oxford University Press, 1996. 
DRUMMOND, Helga; HODGSON, Julia. Escalation in Decision Making: Behavioural Economics in Business. Farnham, Surrey: Gower Publishing Company, 2011.

DUBÉ, Line; PARÉ, Guy. Rigor in Information Systems Positivist Case Research: current practices, trends, and recommendations. MIS Quarterly, Minneapolis, v. 27, n. 4, p. 597$635,12 / 2003$.

DUNLEAVY, Patrick; MARGETTS, Helen; BASTOW, Simon; TINKLER, Jane. New Public Management Is Dead-Long, Live Digital-Era Governance. Journal of Public Administration Research and Theory, v. 16, n. 3, p. 467-494, 07/2006.

DUNEGAN, Kenneth J. Framing, Cognitive Modes, and Image Theory: Toward an Understanding of a Glass Half Full. Journal of Applied Psychology, v. 78, n. 3, p. 491-503, 1993.

EISENHARDT, Kathleen. Building Theories from Case Study Research. The Academy of Management Review, v. 14, n. 4, p. 532-550, 10/1989.

EISENHARDT, Kathleen; GRAEBNER, Melissa E. Theory Building from Cases: Opportunities and Challenges. The Academy of Management Journal, v. 50, n. 1, p. 25-32, 02/2007.

ENCONTRO NACIONAL DE COORDENADORES E ADMINISTRADORES TRIBUTÁRIOS ESTADUAIS - ENCAT. Manual de Integração - Contribuinte: Padrões Técnicos de Comunicação. v. 1.1.1. 05/2006. Disponível em: https://www.fazenda.sp.gov.br/nfe/downloads/Manual_de_Integracao_Contribuinte_versao_1 11-2006-05-30.pdf>. Acesso em: 09/12/2011.

EWUSI-MENSAH, Kweku; PRZASNYSKI, Zbigniew. On Information Systems Project Abandonment: an Exploratory Study of Organizational Practices. MIS Quarterly, Minneapolis, v. 15, n. 1, p. 67-85, 03/1991. 
FERNANDES, Aguinaldo Aragon, ABREU, Vladimir Ferraz de. Implantando a Governança de TI: da estratégia à gestão dos processos e serviços. 2. ed. Rio de Janeiro: Brasport, 2008.

FERREIRA, Ricardo J. Manual do ICMS do Estado de São Paulo. 2. ed. Rio de Janeiro: Editora Ferreira, 2009.

FESTINGER, L. A Theory of Cognitive Dissonance. Evanston, IL: Row, Peterson and Company, 1957.

FLYNN, Donal; PAN, Gary; KEIL, Mark; MÄHRING, Magnus. De-Escalating IT Projects: The DMM Model. Communications of the ACM. New York, v. 52, n. 10, p. 131-134, $10 / 2009$.

FLYVBJERG, Bent. Over Budget, Over Time, Over and Over Again: Managing Major Projects. In: MORRIS, Peter W. G.; PINTO, Jeffrey K.; SÖDERLUND, Jonas (orgs.). The Oxford Handbook of Project Management. Oxford University Press, 2011, p. 321-344.

FURLONG, Shauneen; AL-KARAGHOULI, Wafi. Delivering Professional Projects: The Effectiveness of Project Management in Transformational e-Government Initiatives. Transforming Government: People, Process and Policy, v. 4, n. 1, p. 73-94, 2010.

GALLIERS, Robert D. Choosing Appropriate Information Systems Research Approaches: A Revised Taxonomy. In: NISSEN, H. E.; KLEIN, H. K.; HIRSCHEIM, R. (Orgs.). Information Systems Research: Contemporary Approaches and Emergent Traditions. NorthHoland: Elsevier Science Publishers B. V., 1991.

GARLAND, Howard. Throwing Good Money After Bad: The Effect of Sunk Costs on the Decision to Escalate Commitment to an Ongoing Project. Journal of Applied Psychology, v. 75, n. 6, p. 728-731, 1990.

GARLAND, Howard; SANDEFUR, Craig A.; ROGERS, Anne C. De-Escalation of Commitment in Oil Exploration: When Sunk Costs and Negative Feedback Coincide. Journal of Applied Psychology, v. 75, n. 6, p. 721-727, 1990. 
GARLAND, Howard; CONLON, Donald E. Too Close to Quit: The Role of Project Completion in Maintaining Commitment. Journal of Applied Social Psychology, v. 28, n. 22, p. 2025-2048, 1998.

GILLIES, Christina. Managing Major Programs and Projects: A View from the Boardroom. In: WANNA, John (Ed.). Improving Implementation: Organisational Change and Project Management. The Australia and New Zealand School of Government, The Australian National University E-Press, 2007. p. 23-32.

GOODYEAR, Marilu; NELSON, Mark R. Leadership Strategies for Large-scale IT Implementations in Government. In: MORSE, Ricardo S.; BUSS, Terry F.; KINGHORN, C. Morgan (Orgs.). Transforming Public Leadership for the 21st Century. Armonk, New York: M.E. Sharpe, 2007, p. 308-324. (Transformational Trends in Governance \& Democracy Series).

GREGOR, Shirley. The Nature of Theory in Information Systems. MIS Quarterly, Minneapolis, v. 30, n. 3, p. 611-642, 09/2006.

GUBA, G. Egon; LINCOLN, Yvonna S. Paradigmatic Controversies, Contradictions, and Emerging Confluences. In: DENZIN, Norman K. (Ed.); LINCOLN, Yvonna S. (Ed.). The SAGE Handbook of Qualitative Research, 3rd ed. Thousand Oaks: SAGE Publications, 2005, p. 191-215.

HARRELL, Adrian; HARRISON, Paul. An Incentive to Shirk, Privately Held Information and Managers' Project Evaluation Decisions. Accounting, Organizations and Society, v. 19, n. 7, p. 569-577, 10/1994.

HARRISON, Paul; HARRELL, Adrian. Impact of “Adverse Selection” on Managers' Project Evaluation Decisions. Academy of Management Journal, v. 3, n. 3, p. 635-643, 06/1993.

HEEKS, Richard. Most e-Government-for-Development Projects Fail. How Can Risks be Reduced? United Nations Public Administration Network, 2003. Disponível em: < http://unpan1.un.org/intradoc/groups/public/documents/CAFRAD/UNPAN011226.pdf>. Acesso em: 21/04/2011. 
. eGovernment as a Carrier of Context. Institute for Development Policy and

Managemen. iGovernment Series, Working paper, no. 15, University of Manchester, UK, 2004. Disponível em: <http://idpm.man.ac.uk/publications/wp/igov/index.shtml>. Acesso em: 26.11.2011.

HEFLEY, William E.; LOESCHE, Ethel A. The eSourcing Capability Model for Client Organizations (eSCM-CL) v1.1: Model Overview. Carnegie Mellon: Information Technology Services Qualification Center, 2006. Disponível em: <http://www.itsqc.org/models/escmcl/index.html>. Acesso em: 12/06/2011.

HENG, Cheng-Shuang; TAN, Bernard C. Y.; WEI, Kwok-Kee. Willingness to Continue with Software Projects: Effects of Feedback Direction and Optimism under High and Low Accountability Conditions. Journal of the Association for Information Systems, v. 4, n. 4, p. 171-194, 09/2003.

HO, David Yau-Fai. On the Concept of Face. American Journal of Sociology, University of Chicago Press, v. 81, n. 4, p. 867-884, 01/1976.

HOFSTEDE, Geert; HOFSTEDE, Gert Jan; MINKOV, Michael. Cultures and Organizations: Software of the Mind. 3. ed. New York: McGraw-Hill, 2010.

HOPPEN, Norberto; MEIRELLES, Fernando S. Sistemas de Informação: Um Panorama da Pesquisa Científica entre 1990 e 2003. Revista de Administração de Empresas - RAE, v. 45, n. 1, p. 24-35, 03/2005.

HOUAISS, Antônio. Dicionário Houaiss da Língua Portuguesa. Rio de Janeiro: Objetiva, 2007.

HUMES, Leila Lage. A Importância do Exercício do Poder para o Desenvolvimento de Infra-Estruturas de Informação, 2006. 270 f. Tese (Doutorado em Administração) Faculdade de Economia, Administração e Contabilidade da Universidade de São Paulo, São Paulo, 2006. 
IACOVOU, Charalambos L.; DEXTER, Albert S. Managing Runaway Projects: A Delphi Survey. In: EUROPEAN CONFERENCE ON INFORMATION SYSTEMS, $6^{\text {th }}, 1998$, Aixen-Provence, France. Proceedings... Aix-en-Provence: Association for Information Systems, 1998. p. $1140-1153$

IACOVOU, Charalambos L.; DEXTER, Albert S. Turning Around Runaway Information Technology Projects. California Management Review, v. 46, n. 4, p. 68-88, 06/2004.

INFORMATION TECHNOLOGY SERVICES QUALIFICATION CENTER - ITSQC. Site Institucional, 2011. Disponível em: < http://www.itsqc.org/>. Acesso em: 21/12/2011.

INTERNATIONAL PROJECT MANAGEMENT ASSOCIATION - IPMA. Site Institucional, 2011. Disponível em: 〈http://www.ipma.ch>. Acesso em: 06/04/2011.

ICB - IPMA Competence Baseline. 3rd ed. Nijkerk, The Netherlands: 2006. Disponível em: <www.ipma.ch>. Acesso em: 06/04/2011.

INFORMATION TECHNOLOGY GOVERNANCE INSTITUTE (ITGI). Control Objectives for Information and related Technology (COBIT). 4.1 Edition, 2007. Disponível em <www.isaca.org>. Acesso em: 03/06/2007.

INTERNATIONAL ORGANIZATION FOR STANDARDIZATION $\quad-\quad$ ISO; INTERNATIONAL ELECTROTECHNICAL COMMISSION - IEC. Corporate governance of information technology. International Standard ISO/IEC 38500, 01/06/2008.

JACOBSON, Ivar; BOOCH, Grady; RUMBAUGH, James. The Unified Software Development Process. Boston: Addison-Wesley, 1999. (Object Technology Series).

JENSEN, M. C; MECKLING, W. H. Theory of the Firm: Managerial Behavior, Agency Costs and Ownership Structure. Journal of Financial Economics, v. 3, n. 4, p. 305-360, 1976.

JOHNSON, Jim. My Life is Failure: 100 Things You Should Know to be a Successful Project Leader. West Yarmouth, MA: The Standish Group International Inc., 2006. 
JUNQUEIRA, Álvaro Ribeiro Botelho. Implementação de projetos de governo eletrônico com múltiplas agências: uma análise dos fatores críticos de sucesso do projeto nota fiscal eletrônica sob a ótica do PMBOK, 2007. Dissertação (Mestrado em Administração de Empresas) - Escola de Administração de Empresas de São Paulo, Fundação Getúlio Vargas, São Paulo, 2007.

KAHNEMAN, D.; TVERSKY, A. Prospect Theory: An Analysis of Decisions Under Risk. Econometrica, v. 47, n. 2, p. 263-291, 03/1979.

KAPLAN, Robert S.; NORTON, David P. The Balanced Scorecard: Measures that Drive Performance. In: Harvard Business Review, Boston, v. 70, n. 1, p. 71-85, 01-02/1992.

KASSEL, David S. Managing Public Sector Projects: A Strategic Framework for Success in an Era of Downsized Government. Boca Raton: CRC Press, 2010. (ASPA Series in Public Administration and Public Policy).

KEIL, Mark. Pulling the Plug: Software Project Management and the Problem of Project Escalation. MIS Quarterly, Minneapolis, v. 19, n. 4, p. 421-447, 12/1995.

KEIL, Mark; CULE, Paul E; LYYTINEN, Kalle, SCHMIDT, Roy C. A Framework for Identifying Software Project Risks. Communications of the ACM, New York, v. 41, n. 11, p. 76-83, 11/1998.

KEIL, Mark; ROBEY, Daniel. Turning Around Troubled Software Projects: An Exploratory Study of the De-Escalation of Commitment to Failing Courses of Action. Journal of Management Information Systems, v. 15, n. 4, p. 63-88, 09/1999.

KEIL, Mark; MANN, Joan; RAI, Arun. Why Software Projects Escalate: An Empirical Analysis and Test of Four Theoretical Models. MIS Quarterly, Minneapolis, v. 24, n. 4, p. 631-664, 12/2000.

KEIL, Mark; TAN, Bernard C. Y.; WEI, Kwok-Kee; SAARINEN, Timo; TUUNAINEN, Virpi; WASSENAAR, Arjen. A Cross-Cultural Study on Escalation of Commitment Behavior on Software Projects. MIS Quarterly, Minneapolis, v. 24, n. 2, p. 299-325, 06/2000. 
KEIL, Mark; DEPLEDGE , Gordon; RAI, Arun. Escalation: The Role of Problem Recognition and Cognitive Bias. Decision Sciences, v. 38, n. 3, p. 391-421, 08/2007.

KERZNER, Harold. Project Management: A systems approach to planning, scheduling, and controlling. 10th ed. Hoboken, New Jersey: John Wiley \& Sons, Inc., 2009.

KRISHNA, S.; WALSHAM, Geoff. Implementing Public Information Systems in Developing Countries: Learning from a Success Story. Information Technology for Development, v. 11, n. 2, p. 123-140, 04/2005.

LAIA, Marconi Martins de; CUNHA, Maria Alexandra Viegas Cortez da; NOGUEIRA, Antonio Roberto Ramos; MAZZON, José Afonso. Electronic Government Policies in Brazil: Context, ICT Management and Outcomes. Revista de Administração de Empresas - RAE, São Paulo, v. 51, n. 1, p. 43-57, 01-02/2011.

LAYNE, Karen; LEE, Jungwoo. Developing Fully Functional E-government: A Four Stage Model. Government Information Quarterly, v. 18, n. 2, p. 122-136, Summer 2001.

LEE, Allen. S. A Scientific Methodology for MIS Case Studies. MIS Quarterly, Minneapolis, v. 13, n. 1, p. $33-50,03 / 1989$.

LEWIN, Kurt. Field Theory in Social Science. New York: Harper \& Row, 1951.

LIENTZ, Bennet P.; LARSSEN, Lee. Risk Management fot IT Projects: How to Deal with Over 150 Issues and Risk. Butterworth-Heinemann, 2006.

LIM, Wee-Kiat; SIA, Siew Kien; YEOW, Adrian. Managing Risks in a Failing IT Project: A Social Constructionist View. Journal of the Association for Information Systems, v. 12, n. 6, p. 414-440, 06/2011.

MATHIASSEN, Lars; STAGE, Jan. The Principle of Limited Reduction in Software Design. Information Technology and People, v. 6, n. 2, p. 171-185, 1992. 
MCGREGOR JR., Eugene B. Toward a Theory of Public Management Success. In: BOZEMAN, Barry (Ed.). Public Management: The State of Art. San Francisco: Jossey-Bass Publishers, 1993. (The Jossey-Bass Public Administration Series).

MELO, Cláudia de Oliveira; FERREIRA, Gisele R. M. Adoção de Métodos Ágeis em uma Instituição Pública de Grande Porte - um estudo de caso. In: WORKSHOP BRASILEIRO DE MÉTODOS ÁGEIS - WBMA, 1º, 2010, Porto Alegre, RS. Anais... Porto Alegre, RS: Agile Brazil, 2010, p. 104-117.

MEREDITH, Jack. Project monitoring for Early Termination. Project Management Journal, v. 19, n. 5, p. 31-38, 11/1988.

MEYER, Marshall W.; ZUCKER, Lynne G. Permanently Failing Organizations. Sage Publications, 1989.

MILES, Matthew B.; HUBERMAN, A. Michael. Qualitative Data Analysis: An Expanded Sourcebook. 2nd ed. Thousand Oaks: SAGE Publications, 1994.

MONTEALEGRE, Ramiro; KEIL, Mark. De-Escalating Information Technology Projects: Lessons from the Denver International Airport. MIS Quarterly, Minneapolis, v. 24, n. 3, p. 417-447, 09/2000.

MORENO, José Alexandre; GOBBO JUNIOR, José Alcides; CAVENAGHI, Vagner. Tecnologia da Informação na Gestão de Cidades: Um Estudo de Caso de Implantação de ERP em um Município Paulista. Revista Gestão Industrial, Ponta Grossa, PR, v. 3, n. 3: p. 11-25, 2007.

MORSE, Ricardo S.; BUSS, Terry F. The Transformation of Public Leadership. In: MORSE, Ricardo S.; BUSS, Terry F.; KINGHORN, C. Morgan (Orgs.). Transforming Public Leadership for the 21st Century. Armonk, New York: M.E. Sharpe, 2007. p. 3-19. (Transformational Trends in Governance \& Democracy Series). 
MÜLLER, Ralf. Project Governance. In: MORRIS, Peter W. G.; PINTO, Jeffrey K.; SÖDERLUND, Jonas (Orgs.). The Oxford Handbook of Project Management. Oxford University Press, 2011. p. 297-320.

MUMFORD, Enid. Defining System Requirements to Meet Business Needs: A Case Study Example. The Computer Journal, v. 28, n. 2, p. 97-104, 05/1985.

MYERS, Mychael D. Qualitative Research in Business and Management. London: SAGE Publications, 2009.

NAÇÕES UNIDAS. Implementing E-Government: Report of the Regional Workshop Bangkok. Bangkok: 31/05 a 01/06, 2004. Disponível em: <http://unescap.org/icstd/Pubs/st_escap_2342.pdf>. Acesso em: 28/02/2011.

NEWMAN, Michael; SABHERWAL, Rajiv. Determinants of Commitment to Information Systems Development: A Longitudinal Investigation. MIS Quarterly, Minneapolis, v. 20, n. 1, p. 23-53, March 1996.

NORTHCRAFT, Gregory B.; WOLF, Gerrit. Dollars, sense and sunk costs: A life cycle model of resource allocation decisions. The Academy of Management Review, v. 9, n. 2, p. 225-234, 04/1984.

OFFICE OF GOVERNMENT COMMERCE - OGC. Managing Successful Projects with PRINCE2 2009 Edition Manual. London: The Stationery Office, 2009a.

Directing Successful Projects with PRINCE2 2009 Edition Manual. London: The Stationery Office, 2009b.

. Site Institucional, 2011. Disponível em: 〈www.ogc.gov.uk〉. Acesso em: 06/04/2011. 
ORGANISATION FOR ECONOMIC CO-OPERATION AND DEVELOPMENT - OECD. The Hidden Threat to E-Government: Avoiding Large Government IT Failures. Puma Policy Brief No. 8, 03/2001. Disponível em: <http://www.oecd.org/dataoecd/19/12/1901677.pdf>. Acesso em: 07/04/2011.

OSBORNE, David; GAEBLER, Ted. Reinventando o Governo: Como o espírito empreendedor está transformando o setor público. 9. ed. Brasília: Editora MH Comunicação, 1997.

OSTERBY, Aaron; HANSON, Robert. Evicence-Based Public Management and ICT: A broad survey of the Literature. In: SHILLABEER, Anna; BUSS, Terry F.; ROUSSEAU, Denise M. (Orgs.). Evidence-Based Public Management: Practices, Issues, and Prospects. Armonk, New York: M.E. Sharpe, 2011.p. 103-116.

OUCHI, W. G. Markets, Bureaucracies, and Clans. Administrative Science Quarterly, v. 25, n. 1, p. 129-141, 03/1980.

PAN, Gary; PAN, Shan L.; NEWMAN, Michael; FLYNN, Donal. Escalation and DeEscalation of Commitment: A Commitment Transformation Analysis of an E-Government Project. Information Systems Journal, v. 16, n. 1, p. 3-21, 01/2006.

PILCHER, Roman. Agile Product Management with Scrum: Creating products that customers love. Upper Saddle River, NJ: Addison-Wesley Professional, 2010. (The AddisonWesley Signature Series).

POPPENDIECK, Mary. Wicked Projects. Software Development Magazine, 05/2002. Disponível em: <http://drdobbs.com/architecture-and-design/184414851>. Acesso em: $22 / 12 / 2011$.

POPPER, Karl. The Logic of Scientific Discovery. London: Routledge, 2002. (Routledge Classics). 
PRASSER, Scott. Overcoming the 'White Elephant' Syndrome in Big and Iconic Projects in the Public and Private Sectors. In: WANNA, John (Ed.). Improving Implementation: Organisational Change and Project Management. The Australia and New Zealand School of Government, The Australian National University E-Press, 2007. p. 47-67.

PRIES-HEJE, Jan; BASKERVILLE, Richard. The Design Theory Nexus. MIS Quarterly, Minneapolis, v. 32, n. 4, p. 731-755, 12/2008.

PROJECT MANAGEMENT INSTITUTE - PMI. A Guide to the Project Management Body of Knowledge-PMBOK® Guide. 4th ed. Newtown Square, PA, 2008.

A Guide to the Project Management Body of Knowledge - PMBOK® Guide. 3rd ed. Newtown Square, PA, 2004.

Government Extension to the PMBOK® Guide Third Edition. Newtown Square, PA, 2006a.

. The Standard for Portfolio Management. 2nd ed. Newtown Square, PA, 2006b.

RAINEY, Hal G. Understanding and Managing Public Organizations. $2^{\text {nd }}$ ed. San Francisco: Jossey-Bass Publishers, 1997. (The Jossey-Bass Public Administration Series).

REMENYI, Dan. Stop IT Project Failures Through Risk Management. Oxford: Butterworth Heinemann, 1999. (Computer Weekly Professional Series).

REMENYI, Dan; WILLIAMS, Brian. The Nature of Research: Qualitative or Quantitative, Narrative or Paradigmatic? Information Systems Journal, v. 6, n. 2, p. 131-146, 1996.

RICHTEY, Tom. Wicked Problems: Structuring Social Messes with Morphological Analysis. Swedish Morphological Society, 2011. Disponível em: <http://www.swemorph.com>. Acesso em: 17/05/2011.

RITTEL, Horst W. J.; WEBBER, Melvin M. Dilemmas in a General Theory of Planning. Policy Sciences, Amsterdam, v. 4, n. 2, p. 155-169, 1973. 
RUBIN, J. Z.; BROCKNER, J. Factors Affecting Entrapment in Waiting Situations: The Rosencrantz and Guildenstern Effect. Journal of Personality and Social Psychology, v. 31, n. 6, p. 1054-1063, 1975.

SACCOL, Amarolinda Zanela; MACADAR, Marie Anne; SOARES, Rodrigo Oliveira. Mudanças Organizacionais e Sistemas ERP. In: SOUZA, Cesar Alexandre de; SACCOL, Amarolinda (Org.). Sistemas ERP no Brasil - Teoria e Casos. São Paulo: Editora Atlas S. A., 2003. p. 173-190.

SANTOS, Ameliara Freire; ARAÚJO, Verlaynne Kelley da Hora Rocha. Estudo Sobre Técnicas de Priorização de Requisitos Aplicadas a Sistemas Corporativos de Governo. Monografia apresentada como requisito parcial para conclusão da disciplina Engenharia de Requisitos do Curso de pós-graduação em Ciência da Computação, Centro de Informática, Universidade Federal de Pernambuco, Pernambuco,2009.

SARANTIS, Demetrios; CHARALABIDIS, Yannis; ASKOUNIS, Dimitris. A Goal-Driven Management Framework for Electronic Government Transformation Projects Implementation. Government Information Quarterly, v. 28, n. 1, p. 117-128, 01/2011.

SCHWABER, Ken. Agile Project Management with Scrum. Redmond, Washington: Microsoft Press, 2004.

. The Enterprise and Scrum. Redmond, Washington: Microsoft Press, 2007.

SECRETARIA DA FAZENDA - SEFAZ. Emitidas as primeiras Notas Fiscais Eletrônicas com plena validade. SEFAZ-SP Notícias, Secretaria da Fazenda do Estado de São Paulo, 2006a. Disponível em: <http://www.fazenda.sp.gov.br/PUBLICACAO/noticia.aspx?id=416>. Acesso em: 16/12/2011.

Sítio de Orientações Gerais do ePAT. 2011a. Disponível em <https://www.fazenda.sp.gov.br/ePAT/portal/>. Acesso em 30/12/2011.

Sítio Institucional da Nota Fiscal Eletrônica do Estado de São Paulo. 2011b. Disponível em: <https://www.fazenda.sp.gov.br/nfe/>. Acesso em: 04/01/2012. 
SHARP, David J.; SALTER, Stephen B. Project Escalation and Sunk Costs: A Test of the International Generalizability of Agency and Prospect Theories. Journal of International Business Studies, v. 28, n. 1, p. 101-121, 03/1997.

SMITH, John M. Troubled IT Projects: Prevention and Turnaround. The Institute of Electrical Engineers: London, 2001. (IEE Professional Applications of Computing Series).

STANDISH GROUP. Chaos Summary: The 10 Laws of CHAOS. 2009.

STAKE, Robert E. Qualitative Case Studies. In: DENZIN, Norman K.; LINCOLN, Yvonna S. The SAGE Handbook of Qualitative Research, 3rd ed. Thousand Oaks: SAGE Publications, p. 443-466, 2005.

STAW, Barry M.; ROSS, Jerry. Commitment to a Policy Decision: A Multi-Theoretical Perspective. Administrative Science Quarterly, v. 23, n. 1, p. 40-64, 3/1978.

Knowing When to Pull the Plug. Harvard Business Review, v. 65, n. 2, p. 68-74, 03/1987.

STONE, Eugene. Research Methods in Organizational Behavior. Santa Monica, California: Scott, Foresman and Company, 1978. (The Scott, Foresman Series in Organizational Behavior and Human Resources).

SUTHERLAND, Jeff; SCHWABER, Ken. The Scrum Guide. 07/2011. Disponível em: <http://www.scrum.org>. Acesso em: 9/10/2011.

TAKEUCHI, Hirotaka; NONAKA, Ikujiro. The New New Product Development Game. Harvard Business Review, v. 64, n. 1, p. 137-146, 01-02/1986.

TRIBUnAL DE CONTAS DA UNIÃO-TCU. Manual de Gestão de Projetos. Brasília, 2006. Disponível em: < http://www.tcu.gov.br>. Acesso em: 05/04/2011. 
TSE, David K.; LEE, Kam-Hon; VERTINSKY, Ilan; WEHRUNG, Donald A. Does Culture Matter? A Cross-Cultural Study of Executives' Choice, Decisiveness, and Risk Adjustment in International Marketing. Journal of Marketing, v. 52, n. 4, p. 81-95, 10/1988.

TURLEY, Frank. An Introduction to Prince2: An Excellent Introduction to Prince2. Belgium: $\quad 2010 . \quad$ Disponível em: <http://www.mgmtplaza.com/elearn/files/Introduction-To-PRINCE2.pdf>. Acesso em: 06/04/2011.

TVERSKY, A.; KAHNEMAN, D. The Framing of Decisions and the Psychology of Choice. Science, v. 211, n. 30, p. 453-458, 01/1981.

UPENDER, Barg. Staying Agile in Government Software Projects. In: THE AGILE DEVElopMEnT CONFERENCE, $3^{\text {rd }}$, 2005, Denver, Colorado. Proceedings... Denver, Colorado: IEEE Computer Society, 2005.

WALLACE, Linda; KEIL, Mark. Software Project Risks and Their Effect on Outcomes: How to identify the risks that interact to pose the most significant threats to successful project outcomes. Communications of the ACM, New York, v. 47, n. 4, p. 68-73, 04/2004.

WEERAKODY, Visanth; SARIKAS, Omiros D.; PATEL, Riten. Exploring the Process and Information Systems Integration Aspects of E-Government. eGovernment Workshop 2005 (eGOV 2005), Brunel University, London, UK, 09/2005. p. 1-17.

WEILL, Peter. Don't Just Lead, Govern: How Top-Performing Firms Govern IT. In: MIS Quarterly Executive, Minneapolis, v. 3, n. 1, p. 1-17, 03/2004.

WEILL, Peter; ROSS, Jeanne W. Governança de TI: Como as empresas de melhor desempenho administram os direitos decisórios de TI em busca de resultados superiores. São Paulo: M. Books, 2006.

WILLIAMSON, Oliver E. Markets and Hierarchies: Analysis and Antitrust Implications. New York: The Free Press, 1975. 
WHYTE, Glen. Escalating Commitment to a Course of Action: A Reinterpretation. Academy of Management Review, v. 11, n. 2, p. 311-321, 04/1986.

WHYTE, Glen. Escalating Commitment in Individual and Group Decision Making: A Prospect Theory Approach. Organizational Behavior and Human Decision Processes, v. 54, n. 3, p. 430-455, 04/1993.

WIRICK, David W. Public-Sector Project Management: Meeting the Challenges and Achieving Results. New Jersey: Wiley, 2009.

XIA, Weidong; LEE, Gwanhoo. Grasping the Complexity of IS Development Projects. Communications of the ACM, New York, v. 47, n. 5, p. 69-74, 05/2004.

YIN, Robert K. Estudo de Caso: Planejamento e Métodos. 3. edição. Porto Alegre: Bookman, 2005.

YOUNG, Raymond C. How Boards and Senior Managers Have Governed. In: WANNA, John (Ed.). Improving Implementation: Organisational Change and Project Management. The Australia and New Zealand School of Government, The Australian National University E-Press, 2007. p. 35-45.

ZMUD, Robert W. Management of Large Software Development Efforts. MIS Quarterly, Minneapolis, v. 4, n. 2, p. 45-55, 03/1980.

ZWICKER, Ronaldo; SOUZA, Cesar Alexandre de. Sistemas ERP: Conceituação, Ciclo de Vida e Estudos de Casos Comparados. In: SOUZA, Cesar Alexandre de; SACCOL, Amarolinda (Org.). Sistemas ERP no Brasil - Teoria e Casos. São Paulo, Editora Atlas S. A., 2003. p. 63-87. 


\subsection{Projeto ePAT}

SECRETARIA DA FAZENDA - SEFAZ. Justificativa de Adoção de Software. Secretaria da Fazenda do Estado de São Paulo, 21/05/2009a. Documento interno.

Edital de Pregão (eletrônico) NCC n. ${ }^{\circ}$ 61/2009. Secretaria da Fazenda do Estado de São Paulo, 22/07/2009b. Documento interno.

Anexo I b: Memorial Descritivo do Pregão (eletrônico) NCC n. ${ }^{\circ}$ 61/2009. Secretaria da Fazenda do Estado de São Paulo, 22/07/2009c Documento interno.

. Documento de Visão: e-PAT - Processo Administrativo Tributário. Secretaria da Fazenda do Estado de São Paulo, 28/04/2010a. Documento interno.

- Ata de Reunião do ePAT. Secretaria da Fazenda do Estado de São Paulo, 23/04/2010b. Documento interno.

. ePAT: Apresentação da Reunião de Acompanhamento do Projeto. Secretaria da Fazenda do Estado de São Paulo, 28/04/ 2010c. Documento interno.

.ePAT: Apresentação da Reunião de Acompanhamento do Projeto. Secretaria da Fazenda do Estado de São Paulo, 05/05/2010d. Documento interno.

.ePAT: Apresentação da Reunião de Acompanhamento do Projeto. Secretaria da Fazenda do Estado de São Paulo, 12/05/2010e. Documento interno.

.ePAT: Apresentação da Reunião de Acompanhamento do Projeto. Secretaria da Fazenda do Estado de São Paulo, 19/05/2010f. Documento interno.

.ePAT: Apresentação da Reunião de Acompanhamento do Projeto. Secretaria da Fazenda do Estado de São Paulo, 26/05/2010g. Documento interno. 
.ePAT: Apresentação da Reunião de Acompanhamento do Projeto. Secretaria da Fazenda do Estado de São Paulo, 02/06/2010h. Documento interno.

.ePAT: Apresentação da Reunião de Acompanhamento do Projeto. Secretaria da Fazenda do Estado de São Paulo, 09/06/2010i. Documento interno.

.ePAT: Apresentação da Reunião de Acompanhamento do Projeto. Secretaria da Fazenda do Estado de São Paulo, 16/06/2010j. Documento interno.

.ePAT: Apresentação da Reunião de Acompanhamento do Projeto. Secretaria da Fazenda do Estado de São Paulo, 23/06/2010k. Documento interno.

.ePAT: Apresentação da Reunião de Acompanhamento do Projeto. Secretaria da Fazenda do Estado de São Paulo, 30/06/20101. Documento interno.

.ePAT: Apresentação da Reunião de Acompanhamento do Projeto. Secretaria da Fazenda do Estado de São Paulo, 07/07/2010m. Documento interno.

ePAT: Apresentação da Reunião de Acompanhamento do Projeto. Secretaria da Fazenda do Estado de São Paulo, 14/07/2010n. Documento interno.

.ePAT: Apresentação da Reunião de Acompanhamento do Projeto. Secretaria da Fazenda do Estado de São Paulo, 21/07/2010o. Documento interno.

\subsection{Projeto NFe}

SECRETARIA DA FAZENDA - SEFAZ. Prêmio Mário Covas: Nota Fiscal Eletrônica, a modernização do Fisco a serviço da sociedade. Secretaria da Fazenda do Estado de São Paulo, 2006b. Documento interno.

. Estrutura do Processo de Desenvolvimento PROFFIS. Secretaria da Fazenda do Estado de São Paulo, 2006c. Documento interno. 


\subsection{Projeto Rainha Vermelha}

DISPATER. Rainha Vermelha: Edital da Licitação do Projeto. [S.1.], 4 de agosto de 2009. Documento interno.

DISPATER; JANUS. Rainha Vermelha: Contrato. [S.1.], 25 de setembro de 2009. Documento interno.

JANUS. Rainha Vermelha: Apresentação para a alta administração da Dispater e da Salus. [S.1.], 11 de maio de 2011. Documento interno.

MINERVA. Relatório de Acompanhamento Executivo: Diagnóstico do Projeto Rainha Vermelha. [S.1.], 27 de abril de 2012. Documento interno. 